\title{
Reliability of Generation at a Hanford Nuclear Energy Center (HNEC)
}

by

R. G. Clark

W. J. Dowis

December 1977

Pacific Northwest Laboratory

Richland, Washington 99352

Operated for the

U.S. Department of Energy

by

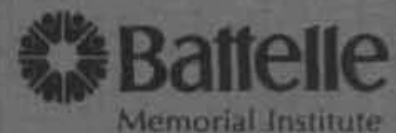




\title{
NOTICE
}

This report was prepared as an account of work sponsored by the United States Government, Neither the United States nor the Department of Energy, nor any of their employees, not any uf their contractors. subcontractors, or their employees, makes any warranty, express or implied, or aisumes any legal itataini, or responsibility for the accuracy, completeness or usefulnest of any intormation, apparatus, orodust or prukess disclosed, or represents that its use would not infringe privately owned rights.

The views, opinions and conclusions contained in this report are those of the contractot und to ron necessarily represent those of the United States Government or the United Stares Department of Energy

\author{
PACIFIC NORTHWEST LABORATCRY \\ operated by \\ BATTELLF \\ for the \\ UNITED STATES DEPARTMENT OF ENERCY \\ Under Contract EY-76-C-06-7830
}

\begin{tabular}{|c|c|c|}
\hline \multicolumn{3}{|c|}{$\begin{array}{l}\text { Printed in the United Staces of America } \\
\text { Available from } \\
\text { National Technical Intormation Service } \\
\text { United Srates Department of Commerice } \\
5285 \text {. Pnrt Royal Road } \\
\text { Springfie!d, Virgiria 22151 }\end{array}$} \\
\hline ce: & Printed Copy & $5 \quad$; Microfiche 53.00 \\
\hline & Pages & $\begin{array}{c}\text { NIt's } \\
\text { Seliling Price }\end{array}$ \\
\hline & $007-075$ & $\$ 4.50$ \\
\hline & $026-650$ & $\$ 5.00$ \\
\hline & $151-1275$ & $\$ 5.50$ \\
\hline & $076-100$ & 56.00 \\
\hline & $101-125$ & $\$ 6.50$ \\
\hline & $726-150$ & 57.00 \\
\hline & $151-175$ & $\$ 775$ \\
\hline & $756+200$ & 58.50 \\
\hline & $201-275$ & $\operatorname{sen} 5$ \\
\hline & $226-150$ & 5900 \\
\hline & $251-275$ & 510.00 \\
\hline & $256-100$ & 310.25 \\
\hline
\end{tabular}


RELIABILITY OF GENERATION AT A HANFORD NUCLEAR ENERGY CENTER (HNEC)

by

R.G. Clark

W.J. Dowis, Consultant

December 1977

Pacific Northwest Laboratory

Richland, Washington 99352

Prepared for the U.S. Department of

Energy under Contract EY-76-C-06-1830 


\section{ACKNOWLEDGEMENTS}

The services of the following individuals in the preparation of this report is gratefully acknowledged:

George Bailey and Bruce Bentley, of the Washington Public Power Supply System (WPPSS), for counsel and support in using available analytical facilities for this study.

Richard Duncan, of the Northwest Power Pool Coordinating Group, for the programming and use of the Energy Reserve Planning Model to determine the probable effects on the Pacific Northwest System of loss of energy production at an HNEC.

Donald Baldrica, and other members of the Power Planning Branch of the Bonneville Power Administration, for assistance on system response to interruption of power flow from an HNEC.

Clifford Diemond, Counsultant, for assistance on fault clearing technology.

Randy Brown, Counsultant, for assistance on ashfall and river blockage.

James Stottlemyre, of Battelle Pacific Northwest Laboratories (PNL) for assistance in study of earthquake effects.

J. V. Ramsdell of PNL, for information on meteorological effects on dispersion of radioactive releases, and on tornado incidence in the Hanford area.

Albion Brandstetter, of PNL, on overflow of river blockage.

Glen Wilfert, of PNL, for contributions to the section on societal effects of energy shortage. 


\section{C.ONTENTS}

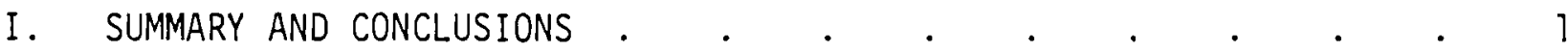

Risk of Forced Outage

Risk of User Power Shortage . . . . . . . . .

CONCLUSIONS

II. INTRODUCTION

III. DESCRIPTION OF HNEC AND DS CASES

REFERENCES I, I I, AND II I

IV. INITIATING EVENTS

V. COMPARISON OF RISKS

RELIABILITY STANDARDS

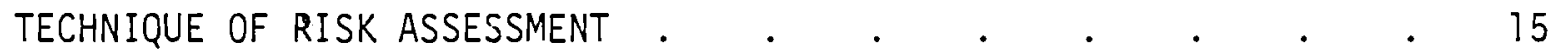

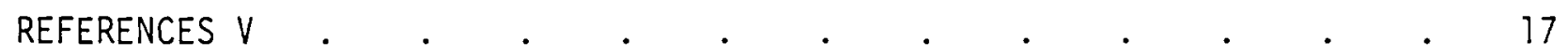

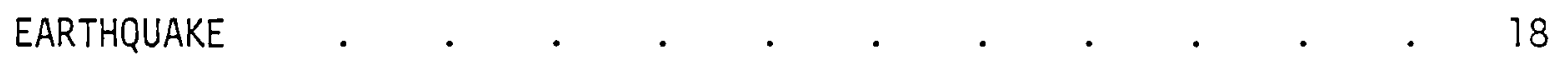

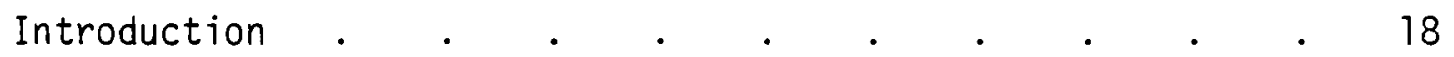

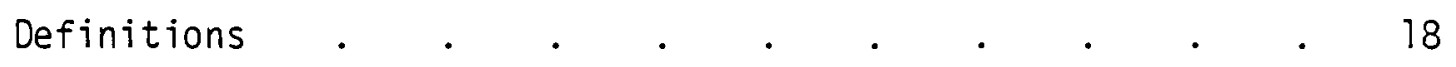

Criteria for HNEC Plants . . . . . . . . . . 18

Criteria for Dispersed Sites . . . . . . . . . . 19

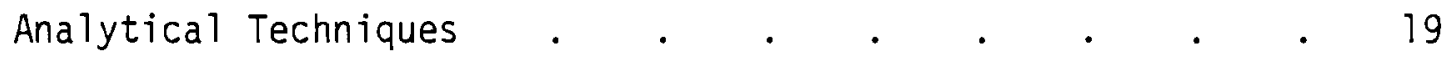

Earthquake Characteristics . . . . . . . . . 20

Ground Characteristics-Attenuation . • . • • • . 22

Probability of Earthquake Occurrence . . . • . . $\quad$. 22

Probability of Forced Outage . . . . . . . . . 26

Probability of Forced Outage Through

Failure of Essential Facilities . . . . . . . . 26

Probable Site Intensity . . . . . . . . . . . 28

Estimate of Outage Period . $\quad . \quad$. $\quad . \quad$. $\quad . \quad$. 29

Earthquake Risk . . . . . . . . . . . . . 32

REFERENCES - EARTHQUAKE . . . . . . . . . . . . . . . . . 34

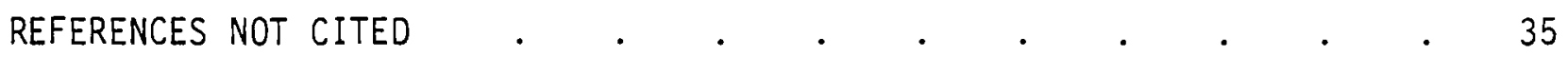

TORNADO

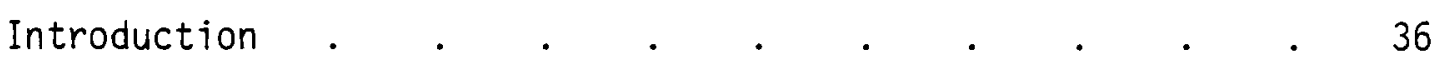

Nuclear Regulatory Commission Criteria . $\quad . \quad \ldots \quad$. $\quad . \quad 36$ 


\section{CONTENTS (contd)}

Direction of Tornado Movement . . . . . . . . 38

Tornado Start Points . . . . . . . . . . . 40

Regional Tornato Experience . . . . . . . . 40

Probability of Exposure to a Tornado . . . . . . 42

Probability of Occurrence . . . . . . . . . . 43

Probability of Forced Outage . . . . . . . . . 43

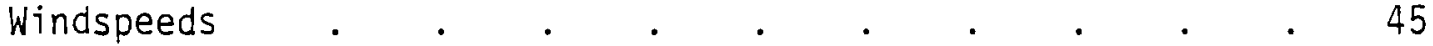

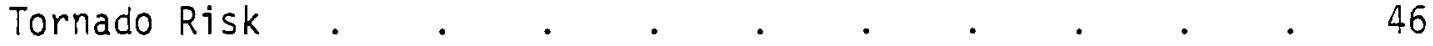

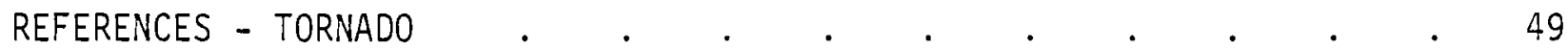

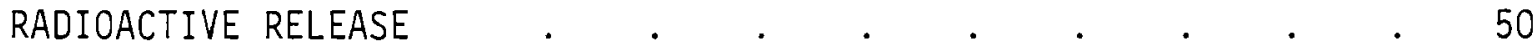

Introduction $. \quad . \quad . \quad . \quad . \quad . \quad . \quad . \quad . \quad .50$

PROBABLE CONSEQUENCES - AIR SUBMERSION .

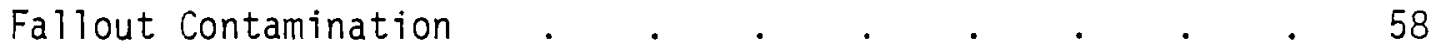

SUMMARY

REFERENCES - ACCIDENTAL RADIOACTIVE RELEASE . . . . . . . . 61

FLOOD . . . . . . . . . . . . . . . . . . 62

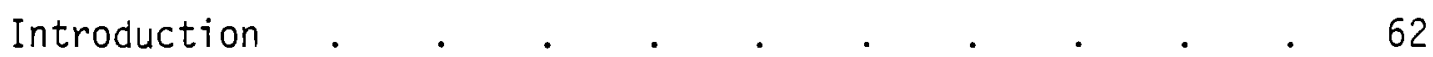

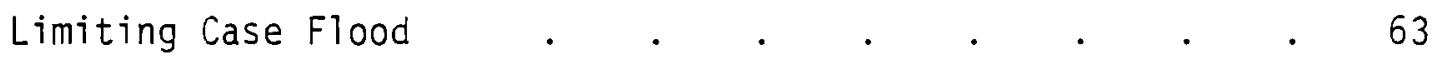

Probability of Exceeding the Probable Maximum Flood . . 63

Probability of Occurrence of Artificial Flood No. 1. . . 64

Probability of Forced Outage from Flood . . . . . 65

Risk from Floods . . . . . . . . . . . . . 66

REFERENCES - FLOOD

ASHFALL FROM CASCADE VOLCANOES

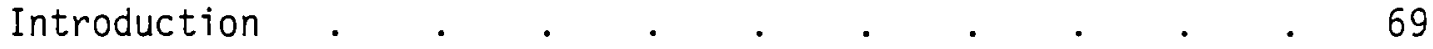

Properties of Ashfalls . . . . . . . . . . . . 69

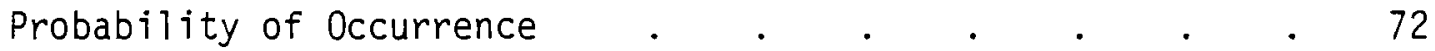

Probitity of Exposure . . . . . . . . . . . . $\quad$. 72

Effects of the Mount Usu Eruption . . . . . . . $\quad$. 74

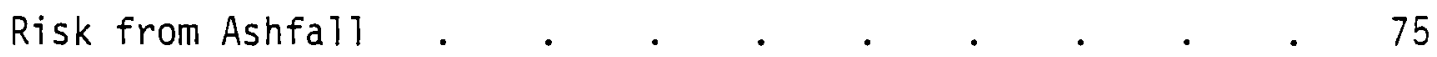

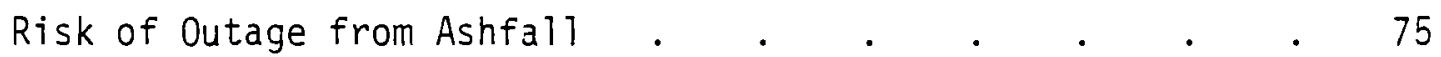

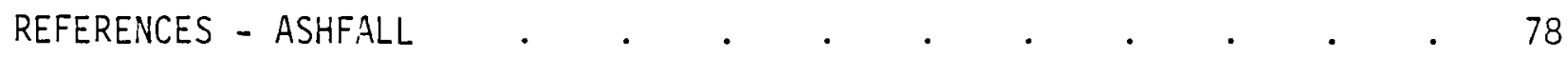




\section{CONTENTS (contd)}

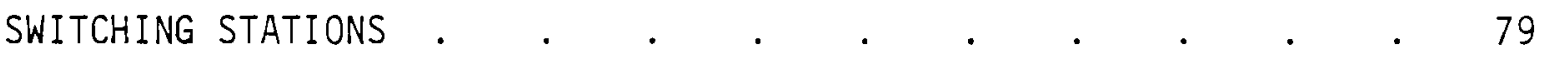

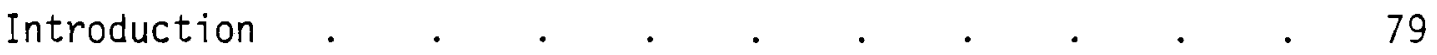

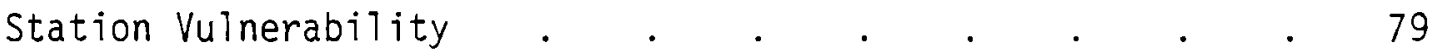

Earthquake Effects . . . . . . . . . . 80

Tornado Effects $\quad . \quad$. $\quad . \quad$. . . . . . . . 81

Radioactive Release Effects . . . . . . . . 82

Ashfall Effects . . . . . . . . . . . . 82

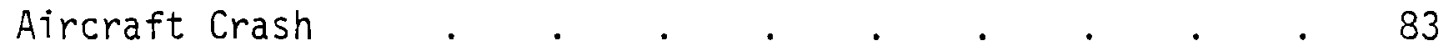

Sabotage . . . . . . . . . . . . 83

Flood . . . . . . . . . . . . . . . . 83

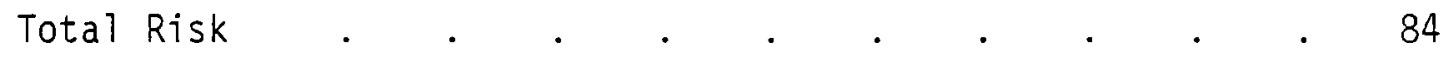

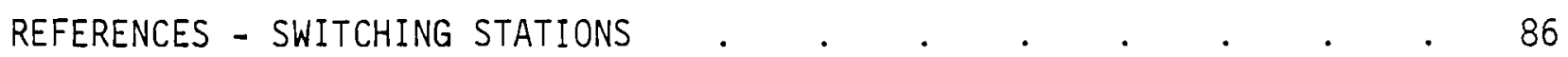

Risk of Forced Outage, HNEC versus DS . . . . . . . 87

VI. SIMULTANEOUS LOSS OF THERMAL AND HYDROELECTRIC CAPACITY . . 94

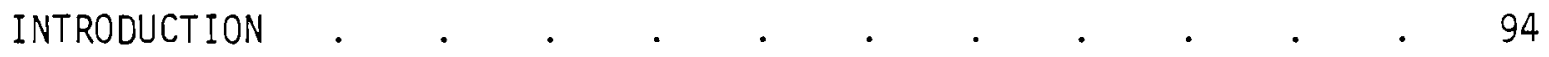

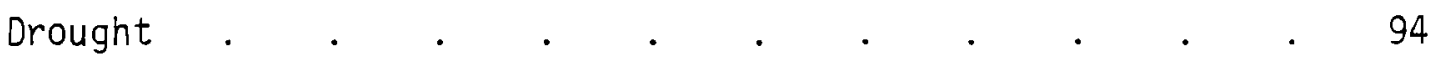

River Blockage or Diversion . . . . . . . . . . . 94

Floods . . . . . . . . . . . . . . . . . . . . 95

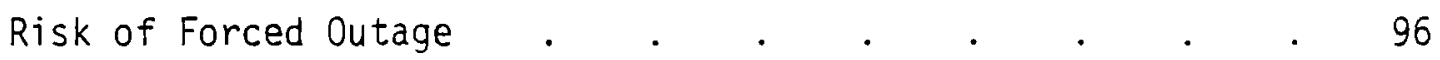

REFERENCES - SIMULTANEOUS LOSS OF THERMAL AND HYDROELECTRIC CAPACITY - 98

VII. IMPACT OF HNEC OUTAGES ON SYSTEM OPERATION.$\quad$. . . . . . . 99

INTRODUCTION

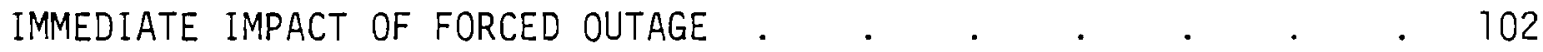

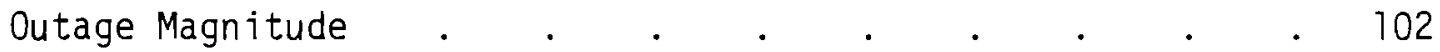

Onset of the Outage $\quad . \quad . \quad . \quad . \quad . \quad . \quad 103$

Capacity Reserves . . . . . . . . . . . 104

Role of the Hydro System in Providing Capacity Reserves . 104

Role of Pumped Storage in Providing Capacity Reserve . . 105

Role of Thermal Plants in Providing Capacity Rerserve . . 105

Emergency Power Inflow Over Tie Lines . . . . . 107

Load Shedding .

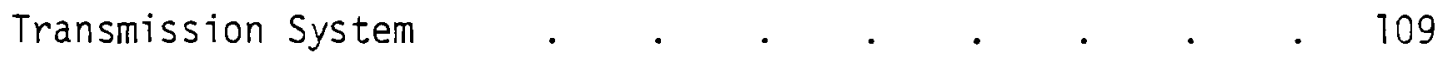




\section{CONTENTS (contd)}

Communications and Planning . . . . . . . . . 109

Summary of System Responses to Large Outages . . . . . 109

Restoration Period . . . . . . . . . . 109

FOLLOW-ON IMPACT OF FORCED OUTAGE

REFERENCES - IMPACT OF HNEC OUTAGES ON SYSTEM OPERATION • . . $\quad 118$

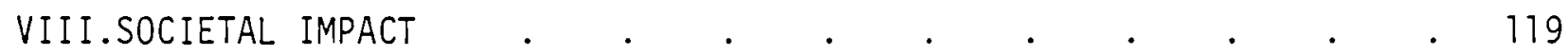

HEALTH AND SAFETY

Economic Effects . . . . . . . . . . . . 120

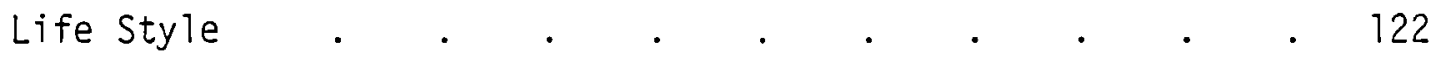

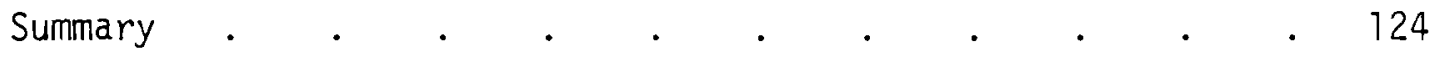

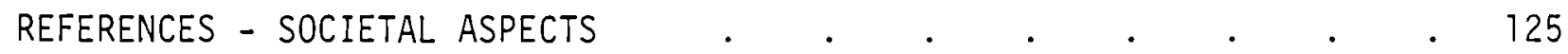

IX. CONSIDERATION OF REDUCTIONS IN THE RISK OF HNEC FORCED OUTAGES $\quad 126$

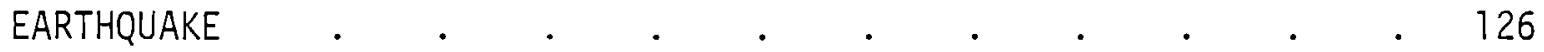

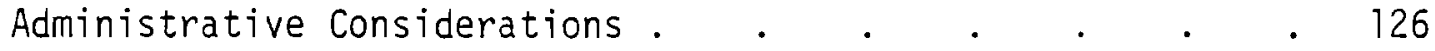

Design Consideration . . . . . . . . . . 127

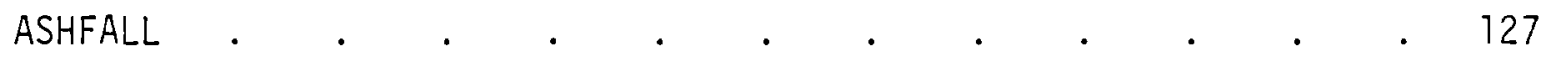

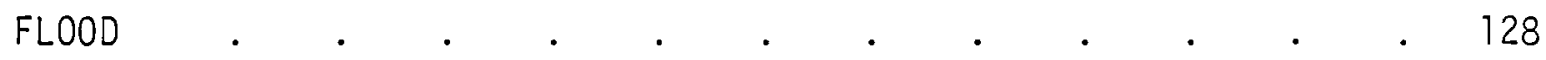

OTHER CAUSES

APPENDIX A - TYPES OF DISRUPTIVE EVENTS EXCLUDED

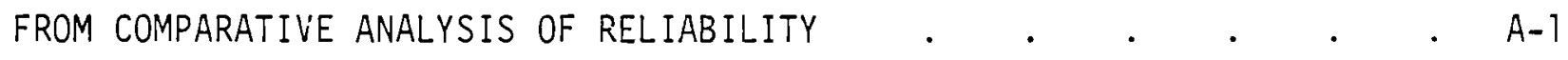

TYPES OF EVENTS EXCLUDED

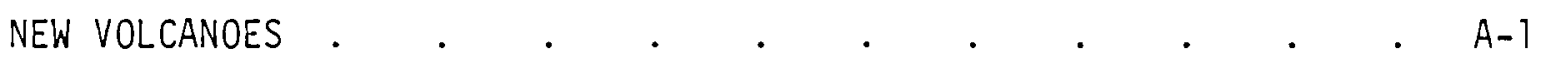

METEORITES

FLOODS OF LOW WATER LEVELS FROM RIVER CHANNEL DIVERSION OR BLOCKAGE A-2

EXTREMELY LOW RIVER FLOW

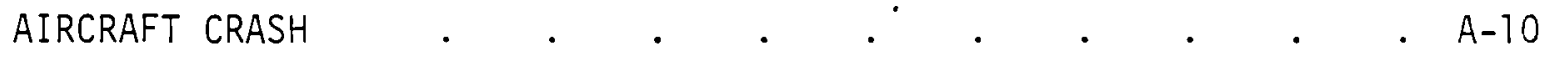

EXPLOSIONS . . . . . . . . . . . . . . . A-10

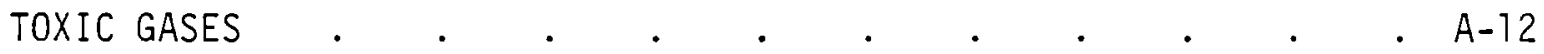

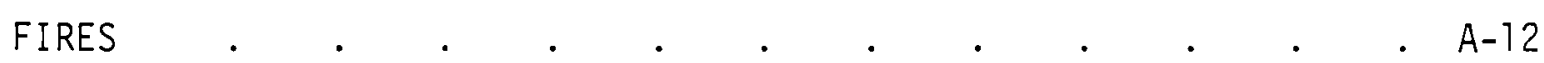

SODIUM FIRES . . . . . . . . . . . . . . . . . A-13

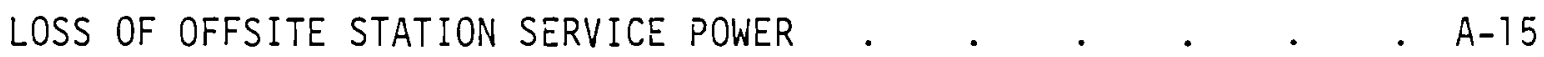

FAULT CLEARING

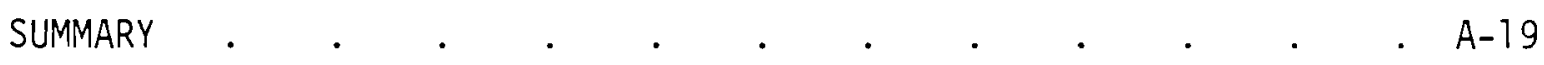




\section{CONTENTS (contd)}

REFERENCES - APPENDIX A . . . . . . . . . . . . A-21 APPENDIX B - COMPUTATION OF PROBABILITIES OF HNEC AND DS OUTAGES . - B-1

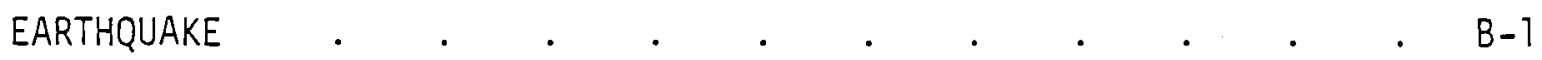

TORNADO . $. \quad . \quad . \quad . \quad . \quad . \quad . \quad . \quad . \quad . \quad . \quad$.

RADIOACTIVE RELEASE . . . . . . . . . . . . . .

EXTERNAL TOTAL-BODY DOSE FROM RSS ACCIDENT PWR-2 . . . . . B-16

ASHFALL . . . . . . . . . . . . . . B-22

APPENDIX C - EXAMPLES OF PACIFIC NORTHWEST SYSTEM

RESPONSE TO HNEC AND DS OUTAGES . . . . . . . . . . C C-1

EXAMPLE 1 - HNEC, 7161 AVERAGE MW DEFICIET PER

(OVER FOUR MONTHS) . . . . . . . . . . . . C-1

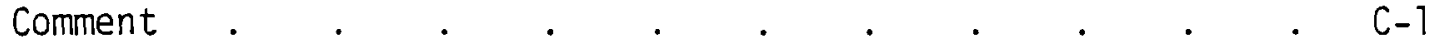

EXAMPLE 2 - HNEC, 7518 AVERAGE MW DEFICIT . . . . . C C-2

Comment . . . . . . . . . . . C C

EXAMPLE 3 - HNEC, 6533 AVERAgE MW SURPLUS . . . . . C-3

Comment . . . . . . . . . . C $\mathrm{C}-3$

EXAMPLE 4 - HNEC, 1300 AVERAGE MW SURPLUS . . . . . $\mathrm{C}-3$

Comment . . . . . . . . . . . C -4

EXAMPLE 5 - DS CASE, 1842 MW DEFICIT . . . . . . C -4

Comment . . . . . . . . . . . . . C $4-4$

EXAMPLE 6 - DS CASE, 1098 MW DEFICIT . . . . . . . C C 5

Comment . . . . . . . . . . . . C

RATIONALE FOR ADJUSTMENT OF NUMBERS OF DEFICIT

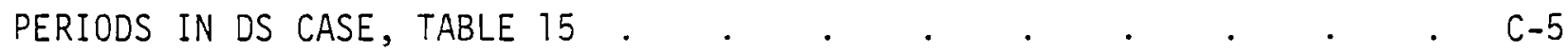

Calculations from Table 15 . . . . . . . C C 6

Calculation of User Energy Shortage Probabilities . . . C-6 


\section{LIST OF FIGURES}

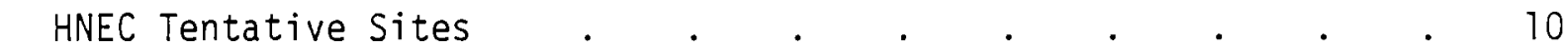

2 HNEC Switching Stations - 24 GW $(500 \mathrm{kV})$. . . . . . . 11

3 General Locations of Dispersed Sites . . . . . . . . . 12

4 Earthquake Zones Near Site Boundaries . . . . . . . . 21

5 Intensity IV, Isoseismal for Major Earthquakes in Pacific Northwest . 23

6 Isoseisma 1 Map - 1936 Milton-Freewater Earthquake _ . . . 23

7 Average Values of Maximum Accelerations in Rock . . . . . 25

8 Probability of Earthquake Occurrence . . . . . . . . . 25

9 Probability of Forced Outage of Generating Units

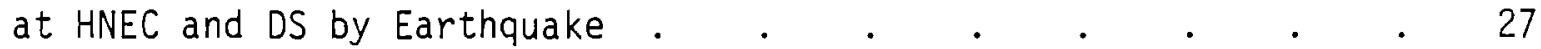

10 Risk of Both Capacity and Energy Generation

Loss from Earthquake at HNEC . . . . . . . . . . . . . 33

11 Pathways for Tornadoes at HNEC . . . . . . . . . . . . 39

12 Direction of Movement of Characterized

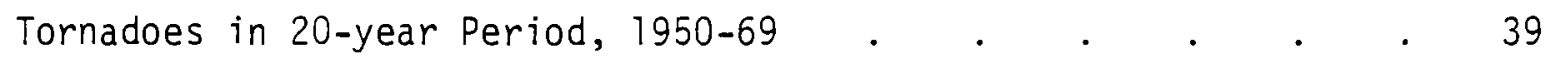

13 Probability of Forced Outage of Generating

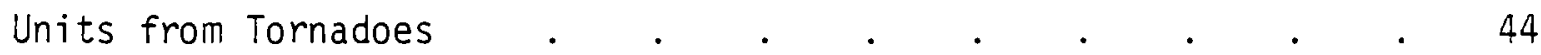

14 Risk of Capacity and Energy Generation

Loss from Tornado at HNEC . . . . . . . . . . . . . 48

15 Schematic Outiine of Consequence Mode 1

Radioactivity Release . . . . . . . . . . . . . . 52

17 Risk of Loss of Capacity and Energy Generation

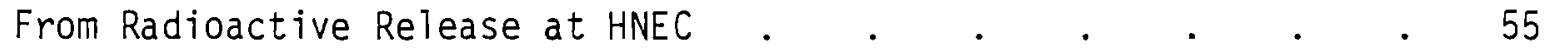

18 Discharge Frequency Curve Columbia River Near Richland . . . . 64

19 Risk of Loss of Capacity and Energy Generation From

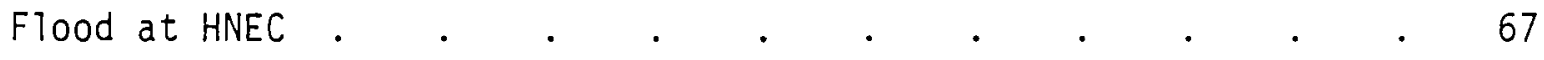

20 Volcanic Peaks and Plant Site Locations . . . . . . . . 71

21 Probability of Ash Discharge from Cascade Volcanoes . . . . 73

22 Probability of Forced Outage of Generating Units

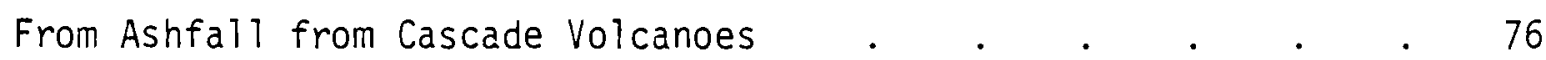




\section{LIST OF FIGURES (contd)}

23 Risk of Loss of Capacity and Energy Generation From Ashfall at HNEC . . . . . . . . . . 77

24 Risk of Capacity and Energy Generation Loss Caused by Switching Station Outage at HNEC . . . . . 85

25 Probability of Forced Outage - All Causes at HNEC . . . . 89

26 Probability of Forced Outage - All Caused at DS . . . . 90

27 Probability of Forced Outage, HNEC vs DS . . . . . . 91

28 Risk of Forced Outage at HNEC . . . . . . . . . . 92

29 Percent of Seasonal Instantaneous Peak Sustainable Hydro MW vs Number of Hours Per Day of Peaking . . . . 106

30 A Comparison of Risk of Energy Shortages Resulting From HNEC and DS Outages . . . . . . . . . . 117

B-1 Circular Areas Within which an Occurrence of an Earthquake of Richter 7.6 Cause Horizontal Accleration $\geq 0.125 \mathrm{~g}$ at the Center. B-3

B-2 Circular Areas Within Which an Occurrence of Earthquakes of Richter 6.6 Cause Horizontal Acceleration $\geq 0.125 \mathrm{~g}$ at the Center . B-3

B-3 Circular Areas Within Which an Occurrence of Earthquakes of Richter 5.6 Cause Horizontal Acceleration $\geq 0.125$ at the Center . . . B-4

B-4 Circular Areas Within Which an Occurrence of Earthquakes of Richter 5.2 Cause Horizontal Acceleration $\geq 0.125 \mathrm{~g}$ at the Center . . . B-4

B-5 Threshold Conditions for Forced Outage From Ashfall . . . B-23

B-6 Seasonal Migration of the Mean Wind Direction Off the Coasts of Washington and Oregon . . . . . . . B-24 


\section{LIST OF TABLES}

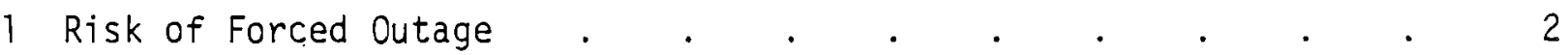

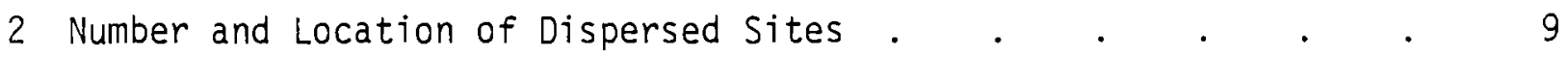

3 Events Considered for Analysis . . . . . . . . . . . . . 13

4 Factors to Adjust Western U.S. Earthquake Data to Site Areas . 26

5 Probable Horizontal Accelerations at Site, Within the

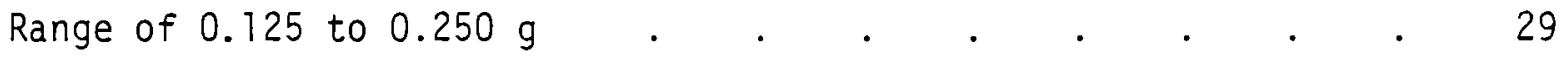

6 Design Basis Tornado Characteristics . . . . . . . . . . 37

7 Size Distribution of Tornadoes . . . . . . . . . . . . . 41

8 Tornadoes With Path Length Over 4 Miles . . . . . . . . 42

9 Tornado Windspeeds Associated With Path Area . . . . . . . 46

10 Dose to Personnel Remaining Inside $M$ Reactors as a Function of Probability of M Reactors Being Involved . . . . 56

11 Probability of Personnel Inside of M Reactors Receiving

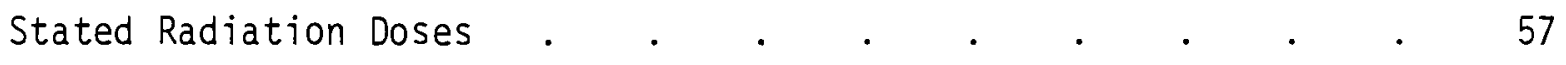

12 Comparison of Probability that a Certain Dose Rate Would be Received in the Control Room From Desposited Material During the First Day Following an Accident . . . . . . . . . 59

13 Probabilities of Persons in Control Rooms Receiving Dose Rates of $\geq 1 \mathrm{mrem} / \mathrm{hr}$ at Varing Intervals Following the Accident . 60

14 Reduction of Expected Radiation Dose Rates to People Within a Control Room From Ground Contamination With Time After Accident . 60

15 Summary of Risk of Interruption of Power Flow at Switching Station . 85

16 Hydroelectric Capacity on the Columbia River from Grand Coulee to the River Mouth, GW $\quad$. $\quad$. 96

17 Generation Affected by an Artificial Flood No. 1 in 1977 . • . 96

18 Generation Affected by an Artificial Flood No. 1 in 2005 . . 97

19 Summary of Generating Outage Relief Capabilities, Without Shedding of Commercial and Residential Loads . . . . . . 110

20 Number of Load-Loss Events Due to Generation Outages . . . . 114

21 Societal Impact of Energy Deficits . . . . . . . . . . . . 124

A-1 Summary of Effects of Miscellaneous Outage Causes . . . . . A-20

B-1 Calculation - Outage, Probabilities, Earthquake, HNEC . . . B-5 


\section{LIST OF TABLES (contd)}

B-2 Probabilities of OBE Accelerations Being Exceeded at $n, n+L$, etc. Generating Units . . . . . . . B-7

B-3 Probabilities of Outages Forced by Failure of Essential Facilities. . . . . . . . . . B-8

B-4 Possible Path in Which a Tornado Could Affect Two or More Clusters . B-9

B-5 Arrangement of Numbers of Units Affected, in Descending Order of Distance . . . . . . . . . . B-10

B-6 Event Probability . . . . . . . . . . B-11

B-7 Combined Probabilities . . . . . . . . . B-12

B-8 Collection of Like Numbers of Units Affected, HNEC . . . B-13

B-9 Initial Activity of Radionuclides in the Nuclear Reactor Core at the Time of the Hypothetical Accident . . . . B-15

B-10 External Total-Body Dose for Accident PWR-2 . . . . . B-16

B-11 Conditional Probability that Personnel in at Least 3 or 4 or 5 Reactors Would Experience the Stated Radiation Doses From the Passina Cloud Following a Release From a Reactor Accident at an HNEC B-17

B-12 Ground Level Summation . . . . . . . . . B-18

B-13 External Dose Conversion Factor vs Time. . . . . . B-19

B-14 Probabilities of 11 or More Reactors Having Different Radiation Levels 14 Days Following an Accident Assuming Preliminary Decontamination Efforts Have Reduced Radiation Levels by a Factor of 10 . . . . . . . . . . . B-21

B-15 Probability of Outage From Ashfa11, HNEC . . . . . B-25

B-16 Probability of Outage From Ashfa11, OS Case . . . . . B-26

B-17 Sum of Probabilities for $n$ Units Affected, DS Case Probabilities, $10^{-4}$. . . . . . . . . B-28

C-1 Data For Figure 30, Comparison of Risk of Energy Shortage . . C-8 


\section{SUMMARY AND CONCLUSIONS}

A nuclear energy center characteristically would have large amounts of electric generating capacity in a relatively small geographical area. For an HNEC (20 plants) in year 2005 this could amount to $30 \%$ of system capacity; typically utilities limit concentration of thermal plant generation to about $15 \%$ of system requirements. For this reason it is appropriate to examine the reliability of generation at a nuclear energy center to determine if it could be less than at dispersed sites because of local conditions and the close proximity of many generating units. In this report, reliability of generation at a Hanford Nuclear Energy Center (HNEC) ${ }^{(a)}$ is assessed by comparing it with that at Dispersed Sites (DS) ${ }^{(b)}$ throughout the Pacific Northwest.

Reliability as considered here is measured in terms of two sets of risks:

Risk of forced outage, which is the probability of the occurrence of events that could cause plant outages, with the loss of generating capacity and energy that would otherwise be available to the system as the consequence.

Risk of user power shortage, which is similar to the probability of forced outage as defined above, but considers in addition the probable state of system reserves at the time of a forced outage. A surplus or a deficit of capacity and energy to serve system loads is the consequence in this case. Risk of Forced Outage

Events that could cause greater and, or, more frequent outages in the HNEC case than in the DS case include earthquake, volcanic ashfall, release of radioactive contaminants, flood, switching station failure from aircraft crash and sabotage, and tornado. Other types of external forces or internal failures (of which 12 were analyzed) would affect HNEC and DS equally, and were excluded from the risk comparisons.

- (a) HNEC, a conceptual nuclear energy center containing 20 generating units of $1200 \mathrm{MW}$ capacity each, located at Hanford, Washington.

(b) DS, an alternative concept; namely, 20 generating units of similar capacity in six clusters at sites along the Columbia and Willamette rivers in Washington and Oregon. 
The combined risk from these causes, is estimated in Table 1 . The scenario considers a mature HNEC in the year 2005 with 20 units assumed in place. (a)

\section{TABLE 1. RISK OF FORCED OUTAGE}

\section{Consequent Generating Capability Loss}

\begin{tabular}{|c|c|c|c|}
\hline $\begin{array}{l}\text { Proba } \\
\text { Events }\end{array}$ & $\begin{array}{l}\text { ity, } \\
\text { Year } \\
\end{array}$ & Capacity, GW & $\begin{array}{l}\text { Probal } \\
\text { Duratio }\end{array}$ \\
\hline HNEC & DS & & \\
\hline $1.1 \times 10^{-2}$ & $1 . \overline{1} \times 10^{-2}$ & 5 & \\
\hline $6.0 \times 10^{-3}$ & $1.1 \times 10^{-5}$ & 12 & \\
\hline $1.6 \times 10^{-3}$ & 0 & 24 & 4 \\
\hline
\end{tabular}

From the above comparison, the risk of a $5 \mathrm{GW}$ outage at single clusters is approximately the same for HNEC and DS, but the risk of simultaneous outages at two or more clusters ( 12 to $24 \mathrm{GW}$ ) is substantially greater for HNEC. Although the risk of forced outage is greater for HNEC it may nevertheless be acceptable from the standpoint of the power user because of the effectiveness of reserves in the PNW system as reflected in the risk of power shortage.

\section{Risk of User Power Shortage}

The greatest possible forced outage is one involving 100 percent of the HNEC capacity on 1 ine, or 30 percent of the operating capacity on the system in the year 2005. If such an outage occurred instantaneous7y, it could be partially offset by spinning reserves and inflow of power over tie lines to the south; but system loads would have to be reduced by shedding some industrial load and about 20 percent of the system commercial and residential load. Additional reserves would be brought on line immediately following the onset of the outage, and a few hours later the system could enter a regime of management of an energy shortage of about 16 percent of normal usage, for a period of about four months.

(a) No analyses of interim periods were considered. 
The risk of user power shortage would be:

Probability: $1 \times 10^{-4}$ per year; once in 10,000 years.

Consequence: Shedding of 20 percent of mixed loads for up to six hours, followed by a 16 percent energy shortage for four months.

Instantaneous interruption of 30 percent of the system power flow would severely shock the system. If sufficient load were not shed, there would be substantial risk of system breakup, resulting in black-out pockets in the region for up to 12 hours duration. If black-outs did occur, they would threaten the health and safety of the public to some extent but probably not seriously if reasonable emergency procedures were in place and followed. Black-outs would not be a threat with instantaneous loss of 20 percent of the system capacity or less, or with a 30 percent loss in stages over an hour or more.

The impact of energy curtailment would be controlled by emergency measures now being put in place. With priority use of energy, the adverse economic effects of 16 percent curtailment are not expected to be severe. Lifestyles would be affected and real hardships can be expected for some whose employment would be curtailed.

The risk described above is for the greatest possible outage. Lesser outages would occur more frequently but have diminished consequences. For example, the risk of interruption of half of the HNEC operating capacity, would be:

Probability: $9 \times 10^{-4}$ events per year; once in 1100 years.

Consequences: Shedding of about 10 percent of mixed loads in PNW for tens of minutes until added reserves are placed on line, with no following load curtailment. (A 5\% reduction in energy consumption resulted largely through conservation efforts as a result of the drought of 1976-77.)

Danger of blackouts under such conditions is virtually eliminated, and societal effects would be considerably reduced. Societal risks from substanial generating loss at an HNEC are more meaningful when compared with those from natural disasters (rather than with DS risks). 
As a general rule society seems to be willing to accept accident probabilities of $10^{-7}$ events per year or less where the consequences could be considerable loss of life, or probability in the range $10^{-6}$ to $10^{-4}$ where some loss of life may occur along with extensive property loss. Somewhat greater risks are acceptable where the property or economic loss would be moderate with little or no loss of life such as from a maximum HNEC outage.

Under these criteria the HNEC reliability risks described above may be acceptable. However, if they are not, the risk may be reducible by a factor of 10 or more. Earthquake is the predominant contributor to HNEC risk. Reduction of that contribution by a factor of 10 would result in an overall reduction of the risk by approximately the same factor. Modifications to the NRC inspection requirements, along with designing essential power handling structures and equipment outside the reactor facility to an earthquake resistance level somewhat above that of the Operating Basis Earthquake (OBE), have reasonable prospects of being effective and feasible.

CONCLUSIONS

Conclusions reached as a result of this study are:

1. The risks of forced outage of generating capacity arising from the kinds of events analyzed herein are greater for HNEC than for the DS case site configuration.

2. With HNEC the probability of occurrence of the greatest capacity and energy shortages as felt by the power users is once in 10,000 years. The consequences would not be expected to include loss of life or great economic loss.

3. If this risk is deemed unacceptable, it can be significantly reduced in ways now considered feasible.

4. The reliability of energy centers relative to the risk of loss of power to users is definitely site-dependent. The HNEC has space available for relatively wide separation of clusters within the Center to increase their reliability by increasing the independence of each from activities at another cluster. More importantly, the HNEC has the advantage of being tied to a hydroelectric system with a large amount of energy storage capacity which lessens the consequences of large outages of thermal plants in the Pacific Northwest System. 
5. The major uncertainties in this assessment are the risks from ashfall, due to sparcity of data; and the duration of outages from all catastrophic events, due to lack of statistics because of the rarity of such occurrence at major thermal power plants.

6. The potentially most productive areas for additional study are: 1) finding ways in which the safety of nuclear plants following an OBE (Operating Basis Earthquake) but less than an SSE (Safe Shutdown Earthquake) could be assured without requiring immediate shutdown of operating plants for inspection. Permission to stagger the inspections following an earthquake less than an SSE would reduce the probability of the greatest HNEC power shortage from once in 10,000 years to once in 40,000 years (perhaps information from seismic instrumentation in the facility will become sufficiently acceptable to relieve the current regulation to shut down immediately to inspect), and 2) estimating the monetary costs of designing the non-Category I portions of the plant essential to continuous generation, to earthquake resistance criteria somewhat above code levels. 


\section{INTRODUCTION}

A nuclear energy center (NEC) would have a large number of generating units that could be affected simultaneously by natural disasters or that could experience cascading failures triggered by a serious accident at one of the units. In the nuclear energy center concept, a number of generating units are relatively closely spaced, and the reliability of the generation as a result of their proximity could have an important bearing on the feasibility of the concept. The risk of forced outage $(a)$ of a large amount of capacity must be carefully assessed. Risk is a combination of the probability of occurrence of a causative event, and the consequences of that event. The consequences of a forced outage are its impact on the Pacific Northwest generating and transmission system, and on the power consumer if lost generation exceeds reserve capacity and loads must be dropped.

These risks have been discussed briefly in prior studies on NECs. $(1,2,3)$ In this report comparative risks between an energy center at HNEC and at dispersed sites in the PNW have been analyzed in more detail.

The reliability of a nuclear energy center at Hanford (HNEC) was compared to that of a dispersed case (DS) consisting of sites at generalized locations in washington and Oregon. HNEC is assumed to contain up to 20 generating units of $1200 \mathrm{MW}$ net capacity each. The dispersed case is assumed to contain an equal number of units in six clusters of three or four units each.

The base assumptions are similar to those adopted in prior studies of transmission for an HNEC. (b)(4,5) The analysis is not intended to apply generally to nuclear energy centers since its results are strongly influenced by regional characteristics and the unique configuration of the HNEC case. However, certain inferences regarding a general case can perhaps be made as a result of the analysis.

(a) The assumption that load growth in the region to the year 2005 could be balanced by 24 GW of capacity at HNEC in addition to existing generating facilities at other sites. Thus future thermal plants, not now committed to other sites are assumed for this study to be located at HNEC.

(b) A forced outage is defined as an unplanned loss of generating capacity which must be immediately replaced by reserve generating capacity. 
Three generating units are under construction by the Washington Public Power Supply System (WPPSS) at Hanford. The characteristics of these plants are used as examples in the analysis.

Under the assumptions adopted for the study, the generating capacity in the HNEC case would be in five clusters with distances between adjacent clusters of $3 \mathrm{mi}$ to $8 \mathrm{mi}$.

In the DS case the capacity would be in six clusters, within a triangular area defined by Hanford, WA, Portland and Eugene, OR.

Causes of forced outages in both cases may be categorized as internal or external, and man-made or natural. Exposure to failure from internal causes would be approximately equal for the two cases. With the exception of certain types of failure in a common switching station, a failure would affect only one plant at a time. If one unit fails within a cluster and transmits failure to an adjacent unit in that cluster, however, an internal failure could affect more than one unit. Whenever a failure transmits no farther than the confines of one cluster, exposure is the same for the HNEC and DS cases. If the event could affect adjacent clusters at HNEC, a potential difference in risk between the HNEC and DS cases would result. Only one type of communicable failure for either case has been hypothesized, namely, a class 9 accident with consequent release of radioactive gases and particulates that are airborne to plants in adjacent clusters causing them to be shut down for evacuation of personnel.

If disturbances due to external causes are sufficiently widespread and if the conditions generated by them are beyond design levels, these obviously can affect more than one cluster in the HNEC case. For such causes to affect more than one such cluster in the DS case they would have to be extremely widespread. Severe earthquake, volcanic ashfall, and widespread floods are examples and these possibilities are examined in the report.

A forced outage can occur through failure of either the nuclear or nonnuclear portions of the plant. For safety reasons, the nuclear portions are built to more rigid standards than are the non-nuclear portions, and can be expected to withstand greater stresses from external causes without failure than can the non-nuclear portions. However, after an earthquake exceeding the 
OBE level, but less than the SSE, shutdown for inspection is required whether the plant is damaged or not. This would constitute a forced outage and loss of generation as serious as any shutdown forced by damage to essential facilities.

The concern here is the risk of losing more than one cluster at one time, thereby stressing the capacity reserves on the system, plus the risk of losing this capacity for long periods of time thereby depleting the energy reserves of the system. The loss of one cluster of four units is considered an acceptable (if undesirable) risk since it may have approximately equal probabilities of occurrence in either the HNEC or DS cases. Therefore, the difference in probabilities of concurrent outages of more than four units in either the HNEC or DS is the key element in the study. Note that the average forced outage rate of al1 the units studied over a period of years may be essentially equal between the HNEC and DS cases. (a) Further, if no single outage were greater than, for example, $5 \mathrm{GW}$ from either case, the impact on the system would be manageable. If one single outage were to involve 15 to $24 \mathrm{GW}$, however, the impact would be serious. (In view of the consequences, the probability of the latter occurrence must be low for the risk to be acceptable).

The consequences must be understood in the acceptance of even a very low level of probability of occurrence. The consequences of a forced outage of 15 to $24 \mathrm{GW}$ on the PNW system are examined as of the year 2005, when total system generating capacity is expected to total more than $80 \mathrm{GW}$. Assumptions that are made regarding the state of the system at that time and the measures that might have to be taken to manage such an outage are discussed later in the report. Societal impact following the power curtailment is discussed. Finally, consideration is given to possible modifications to the HNEC case that might result in reduction of probability of major outage or in reduction of the impact.

(a) Any failures due to generic weaknesses in nuclear plant design or construction would involve equal capacities in the HNEC and DS cases. 


\section{DESCRIPTION OF HNEC AND DS CASES}

The HNEC case in its full development in the period 2000-2005 consists of twenty $1200 \mathrm{MW}$ (net) units located at site areas 1 through 5 shown in the map of the Hanford reservation, Figure 1 . This assumes that essentially all new therma 1 plants on the system, other than those now committed elsewhere wil1 be sited at HNEC. Output from the generating units is assumed to be fed into three switching stations which are connected to the $500 \mathrm{kV}$ transmission network. The switching arrangement is shown in Figure 2. A preliminary analysis indicates that the critical time with respect to the reliability of the HNEC would be at or near its full development. The HNEC generation in terms of percentage of total generation in the system would be greatest. For this reason the risk comparisons between HNEC and DS cases are made with 20 units in place.

The Dispersed Case deals with generalized rather than specific sites, since specific sites have not been designated or, to our knowledge, studied in detai1. They are intended to be representative of sites that might be selected in view of growth at load centers, availability of cooling water, seismicity, and other general siting criteria. The generalized site areas, taken from Reference $4^{(6)}$ are shown in Table 2 . These general site areas are shown on the map, Figure 3 . One switching station would serve each cluster.

For purposes of this study the arrangement of generating units within each cluster is assumed to resemble that of the Palo Verde or Alan Barton plot plans for three or four units, or the Hanford arrangement of three to five units.

TABLE 2. Number and Location of Dispersed Sites

\begin{tabular}{|c|c|}
\hline Site Areas & Gene \\
\hline Hanford & $\begin{array}{r}3 \text { (in addi } \\
\text { present } 1\end{array}$ \\
\hline $\begin{array}{l}\text { Pebble Springs or } \\
\text { W. Roosevelt }\end{array}$ & 4 \\
\hline N.E. of Portland & 4 \\
\hline Willamette Valley, A & 3 \\
\hline Willamette valley, B & $\frac{3}{17}+3=20$ \\
\hline
\end{tabular}




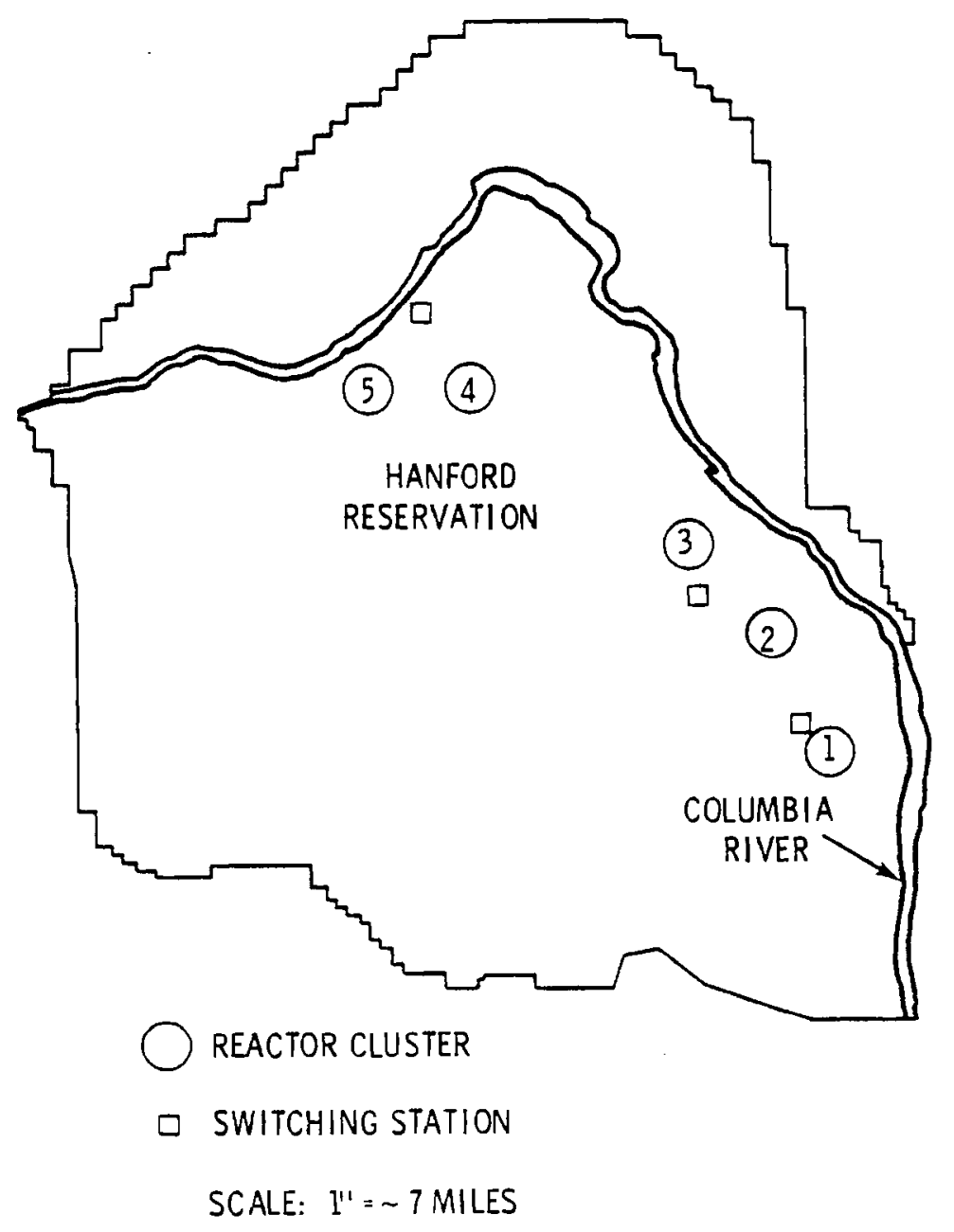

FIGURE 1. HNEC Tentative Sites 


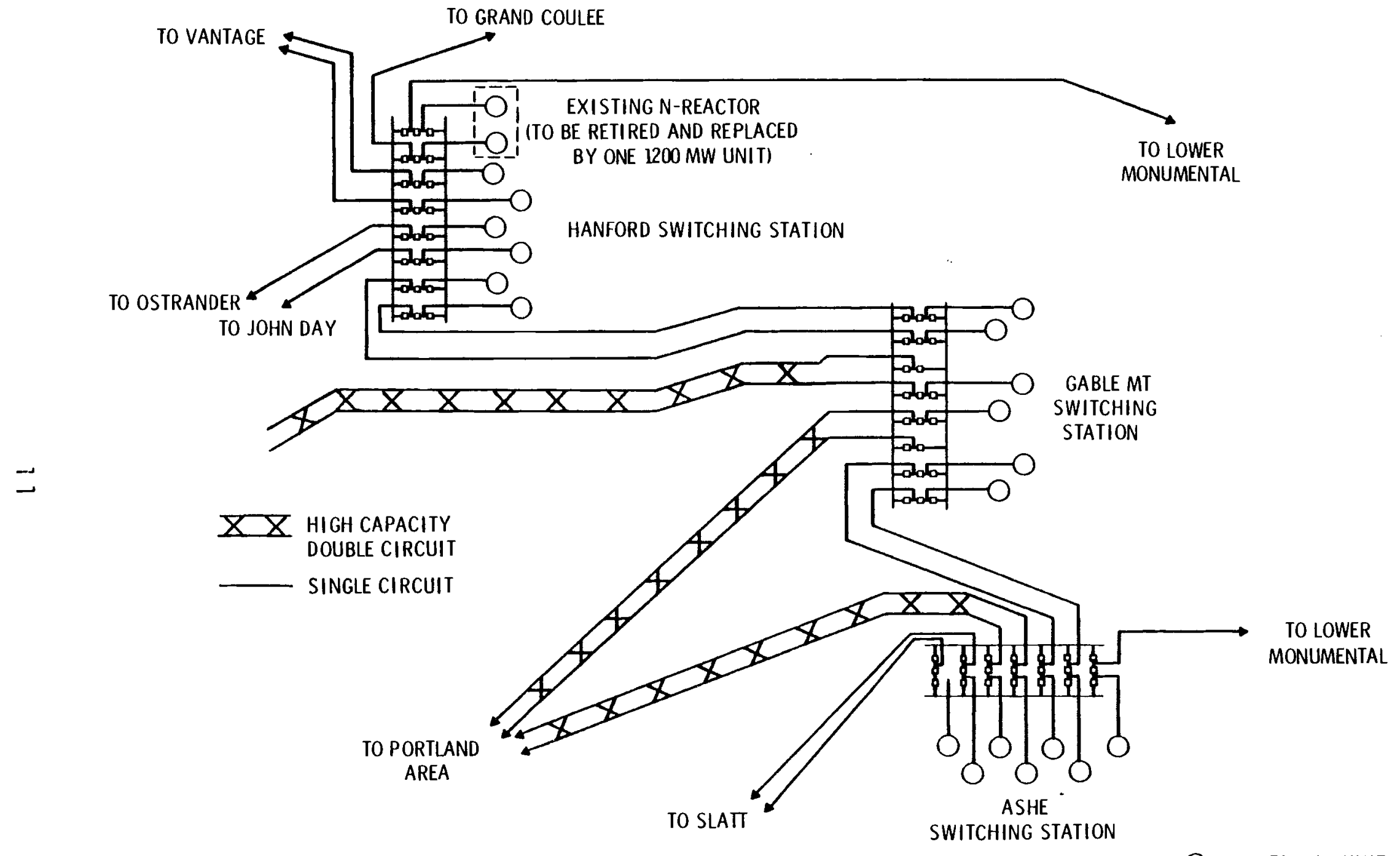

O ONE REACTOR UNIT

FIGURE 2. HNEC Switching Stations - 24 GW (500 kV) 


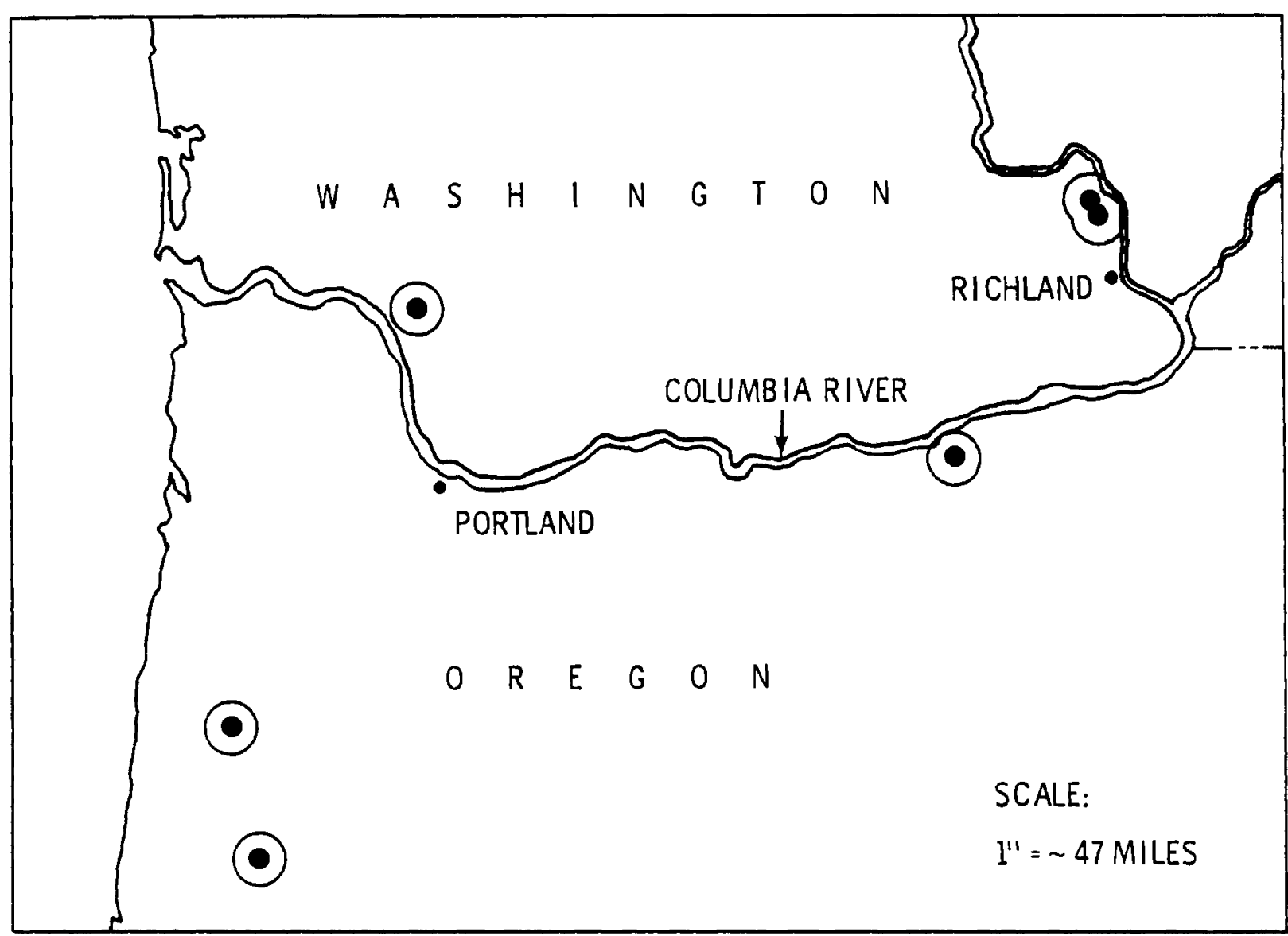

FIGURE 3. General Locations of Dispersed Sites

$$
\text { REFERENCES - I, II AND III }
$$

1. USNRC, Nuclear Energy Center Site Survey--1975, NUREG-0001, January 1976.

2. USAEC, Evaluation of Nuclear Energy Centers, WASH-1288, January 1974.

3. Battelle PNL Staff, Harold Harty, Project Manager, Hanford Nuclear Energy Center, An Interim Conceptual Study, BNWL-B-458, VC-80, November 1976.

4. Battelle Northwest Laboratories, Electric Power Transmission for a Hanford Nuclear Energy Center, BNWL-B-426, UC-80, September 1975.

5. R. L. Richardson and W. J. Dowis, Station Service Power Supply for a Hanford Nuclear Energy Center (HNEC), BNWL-2076, UC-80, December 1976.

6. Oregon Nuclear and Thermal Energy Council, State-Wide Siting Task Force Report, July 1974. 


\section{INITIATING EVENTS}

Events that conceivably could cause forced outages at more than one cluster concurrently were screened. Those considered are listed below. The reasons for excluding the events 1 isted under that caption are developed in Appendix A. Briefly, either the probability of the event was too low to have any significance, or the risks associated with the event were approximately equal between the DS and HNEC cases.

TABLE 3. Events Considered for Analys is

Natural

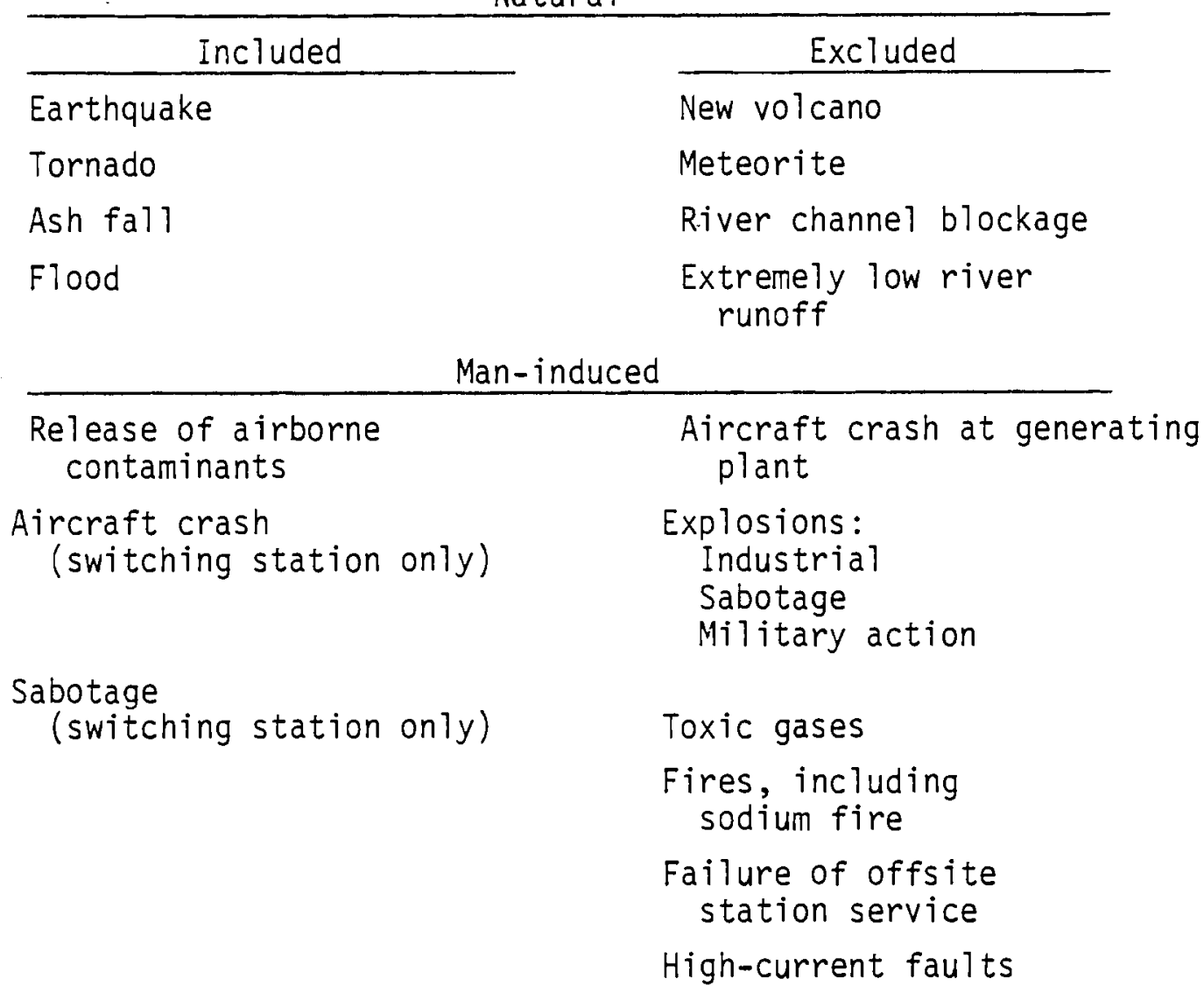




\section{COMPARISON OF RISKS}

\section{RELIABILITY STANDARDS}

Reliability in the larger sense includes the effects of both scheduled and forced unplanned outages. Any difference in reliability between plants at these sites would be in the number and length of forced outages. Scheduled outages would be expected to be equal for a plant of the same design whether it was at a center or a dispersed site. Scheduled inspections and repairs might be accomplished in less time at a center because of the greater work forces that may be concentrated there, but in this report no differences were assumed to exist.

A nuclear generating plant of 1200 MW capacity has an expected forced outage rate of $5.5 \%$, or $482 \mathrm{hr} / \mathrm{yr}$. (1) (System reserve needs are determined in part by this rate.) Of that total, less than two hours, on the average, are due to external events of the type of concern in this study. (2) The major cause of forced outage are equipment failures and malfunctions, and operator error. If HNEC outages from external events were to double or triple, it would make 1 ittle difference in the $5.5 \%$ outage rate above, since the doubling or tripling would apply to just the $2 \mathrm{hr}$. On the other hand, if on rare occasions 20 large generating units were to be affected by a single event, the temporary demand on system reserves could be enormous. The types of outages of concern here have very low probability but serious consequences. Adequate reserves for such contingencies cannot be maintained economically. The outcome of this study is to ascertain the extent to which normal reserves, based on conventional forced outages of lesser magnitude, would provide for system service and stability in the event of the rare HNEC outage involving more than one cluster.

It is apparent that there is no norm for forced outages of generating capacity of the magnitude of those to be discussed. The risks necessarily have to be evaluated on the basis of other risks assumed by society. The risks examined here pertain to power outages and energy shortages that could result in economic loss. Some loss of life could result, but such risk is expected to be minimal and was not studied in detail. 
The major focus here is the loss of generation with its effect on the production of goods and services and the lifestyle of the power consumer.

As a general rule society seems to be willing to accept accident probabilities of $10^{-7}$ or less per year where the consequences could be considerable loss of life, or probability in the $10^{-4}$ to $10^{-6}$ range when some loss of life may occur along with extensive property loss. Somewhat greater risks are acceptable when the property loss would be moderate with little or no loss of life. For events of major magnitude, each case has to be examined separately in relation to the benefits of the endeavor versus its risks.

\section{TECHNIQUE OF RISK ASSESSMENT}

A basic assumption in the assessment of difference in risk between HNEC and DS cases is that the risk of an outage of all units in one cluster is approximately the same in both cases. Any difference in risk arises from the effects of a single event on additional clusters at HNEC, effects which are avoided in most DS cases because of the greater distances between sites. The risk of forced outage of all units at a single cluster at different sites may be somewhat different, because of the site characteristics. However, these differences are compensated sufficiently in the plant design, and are not included in this analysis.

The causes of outages examined include those such as earthquake and ashfall in which the effects may be felt over wide areas, and those such as tornado and accidental radioactive release in which the effects are more localized. In all cases, however, the techniques employed are similar. Two sets of probabilities are developed 1) that of the occurrence of the event, and 2) that of multiple clusters being exposed to the event. These probabilities are combined to arrive at a cumulative probability distribution for the number of generating units at which design levels would be exceeded. A third set of probabilities is applied for earthquakes of various severity levels resulting in failure of essential equipment other than Category I for the purpose of examining the effect of NRC post-earthquake inspection requirements. Estimates are then made of the time required to inspect and or repair the plants. 
The probability of occurrence of the initiating event is taken from authoritative sources to the extent that such information is available for the PNW and specificaliy for the HNEC site in Eastern Washington. When such source information is too general or data are too sparse, the probabilities are modified through the use of records on local incidence, or through simulations based on available data.

Probabilities of exposure of multiple clusters to events are obtained by compiling all possible ways in which 1 to 20 generating units can be affected by a single cause, and compiling a probability distribution of numbers of units forced out of service per event. The number of units exposed is a function of configuration of clusters, tendency of the disturbing force to move in certain directions, and the distance over which threshold intensity is exceeded at exposed sites. In all cases, the probability of exposure of multiple units (sites) to an event is independent of the occurrence of that event.

Certain assumptions were required to develop probabilities of exposure. For example, it was assumed that attenuation of earthquake ground motion be uniform in different directions from the epicenter, that tornadoes move in a straight line, and that wind direction during an accidental release of airborne contaminants will not change during the release so that deposition will be within a $22.5^{\circ}$ sector.

The results of developing the above probabilities are elements of histograms of $P(E)$, where $E$ is relative exposure in terms of units exposed per event, and $P(F)$, where $F$ is frequency of occurrence in terms of events per year. Combining these two elements gives $P(N)$ where $N$ is number of units forced down in terms of units per year:

$$
P(N)=P(E) \times P(F)
$$

$P(N)$ values are generated for each kind of event affecting more than one cluster. For example, consider exactly 7 units affected by tornadoes, $\left[P(N)_{7}\right]$. This is all cases of tornadoes of various wind speeds, direction, path widths acting on the HNEC and DS configurations of clusters to result in a forced outage of 7 units at either. All probabilities of $P(N)_{7}$ are added similarly, probabilities of tornadoes forcing $2,3,4,5$, and 6 units out of service are discretely summed. 
The above sums form histograms of numbers of units affected by an event, with which cumulative probability curves are constructed as it is detailed in later sections.

The probability that a generating unit would be forced out of service when the design threshold conditions are encountered is taken as 1.0 for all types of events. For example, if an earthquake is at or beyond the OBE level, if flood waters reach a given level, or two inches of ashes have been deposited, it is assumed that there is a probability of 1.0 that the plant would have to shut down. However, in one case, that of earthquake, data are available on the probability of failure versus the degree to which the threshold has been exceeded. These data were used in supplementary calculations to illustrate the probabilities of given amounts of generating capacity being forced out of service by earthquakes in the absence of current NRC inspection requirements applying in such cases.

Information on extent of damage versus intensity of the event was obtained partially from literature and discussions with operators of facilities who had experienced such incidents, and partially from engineers, plant operators, and maintenance people with knowledge based on the vulnerability of plant structures and equipment. The estimate of repair time was approached by setting upper and lower bounds.

The above procedures are carried out for each of the events considered, and the results added to arrive at the overall risk difference.

\section{REFERENCES V, Reliability, Standards, and Technique}

1. Pacific Northwest Coordination Agreement, Contract No. 14-02-48221, September 1964.

2. EEI Equipment Availability Task Force, Equipment Availability Fossil Component Cause Code Summary Report - 1973.

3. Chauncey Starr, Benefit-Cost Studies in Sociotechnical Systems, Perspectives on Benefit-Risk Decision Making, NatT. Academy of Engineering, Apri1 26-27, 1971 . 


\section{EARTHQUAKE}

Introduction

Under certain circumstances, an earthquake could shut down all generating units at an HNEC. An estimate of the probability and consequences of such an event is made in this section, and the results are compared with those of a parallel study of effects of earthquake on dispersed plants.

Earthquakes that would cause horizontal acceleration, at a site, at the OBE level ( $0.125 \mathrm{~g}$ at Hanford) would necessitate shutdown of a plant at that site for inspection. If the ground shaking were above OBE horizontal acceleration there would be some potential for damage to code-design equipment and structures. After inspection, and repair of any damage to essential facilities, the plants could be returned to service. Safety-related facilities would have an extremely low probability of damage for accelerations below the SSE level $(0.250 \mathrm{~g}$ at Hanford); i.e., too low to be of interest in this study.

\section{Definitions}

Appendix A to 10 CFR Part 100 defines the Safe Shutdown Earthquake (SSE) as "based on an evaluation of the maximum earthquake potential...", and the Operating Basis Earthquake (OBE) as one that "...could reasonably be expected to affect the plant site during the operating life of the plant...".

The nuclear reactor and its appurtenances essential to plant safety are designed for ground accelerations corresponding to the SSE intensity level, and the remainder of the plant to building codes in which the design ground accelerations usually lie close to those of the OBE. (11)

Criteria for HNEC Plants

The following statements taken from Reference 3 present the basis for selection of the OBE and SSE design levels for existing Hanford plants (a) and presumably for all units at HNEC.

(a) These are units 1,2 , and 4 under construction for the Washington Public Power Supply System (WPPSS). 
"The maximum vibration level at the site from historic earthquakes has been $0.015 \mathrm{~g}$ associated with the site intensity IV(MM) from the Milton-Freewater earthquake. The greatest vibration level expected at the site from the 'maximum earthquake' is $0.125 \mathrm{~g} . "$

"An $0.25 \mathrm{~g}$ vibration level is assigned as a value at ground surface in the site area. This value is consistent with the conservatism previously adopted for design criteria at the Hanford reservation and is consistent with the vibratory accelerations associated with an intensity VIII(MM) earthquake.... . This earthquake is assigned to the Rattlesnake-Wallula alignment, the closest tectonic structure of significance to the site. Since no attenuation was taken in the selection of the SSE, this is a conservative approach. $0.25 \mathrm{~g}$ acceleration value is adopted for the SSE."

"An OBE equivalent to $0.125 \mathrm{~g}(1 / 2 \mathrm{SSE})$ wi11 be used in the design of all Seismic Category I structures. The chosen value for the OBE is based on the greatest vibration level expected at the site," during the normal lifetime of the facility.

Criteria for Dispersed Sites

Local seismic conditions at the DS sites may be such that the design accelerations could differ from those in effect at Hanford. The OBE design points for plants planned for western Washington are $0.16 \mathrm{~g}$ and $0.12 \mathrm{~g}$. However, to simplify the analyses of this report it can be assumed that the OBE and SSE levels would be approximately the same as at Hanford. Small differences in the OBE and SSE levels from those in effect at HNEC would not affect the validity of the analysis to follow.

Analytical Techniques

The objective of this part of the study was to estimate the probability of outage of $(x)$ megawatts of capacity as a function of the probability of a) occurrence of earthquakes of different magnitudes, and b) two or more clusters being at a distance from the epicenter at which they would be subjected to horizontal ground acceleration of $0.125 \mathrm{~g}$ or greater. 
As a minimum, the outage time will be that required by NRC for inspection. As a maximum, the outage must include time for the above and necessary repairs from actual damage from an earthquake of probable intensity (above $0.125 \mathrm{~g}$ ).

A simplistic approach is the only one possible within the scope of this study. In this approach, computed free field ground movement at the study sites due to earthquakes centered in sensitive zones common to two or more clusters determines the probable number of generating units affected by $a$ given earthquake. It is assumed that transmission of vibratory movement through rock is uniform in all directions, giving a circular isoseismic pattern. It is not expected that perfect circular isoseismic patterns would actually develop but, as discussed under Attenuation, such patterns would be true enough to give meaningful comparisons between the HNEC and DS case outage probabilities.

Also, no cognizance was taken of known faults in the immediate vicinity of sites. Those at Hanford were, of course, taken into consideration in the setting of the SSE for WPPSS plants, but the effects of any faults near or between DS sites of this study were ignored. The possible effects of any vibratory feedback of plant structures to the soil was not examined, but it is assumed that these would not extend beyond the area containing a cluster.

Those areas in which earthquakes are expected to occur most frequentiy were identified. (6)

"Significant potential epicentral areas were defined based upon the seismic history of the region and a general consideration of known tectonic structures. The maximum earthquake magnitude that can reasonably be expected to occur in each significant potential epicentral area was predicted by a statistical consideration of historical earthquakes of different magnitudes and a consideration of known fault conditions."

The location of sites relative to these seismicly active areas as shown in Figure 4 was considered in the adoption of earthquake frequencies to be described later.

Earthquake Characteristics

This study is concerned with single earthquake events. It is recognized that earthquakes can occur at different epicenters in the same region within 


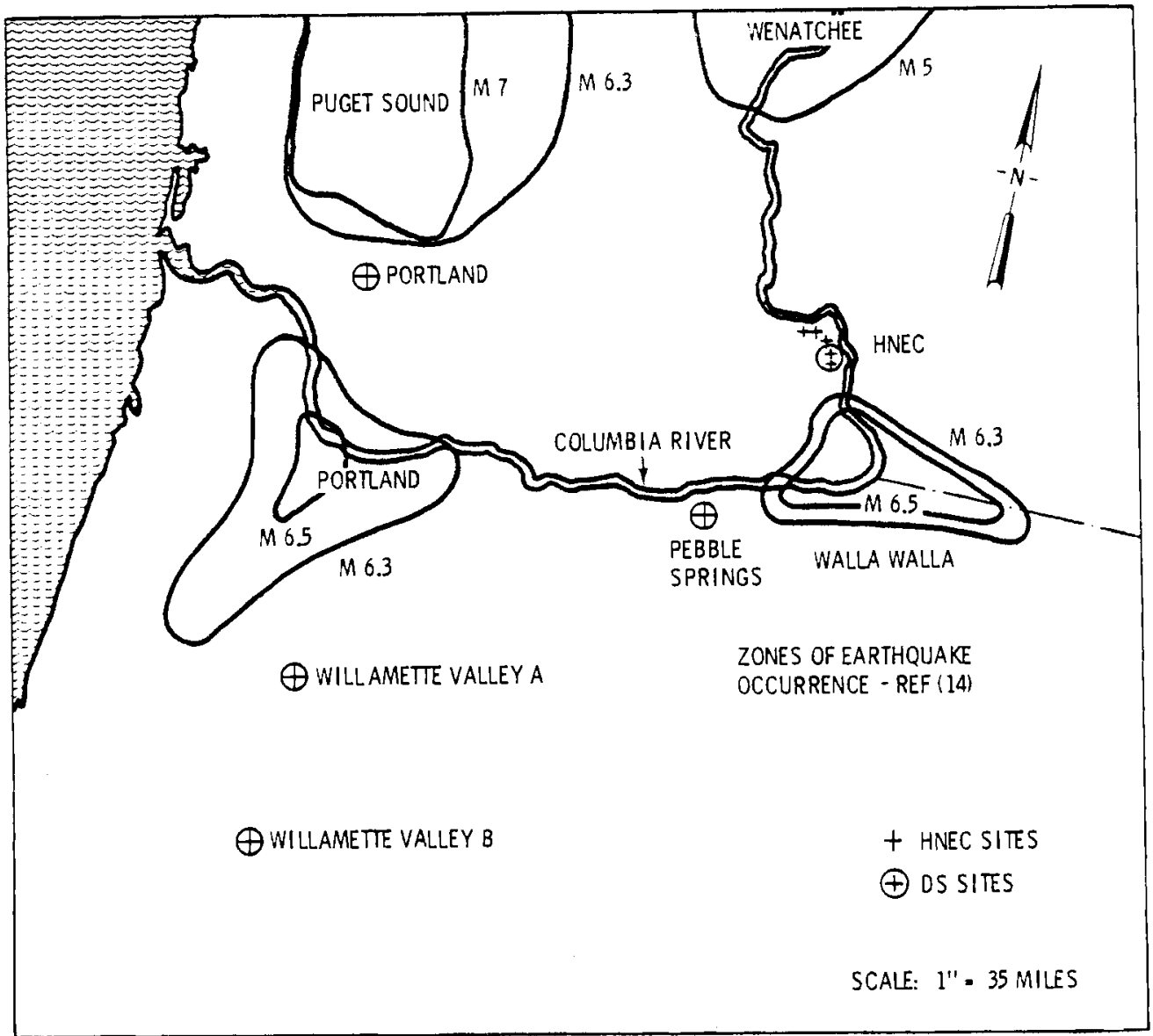

FIGURE 4. Earthquake Zones Near Site Boundaries

a short time interval, but such combinations of events are too improbable to consider. Also ignored are afterquakes of lesser magnitude, which may cause added damage to structures weakened by the first shock.

It is recognized that earthquake resistant designs must take into consideration a number of phenomena other than ground horizontal acceleration. Among them are frequencies, velocities, displacements, vertical accelerations, and effect of different types of underlying material. Structural design in response to the ground shaking must take into account the damping, elastic limits, and other factors. It is assumed here that all of these aspects would have been adequately accommodated in the design, so that structures that respond to maximum ground horizontal acceleration, responds similarly in all other respects.

Earthquakes are classified by magnitude of energy release on the Richter scale, and by ground shaking intensity (at any distance from the epicenter) on the Modified Mercali Intensity (MMI) scale. 
"Earthquakes of MMI greater than VI are of principal interest, because only these are strong enough to cause damage to structures." $(i)$

Intensities above $X$ (MMI) are considered to be greater than the earthquake potential at any of the study sites.

Ground Characteristics-Attenuation

"Seismic energy is not uniformly radiated from the source; in addition, variations in attenuation characteristics along the ray paths of the propagating waves cause nonuniform attenuation, hence the surface excitation pattern is not symmetric and in fact is very complex and difficult to predict." $(6)$

Figure 5 from the same reference shows the patterns of attenuation of certain earthquakes in the region of interest. The earthquake epicentered near Walla walla has an approximately circular pattern, lending some assurance that the assumption discussed previously is acceptable for that area including HNEC. Some isoseismic plots, such as that of Figure 6 are very irregular, and in many cases are elongated on the east-west axis. This may be due to inconsistent reporting, to local faults, or to geological features that may have influenced the analysis. If elongation in the east-west direction is present, it would not reduce the conservatism of the analysis in that propagation in the north-south and northwest-southeast directions are of most importance in HNEC studies.

The use of circular patterns from DS sites around Portland where historical patterns are irregular is questionable. However, the study findings are less sensitive in Portland cases as only one cluster would be affected by irregular attenuation rates.

Attenuation curves used in this study are from Schnabel and Seed. (5) Average values of attenuation in rock from this reference are shown in Figure 7 . Probability of Earthquake Occurrence

The probability of occurrence of earthquakes encompassing the HNEC and DS sites was derived in the following way. The probable occurrence data for the calculations were based on the seismiscity of the western U.S. (2) Several curves are presented in this reference. The one chosen for use in this report 


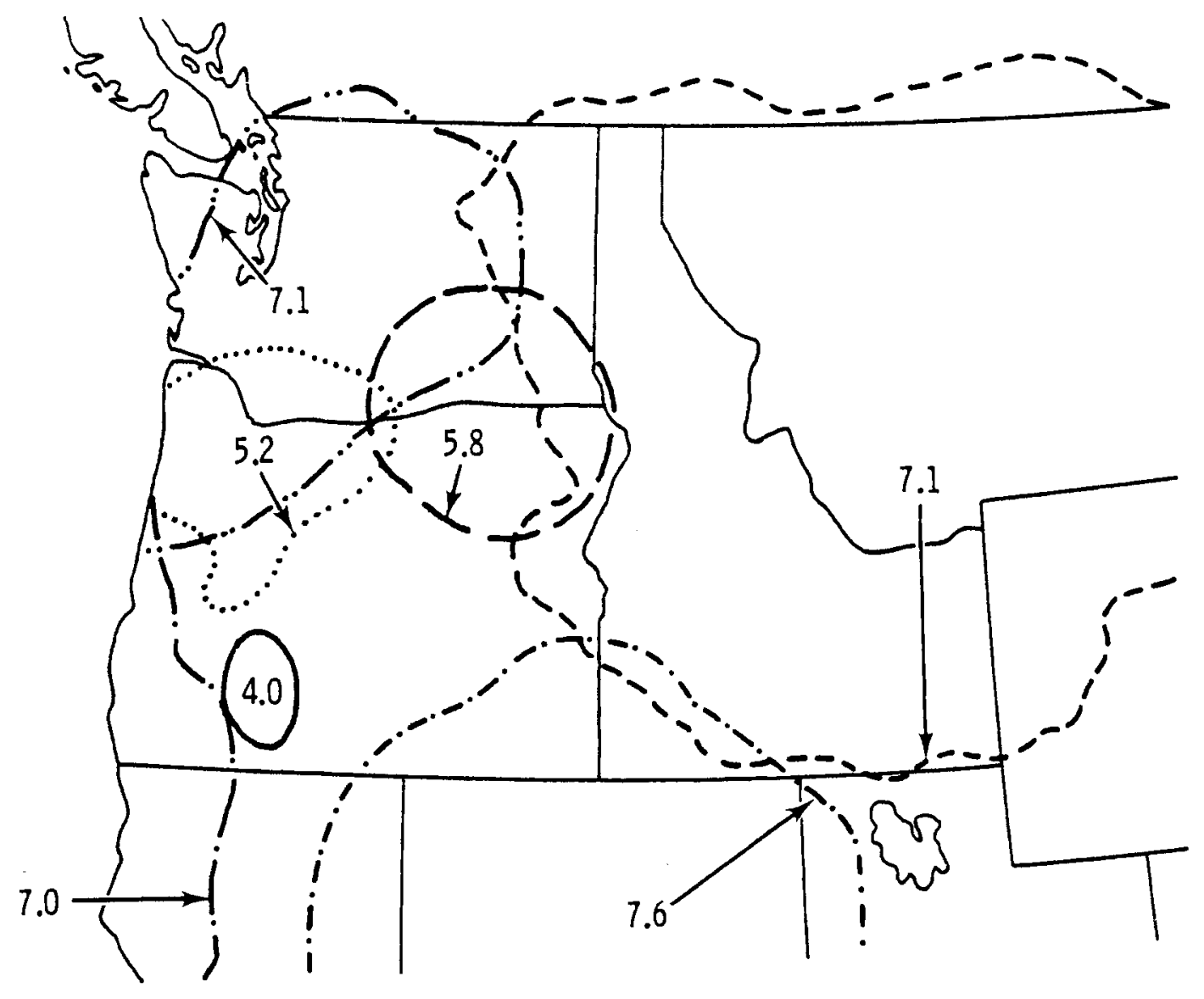

FIGURE 5. Intensity IV, Isoseismal for Major Earthquakes in Pacific Northwest

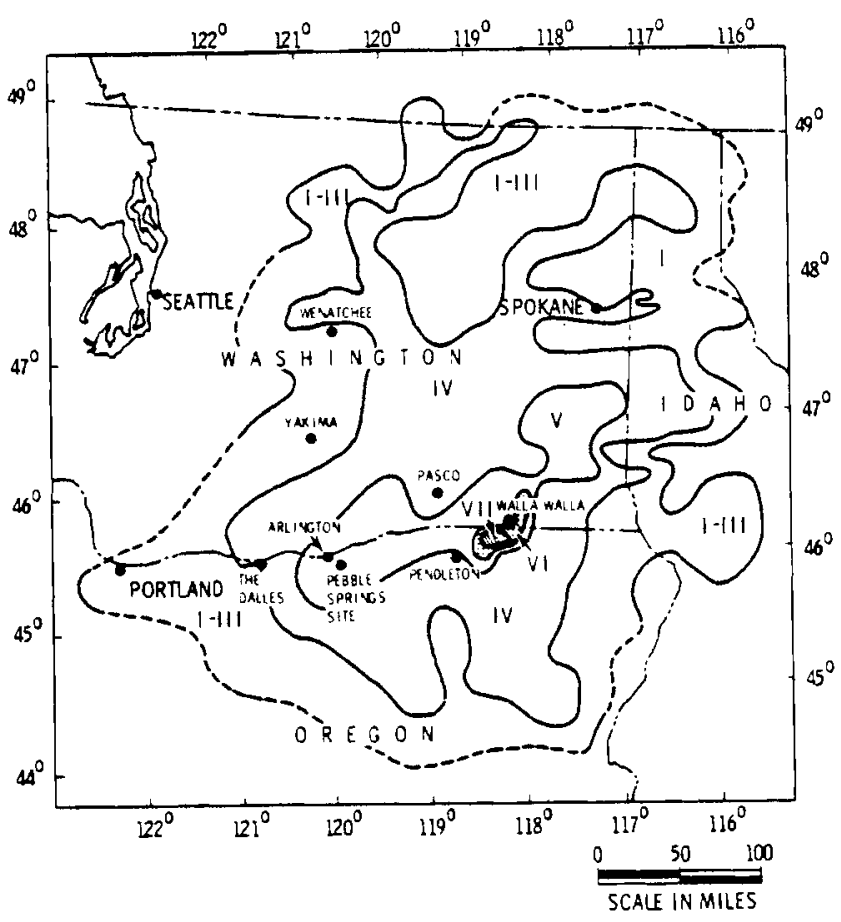

FIGURE 6. Isoseismal Map - 1936 Milton-Freewater Earthquake 
appeared to match data points well in the Richter 5.5 to 7.0 range of principle interest here. The correlation is:

$$
\log N=-0.662-0.881 M
$$

where $N$ is the number of earthquakes equal to or greater than the magnitude point, and $M$ is the magnitude on the Richter scale.

This expectation, based on earthquakes over a wide area, was compared with a record of earthquake frequency experienced in the Puget Sound area. (7)

Figure 8 contains plots of the two curves. The Puget Sound area has had more seismic events than areas east of the Cascades, and it would be expected that the frequency per unit area computed for $42,000 \mathrm{mi}^{2}$ of the Puget Sound area would be greater than for the western U.S. as a whole. Since the $121,000 \mathrm{mi}^{2}$ of interest in the Pacific Northwest for this reliability study have large areas to the east and south of Puget Sound having a low level of seismic activity, it was concluded that the use of the western U.S. curve would be appropriate as an overall indication of seismicity in this region. As discussed below, this average value is adjusted on the basis of the history of earthquakes in the site areas.

A record was obtained of known earthquakes in longitude range $-125^{\circ}$ to $-115^{\circ}$, and 1 atitude range $43^{\circ}$ to $51^{\circ}$, an area considered representative of the western U.S. It covered maximum intensities equal to or greater than VI (MMI) or having a magnitude equal to or greater than M5.5. (10) Earthquake occurrence in the $1^{\circ}$ rectangles containing the study sites were noted, and the western U.S. frequency curve data were adjusted by the ratio of the earthquake occurrence in that rectangle to the average occurrence over the entire region. For example, the HNEC site lies in a rectangle that had three earthquakes of the 77 isted, and the rectangle occupied approximately $1 / 80$ of the region. The adjustment factor for that site was $3 / 77 \div 1 / 80=w 3$ for intensities of VI to VII corresponding to magnitudes of 5.2 to 5.6. Factors for magnitudes 6.6 and 7.6 were set according to general seismic information concerning the site areas. The resulting factors are listed in Table 4 .

These factors are intended to be conservatively high, and also consistent with seismic data presented for sites that are being developed. 


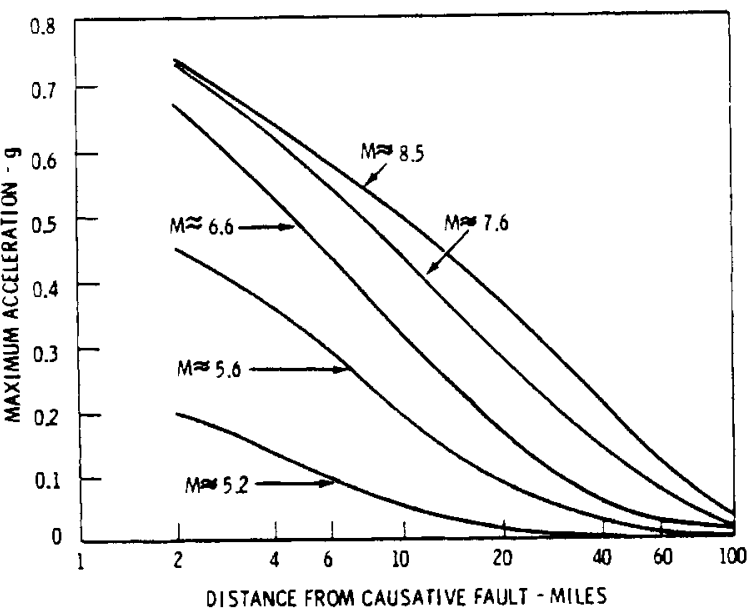

FIGURE 7. Average Values of Maximum Accelerations in Rock

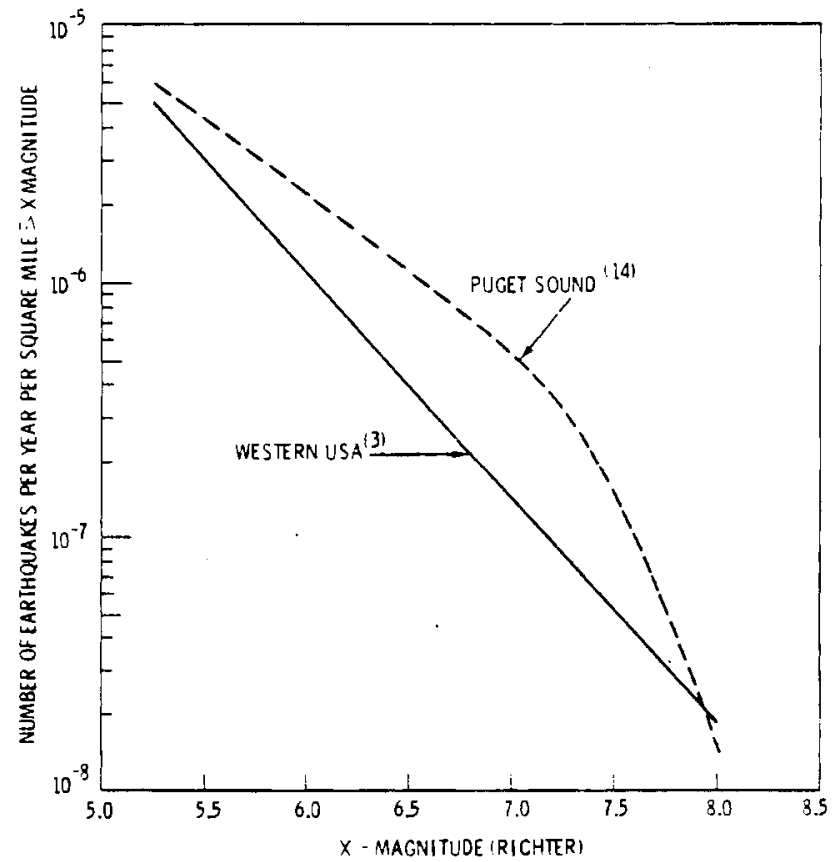

FIGURE 8. Probability of Earthquake Occurrence 
TABLE 4. Factors to Adjust Western U.S. Earthquake Data to Site Areas

HNEC

Pebble Springs

Portland

Willamette valley

\begin{tabular}{cccc}
\multicolumn{4}{c}{ Magnitude, Richter Scale } \\
\hline 5.2 & $\frac{5.6}{3.0}$ & 6.6 & 7.6 \\
\hline 3.0 & 1.0 & 0.75 & 0 \\
1.0 & 3.0 & 3.33 & 0 \\
3.0 & 1.0 & 0.33 & 3.0 \\
1.0 & 1.0 & & 0
\end{tabular}

Probability of Forced Outage

The overlap areas in which earthquakes occur to affect multiple clusters are presented in the maps of Figures B1, B2, B3 and B4 of Appendix B. Calculations of probability of outage of generating units by earthquake are also in Appendix $B$. The results of analysis are presented in Figure 9, Zone $A$.

The immediate effect of an earthquake above the OBE intensity is a programmed shutdown of the plant for inspection of all Category I systems.

NRC regulations state:

"If vibratory ground motion exceeding that of the Operating Basis Earthquake occurs, shutdown of the nuclear power plant will be required. Prior to resuming operations the 1 icensee will be required to demonstrate to the Commission that no functional damage has occurred to those features required for continued operation without undue risk to the health and safety of the public."

Forced outages to fulfill the inspection requirement have the probabilities shown in curve $A$, Figure 9 . Curve $B$ shows probable forced outages due to actual failure of structures or equipment from the effects of earthquakes.

\section{Probability of Forced Outage Through Failure of Essential Facilities}

If a structure built to Code standards is subjected to its design acceleration, $(0.125 \mathrm{~g}$ at HNEC, the OBE) the probability of failure has been estimated at 0.03. (4) For the same structure subjected to twice this acceleration, namely $0.25 \mathrm{~g}$, the probability of failure has been estimated to increase to about 0.25 . The latter results from projections based on estimates of increased probability of damage to Category I structures at twice their design acceleration level. (11) For non-Category I structures the estimate is not based on a rigorous development but is assumed to be a reasonable approximation. 


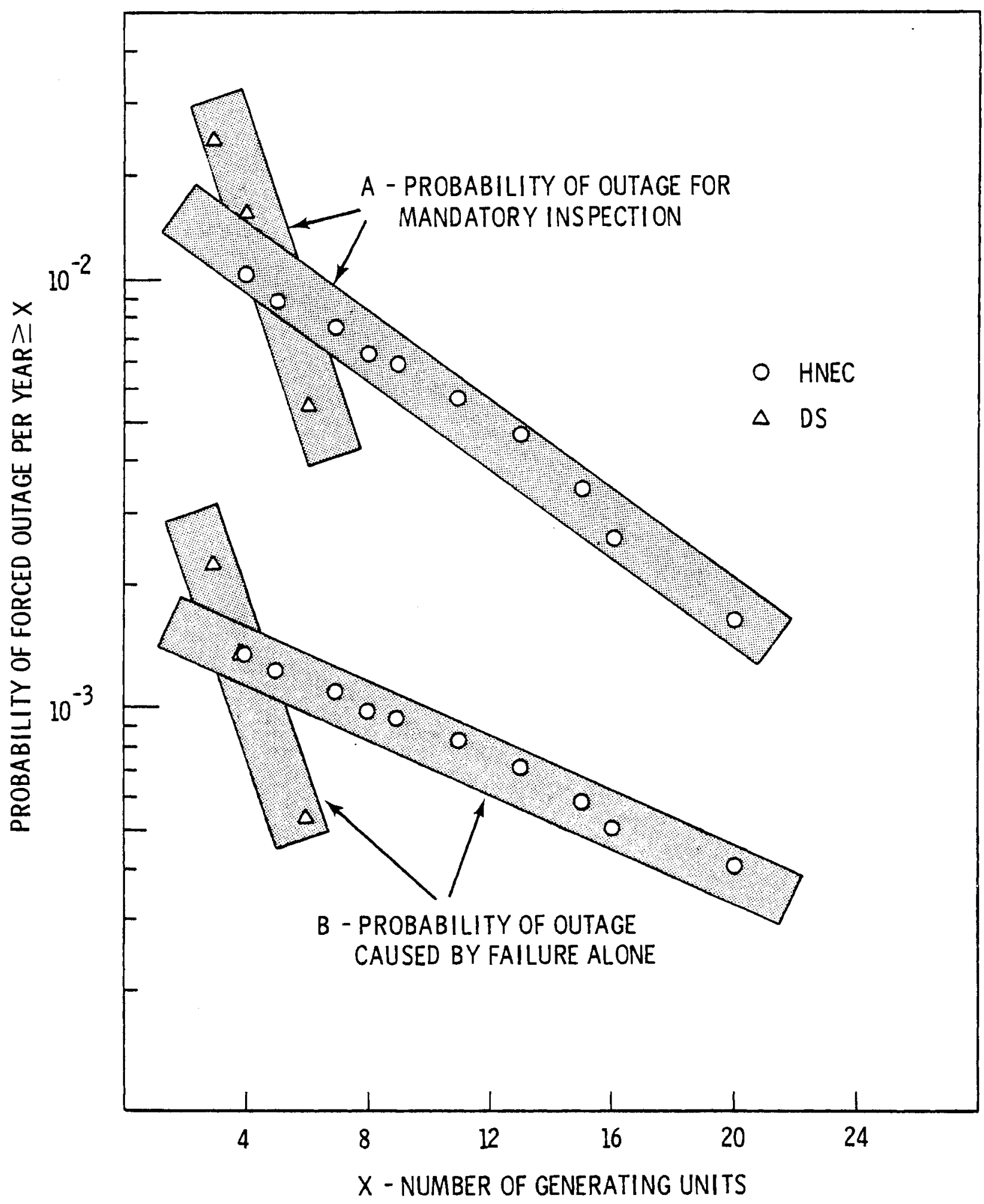

FIGURE 9. Probability of Forced Outage of Generating Units at HNEC and DS by Earthquake 
This probability of failure reflects the effect of factors of safety normaliy used in designs, and the observed response of structures to earthquake forces. The intensities of earthquakes of interest here range from the OBE level $(0.125 \mathrm{~g})$ to about $90 \%$ of the SSE level $(0.22 \mathrm{~g})$. Values of 0.10 to 0.25 have been used as the probability of forced shutdown because of damage suffered to Code structures from accelerations in the range 0.015 to $0.022 \mathrm{~g}$. The probabilities of forced outage due to failure from an earthquake causing accelerations in this range are shown in Zone $B$ of Figure 9.

The comparative data shown in Figure 9 reveal that:

- The probability that one cluster would experience ground acceleration exceeding $0.125 \mathrm{~g}$ is greater for the DS case because of the greater number of exposed locations. The probability levels for single clusters are reasonably consistent with the definition of the OBE--an earthquake that could "reasonably be expected to affect the plant site during the operating life of the plant".

- In this study six generating units is the maximum number that could be affected by one earthquake in the DS case, and 20 in the HNEC case. The probability of multiple clusters being affected in the DS case drops off rapidiy to $5.5 \times 10^{-4}$ events per year for six units; for HNEC it drops off more slowly to $1.6 \times 10^{-3}$ events per year for 20 units.

- Outages following earthquakes of increasing intensities in the OBE-SSE range are from 10 to 4 times more likely to occur in fulfilling the inspection requirement, than to occur from the effects of damage to essential facilities. The inspection requirements significantly increase the risk of loss of large amounts of generating capacity.

Probable Site Intensity

Where one or more clusters (both HNEC and DS) are affected by one earthquake, the most probable horizontal acceleration has been estimated as shown in Table 5. The estimates are made from computations of intensity at the site from earthquakes having epicenters spaced throughout the overlap areas, or, for single clusters, spaced throughout the annulus around the site. 
TABLE 5. Probable Horizontal Accelerations at Sites, Within the Range of 0.125 to $0.250 \mathrm{~g}$

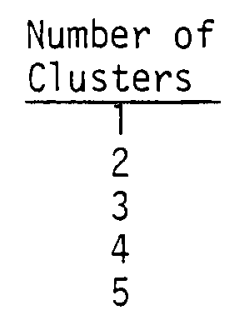

\begin{tabular}{lc} 
Horizontal & Acceleration, $g$ \\
\hline HNEC & $\frac{D S}{0.167}$ \\
\hline 0.142 & 0.175 \\
0.151 & 0.180 \\
0.150 & -- \\
0.153 & --
\end{tabular}

Estimate of Outage Period

If the outage is solely for inspection, i.e., if there is no obvious damage and if no indications of damage are found in the course of the inspection, the time requirement estimate would be governed by the scope of the inspection. That could range from a walk-through visual inspection to a thorough-going test of system functions.

The scope of inspection required to satisfy both the plant operator and the NRC has not yet been defined, nor have criteria for acceptance of test results been issued. NRC is currently preparing proposed criteria.

Regulatory Guide 1.12, Instrumentation for Earthquakes Revision 1, was issued in April 1974. This guide sets forth the instrumentation considered desirable to detect and record the effects of seismic motion, from which floor response spectra as wel1 as other effects can be calculated.

"This information wil1 be needed to determine 1) the conservatism in the modeling and design assumptions made for the structure and design input motion to the supported systems and components, and 2) the advisability of continuing the operation of the plant without a safety analysis following an earthquake."(21)

It would appear that as a minimum, the inspection will include an analys is of al1 pertinent instrumentation readings and records; identification of the structures and facilities that are most likely to have been affected by vibratory motion at frequencies having high amplitude; a thorough inspection of any vulnerable structures, equipment, vessels and piping; and perhaps tests on safety systems. 
The extent of the inspection will depend on the intensity of the earthquake, unusual phenomena observed in plant operation following the earthquake, the extent of readily observable damage, and the preparation of the analysis.

The work necessary to accomplish an inspection on the above general grounds, following a quake with a ground intensity in the range indicated was estimated for purposes of this report, at from 3 to 60 days. The inspection time associated with the most probable acceleration, $0.15 \mathrm{~g}$, was estimated to be 7 days on the average. That period is used in the computations on energy production loss to follow.

Estimates of damage caused by earthquakes, and time required to restore service, are based on certain assumptions:

- That knowledge gained from analysis of well-instrumented and thoroughly analyzed earthquakes such as the San Fernando earthquake of February 1971 would be applied in the designs of generating plants and switching stations. (The San Fernando earthquake caused peak ground accelerations in certain areas of 0.30 to $0.50 \mathrm{~g}$, considerably greater than the $0.125 \mathrm{~g}$ to $0.25 \mathrm{~g}$ range discussed here).

- That HNEC operation and maintenance forces would be prepared to cope with earthquake effects in a manner similar to that of California utilities.

- That temporary measures to restore service would be taken wherever possible, with permanent repair to follow, as technical specifications permit.

If significant damage is suffered to non-Category I facilities, repair times will depend on the nature and extent, the availability and competence of repair crews, and the management of materials and spare equipment.

Failure can take place either through malfunction of certain instruments or equipment causing automatic or manual shutdown of the plant, or through physical damage to structures, 1 ines or equipment, causing automatic or manua 1 shutdown. In a malfunction there may be little or no damage, and the principal work during the shutdown will be for inspection and analysis. In the event of physical damage, repair of obvious damage can proceed concurrently with inspection of other portions of the plant. 
Malfunction may be due to sensing instrument contacts closing or opening in error, the effects of sloshing liquid levels on instrumentation, leaks in air pressure or hydraulic lines, vibration instrumentation on rotating equipment, or others.

Damage to non-Category I facilities could result from:

- Shifting of massive equipment on foundations, or failure of foundations with damage to interconnecting piping or conduits systems, and possible damage to the equipment itself.

- Shaft bending in rotating equipment with consequent rubbing or bearing misalignment.

- Toppling of panelboards or tall slender structures not properly braced.

- Secondary effects of broken pressure piping.

- Structural failure.

- Failure due to faulty materiais or design (even though presumably designed to respond properly to the spectra of earthquake motion.)

Non-Category I facilities of a typical LWR plant most vulnerable to earthquakes in the OBE-SSE range were considered in relation to the probable intensity range given previously. The estimates of time required to repair damage to these facilities at an LWR, subjected to horizontal accelerations are:

$\begin{array}{lcr}\text { Maximum } & \frac{0.150 \mathrm{~g}}{20 \text { days }} & \frac{0.22 \mathrm{~g}}{100 \text { days }} \\ \text { Minimum } & 3 \text { days } & 15 \text { days } \\ \text { Probable } & 7 \text { days } & 40 \text { days }\end{array}$

These estimates are used in the calculation of loss of energy production due to earthquake.

For example, an earthquake in the OBE-SSE range would result in:

- a programmed shutdown for an inspection expected to require 7 days, even if no malfunction takes place or no damage is suffered,

- a damage repair requirement of 7 to 40 days which could run concurrently during much of the inspection time. 
To arrive at a probability of loss of available energy, the capacity shown as the abscissa of Figure 9 was multiplied by the time to inspect, as a minimum, . and possibly the time to both inspect and repair. For example, the loss of 12 generating units $(14.4 \mathrm{GW})$, shown on curve $A$ of Figure 8 as having a probability of $5.3 \times 10^{-3}$ events per year, is multiplied by the probable outage period, 7 days, and by the assumed plant capacity factor, $87 \%$, to give loss of available energy, $2105 \mathrm{GWh}$. This energy loss has the same probability as the capacity loss since it derives from the latter.

Earthquake Risk

Both the capacity and energy loss curves are shown in Figure 10, in terms of GW and GWh.

From these curves, risk to earthquakes for several specific losses of capacity or energy are:

\begin{tabular}{ccc}
$\begin{array}{ccc}\text { Capacity } \\
\text { Loss, GW }\end{array}$ & $\begin{array}{c}\text { Loss of Available } \\
\text { Probable Energy, GWh }\end{array}$ & $\begin{array}{c}\text { Probability of } \\
\text { Occurrence/year }\end{array}$ \\
\cline { 3 - 3 } 8 & $500(\min )$ & 0.0086 \\
18 & 3300 & 0.0086 \\
24 & 2600 & 0.0034 \\
24 & 20,000 & 0.0016 \\
& $50,000(\max )$ & 0.0016
\end{tabular}


ENERGY GENERATION LOSS,

PROBABILITY OF LOSS

OF CAPACITY AND ENERGY GENERATION PER YEAR $\geq X$

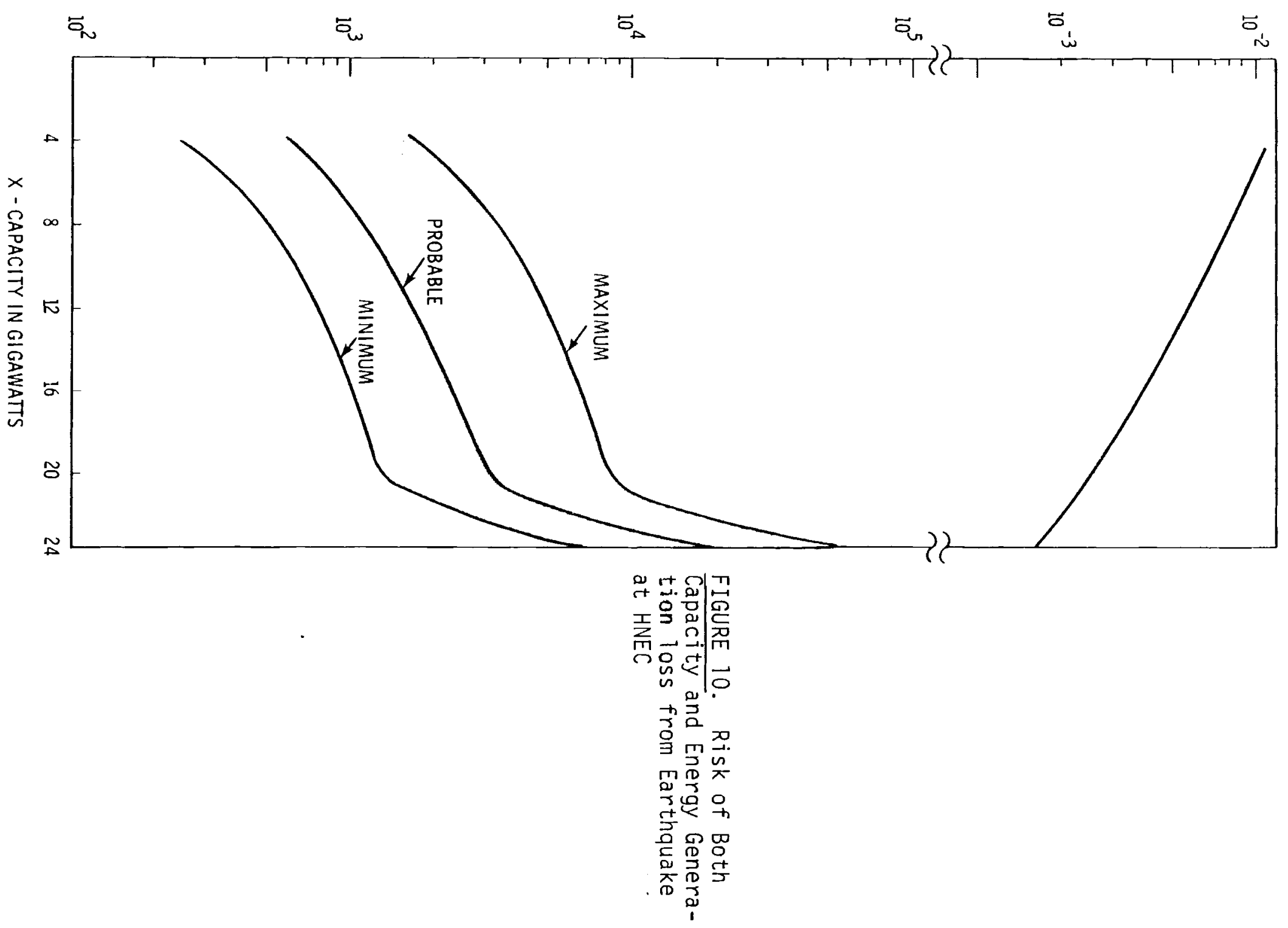




\section{REFERENCES - EARTHQUAKE}

1. Otto W. Nuttle, State of the Art for Assessing Earthquake Hazards in the United States, Design Earthquakes for the Central United States, Nat?. Tech. Inf. Service, U.S. Dept. of Commerce, January 1973.

2. T. Hsieh, D. Okrent, and G. E. Apostlolakis, On the Average Probability Distribution of Peak Ground Acceleration in the U.S. Continent Due to Strong Earthquakes, UCLA-ENG-7516, March 1975.

3. Washington Public Power Supply System, WPPSS Nuclear Project No. 1, Preliminary Safety Analys is Report.

4. N. M. Newmark, "Overview of Seismic Design Margins," Project Report, Reactor Licensing and Safety, Vol. 2, No. 1, pp. 63-84, Atomic Industrial Forum, May 1975.

5. P. B. Schnabel and H. Bolton Seed, Accelerations in Rock for Earthquakes in the Western United States, Bulletin of the Seismological Society of the U.S.A., Vol. 63, No. 2, pp. 501-516, April 1973.

6. Agbabian Associates, Procedures and Criteria for Increasing the Earthquake Resistance Level of Electrical Substations and Special Installations, for BPA, September 30, 1973.

7. U.S. Dept. of Interior, A Study of Earthquake Losses in the Puget Sound, Washington, Area, Open File Report 75-375, 1975.

8. U.S. Department of Commerce, San Fernando, California, Earthquake of February 9, 1971, 1973.

9. Utilities Say They're Ready for Earthquakes, Electrical World, June 15, 1976.

10. Woodward Clyde Consultants, Preliminary Report of Seismicity Listing for the Pacific Northwest, for WPPSS, October 20, 1976.

11. Uniform Building Code, Informational Conference of Building Officials.

12. NRC Regulatory Guide 1.12, Instrumentation for Earthquakes, Apri1 1974. 


\section{REFERENCES NOT CITED}

T. F. Lomenick and NSIC Staff, Earthquakes and Nuclear Power Plant Design, ORNL-NSIC-28, pp. 7-8, July 1970 .

U.S. Nuclear Regulatory Commission, Nuclear Energy Center Site Survey - 1975, NUREG-0001, NTIS, January 1976.

U.S. Department of Commerce, Earthquake History of the United States, 1973, U.S. Govt. Printing Office Publication 41-1.

G. W. Housner, Recommended Seismic Design Criteria for Hanford Nuclear Facility DUN 3130, October 1, 1967.

C. V. Chalapati and I. B. Wa11, Probabilistic Assessment of Seismic Risk for Nuclear Power Plants, ANS Winter Meeting, December 2, 1969.

W. B. Cottre11, Protection of Nuclear Power Plants Aga inst External Disasters ORNL-NRC, Apri1 1975.

N. M. Newmark, Probability of Predicted Seismic Damage in Relation to Nuclear Reactor Facility Design, Draft for NRC, September 30, 1975.

General Atomic HTGR Accident Initiation and Progression Analysis Status Report, AIPA Risk Assessment Methodology, Vol. II, NTIS, U.S. Dept of Commerce, October 1975.

S. T. Algermissen and David M. Perkins, A Probablistic Estimate of Maximum Acceleration in Rock in the Contiguous United States, Open File Report $76-416,1976$.

Brazee, R. J., "Attenuation of MMI with Distance for the United States East of

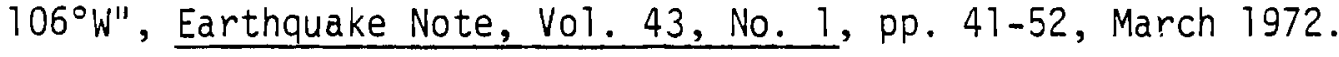

Cornel1, C. A., and H. A. Merz, "Seismic Risk Analysis of Boston," Journal of the Structural Division ASCE, Vol. 101, No. STT0, pp. 2027-2043, october 1975.

Corne11, C. Allin, Some Observations on Probabilistic Methods in the Seismic Design of Nuclear Power Plants.

Milne, W. G., and A. G. Davenport, "Distribution of Earthquake Risk in Canada," Bullet in of the Seismological Society of America, Vol. 59, No. 2, pp. 729-754, April 1969.

- Okrent, D., "A Survey of Expert Opinion on Low Probability Earthquakes," UCLA-Eng-7515, February 1975.

U.S. Nuclear Regulatory Commission, Reactor Safety Study, an Assessment of Accident Risks in U.S. Commercial Nuclear Power PTants, NTIS, October 1975.

N. M. Newmark, Comments on Conservatism in Earthquake Resistant Design, AIF, September 18, 1974. 
TORNADO

Introduction

This section contains an assessment of the risk of forced outage of generating units at multiple clusters because of tornadoes. The probability of a tornado striking the first cluster is a function of the number of tornadoes experienced, and their path areas in the region. The probability of the same tornado striking a second cluster is a function of expected path length, the configuration of the clusters relative to each other, and to the prevailing direction of movement of tornadoes in the region. The number of units affected within a cluster is a function of path direction. It could also be a function of path width but the plant layout and probable path width are not sufficiently definitive to distinguish path width effects.

The only tornadoes considered here are those that would move in such directions that they could affect more than one cluster at Hanford. As discussed later, about $68 \%$ of the tornadoes in this area may be expected to move in a northeasterly direction, but the configuration of cluster sites is such that a single tornado moving in that direction could not strike more than one cluster. Therefore, the probabilities of tornado strikes that are developed herein do not include all strikes that could affect individual clusters in either the HNEC or DS cases. The only group of tornadoes considered (those other than the 68\%) are the same for both the HNEC and DS cases to permit valid comparisons. These are tornadoes with movement along northwest-southeast, and east-west axis, comprising only about $32 \%$ of all tornadoes.

Nuclear Regulatory Commission Criteria

Facilities essential to reactor safety must meet NRC requirements set forth in Regulatory Guide 1.76 with respect to resistance to tornado damage. They must be designed and constructed to withstand a Design Basis Tornado (DBT). OBT characteristics are given in the following table from Guide 1.76.

The Hanford reservation lies in Region III of the table. The peak tornado velocity estimated for the HNEC site is $214 \mathrm{mph}$, somewhat below the $240 \mathrm{mph}$ criterion of Region III. (3) ive portions of plants authorized to date are designed to comply with the $240 \mathrm{mph}$ criteria of the above table, and al1 
TABLE 6. Design Basis Tornado Characteristics

\begin{tabular}{|c|c|c|c|c|c|c|c|}
\hline Region & $\begin{array}{l}\text { Maximum } \\
\text { Wind Speed } \\
(\mathrm{mph})(\mathrm{a})\end{array}$ & $\begin{array}{l}\text { Rotational } \\
\text { Speed (mph) }\end{array}$ & $\frac{\text { Translational }}{\text { Maximunl }}$ & Speed (mph) & $\begin{array}{l}\text { Radius of } \\
\text { Maximum } \\
\text { Rotational } \\
\text { Speed ( } \mathrm{ft} \text { ) }\end{array}$ & $\begin{array}{l}\text { Pressure } \\
\text { Drop (psi) }\end{array}$ & $\begin{array}{l}\text { Rate of } \\
\text { Pressure } \\
\text { Drop (psi/sec) }\end{array}$ \\
\hline I & 360 & 290 & 70 & 5 & 150 & 3.0 & 2.0 \\
\hline I I & 300 & 240 & 60 & 5 & 150 & 2.25 & 1.2 \\
\hline I I I & 240 & 190 & 50 & 5 & 150 & 1.5 & 0.6 \\
\hline
\end{tabular}

(a) The maximum wind speed is the sum of the rotational speed component and the maximum translational speed component.

(b) The minimum translational speed, which allows maximum transit time of the tornado across exposed plant features, is to be used whenever low travel speeds (maximum transit time) are a limiting factor in design of the ultimate heat sink. The ultimate heat sink is that complex of water sources, including associated retaining structures, and any canals or conduits connecting the sources with, but not including, the intake structures of nuclear reactor units. Regulatory Guide 1.27 (Safety Guide 27), "Ultimate Heat Sink," describes a basis that may be used to implement General Design Criterion 44 of Appendix A to 10 CFR Part 50 with regard to the ultimate heat sink. 
future plants in HNEC would similarly comply. DS plants at the more westerly sites may lie in Region II. Reactor facilities wherever located would be designed to meet tornado conditions. The probability of exceeding the DBT therefore would be the same (about $10^{-7}$ events per year) for a 11 sites.

Non-Category I facilities are designed to withstand tornado windspeeds of up to about $100 \mathrm{mph}$ and remain in service. Many of these may be essential to continued plant operation. This study is therefore concerned with the probability of occurrence of tornadoes having a windspeed of $100 \mathrm{mph}$ and above. It is assumed that design for pressure change and for impact of tornado-propelled missiles would be consistent with that for windspeed. Windspeed alone is a suitable measure of tornado intensity.

A general correlation between windspeed and path area is given in Reference 4 ,

"If one knows the tornado area is $z$, then the best estimate of windspeed is $w=2400\left(15+e^{-0.41} \ln z-1\right)$, and the windspeed wi 11 have a standard deviation of $25 \mathrm{mph}$ around this best estimate".

Thus windspeed can be related to path area, $z$. Path area can then be related to probable width and length of path. Those windspeeds in excess of $100 \mathrm{mph}$ determine the extent of damage and consequently the estimated repair time. Direction of Tornado Movement

Pathways followed by tornadoes striking more than one cluster are shown in Figure 11.

The direction in which tornadoes tend to move in the Hanford area is shown in Figure 12. An analysis of tornadoes experienced in the area gives the following percentages for tornado movement in different compass directions: 


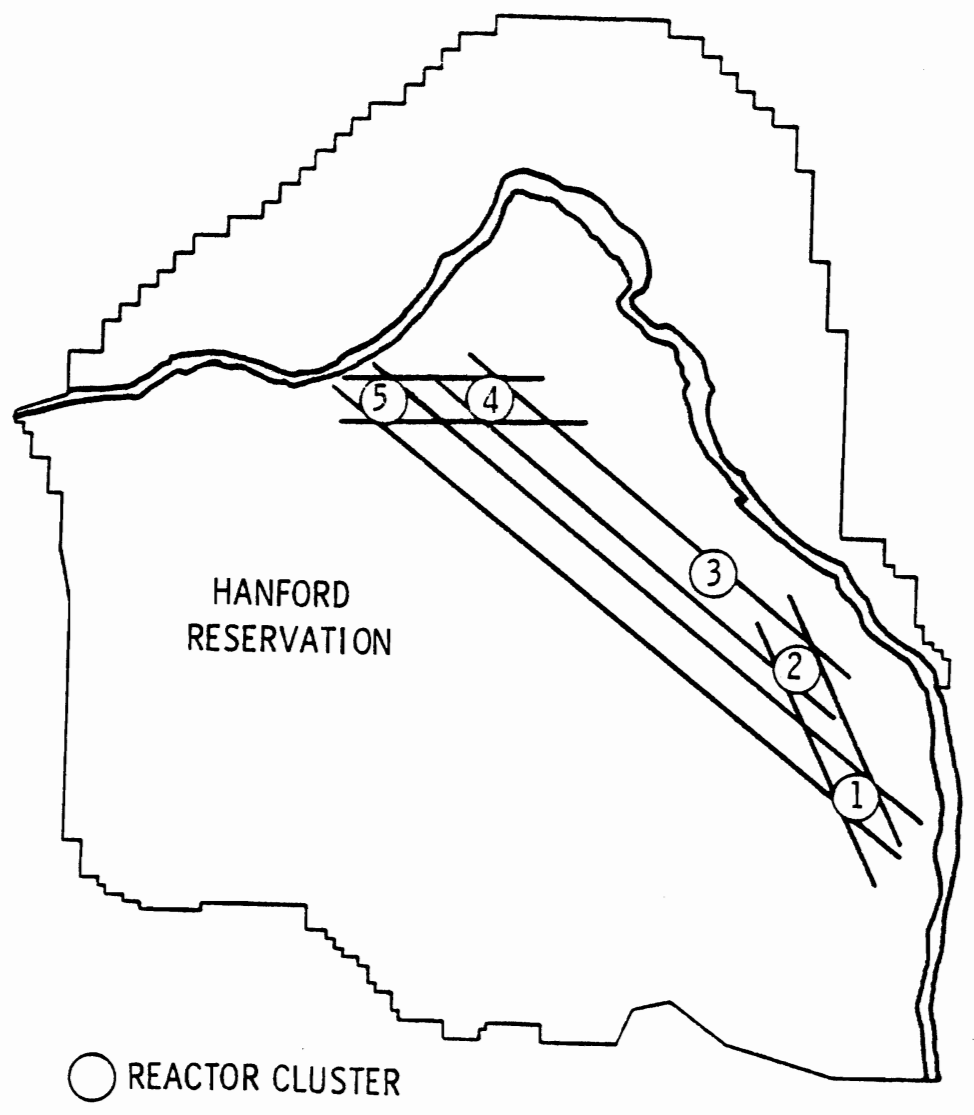

FIGURE 11. Pathways for Tornadoes at HNEC

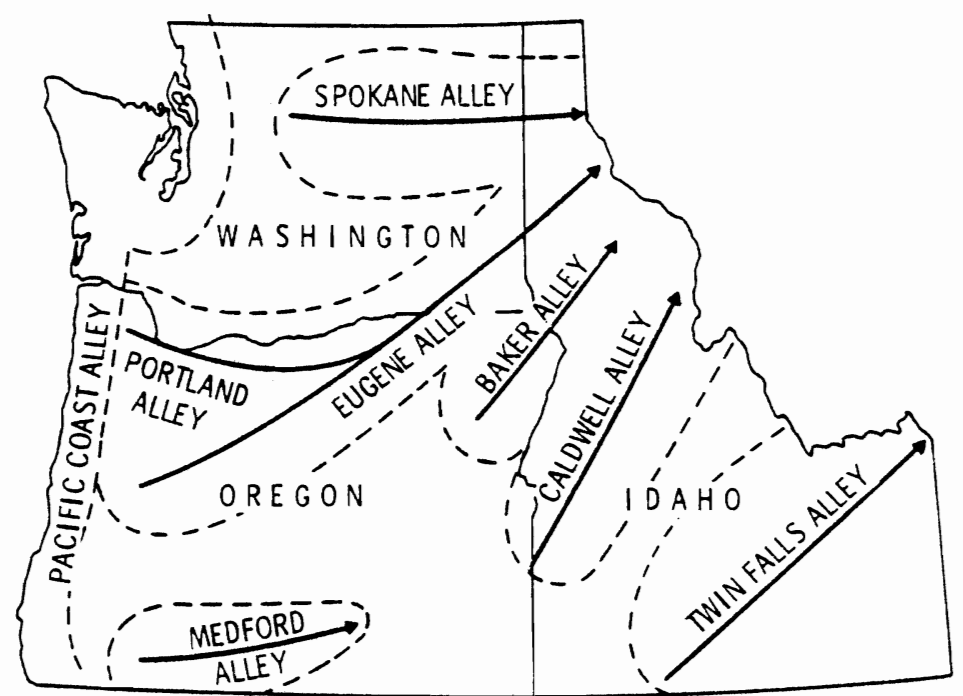

FIGURE 12. Direction of Movement of Characterized Tornadoes in 20-Year Period, 1950-69 


\begin{tabular}{lc}
$\begin{array}{c}\text { Direction } \\
\text { Toward }\end{array}$ & $\begin{array}{c}\text { Percent of Total } \\
\text { No. of Tornadoes }\end{array}$ \\
\cline { 2 - 3 } NW & 13.6 \\
NNW & 4.5 \\
N & 4.5 \\
NNE & 0 \\
NE & 68.4 \\
ENE & 0 \\
E & 4.5 \\
ESE & 0 \\
SE & 4.5 \\
SSE & 0
\end{tabular}

Sites lying along axes parallel to the axis of the "alleys" shown in Figure 12 have a greater probability of being affected in common by a tornado than sites, such as HNEC, lying along an axis at right angles to the axis of the alley.

Tornado Start Points

A tornado may start at any point inside or outside of a cluster of generating plants. The probability of one tornado striking a second cluster will depend on the starting point as well as the path length. To deal with this aspect, the percentage of path length remaining after the tornado has struck the first cluster was taken as a random percentage of the path length.

\section{Regional Tornado Experience}

The data on which the following estimates are based consists of:

1) records of tornadoes in the states of Washington, Oregon and Idaho over the period 1950-69. The size distribution of 46 tornadoes is given in Table 7 from Reference 4. 
TABLE 7. Size Distribution of Tornadoes $\left(\mathrm{Mc}^{-2}\right)$

\begin{tabular}{ccc} 
No. of Events & & Area $\mathrm{Mi}^{2}$ \\
\cline { 1 - 1 } 34 & & 0.1 \\
2 & 0.1 \\
2 & 0.15 \\
2 & 0.16 \\
1 & 0.30 \\
1 & 0.50 \\
1 & 0.72 \\
1 & 1.15 \\
1 & 2.7 \\
1 & 6.0
\end{tabular}

2) a simulation of $200 \mathrm{yr}$ of tornado incidence at a Hanford site, based on the above data. ${ }^{(4)}$ The simulated tornadoes of interest in this study, i.e., those having a probable path length as great as or greater than the distances between clusters, are used for risk computation.

3) records over the period 1965-74 in the states of Washington, Oregon and Idaho, including length and width of path, and direction of movement. These data were used for path length and width correlation with the 200 yr simulation.

These records and simulations indicated that:

1) The additional data on path areas of the 1965-74 record was consistent with the 1950-69 data with regard to the distribution of path size, except for the $0.001 \mathrm{mi}^{2}$ group which is not pertinent to this study.

2) In the 1965-74 list, five tornadoes have a path length of 4 mi or greater. Consequently 13 tornadoes having a path length of $4 \mathrm{mi}$ or greater are predicted when projecting the above record to a $200 \mathrm{yr}$ period. In the 1965-74 period, a path length to path width ratio of 50 occurred in more than $74 \%$ of the tornadoes. These 13 simulated tornadoes which were used in the study are given in Table 8. 
TABLE 8. Tornadoes with Path Length over 4 Miles

\begin{tabular}{|c|c|c|}
\hline $\begin{array}{l}\text { Area } \\
M i 2\end{array}$ & $\begin{array}{l}\text { Path } \\
\text { Width, } \\
\text { Yards } \\
\end{array}$ & $\begin{array}{l}\text { Path } \\
\text { Length, } \\
\text { Miles } \\
\end{array}$ \\
\hline 0.90 & 236 & 6.70 \\
\hline 0.48 & 172 & 4.90 \\
\hline 0.44 & 165 & 4.69 \\
\hline 1.70 & 325 & 9.22 \\
\hline 7.80 & 695 & 19.74 \\
\hline 2.70 & 409 & 11.62 \\
\hline 0.82 & 225 & 6.40 \\
\hline 0.45 & 167 & 4.74 \\
\hline 2.60 & 401 & 11.40 \\
\hline 0.30 & 136 & 3.87 \\
\hline 4.50 & 528 & 15.00 \\
\hline 0.29 & 134 & 3.81 \\
\hline 3.80 & 485 & 13.78 \\
\hline
\end{tabular}

Probability of Exposure to a Tornado

The points most vulnerable to tornadoes are cooling towers, overhead lines and switching stations. Typical locations of those plant components are noted in connection with width and direction, to determine the probable number of units affected.

Cooling towers of the forced draft type are reported to be costly to build to withstand windspeeds above $110 \mathrm{mph}$. At sites in western Washington and Oregon towers may be of the natural draft type which reportedly can be economically designed for higher windspeeds. Or at sites such as Pebble Springs, ponds may be used instead of towers. These features might make marginal differences in tornado risks at DS sites but not in the analysis of effects of strikes at HNEC, where c00ling towers presumably would be of the forced draft type but would have tal1 enclosures to reduce fog. They may have construction features similar to natural draft towers, and may be more resistant to tornadoes than conventional forced draft towers. 


\section{Probability of Occurrence}

The tornado event probability was obtained by applying to the list of 13 tornadoes having a path length sufficient to reach a second cluster, a random number designating the path length remaining after the tornado has struck the first cluster. This reduced the number of tornadoes likely to reach a second cluster to seven in $200 \mathrm{yr}$. Since each tornado occurred once in a 100 -mi radius area in $200 \mathrm{yr}$, the probable annual frequency of its touching any point would be:

Probable Annual Frequency of Tornadoes $=\frac{\text { Path Area }\left(\mathrm{mi}^{2}\right)}{100^{2} \pi\left(\mathrm{mi}^{2}\right) \times 200 \mathrm{yr}}$

This probable annual frequency was multiplied by the exposure probabilities associated with tornado paths. These products were summed over all combinations of tornadoes associated with one, two and four generating units. Since a single tornado would occur only at any one of five possible clusters, the sum of the combinations developed above was divided by five.

The two clusters at Hanford which make up part of the DS case were treated in the same way. The other clusters in the DS case were too far apart to be affected by one tornado.

It was assumed that the first cluster struck by a tornado would suffer the same effect in both the HNEC and DS cases. It was estimated that, on the average, two units of the first cluster may be affected in both DS and HNEC cases, by tornadoes strong enough to reach two clusters at HNEC. In figures to follow, two units (from the first cluster) were added to the number of units forced out of service in the second cluster to give total capacity affected.

Probability of Forced Outage

The results of the analysis are presented in tables in Appendix $B$ and in Figure 13.

It will be noted that:

1) In the HNEC case, four units are the probable maximum number forced out of service in clusters beyond the first, for a total of six. In 


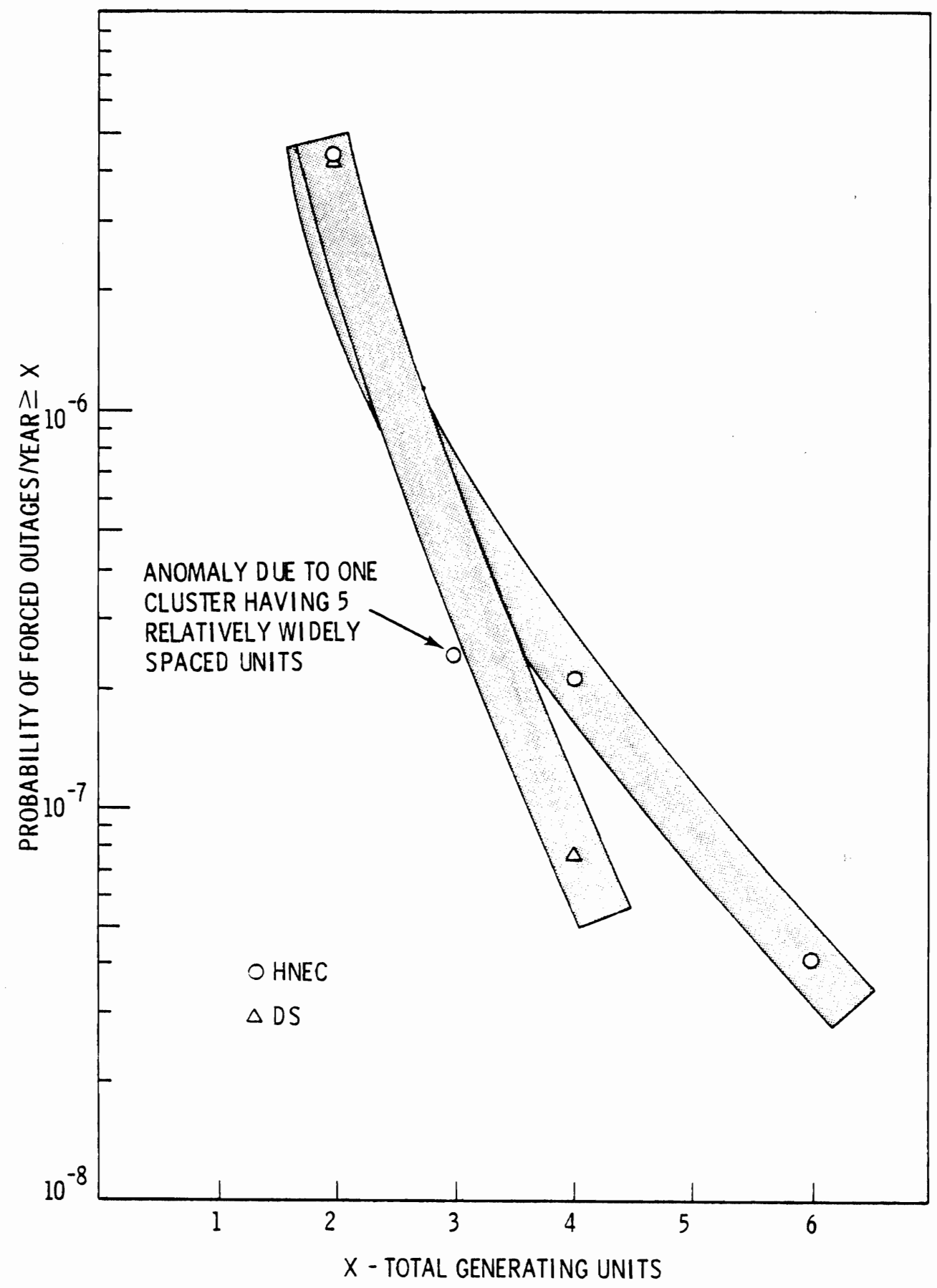

FIGURE 13. Probability of Forced Outage of Generating Units from Tornadoes 
the DS case, two units are the probable maximum number forced out of service beyond the first cluster for a total of four, maximum.

2) The probability of a second cluster in an HNEC being struck is very low, $7.5 \times 10^{-8}$ in the DS case, and $2.5 \times 10^{-7}$ in the HNEC case.

3) The results are somewhat sensitive to assumptions as to plant layout. If all clusters were as spread out as cluster No. 1, the southernmost cluster, the total number of units to be struck would be less.

4) There is only one combination involving three clusters at HNEC.

5) A perspective on tornadoes as a cause of forced outage of multiple units may be gained from the following:

- Tornado strike probability from map of $5^{\circ}$ squares in the contiguous U.S. from Wash-1300(1) containing all tornadoes above $73 \mathrm{mph}$.

Probability/yr

- Windspeeds $100 \mathrm{mph}$ or over, from simulation of Reference 4.

$3.7 \times 10^{-5}$

- Probability of second cluster at HNEC being struck by tornadoes in excess of $100 \mathrm{mph}$.

- Probability of a Design Basis Tornado

$4.4 \times 10^{-6}$

$2.4 \times 10^{-7}$

$1 \times 10^{-7}$

Windspeeds

As noted previously the damage inflicted on a plant by a tornado is a function of windspeed. Windspeeds associated with the 13 tornadoes of interest are given below in Table 9. Six of these have path lengths too short to affect units beyond those in one cluster. Then, the effects of only seven tornadoes are analyzed.

These are all well below the Design Bases Tornado, $240 \mathrm{mph}$, however, all except for one have windspeeds above the threshold of possible damage to facilities. 
TABLE 9. Tornado Windspeeds Associated with Path Area

\begin{tabular}{cc}
$\begin{array}{c}\text { Path Area } \\
\mathrm{Mi}^{2}\end{array}$ & $\begin{array}{c}\text { Windspeed } \\
\mathrm{mph}\end{array}$ \\
\cline { 2 - 2 } 0.9 & 163 \\
0.48 & 137 \\
0.44 & 163 \\
1.70 & 172 \\
7.80 & 149 \\
2.70 & 141 \\
0.82 & 154 \\
0.45 & 116 \\
2.60 & 153 \\
0.30 & 154 \\
4.50 & 117 \\
0.29 & 98 \\
3.80 & 179
\end{tabular}

Tornado Risk

Mandatory inspections following a tornado are not required by regulation. A plant struck by a tornado would shut down only if damaged to the extent that shutdown is actualiy forced or is considered prudent in view of the circumstances.

Damage can occur because of wind forces, pressure differentials or wind driven missiles. Only missiles associated with normal plant operation are assumed available such as wood poles, timbers, small vehicles that could damage outside transformers, switchgear or similar equipment. No nearby construction is assumed in progress.

Code design structures and equipment can expect to be affected, such as cooling towers of the forced draft type, overhead electric lines, switching stations, high tanks, stacks and buildings with sheet metal sidings.

It is assumed that temporary repairs to restore service would be made wherever they are feasible.

Under these conditions the estimated average forced outage times following tornadoes of the windspeeds 1 isted are: 


\begin{tabular}{ll} 
& Days \\
\cline { 2 - 2 } & 80 \\
Minimum & 10 \\
Probable & 40
\end{tabular}

The "probable" estimate is used in the computation of loss of energy production capability.

Risk of forced outage at HNEC is shown in Figure 14 . The risk at selected points is:

\begin{tabular}{ccc}
$\begin{array}{c}\text { Capacity } \\
\text { GW }\end{array}$ & $\begin{array}{c}\text { Probable } \\
\text { Energy } \\
\text { Loss, GWh }\end{array}$ & $\begin{array}{c}\text { Probabi1ity of } \\
\text { Occurrence/yr }\end{array}$ \\
\hline 4.8 & 1000 & $1.4 \times 10^{-7}$ \\
4.8 & 4000 & $1.4 \times 10^{-7}$ \\
7.2 & 6100 & $4.0 \times 10^{-8}$ \\
7.2 & 17,500 & $4.0 \times 10^{-8}$
\end{tabular}

The analysis shows that the HNEC risk from tornadoes is very low relative to risk from other causes evaluated in the study. 


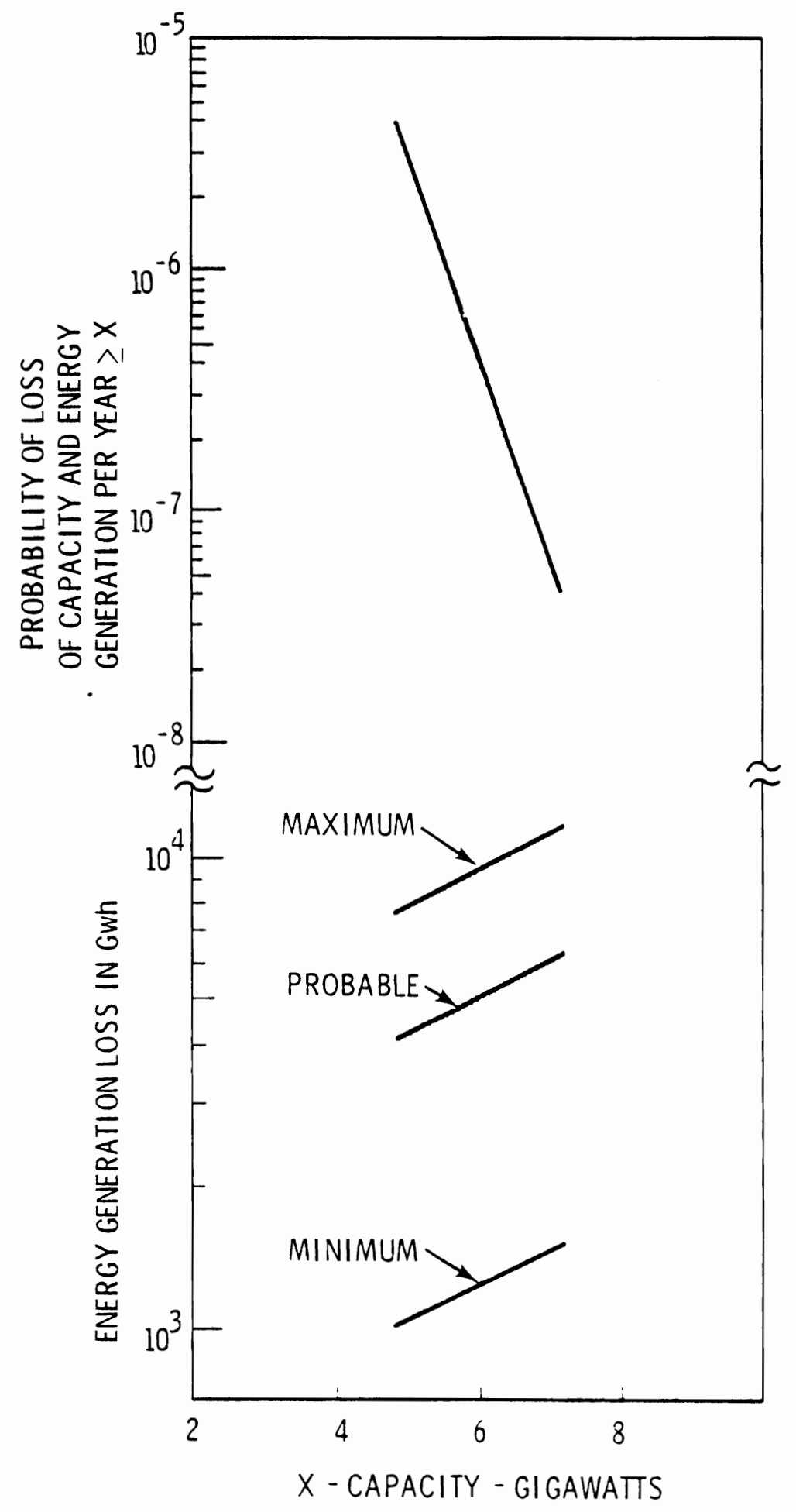

FIGURE 14. Risk of Capacity and Energy Generation Loss from Tornado at HNEC 


\section{REFERENCES - TORNADO}

1. USAEC Office of Regulation, Technical Basis for Interim Regional Tornado Criteria, WASH-1300, May 1974.

2. NRC Regulatory Guide 1.76, Design Basis Tornado for Nuclear Plants, Apri1 1974.

3. Washington Public Power Supply System, WPPSS Nuclear Project No. 1, Prel iminary Safety Analys is Report.

4. J. L. Jaech, Statistical Analysis of Tornado Data for Three Northwestern States, December 1970.

5. William B. Cottrell, Protection of Nuclear Power Plants Against External Disasters, p. 21, ORNL-NSIC-177, April 1975.

\section{REFERENCES NOT CITED}

NRC, Nuclear Energy Center Site Survey - 1975, Part IV, pp. 6-17 to 6-23, NUREG-0001.

T. T. Fujita, Proposed Chararacterization of Tornadoes and Hurricanes by Area and Intensity, SMRP Research Paper No. 92, February 1971.

H. C. S. Thom, "Tornado Probabilities", Monthly Weather Review, 91 (10-12): 730-736, October-December 1963.

T. T. Fujita, Estimate of Maximum Windspeed of Tornadoes in Three Northwestern States, SMRP Research Paper No. 91, University of Chicago, December 1970 .

N. K. Anderson, "Optimistic Goal Speeds Storm Reconstruction", Electrical World, June 1, 1976. 


\section{RADIOACTIVE RELEASE}

\section{Introduction}

The risk to be assessed in this section is that of forced shutdown of generating plants due to accidental release of radioactivity from a class 9 accident; i.e., a fuel melt and breach of containment at one of the nuclear generating plants. Such a release would occur only after failure of multiple safety systems. The chain of events would consist of 1) failure of containment at one plant, 2) rapid shutdown of other plants at that cluster and immediate evacuation of personnel at that cluster, 3) orderly shutdown of plants at other clusters where the potential for radiation exposure will force evacuation of operating personnel, and 4) decontamination of these plants and their immediate environs, with resumption of operation when radiation levels are acceptable. The unit releasing the radioactivity is assumed to be no longer available.

Before the full development of the 20-unit HNEC could be completed, it is possible that LMFBRs would replace some of the planned LWR generating units. In Reference 5, Proposed Final Environmental Statement, Liquid Metal Fast Breeder Reactor Program, the authors note that, "detailed probabilistic risk assessments have not yet been performed, al though some preliminary studies have begun." The report refers to the Reactor Safety Study regarding LWR plants. It implies that some of the same phenomena tending to limit releases, and the very low probability of occurrence of large releases, may apply at LMFBRs also.

Since, presumably, the LMFBRs would occupy the same sites (within the clusters) as the LWRs, be subject to the same wind conditions, and have the same order of probability of occurrence, the only significant change in the event of a class 9 accident at an LMFBR would be the somewhat different radioactive releases. If it can be assumed that the affected plants could still be shut down safely and be decontaminated with comparable applied effort, then the risks to adjacent clusters from a class 9 accident at an LMFBR would be comparable to those from an LWR. 
In this report, therefore, it is assumed that no difference in risk of forced outage from radioactive releases would exist by reason of a few of the LWR positions being filled by LMFBRs.

One or two fuels reprocessing plants can be assumed to be in operation at or near the HNEC. The unit in existence currently, however, and associated with the weapons program is assumed to have been decommissioned by the year 2000. Risks of loss of generation and of power shortages at an HNEC due to release of radioactivity following an accident exceeding the design bases at a fuels reprocessing plant are not included in this report. They are not included for two reasons. First, a source term, i.e., the amount of radioactivity that can be expected to be released following a major accident at a fuels reprocessing plant is not available. Preliminary reviews indicate that this source term would not exceed and probably be less than the source term from a fuel melt accident and release at a reactor. (1) The second reason is that probable sites for fuels reprocessing plants were not identified. Hence, these were not included in the meteorological model developed for the HNEC conditions (3). When these two factors become available, the contribution of a fuels reprocessing plant at an HNEC to the risk of loss of generation at an HNEC can be readily estimated.

WASH-1400, Reactor Safety Study, a report of the NRC published in October $1975^{(2)}$ contains the results of a comprehensive study on the subject of accidental radioactive releases from light water reactors and their probable effect on populations and property. While the safety of the general public following a reactor accident is always of paramount importance, such concerns are not a part of the current review. This reliability study on radioactive releases considers only two scenarios. The first is the potential for exposure to generating plant operating personnel during the passage of the radioactive cloud forcing their evacuation, thus causing plant shutdowns. Second, the number of plants forced out of service temporarily because of ground contamination following the accident may deny access or occupancy to control rooms or other parts of the facility and force a loss of generating capability. Decontamination

(1) K. J. Schneider - Private Communication, 1978. 
of the facilities and grounds sufficient to return them to operation in the shortest possible time is assumed and only activities addressed to maintaining or restoring generating capacity are considered.

SOURCE $^{(2)}$ METEOROLOGY MODEL ${ }^{(3)}$ DOSE MODEL ${ }^{(4)}$

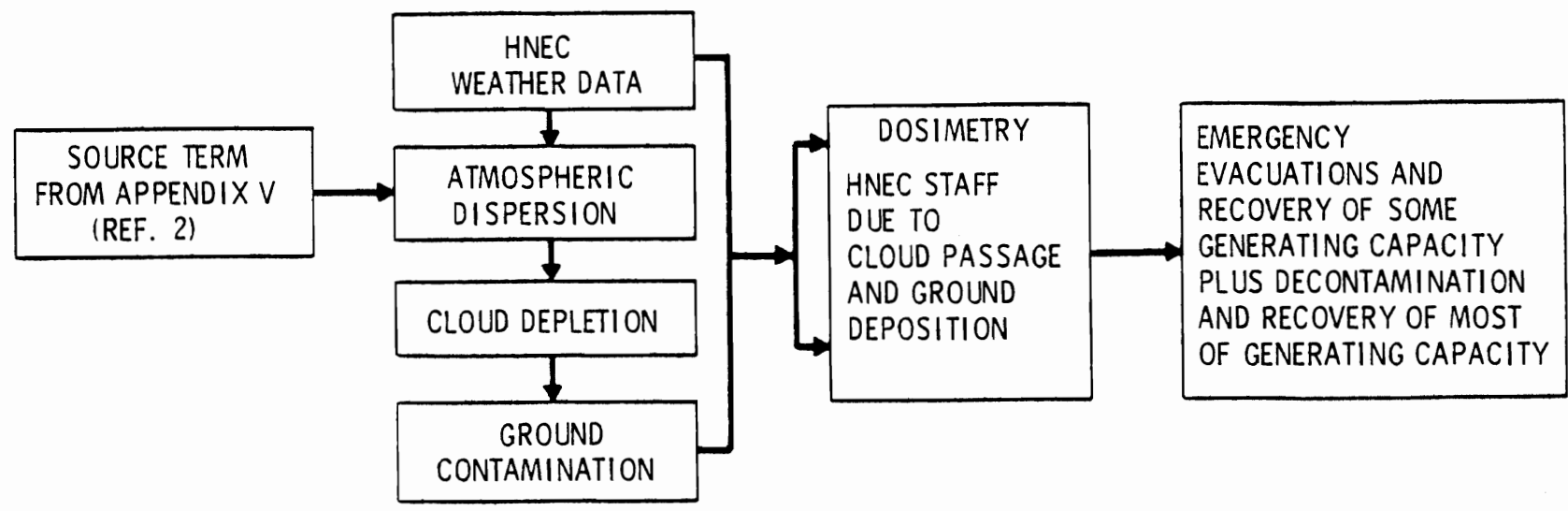

FIGURE 15. Schematic OutTine of Consequence

Model Radioactivity Release

As indicated by Figure 15, the source term was taken from the Reactor Safety Study. Any of the accident source terms identified in that study could be used to indicate the potential dose rates in reactor control rooms, (a) from the passing cloud following the accident; and (b) from ground level contamination during the period following deposition. Specifically, as an example, the class 9 accident identified as release category PWR-2 was selected (Table 5-1, Ref. 2). This was judged to be as probable as any other event. It also postulates great or greater quantities of radioactive material released as any other accident. It can be considered as worst case. The tabulation of radionuclides released in this event is given in Appendix $B$.

The HNEC model assumed that the containment breach resulted in a source 100 meters wide which spread downwind over a $221 / 2^{\circ}$ as it moved out from the point of release. Figure 16 illustrates one such release at Cluster No. 2 with 
clusters 3 and 4 shown within a $221 / 2^{\circ}$ sector downwind. The model integrates Hanford meteorological history and has provided a tabulation of the probabilities of one or more reactor sites having specific values of air concentrations normalized to release rate $\bar{X} / Q^{\prime}$ with units of $\mathrm{sec} / \mathrm{m}^{3}$. (3)

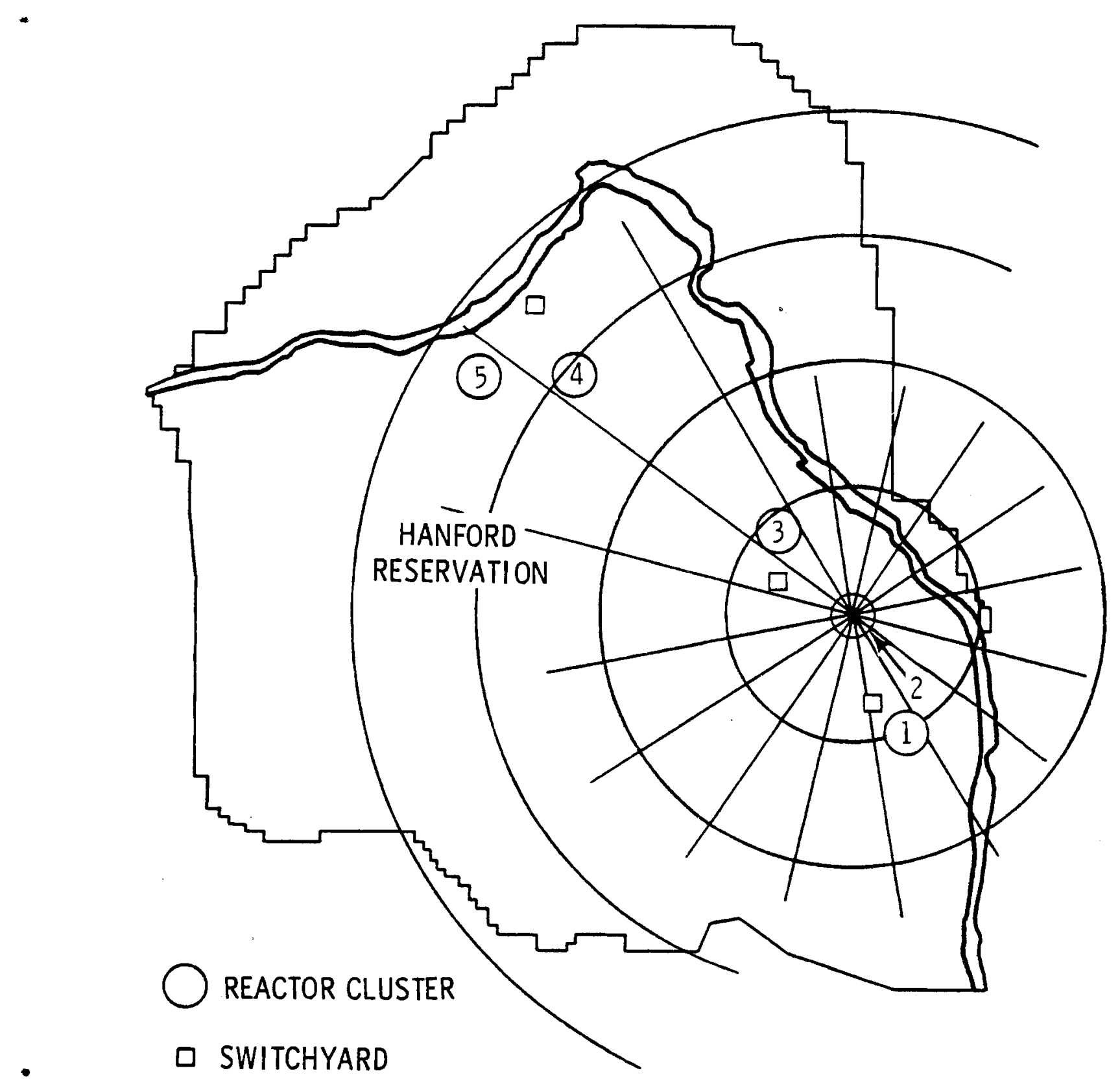

FIGURE 16. Sites and Areas Involved in Radioactive Release at HNEC

(Example: Release at cluster 2) 
As above, the dispersion of the radioactive cloud results in radiation exposure to those inside the facility during the assumed half hour passage of the cloud (referred to as the air submersion dose), and exposure to these same personnel from ground contamination following passage of the cloud. Inhatation of cloud debris or radioactive material resuspended from contaminated surfaces, are not primary factors. It was assumed that adequate filtering would be in place to isolate work areas and personnel from all airborne radioactivity. Similarly, short-and long-term health effects from drinking potentialiy contaminated water or eating contaminated food are assumed not to be significant for these scenarios. Oniy potential external exposures to occupational workers, i.e., staff members at the generating facilities, are assumed. These potential exposures are assumed to become a part of the routine administrative responsibilities that limit occupational exposures. Relaxation of administrative controls to facilitate a more rapid recovery of generating capacity is not assumed.

The release of radioactive material during the accident is assumed to occur over a half-hour period (Ref. 2) and the subsequent radiation levels from the air immersion dose are assumed to persist for a one-half hour period regardless of the distance of each area from the source or the time it took for the cloud to arrive.

PROBABLE CONSEQUENCES - AIR SUBMERSION

The potential radiation dose to personnel who remain inside a facility such as a control room have been developed as a probability function of at least $M$ reactors at an HNEC receiving a stated dose, given that a class 9 accident of the PWR-2 type has occurred in one unit. The probability for the class 9 accident at any one of twenty units is given as $1.6 \times 10^{-4} /$ year (Ref. 2, Table 5-1) or once every 6000 years.

The conversions to potential dose as indicated in Figure 17 are made by using the following:

$$
\begin{aligned}
\text { Dose }(\mathrm{rem}) & =\left(\frac{\operatorname{Rem}, \mathrm{s}^{3}}{\mathrm{sec} / \mathrm{m}^{3}}\right) \times\left(\frac{x}{Q} \mathrm{sec} / \mathrm{m}^{3}\right) \\
& =\text { Rem, as a function of time after release, and, of Hanford } \\
\text { meteorology } &
\end{aligned}
$$




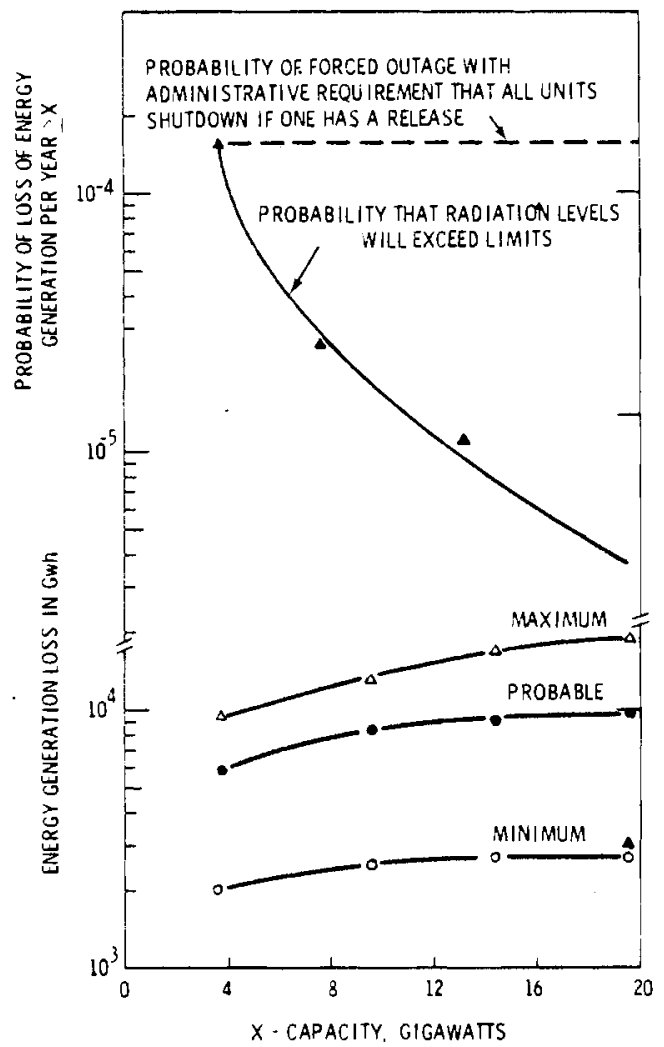

\section{FIGURE 17. Risk of Loss of Capacity and Energy Generation from Radioactive Release} at HNEC

The Shielding reduces the calculated exposure received by those inside the buidling by a factor of 10 (Ref. 2, Appendix VI, Table 11-8).

Table 10 below gives different probabilities of various radiation levels occurring at more than one facility given the condition that a PWR-2 accident has occurred in one and that 1000 seconds have elapsed since the release began. Time since release is a factor because of the distance the cloud can travel, assuming the average wind speed of 3 meters per second. (3) For example, at HNEC after one thousand seconds, reactors only in the cluster containing the affected unit could be exposed to the cloud. 


\section{TABLE 10. Dose to Personnel Remaining Inside M Reactors As a Function of Probability of M Reactors Being Involved}

\begin{tabular}{|c|c|c|c|c|}
\hline se, Rem & $\begin{array}{c}\text { Probability } \\
\text { Receiving }\end{array}$ & $\begin{array}{l}\text { of } 3, \\
\text { tated }\end{array}$ & $\begin{array}{l}4,5 \\
\text { Dose }\end{array}$ & Units \\
\hline & 3 & 4 & & 5 \\
\hline 280 & 1.0 & 0.85 & & 0.25 \\
\hline 130 & & 0.85 & & 0.26 \\
\hline 60 & & 0.85 & & 0.27 \\
\hline 28 & & 0.85 & & 0.29 \\
\hline 13 & & 0.86 & & 0.31 \\
\hline 6 & & 0.88 & & 0.37 \\
\hline 2.8 & & 0.88 & & 0.40 \\
\hline 1.3 & & 0.88 & & 0.41 \\
\hline 0.6 & & 0.88 & & 0.42 \\
\hline 0.3 & 1.0 & 0.88 & & 0.42 \\
\hline
\end{tabular}

The tabulation indicates that the conditional probability of people in up to 3 units in the cluster receiving exposure varying from 280 rem to $0.3 \mathrm{rem}$ is 1.00 . The difference would be caused by varying meteorology. Similarly, the probability of up to 5 units at a cluster receiving similar exposures varies from 0.25 to 0.42 . The amount of exposure at nearby reactors and sites depends on the wind speed and wind direction at the time of the accident. It is entirely possible for no reactors except the affected unit to be involved.

The following, Table 11, tabulates similarly derived probabilites at 10,000 seconds following the initiation of the release. During this interval the cloud would have had time to travel to the most distant reactor assuming the event occurred at cluster 1 or cluster 5 . See Figure 16. 
TABLE 11. Probability of Personnel Inside of M Reactors Receiving Stated Radiation Doses

\begin{tabular}{|c|c|c|c|c|c|}
\hline Dose, Rem & $\begin{array}{l}\text { Dose Rate } \\
\text { (Rem/Min) } \\
\end{array}$ & $\begin{array}{r}3,4,5 \\
\text { At 1st } \\
\text { Cluster } \\
\end{array}$ & $\begin{array}{r}7,8,9 \\
\text { At 2nd } \\
\text { Cluster } \\
\end{array}$ & $\begin{array}{l}11,12,13 \\
\text { At 3rd } \\
\text { Cluster }\end{array}$ & $\begin{array}{l}16-20 \\
\text { At } 4 \text { th } \\
\text { Cluster } \\
\end{array}$ \\
\hline 2.0 & 0.070 & $1.00-0.8-0.4$ & $0.16-0.13-0.08$ & $0.01-0.01-0.01$ & 0.02 \\
\hline 0.93 & 0.030 & & & & 0.02 \\
\hline 0.43 & 0.010 & & & & 0.02 \\
\hline 0.2 & 0.007 & $1.00-0.8-0.4$ & $0.19-0.15-0.11$ & $0.90-0.09-0.08$ & 0.03 \\
\hline \multicolumn{5}{|c|}{ Probability of 0.2 thru 2.} & $\varepsilon 0.1$ \\
\hline
\end{tabular}

The above indicates that the probability of the people located at the four reactors in the most distant cluster ( 4 th) receiving doses from 2 to 0.2 rem is either 0.02 or 0.03 . This can be interpreted as saying that the probability of receiving at least 2 rem exposure in the control room after 10,000 seconds is at least 0.02 , given that the PWR-2 accident occurred in the most distant cluster. The overall probability of the distant reactors being affected is 1.6 to $10^{-4} \times>0.02$, or, $>2 \times 10^{-6}$ or at least about once per $5 \times 10^{7}$ years.

Similarly, personnel in control rooms in the nearest 3 reactors can expect any dose up to 280 rem if they remain in the control room, given that a class 9 accident has occurred. All units in this cluster would immediately shut down and all crews would rapidly evacuate (only if doses were significant). Further, emergency evacuation procedures will be followed by the operating staff in all units at an HNEC if a class 9 accident has occurred in any. Depending on the time for the accidental release to develop from the containment vessel following the accident and possible obvious meterological conditions, it may not be necessary to shut down many of the more distant reactors and evacuate personnel. Further it may be more prudent to stay put to utilize the building for shielding rather than evacuate and risk exposure to the passing cloud with the shielding of only an auto. However, in this review all reactors are assumed to shut down to at least a hot stand-by condition with an average electrical energy loss of 57.6 GWh (2 days) per unit. 
Hence, the instantaneous loss of 1.2 GW from the affected reactor plus up to an additional $4.8 \mathrm{GW}$ from units in the same cluster can be expected and probably without warning to the electrical grid system operators. Time would be available to notify the electrical grid system operators of pending emergency shutdowns at most of the remaining units. This has been assumed in the analyses. .

For the dispersed option the consequences from potential air submersion doses following a class 9 accident at any one of the reactors is significantly less. Two of the five clusters assumed to be located at the Hanford site in the dispersed concept are close enough to be affected if a class 9 accident does occur in a reactor in one of these two. The other three clusters, however, are separated such that an accident in any one of these will not affect the operation of any reactors in any of the other four.

Fallout Contamination

The immediate consequences from the passing cloud are relatively short lived. Potential radiation levels within generating facilities (control rooms) from outside ground contamination from fallout from the cloud, however, may deny access to these facilities until decontamination efforts or radioactive decay have reduced the levels to acceptable amounts. To quantify this analysis, the following table compares the probabilities of having measurable control room radiation levels on the day of the accident prior to decontamination and before significant radioactive decay.

For the assumptions made, note that the probability is about 1 in $8(0.12)$ that at least 9 reactors will have a radiation level of $0.2 \mathrm{rem} / \mathrm{hr}$ in their control room from ground contamination.

In the model shown in Figure 17, the concentrations of activity per square meter have been estimated (3) using the Hanford meteorological data as before including the appropriate deposition factors. The buildup of radioactivity deposited is assumed to have come to equilibrium during the passage of the cloud. The radiation levels within the facility were reduced by a factor of 0.7 to account for normal ground terrain (non-smooth surfaces). It is assumed that immediate efforts will be undertaken to reduce the dose rates due to contamination around the facilities. Thus an additional factor of $1 / 7$ was 
TABLE 12. Comparison of Probility That a Certain Dose Rate Would be Received in the Control Room From Deposited Material During the First Day Following An Accident

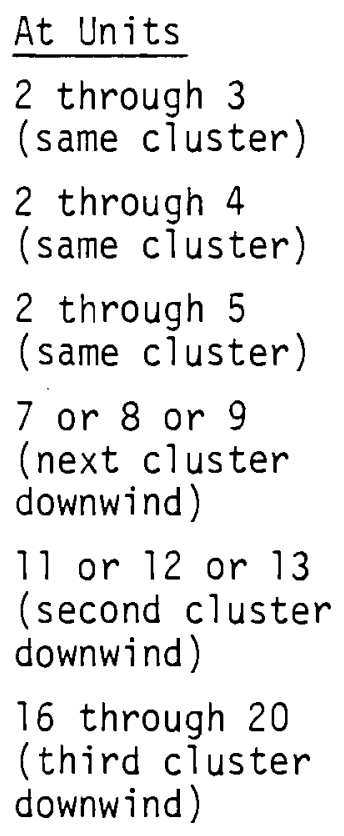

\begin{tabular}{|c|c|c|}
\hline \multirow[b]{2}{*}{$\begin{array}{l}\text { Dose Rate to Persons } \\
\text { In The Control Room }\end{array}$} & \multicolumn{2}{|c|}{ Probability } \\
\hline & $\begin{array}{l}\text { PartiaT, (i.e., } \\
\text { Given That An } \\
\text { Accident Occurs) }\end{array}$ & $\begin{array}{l}\text { Total (including } \\
\text { The Probability } \\
\text { of The Event) }\end{array}$ \\
\hline (2 rem/hr) & 1.0 & $1.6 \times 10^{-4}$ \\
\hline (2 rem/hr) & 0.88 & 1.4 \\
\hline$(0.02 \mathrm{rem} / \mathrm{hr})$ & 0.40 & 0.64 \\
\hline $0.2 \mathrm{rem} / \mathrm{hr}$ & 0.12 & 0.19 \\
\hline $0.02 \mathrm{rem} / \mathrm{hr}$ & 0.06 & 0.09 \\
\hline $0.002 \mathrm{rem} / \mathrm{hr}$ & 0.02 & $0.03 \times 10^{-4}$ \\
\hline
\end{tabular}

chosen (Ref. 2, Table VI 11-8) as a result of preliminary decontamination efforts at each affected facility. The potential exposures are thus reduced by a factor of ten. In addition, the sheilding afforded by the building to those inside further reduces their doses by a factor of 0.1 (Ref. 2, Table VI 11-8).

For those isotopes of interest (see Appendix $B$ ), the effects of radioactive decay over $7,14,30$, and 60 day intervals are shown in Table 13.

The following tabulation shows that the third cluster (the first cluster includes the affected unit) and an average $15-18 \mathrm{~km}$ away, that the probabilities of units in this cluster having at least $1 \mathrm{mrem} / \mathrm{hr}$ in their control rooms 14 days after the accident is only about 12 times less (0.08) probable than the accident itself. Stated in other words, after 14 days the probability of a dose rate of at least $1 \mathrm{mrem} / \mathrm{hr}$ in the control of reactors up to $15-18 \mathrm{~km}$ away is at least 1 in $12(0.08)$. 
TABLE 13. Probabilities of Persons in Control Rooms Receiving Dose Rates of $\geq 1 \mathrm{mrem} / \mathrm{hr}$ at Varing Intervals Following the Accident

No. of Number of Days Following Accident

Units

$\begin{array}{lllllll} & 3 & \overline{1.00} & \overline{1.00} & \frac{14}{1.00} & \frac{30}{1.00} & \overline{1.00} \\ \text { lst } & 4 & 0.88 & 0.88 & 0.88 & 0.88 & 0.88 \\ \text { cluster } & 5 & 0.42 & 0.42 & 0.42 & 0.42 & 0.42\end{array}$

7 or 8 or 9

2nd cluster

0.160

0.136

0.136

0.122

0.12

11 or 12 or 13

3rd cluster

0.100

0.08

0.08

0.06

0.06

15 or 16

4 th cluster

0.030

0.023

0.023

0.018

0.018

Decontamination efforts greater than those reducing the levels by a factor of $1 / 7$ may have to be undertaken in many facilities. This appears entirely feasible.

For this unit close to the affected reactor, extensive decontamination procedures of the environs around each facility will be required to reduce radiation levels inside the facility to acceptable amounts ( $\overline{<} 1 \mathrm{mrem} / \mathrm{hr}$ ) so that these generating units can be restored to service. Table 14 shows these estimates.

TABLE 14. Reductior of Expected Radiation Dose Rates To People Within a Control Room From Ground Contamination With Time After Accident (a)

Control Rooms

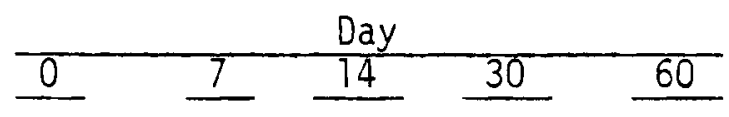

of Any of the

Other 3 Units

(within same

cluster as

accident)

(a) Assuring a decontamination factor of $1 / 7$ 
The data in the above table indicates that after an accident occurs, the radiation dose rate in the control rooms of adjacent reactors will not be acceptable for routine occupancy for at least 60 days. Thus, a loss of 4.8 gigawatts (entire site) for probabiy up to 2 months has the same probability of occurrence as the accident itself, unless additional decontamination efforts are applied to these facilities and their common site.

SUMMARY

The results are summarized in Figure 17. The three lower curves estimate the loss of energy in Gw-hr for various losses of generating capacity. The curves differ by the estimates of times to decontaminate and recover operating capability. For example, the maximum curve estimates 60 days to recover any capacity at the cluster in which the event occurred, that 5 units were located at the cluster, and that 45,30 and 15 days were required at the other clusters. The minimum estimate was for 2 days for those units not affected at the site of the accident plus 7, 3, and 2 days for the other clusters. The probable estimate is that maximum estimated by several utilities operating nuclear facilities.

\section{REFERENCES - ACCIDENTAL RADIOACTIVE RELEASE}

1. Nuclear Regulatory Commission, Nuclear Energy Center Site Survey-1975, NUREG-0001, January 1976.

2. Nuclear Regulatory Conmission, Reactor Safety Study, WASH-1400, October 1975.

3. Meterological Evaluation of Multiple Reactor Contamination Probabilities for HNEC, PNL 2452 UC-80, J. V. Ramsde11, D. I. Diebel, March 1978.

4. SUBDOSA, BNWL-B-351, June, 1975, D. L. Strenge, E. C. Watson and J. R. Houston, A Computer Program for Calculating External Doses from Accidental Atmospheric Releases of Radionuclides, ERDA Report, Battelle PNL MTIS, June 1975.

5. U.S. Atomic Energy Commission, Proposed Final Environmental Statement, Liquid Metal Fast Breeder Reactor Program, Vol II, WASH-1535, December 1974. 
FLOOD

Introduction

One hundred percent of the HNEC capacity and $70 \%$ of the DS case capacity would be on a single river, the Columbia. Of the $70 \%$ of DS capacity, the $20 \%$ at Pebble Springs is isolated from effects of floods on the Columbia because of its elevation and an independent water supply at that site. Other DS sites are not identified specifically and consequently site elevations or plans for cooling facilities are not available. A comparison of flood risk, therefore, can be drawn only by making the broad assumption that if 100\% of HNEC capacity is affected by flood, $50 \%$ of the DS capacity would likewise be affected.

Flooding of river pump houses is the only way operation of any of the plants would be affected. As will be seen, most of the critical HNEC facilities, with the exception of their river pump houses, are at elevations above the level of the Limiting Case Flood, as for example, the elevations set for WPPSS plants No. 1,2 and 4 .

The c00ling pond at Pebble Springs, 60,000 acre-ft, provides c00ling water for routine operation for extended periods. (1) Loss of river pump facilities due to flooding on the Columbia would not affect electrical generation at this site. Even with some use of water from the pond for irrigation, the plant could be expected to remain in operation for many weeks before the pond level, without makeup, would be too low for continued operation at full power. Consumptive use for two generating units would average 6000 acre-ft per month, or 12,000 acre-ft per month for four units.

At the Oregon DS sites, where makeup water for $30 \%$ of the DS capacity is assumed to come from the Willamette River or its tributaries, the possible effects of flooding is assumed to be noncoincidental with a Columbia River flood.

The "probable maximum" unregulated flood on the Columbia is 1,600,000 cfs, which as now regulated by flood control by existing dams is 1,400,000 cfs. (2) The largest known historical flood on the Columbia at river mile 352, (position of initial HNEC plants) had a peak discharge estimated at 800,000 cfs. These peak flows are considerably below the peak flow associated with Artificial Flood No. 1, namely a breach of the Grand Coulee Dam. 


\section{Limiting Case Flood}

A Grand Coulee Dam failure has been established as the Limiting Case Flood (also, Artificial Flood \#1) for the Hanford reach of the Columbia. It is based on a breach in which $25 \%$ of the face of the dam would be removed with a consequent outfall peak of $8,800,000$ cfs at Grand Coulee Dam, and a peak discharge at Richland of 4,800,000 cfs. (3) The flow computation took into consideration an evaluation of the effects of the flood on downstream dams, with failure of earthfilled portions and subsequent release of storage pools.

Elevations of the flood peaks for the floods described above are:

Probabie Maximum Flood - 1,400,000 cfs

Limiting Case Flood - 4,800,000 cfs

Plant Elevations (level for water entry into plants)

River Pump House Floor
389

424.5

479

389

Category I structures of plants currently being built are designed to withstand the static and dynamic forces of the Limiting Case Flood, the breach of Grand Coulee Dam.

Although future HNEC plants may have different elevations, it can be expected that they will maintain a comparable relationship with the Limiting Case Flood level at corresponding points on the river. The plant elevations cited above are for the reactor facility. It may be assumed that all code designed facilities essential to power generation will be built at or near this same elevation, except the river pump house.

Probability of Exceeding the Probable Maximum Flood

An estimate of the probability of exceeding the Probable Maximum Flood is given in Reference 4. That report refers to river mile 340 , which is $12 \mathrm{mi}$ downstream from the point at which the WPPSS plants are being built. The reference report uses a Probable Maximum Flood of 1,320,000 cfs. The conditions and assumptions are sufficiently typical of those of HNEC that the findings are pertinent. Figure 18 from Reference 4 is a discharge frequency curve for the Columbia River, applicable to the Richland reach. 


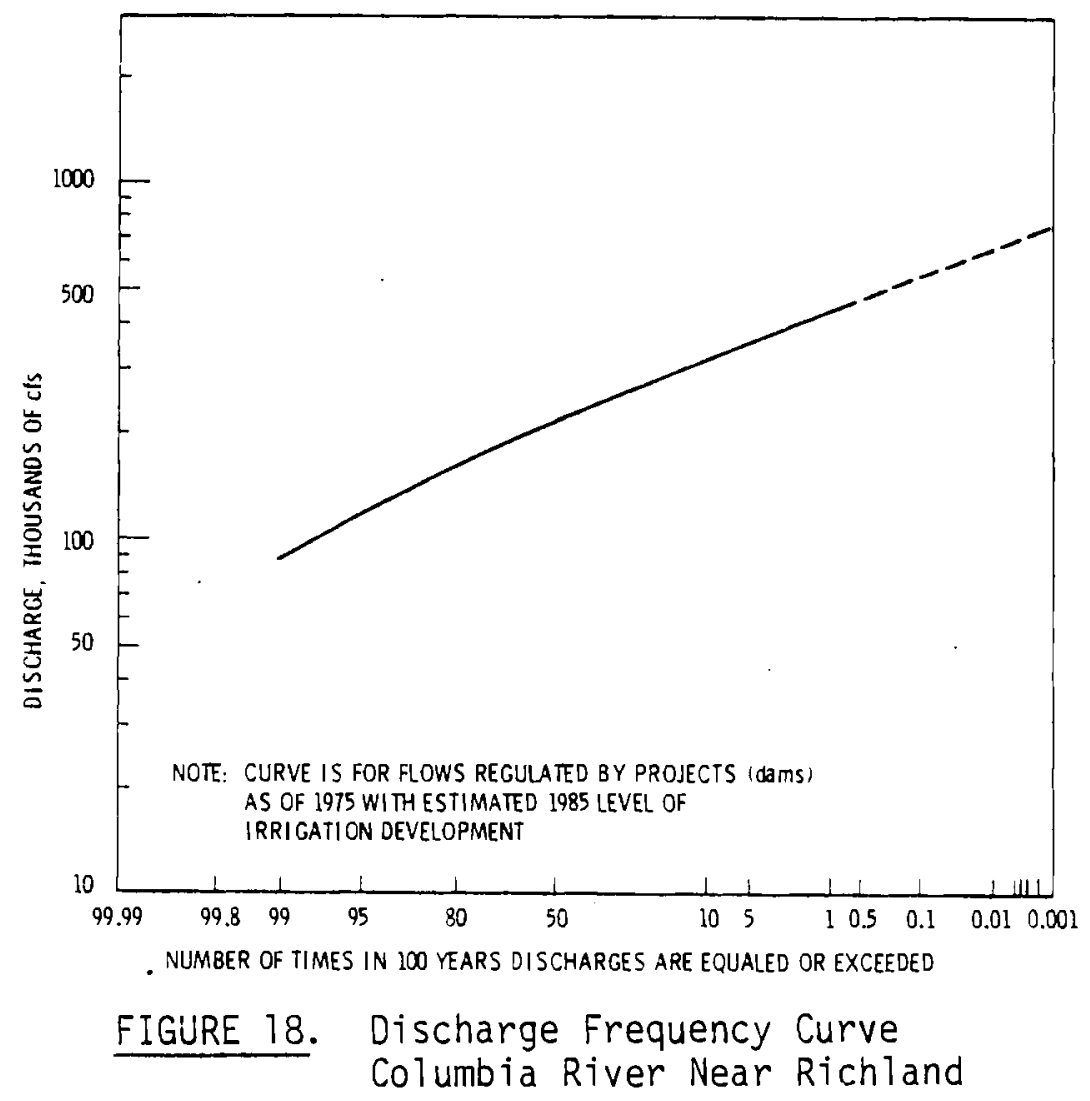

Extrapolation of curve $B$, Figure 1 , to 1.32 million cfs indicates a probability on the order of $10^{-7}$ events per year. (Willamette River flooding conditions were not reviewed. It was assumed that frequency would be the same as for the columbia. This is believed to be a conservative assumption with regard to comparative risk between the HNEC and OS. Flooding at the Willamette River involves the loss of only six generating units in comparing HNEC with DS. This loss has a relatively moderate impact.)

Probability of Occurrence of Artificial Flood No. 1

There are insufficient data for an estimate of the probability of Artificial Flood No. 1 Reference 5 contains an estimate of the probability of failure of concrete arch dams, worldwide, of $10^{-4}$ events per year. Grand Coulee Dam is a massive gravity-type concrete dam for which the only conceivable cause of failure, other than military attack, is earthquake. It is located in an area of relatively low seismicity. ${ }^{(6)}$ In the opinion of a Bureau of Reclamation spokesman, "we can state that worldwide there is no record of any type of concrete dam 
ever having failed due to an earthquake ("Catalog of Dam Disaster, Failures and Accidents", by A. O. Babb and T. W. Mermel). The probabilities of an earthquakeinduced failure is therefore much less than $10^{-4}$ for Grand Coulee. "(7)

For purposes of this report is is assumed that the probability of such a failure is less than for the Probable Maximum Flood, and that it may be disregarded in the risk comparison.

Probability of Forced Outage from Flood

To sum up the findings on flood risk:

1) A Columbia River flood that would effect 100\% of HNEC capacity would be likely to affect $50 \%$ of the DS capacity. Possible floods at other DS sites would probably not be coincidental with Columbia River floods. A flood on the Williamette River could affect $30 \%$ of the DS capacity, but willamette flood conditions were not reviewed since the sites themselves are not specific.

2) The HNEC facilities with the exception of the river pump houses are sited at elevations at or near the Limiting Case (Grand Coulee Dam failure) Flood level. The probability of this flood is believed to be less than $10^{-7}$, and hence possible effects from this flood are disregarded. The risk lies in river pump houses being flooded at flow elevations that are greater than those of the Probable Maximum Flood, but less than the Maximum Case Flood. An extrapolation of dischargefrequency curves indicates that the probability of a Probable Maximum Flood is of the order of $10^{-7} / \mathrm{yr}$.

It is assumed that each group of plants would be affected as a block, i.e., a 11 units in the 20,10 and 6-unit groups would be affected if a flood greater than the Probable Maximum Flood were to occur. A marginal flood might affect only part of the generating units in each of these blocks, but the available information does not justify making a distinction. The cumlulative probabilities are constant since all clusters have equal probability of river pump house flooding in the event of the Probable Maximum Flood $\left(10^{-7} / \mathrm{yr}\right)$, with 10 units being the maximum number that could be affected at once in the DS case, and 20 units in the HNEC case. 


\section{Risk from Floods}

A flood that substantially exceeds the Probable Maximum Flood possibly would incapacitate the river pump house through:

- water soaking of electrical equipment,

- silt deposits in equipment,

- damage to structures caused by impact of water or debris,

- washout of foundations or embankments, and/or

- stress on connecting piping.

The rapidity with which the facilities can be repaired may be governed by other flood effects, i.e., effect on transportation facilities, availability of spare equipment, availability of crews, and the like. The assumptions as to these possible effects and the extent of the damage enters into the estimates of upper and lower bounds, and probable time to return the units to service are given below:

\begin{tabular}{lc} 
& $\begin{array}{c}\text { Average Days of } \\
\text { Forced Outage per } \\
\text { Generating Unit }\end{array}$ \\
\cline { 2 - 3 } Maximum & 45 \\
Minimum & 7 \\
Probable & 20
\end{tabular}

Figure 19 indicates risk of HNEC forced outage from generating capacity loss (curve A) and energy production loss (curve B). For capacity loss in the range of $0-12$ GW there is no difference in risk between the HNEC and DS cases. 


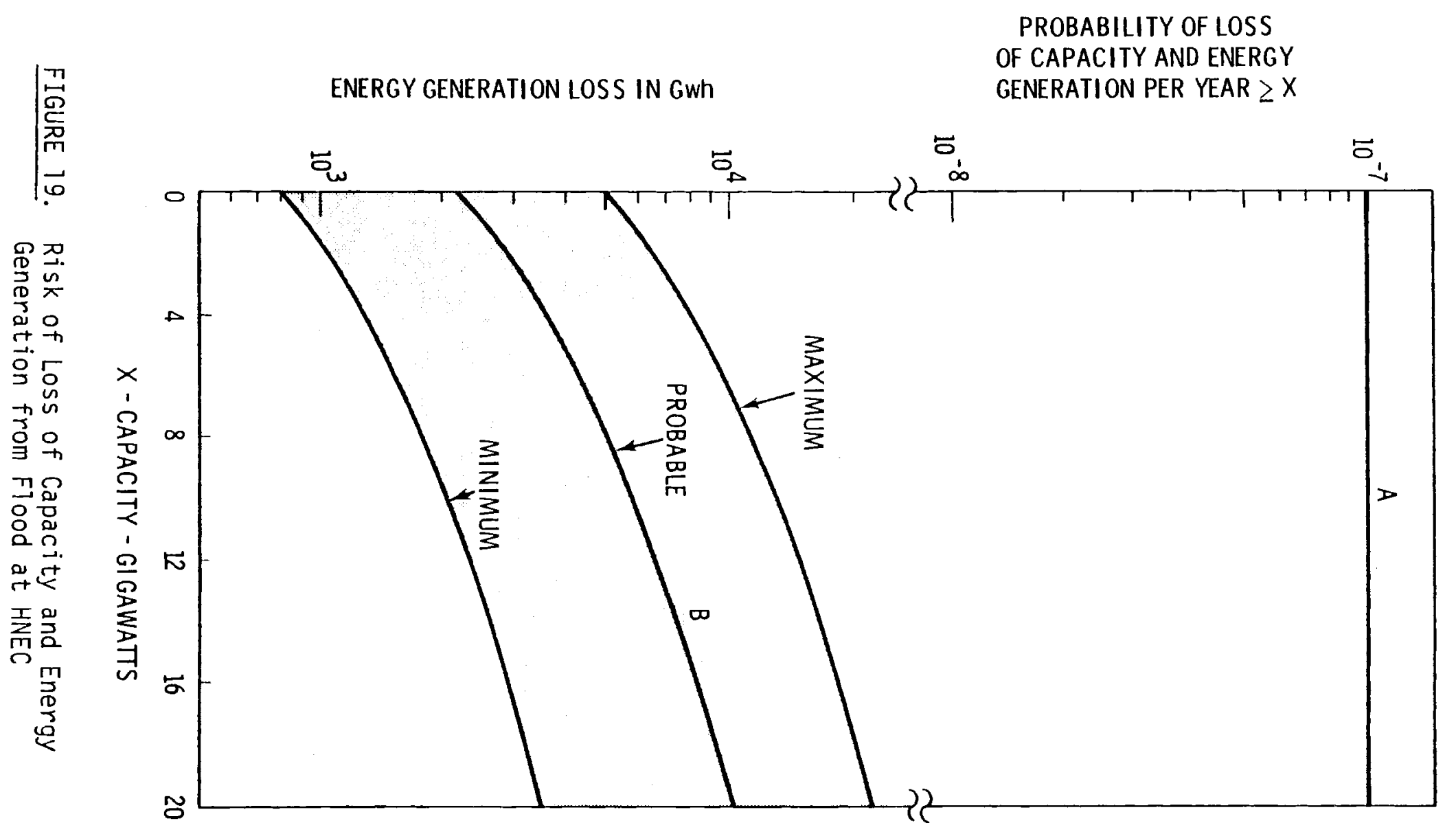




\section{REFERENCES - FLOOD}

1. Preliminary Safety Analys is Report, Pebble Springs.

2. Preliminary Safety Analys is Report, WPPSS Plants 1 and 4.

3. U.S. Corp of Engineers, Artificial Flood Possibilities on the Columbia River, November 20, 1951 .

4. L. V. Kimmel and R. G. Baca, Predictability of Flooding Potential on the Columbia River, Battelle Pacific Northwest Laboratories, BNW/XN-178, January 1975.

5. Paul Gast (ANL), Divergent Public Attitudes Toward Nuclear and Hydorelectric Plant Safety, ANS Meeting, Chicago, IL, June 1973.

6. John A. Blume and Associates, Seismic Exposure and Criteria for Seismic Analys is of Grand Coulee Dam, Columbia River, Grand Coulee, Washington, November 1972.

7. Harley J. Warren, Chief Technical Services and Publications Branch, U.S. Bureau of Reclamation, personal communication, May 10, 1977.

\section{REFERENCES NOT CITED}

U.S. Army Engineer District, Seattle, WA, Artificial Flood Considerations for Columbia River Dams, August 1963.

Safety Evaluation by the Directorate of Licensing, U.S. Atomic Energy Commission in the matter of the WPPSS Hanford No. 2 Nuclear Power Plant Docket No. 50-397, pp. 14-15.

Flood Frequency Curves, Columbia River at Trinidad, Maximum Peaks, Seattle District Corp of Engineers/Water Control Section, data sheet. 
ASHFALL FROM CASCADE VOLCANOES

Introduction

This section develops the risks of HNEC and DS plants being forced out of service by ashfal1. Difficulties are encountered in attempting to quantify such a risk in that information on the magnitude of ash discharges in the past is spotty, and the threshold condition for a forced outage from this cause has not been defined. A threshold would be determined by the characteristics of the ash, and by any added measures taken in the design of the plant to tolerate this event. No record has been found of large thermal power plants having been subjected to such conditions. The only record obtained on the effects of ashfall on electric power generation, transmission, and distribution is that of the eruption of Mount Usu in northern Japan starting on August 7, 1977. The affected generating plants are hydroelectric, and the maximum transmission voltage in the affected area is $100 \mathrm{KV}$. (3)

The frequency and severity of volcanic explosions of the type that could affect plants at the distances involved here can be estimated on the basis of the history of eruptions in the Cascades, although imperfectly so, because of the sparsity of data on the magnitude of ash discharges. The threshold conditions and the time that may be required to return the plant to service after an. incident in which design conditions were exceeded are necessarily conjectural.

\section{Properties of Ashfal1s}

In volcanoes, "the magma is formed far below the earth's surface, where pressures are very high. The high pressure forces gases to dissolve in the molten rock, the most important being water, carbon dioxide, and sulfurous compounds. As the magma reaches the surface through volcanic vents, the pressure is reduced and the dissolved gases are released."(1) Ashes can be propelled to elevations of 30,000 to 49,000 feet, or more. Sulfur dioxide "injected into the atmosphere by a volcanic explosion... is converted through photochemi-

- cal processes into small droplets of sulphuric acid:" "1) These droplets and small ash particles remain in the stratosphere for long periods and are transported many hundreds of miles. Other products remain below the stratosphere and settle of their own weight or are washed from the sky by clouds and rain. 
The possible effects of both volcanic ash and droplets of sulphuric acid are to be considered.

The ash from Glacier Peak, which is typical of that from the Cascade volcanoes, had an average glass content of $85 \%$ and an average crystal content of 15\%. Listed in order of abundance the crystals consist of andesine, hypersthene, hornblende, magnetite, and a trace of augite. (2) The median diameter of the particles decreased from $500 \mu$ at Glacier Peak to only $22 \mu$ at a point 173 mi to the east, and to $24 \mu$ at a point $116 \mathrm{mi}$ to the southwest (particles in the stratosphere are about $2 \mu)$. The size of the particles deposited in the Hanford area (from St. Helens and Mazama) is such that $58 \%$ are greater, and $42 \%$ less, than $74 \mu$.

After an eruption of the explosive type the ash carried by winds is deposited over wide areas. The distances over which Glacier Peak ashes were deposited are indicated above. Ash from the Mount Mazama eruption of about 7000 years ago (Crater Lake Oregon) deposited in the Pasco Basin to a depth of about six inches, demonstrating that with a major eruption, under the right weather conditions, great amounts of ash can be carried over 300 miles.

Over the last 15,000 yr, in addition to the ashfall at Hanford from Mount Mazama noted above, there have been other substantial ashfalls, from Mount St. Helens eruptions of 13,000 and 1500 years ago.

The ashfall from each event ranges from a fraction of an inch to 6 in. (or greater in spot locations) in depth in this area. Local winds and rainfall, and deposits carried in surface runoff, probably account for variation in thickness of ash deposits. Deposits in various localities could be much less or much greater than the average over a wider area.

The pattern of deposits from the events discussed above suggests that the winds at the time of the eruptions were mainly from the southwest, but at times from the west-northwest and the east. Reference 2 contains a hypothesis of atmospheric conditions to give the observed deposition, in which a "low pressure area moving from the Pacific eastward over Glacier Peak during the eruption is the most likely situation that would account for the observed distribution...". 


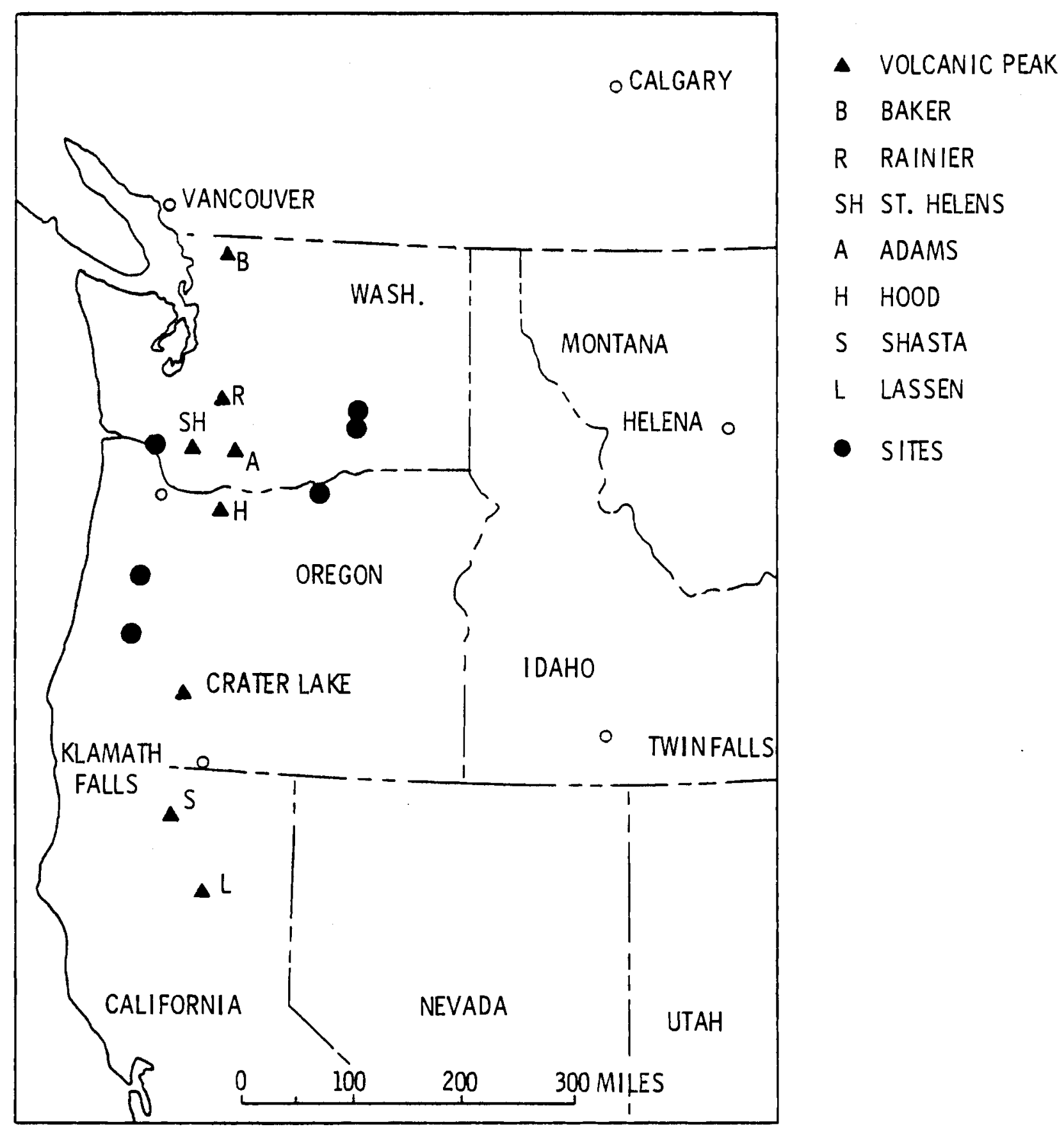

FIGURE 20. Volcanic Peaks and Plant Site Locations 
As to the duration of the eruptions, "From sedimentary and petrographic evidence, it is abundantly clear that the eruption of Glacier Peak was single and short. It may have endured for only a few days or possibly for a few weeks. ... Of these two possibilities the latter appears more plausible..." (2) The probable duration of such eruptions is important in that the effect of an ashfall on plant operations may be manageable if deposition is gradual.

Probability of Occurrence

Reference 4 contains a graph of the relative amounts of volcanic products discharged by "every Cascade eruption over the 1ast 15,000 years so far dated by radiocarbon methods". The ash products shown on this chart were scaled (although "the intensity scale is not an arithmetic progression, it represents the approximate order of ranking of the estimated volume of volcanic products of known Cascade eruptive episodes") and a probability distribution of indexed amounts of ash release was prepared. The result is shown in Figure 21.

Unfortunately, the 19 eruptions that are charted in Reference 4 do not include al1 that are known to have occurred from the Cascades. It is reported that within the last 12,000 yr there have been more than 30 eruptions at Mount St. Helens, three at Lassen Peak, 11 at Mount Rainier, and seven mudflows assocated with volcanic activity at Mount Baker. It is assumed, however, that most of the major ash eruptions are included in the chart. Also, the indexing of ash volumes as described above is imperfect. "The volume of the Mazama eruption, intensity $x$, was between three and five times greater than intensity IX." (4) These are the only two for which volume has been calculated. (The Mazama ash eruption is represented by the point of maximum intensity in Figure 27. It is the only point that has a large deviation from the straight line defined by other points). Even with these defects the data on the 19 events were used since no other was found upon which to base probabilities of volcanic ash discharges.

Proability of Exposure

Whether a cluster would be exposed to ashes from a given volcanic eruption would depend on the amount of ashes expelled (as indicated by the above index), 


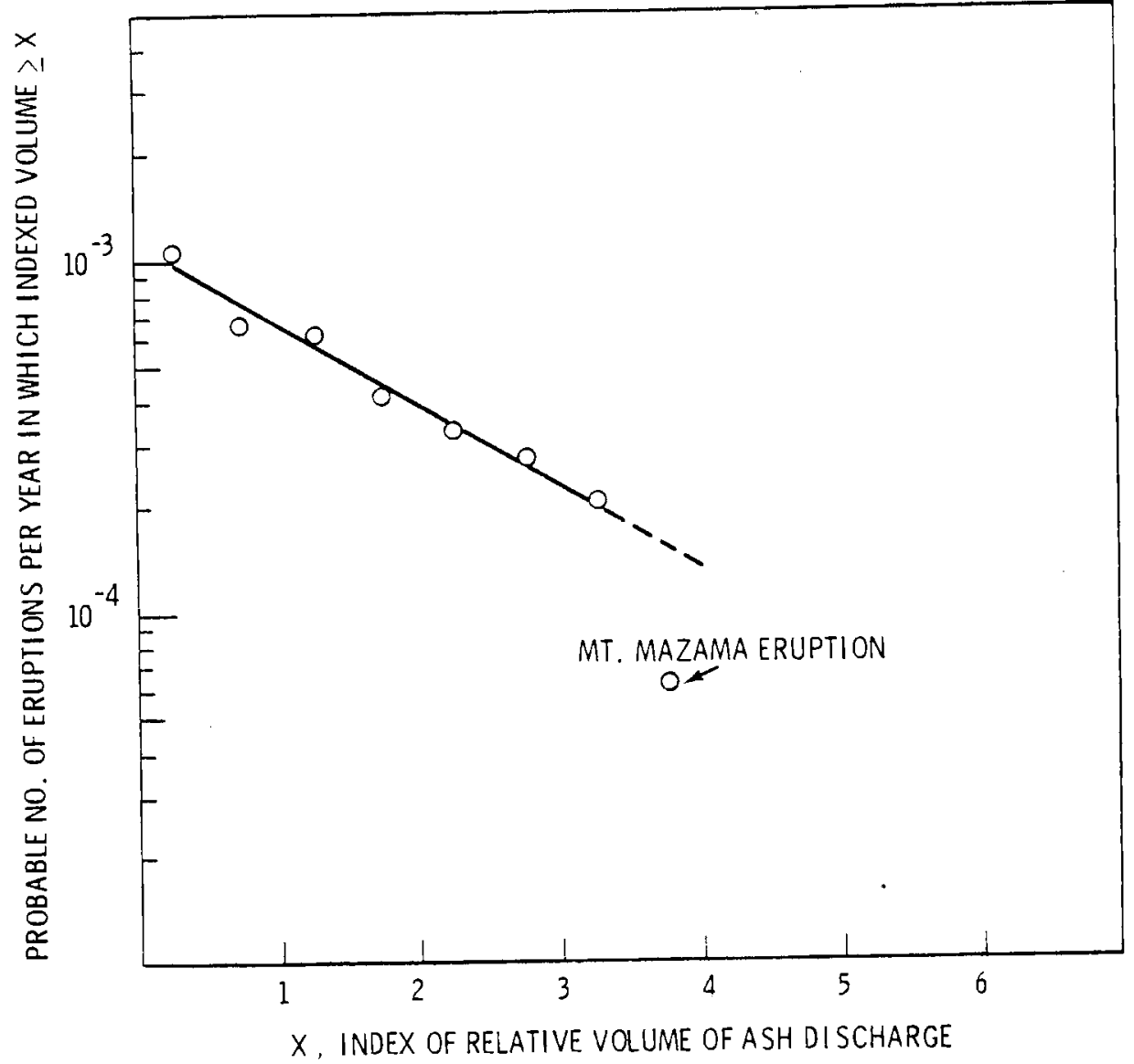

FIGURE 21. Probability of Ash Discharge from Cascade Volcanoes

the wind direction and velocity during the eruption, and the distance of the cluster from the volcano. The variability of high altitude winds and of rainstorms in the path of the plume sometimes cause the deposition to decrease nonuniformly with distance. In the 50-200 mi range, the deposition may be greater at a more distant point than at a point closer to the volcano. However, "Many deposits of this type (coarser debris in deposits, ten to hundreds of miles long) are almost linear, and their configurations reflect the direction of the reactor resultant wind above the volumes at the time of eruption." $(6)$

The procedure used to derive approximate probabilities based on available information is described in Appendix $B$, along with calculations of exposure and occurrence probabilities. The product, i.e., the probability of forced outage versus number of generating units affected, is given in Figure 22. 
Effects of the Mount Usu Eruption (3).

The initial eruption of Mount Usu expelled ash to a height of 39,000 feet, and following eruptions to lesser heights. Six major eruptions, each lasting from two to three hours, occurred over a period of seven days. Minor eruptions followed some of the major ones. Weather conditions were changeable during the period, windy, rainy, cloudy and fair. The wind direction at the time of the eruptions ranged over 180 degrees centered in the southwest. Wind velocity was up to $55 \mathrm{mph}$ out of the northwest in dry weather, and up to 45 mph out of the south in rainy weather. Ash was deposited to a depth of about two inches or more over a 20 to 25 mile radius in the windward direction. Ashfall near the volcano measured up to 40 inches in thickness.

Most damage to the electric power system occurred where the ashfall was two inches or greater in thickness. Two hydroelectric plants at which operation was affected were each about three miles from the volcano. Generation outages were caused by the intakes and penstocks. being choked with pumice, and the outages were prolonged by delays in permission to clear the system by washing the pumice to streams that fed irrigation systems or that flowed into fishing grounds. A major thermal power plant 19 miles east of the volcano was not affected (the weather was dry when ash was blown in that direction).

Transmission and distribution systems were damaged to the extent that service to some 500 homes in the region was interrupted for a total of two to three days, and to some 3000 homes for about 18 hours. These outages were caused largely by volcanic ash and rain, which after deposition would stick to surfaces and "become like solid concrete." It would cause insulators to fail electrically, poles and line conductors to fail structurally, and trees to fall into lines. The greatest damage occurred during periods of simultaneous eruption and rain. The bad effects of the ash-rain mixture on thermal generating plant insulators and lines of HNEC could be similar to that of the reported effects on the distribution systems in the vicinity of Mount Usu. The low probability of rain in eastern washington, unless rain were caused by ash in the atmosphere, would lessen the risk of extensive damage from ashfall. 
Risk from Ashfall

The consequences of a given ashfall would, of course, be equal for HNEC and DS plants receiving equal ashfall.

Corrective operations may involve:

- Replacement of water inventories in open reservoirs that have been made too acid by the ashfall,

- Replacement of clogged filters,

- Removal of ash from heat radiating surfaces,

- Washing of acid and ash residues from insulator surfaces or insulator replacement if the deposits have hardened,

- Check of instruments that may have been affected by infiltration of ash particles where air is not effectively filtered,

- Clearing of drifts from transportation routes,

- Inspection of $0 i l$ reservoirs and oil filters for admittance of abrasive particles,

- Clearing of ash mud from cooling towers.

An estimate of the cleanup time, and if necessary, time for repairs, follows:

$$
\begin{aligned}
& \text { Days of Forced Outage } \\
& 2 \text { to } 8 \mathrm{in.} \text {. of Ash } \\
& \hline
\end{aligned}
$$

$\begin{array}{ll}\text { Maximum } & 7 \\ \text { Minimum } & 2 \\ \text { Probable } & 3\end{array}$

It is assumed that crews can be obtained to work on all of the shutdown plants at the same time.

Risk of Outage from Ashfall

The estimate of risk of forced capacity and energy outage from ashfal1 is shown in Figure 23. Probability of occurrence is shown in curve $A$, and corresponding energy production loss in curve $B$.

From Figure 23, note that the probabilites of capacity loss from ashfalls are constant. 


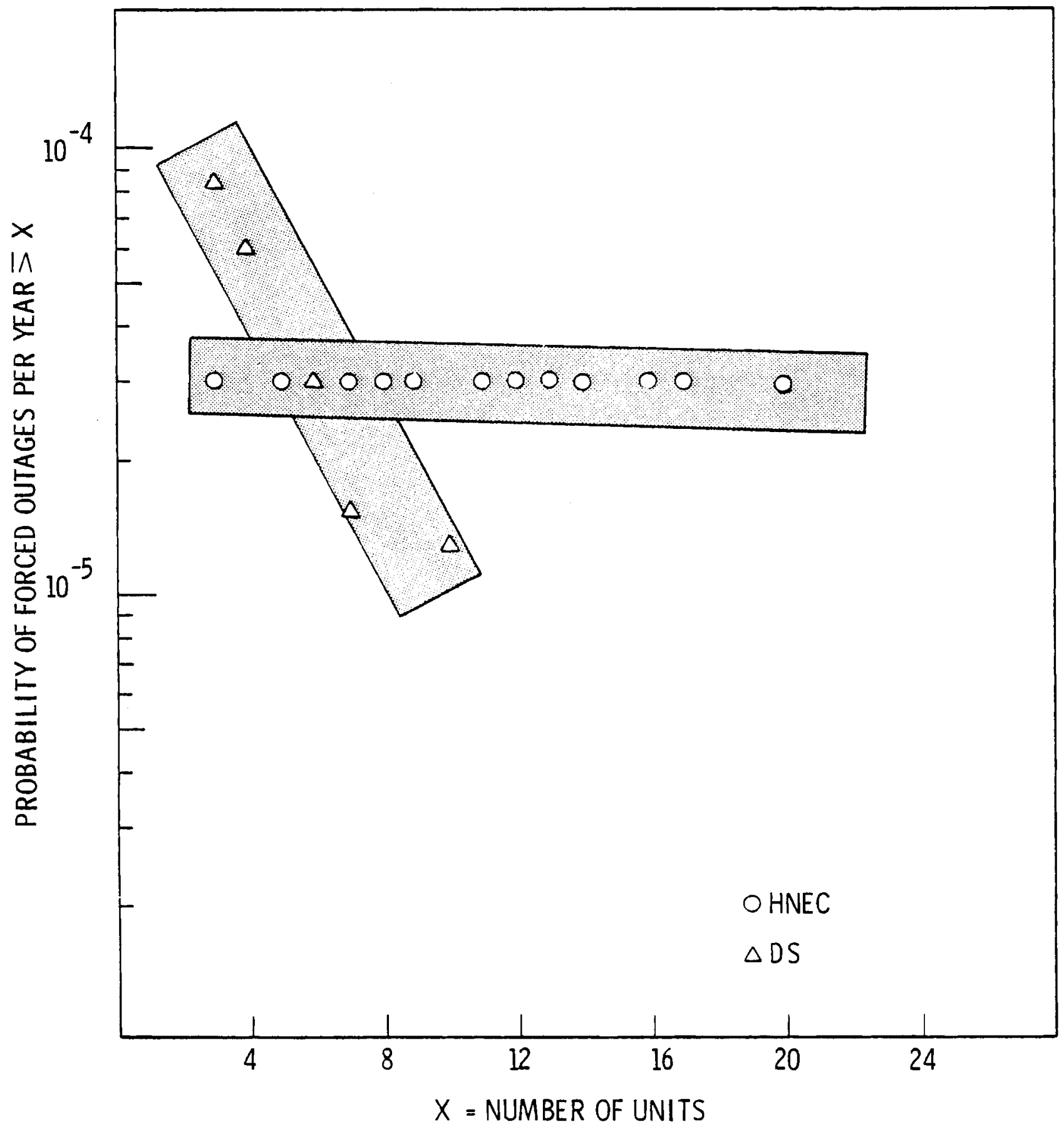

FIGURE 22. Probability of Forced Outage of Generating Units from Ashfall from Cascade Volcanoes 


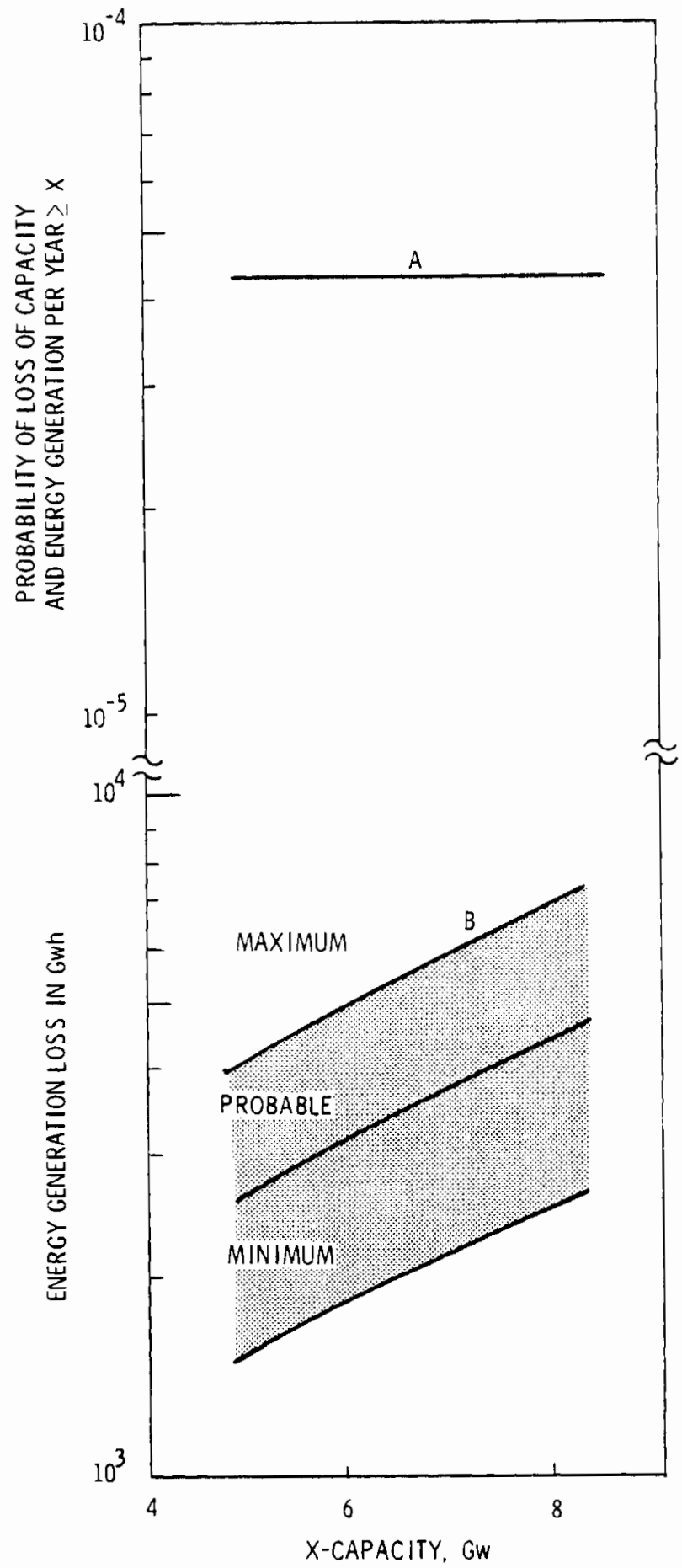

FIGURE 23. Risk of Loss of Capacity and Energy Generation from Ashfall at HNEC 


\section{REFERENCES - ASHFALL}

1. Owen B. Toon and James B. Pollack, "Volcanoes and the Climate", Natural History, pp. 8-26, January 1977.

2. George B. Rigg and Howard R. Gould, "Age of Glacier Peak Eruption and Chronology of Post Glacial Peak Deposits in Washington and Surrounding Areas", American Journal of Science, Vo1. 225, pp. 341-343, May 1957.

3. Yoko Takeda and Norio Yamamoto, "Mt. Usu Eruption, Electric Related Damages," Mitsubishi Research Institute, Inc., 77R-213, Norizo, 1977.

4. P. E. Hammond, "The Pulse of the Cascade Volcanoes", Pacific Search, June 1974.

5. Ward Carithers, Pumice and Pumicite Occurrences of Washington, State of Washington, Division of Mines and Geology, 1948.

6. Gordon P. Eaton, Volcanic Ash Deposits as a Guide to Atmospheric Circulation in the Geologic Past," Journal of Geophysical Research, Vol. 68, No. 2, January $15,1963$. 


\section{SWITCHING STATIONS}

Introduction

The reason for examining switching stations separately is to assess the risk of routing power from six or seven units through one switching point, as at HNEC, relative to that of routing of power from three or four units through a single switching station as at a OS, and to determine whether the vulnerability of the switching station is greater than that of the generating plants.

The same disruptive event could interrupt more power flow when occurring at a switching station than when occurring at the generating stations. For example, an aircraft crash into a switching station could interrupt the power from six or seven units in the HNEC case, or power from three or four units in the DS case. If it crashed at any one of the generating clusters, the shutdown would probably be limited to one or possibly two units at either an HNEC or DS.

This section is confined, therefore, to an assessment of risk at a single switching station. If two switching stations were affected by an initiating event, the magnitude of the event is assumed to be great enough to simultaneously affect all generating units feeding power to these stations.

Station Vulnerability

A typical layout of a $500 \mathrm{kV}$ switching station using the breaker-and-ahalf arrangement now favored by BPA and many other utilities is shown in schematic form in Figure 4 of Section III.

One vulnerable point is the bus structure which runs throughout the station length. If the two buses in this structure are incapacitated at the same time, the "pooling" function of the station is lost, but power flow can be maintained from those generators that are in positions mutually occupied by lines interconnecting with other points in the network. Continuity of operation would be sustained if the stricken buses were cleared by the two outer circuit breakers while the third (middle) breaker remains closed. If one end of the station were damaged, power flow at the other end may continue in this way. Power flow in the system would have to readjust to an incident of that severity. With readjusted flow the output of the station could still be the equivalent of several generating units even though power from some units was reduced. 
All other localized damage would have less impact, cutting off one or more generators or lines while the buses, or at least one bus, remained in service. It may be concluded that to interrupt all power flow through the station, the event would have to disrupt functions throughout the entire station area. For example, a severe earthquake could disrupt all operations.

The station service transformer used in common by three or four generating units ${ }^{(a)}$ for the alternate supply is another vulnerable item. Although damage to this transformer would not shut the generating units down, a regulatory requirement would force shutdown if service is not restored within $72 \mathrm{hr}$.

Another vulnerable item are the battery DC supplies for relaying functions at the station. Damage to this power supply along with damage to the main buses or lines could prevent breakers from opening to isolate trouble. Consequently, one trouble point could involve the entire station if the $D C$ supply were out. Stations as important as these would have redundant battery supplies, both of which would have to be lost.

The area occupied by a $500 \mathrm{kV}$ switching station for seven generating units at an HNEC would be approximately 1500 by $500 \mathrm{ft}$, transmitting $8.4 \mathrm{GW}$. The following analysis concerns the risk of an event that would interrupt 50 to $100 \%$ of the power flow at the station. Events evaluated include those already considered for the generating plants, namely earthquake, flood, tornado, releases of airborne contaminants and ashfall, plus aircraft crash and sabotage.

\section{Earthquake Effects}

Switching station structures and equipment are being designed by BPA for a horizontal ground acceleration of $0.24 \mathrm{~g}$ in the puget Sound area and $0.12 \mathrm{~g}$ in the Portland area. In eastern Washington, with the exception of areas of greater than average seismic activity, the design of the stations is governed by wind resistance criteria rather than ground shaking criteria. The effective resistance to ground shaking is reported to be somewhat less than $0.12 \mathrm{~g}$. For purposes of this study, it is assumed that the switching station's resistance to ground shaking is equivalent to that of a $0.10 \mathrm{~g}$, essentially code design. (2)

(a) This applies to configurations typified by Concept B, Reference 1. 
The probability of ground shaking of this intensity is:

$$
3\left(7.93 \times 10^{-3}\right)=2.4 \times 10^{-2^{(3)}}
$$

With a probability of 0.1 for significant damage to a code design facility, the probability of an earthquake disabling $50 \%$ or more of the switching station is less than $3 \times 10^{-3}$ events per year $\left(0.1 \times 2.37 \times 10^{-2}=2.37 \times 10^{-3}\right)$. Three such stations are assumed at HNEC and the probability of losing any one of the three is $3 \times 2.37 \times 10^{-3}=\sim 7 \times 10^{-3}$.

The design of manufactured equipment affects the resistance of switching stations to earthquakes. The most vulnerable items are the heavy pieces mounted on post insulators, such as a live circuit breaker, lightning arrestors, and potential transformers. (2)

Power transformers are located at the generating plants at HNEC and are not considered switching station equipment. Damage to one transformer would affect only one generating unit.

During the San Fernando earthquake of February 9, 1971, the Sylmar switching station, $(a)$ which appeared to be close to the epicenter, experienced accelerations between 0.35 and $0.50 \mathrm{~g}$. The damage was severe. ${ }^{(4)}$ As a result of that incident, possible ways of increasing the resistance of equipment to ground shaking were studied with the expectation that stations built in subsequent years would suffer less damage if subjected to identical conditions. Although Hanford is never expected to experience ground shaking over $0.25 \mathrm{~g}$, its station design should nevertheless benefit from that experience.

\section{Tornado Effects}

The switching stations footings are designed to $80 \mathrm{mph}$ constant windspeeds, for use at any location, and equipment is designed with gust factors equivalent to 100 to $120 \mathrm{mph}$. (2)

The probability of tornado windspeeds exceeding that level is $4.4 \times 10^{-6}$ strikes per year at points within the HNEC region. The median path width of tornadoes in this region is around $300 \mathrm{yd}$. Moving along the long axis of the

(a) Refers to the switching station only, not the rectifier station which was even more seriously damaged. 
station a tornado with windspeeds in excess of the above levels could possibly disrupt station operation completely. Moving along the short axis it could disrupt some fraction of the power flow, perhaps 50 to $60 \%$. The orientation of the existing Ashe and Hanford stations is such that there would be an approximately $90 \%$ possibility that $50 \%$ or more of the positions would be affected by a tornado strike. The resulting probability of $50 \%$ or more of the power flow being interrupted is $4.0 \times 10^{-6}$ per year.

Radioactive Release Effects

The assumption used in the preceding section on effect of releases on adjacent clusters of generating plants is that significant deposition would take place around the point of release regardless of wind direction. In the HNEC, any one of the three switching stations each serving two clusters would be within a two mile radius or less of adjacent clusters it serves.

Since the switching stations are not normally attended and since the functioning of the station would not be directly affected by the deposits, the station would not be forced out of service immediately following the passage of the plume or from deposition. Decontamination of the station could proceed, part of it while the station remains in operation, and part of it while sections of the station are de-energized. Forced shutdown of parts of the station would take place only in the event of some equipment failure that would entail the use of work forces in a station bay before it had been decontaminated.

In view of the above no significant contribution to the risk of forced outage of generators at the second cluster results from switching station exposure to radioactive releases. Outages necessary for cleanup could be scheduled. Ashfall Effects

Ashfall could possibly cause some forced outage of a switching station, while the connected generating units remain fit for service, by 1) forming conducting paths around insulators in high voltage circuits, 2) placing a blanket of heat insulating material over heat radiating surfaces, and 3 ) clogging filters in equipment that required ventilation. 
The probability of forced outage from this cause is estimated to be the same as that of the generating plants, $3 \times 10^{-5}$ events per year.

\section{Aircraft Crash}

From information presented in Appendix $A$, the possibility of a large aircraft striking a nuclear power plant having a shadow area of $0.137 \mathrm{mi}^{2}$ is $4.6 \times 10^{-7}$. For the switching station alone having a shadow area of about $0.05 \mathrm{mi}^{2}$ the probability would be $1.68 \times 10^{-7}$.

$$
\frac{0.05}{0.137} \times 4.6 \times 10^{-7}=1.7 \times 10^{-7}
$$

The risk is additive to that of the other causes acting upon generating plants. Sabotage

Sabotage at the switching station could be more effective in forcing a number of generating plants out of service than if it were applied at the generating plants themselves. For example, two explosives strategically placed and set to detonate at the same time could incapacitate a station, and interupt the flow of power from up to seven generating units. There is no rational basis upon which to arrive at the probability of such an event. The probability can, of course, be reduced by maintaining adequate security under the provisions of 10 CFR-70.

If sabotage were to be successful in interrupting power flow, the damage to equipment would not be expected to extend throughout the entire station, although it could be severe. Part of the station could probably be put back in operation relatively soon, and the remainder restored on a temporary or permanent construction basis.

Flood

The possible effects of flooding on switching stations is considered for the HNEC model in that some of the stations may be located at somewhat lower elevations than the generating plants. 
The Ashe station site near Cluster 1 has an elevation of about $437 \mathrm{ft}$ above sea level, $48 \mathrm{ft}$ above the Probable Maximum Flood level for WPPSS piants, and $12 \mathrm{ft}$ above the level of Artificial Flood No. 1 at that point on the river. since no underground portions are at risk, the danger of flood interferring with station operation can be ruled out at Ashe. Further checking on relative flood vuinerability would be necessary at the Hanford stations and the proposed Gable Mountain site.

Total Risk

The risks discussed above are in two categories:

A: Additive to the risk of loss of generation from the second cluster, in that either the generators in the second clusters or the switching station could be the cause of the forced outage, and

B: Occurring at the same time and from the same cause as the generating plant outage in the second cluster, and, of significance only if the risk is greater at the switching station.

The probability of a loss of more than 50\% of the power through a switching station and the associated outage periods are given in Table 15.

The probabilities in Category $A$ are additive to the generating plants, and assuming that sabotage risk is controlled, their sum is about $4.3 \times 10^{-6}$ events per year. The repair time would range from 15 to 40 days, with a probable time of 25 days. This probability and their consequence are factors in the added risk of loss of power from a second cluster being affected by a single event at the switching station.

In Category B, all the risks are less than or approximately equal to their counterparts in the generating plant assessment, add nothing to overall risk, and can be ignored.

The resulting switching station risk is shown in Figure 24 . 
TABLE 15. Summary of Risk of Interruption of Power Flow at Switching Station

\begin{tabular}{|c|c|c|}
\hline Event & $\begin{array}{l}\text { Probability of } \\
\text { Interruping } 50 \% \\
\text { or More of } \\
\text { Power Flow/yr } \\
\end{array}$ & $\begin{array}{c}\text { Probable Re- } \\
\text { pair Time/Days }\end{array}$ \\
\hline \multicolumn{3}{|l|}{ Category A } \\
\hline Tornado & $4.0 \times 10^{-6}$ & 25 \\
\hline Aircraft crash & $1.7 \times 10^{-7}$ & 40 \\
\hline Sabotage & Indetermina te & -- \\
\hline Flood & $10^{-7}$ & 15 \\
\hline \multicolumn{3}{|l|}{ Category B } \\
\hline Earthquake & $7 \times 10^{-3}$ & 15 \\
\hline $\begin{array}{l}\text { Release of } \\
\text { Radioactivity }\end{array}$ & $<10^{-7}$ & \\
\hline Ashfall & $3 \times 10^{-5}$ & 4 \\
\hline
\end{tabular}

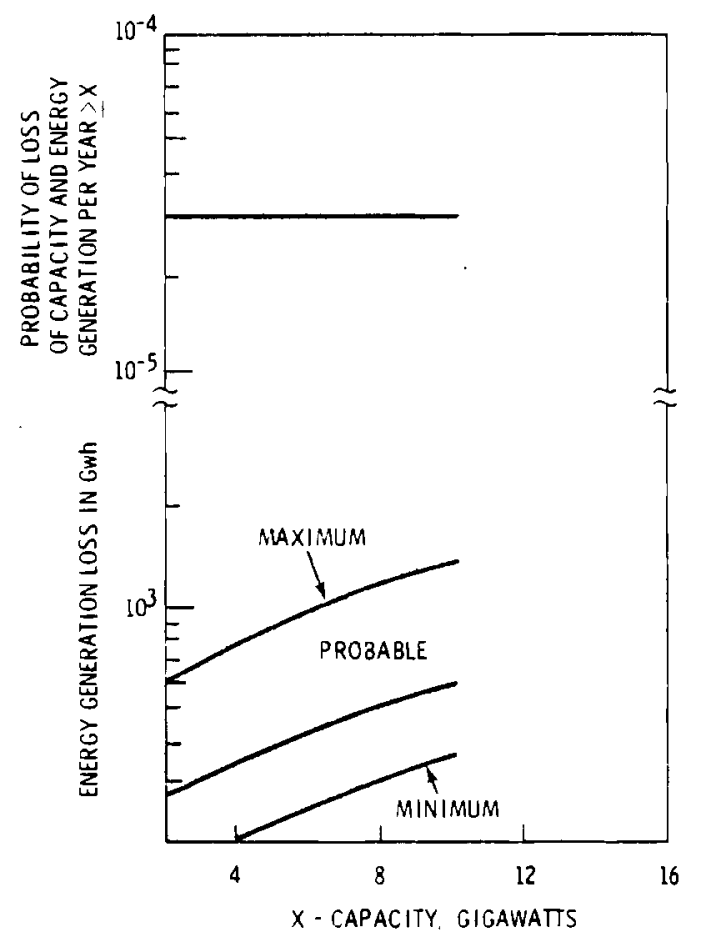

FIGURE 24. Risk of Capacity and Energy Generation Loss Caused by Switching Station Outage at HNEC 
1. Battelle Pacific Northwest Laboratories, Station Service Power Supply for a Hanford Nuclear Energy Center (HNEC), BNWL-2076/UC-80, December 1975.

2. Paul White, BPA Substation Design, Personal Communication, June 3, 1977.

3. T. Hsieh, D. Okrent, and G. E. Apostlolakis, On the Average Probability Distribution of Peak Ground Accelerations in the U.S. Continent Due to Strong Earthquakes, UCLA-ENG-7516, March 1975.

4. Refer to No. 8 in Earthquake Section. 
Risk of Forced Outage, HNEC versus DS

This section combines the data on probabilities of forced outage for an HNEC and DS, and compares the estimated lost energy production during outages, between the two concepts.

Figures 25 and 26 summarize the results developed in prior sections. Here, gigawatts of capacity lost for HNEC and DS are plotted against the respective probabilities of these losses. The dotted line at the top of the figures is the total probability of 4 to 24 GW of capacity being lost through any one of the causes shown separately in curves under the dotted line. The dotted curves for earthquake and ashfall are alternates related to administrative matters. These total probabilities for HNEC and DS are compared in Figure 27.

The principal findings in this comparison are 1) the probability of loss of capacity in the DS case drops off rapidly after $6 \mathrm{GW}$; 2) al though up to 12 GW can be lost, the increment greater than 6 GW has a low probability and for practical purposes can be ignored, and 3) in HNEC, the probability of forced outage from earthquake is dominant, about 25 times the probability of al1 other causes combined. (If outages due to earthquake were forced by plant failure rather than an inspection requirement, the probability would be reduced tenfold for accelerations up to $0.175 \mathrm{~g}$ and fourfold for accelerations up to $0.25 \mathrm{~g}$, as shown by the dashed curve of Figure 25 .

Other findings are:

- Earthquake, ashfal1, and flood could affect up to $100 \%$ of HNEC capacity; radioactive release up to $80 \%$; and tornadoes and switching station failure up to $35 \%$. Flood could affect up to $50 \%$ of total capacity, tornadoes $30 \%$, and others 15 to $20 \%$ at much lower probabilities of occurrence.

- After earthquake, ashfall appears to be the major contributor to probability of outage. However, the basis of assessment of this cause is tenuous.

- Radioactive release occupies an intermediate position on the scale of probability; but if an administrative requirement would shut down all HNEC plants if one were to have a release then this would become the major contributor after earthquake. 
- Flood and tornado are unimportant risk contributors.

- The probability of single clusters being forced out of service is somewhat greater for DS than for HNEC because of greater exposure to earthquake and ashfall. 


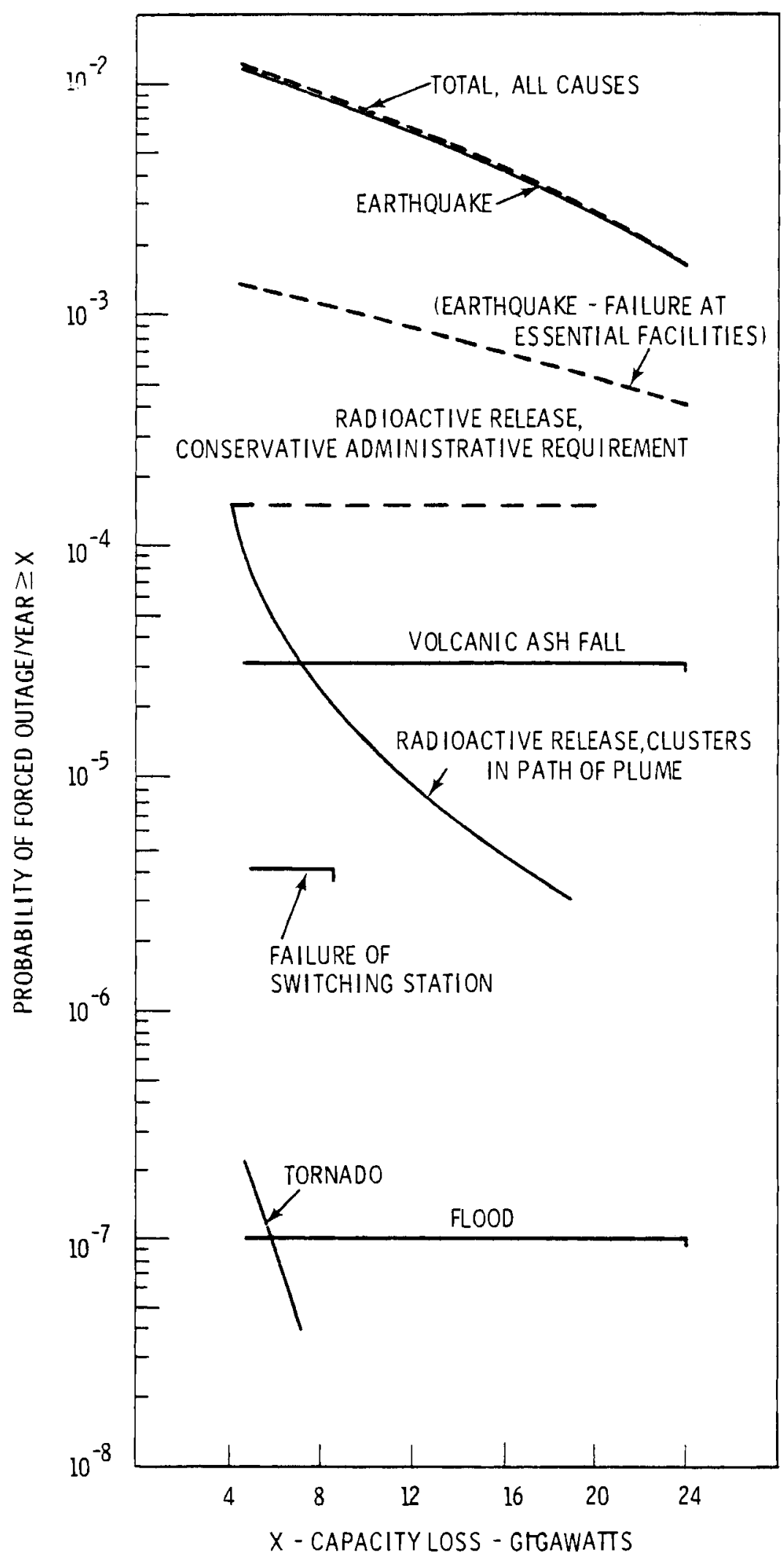

FIGURE 25. Probability of Forced Outage - All Causes at HNEC 


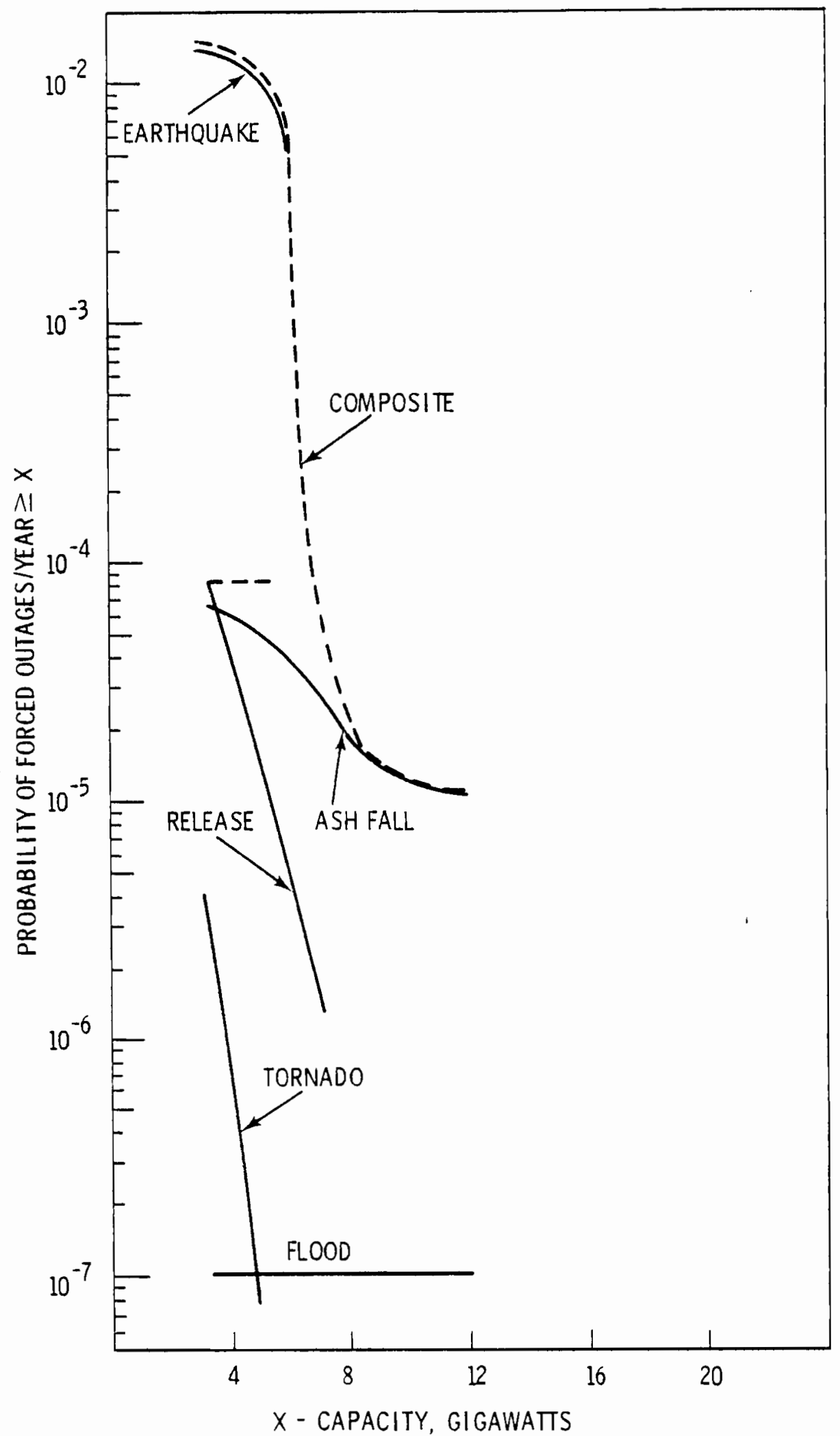

FIGURE 26. Probability of Forced Outage - A11 Causes at DS 


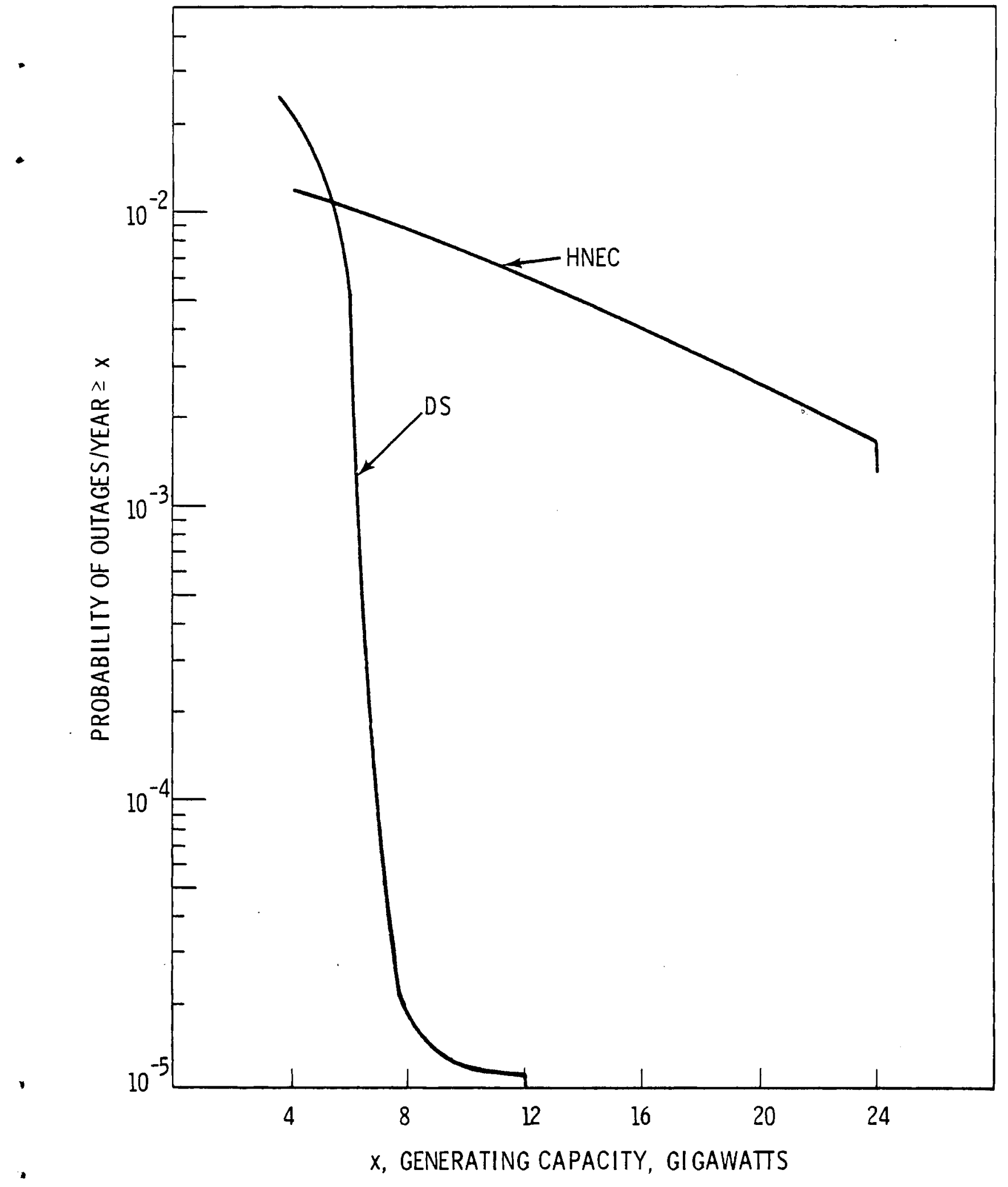

Figure 27. Probability of Forced Outage, HNEC vS DS 


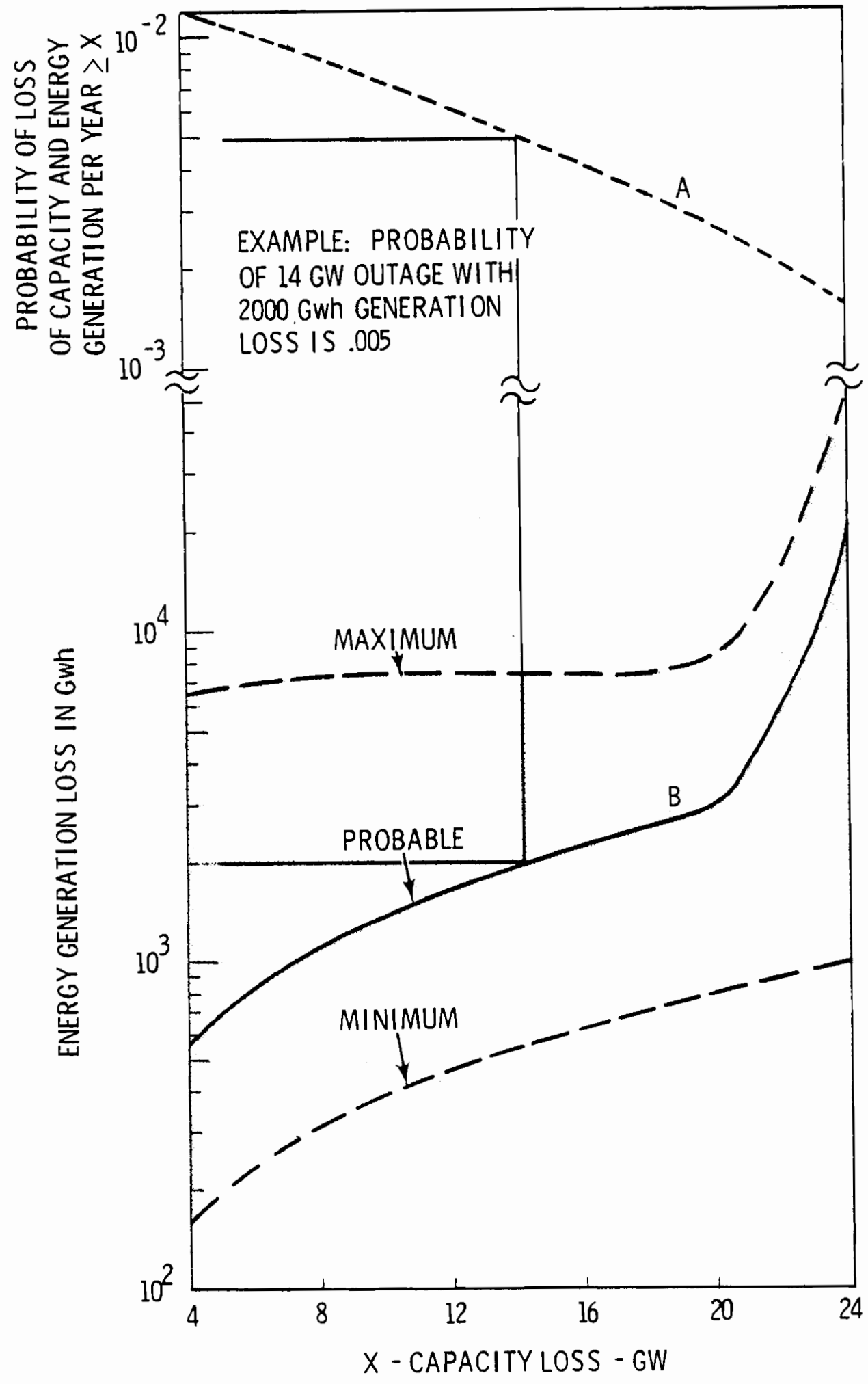

FIGURE 28. Risk of Forced Outage at HNEC 
The probable duration of forced outages under the stated assumptions are tabulated below:

$$
\begin{aligned}
& \text { Earthquake } \\
& (0.125 \text { to } 0.175 \mathrm{~g}) \\
& (0.22 \mathrm{~g})
\end{aligned}
$$

Tornado

Flood

Radioactive release

Volcanic ashfall

Substation

\begin{tabular}{rcc}
\multicolumn{3}{c}{ Average Days } \\
\hline Maximum & Minimum & Probable \\
\cline { 2 - 3 } 20 & 3 & 7 \\
100 & 15 & 40 \\
80 & 10 & 40 \\
45 & 7 & 20 \\
60 & 7 & 15 \\
7 & 2 & 3 \\
40 & 15 & 25
\end{tabular}

These time periods are used to establish potential loss of generation as shown in Figure 28 for HNEC (a similar figure for DS is not given because of low probability). Curve $A$ of this figure is the composite capacity loss probability curve of Figure 25. Curve $B$ and the shaded zone around it show possible generation losses associated with different causative events. For example, an $14 \mathrm{GW}$ outage due to flood may have a probable outage time of 40 days while an 14 GW outage due to volcanic ashfall may have an outage time of only three days. That range is represented in the vertical dimension of the shaded zone. The "probable" line within the zone represents an estimate based on weighting of the probable repair times of each component cause according to its probable frequency of occurrence.

Representative points marked in the diagram are tabulated below to indicate the range of size of the blocks of generation that could be involved versus probability of occurrence.

\begin{tabular}{rrc}
$\begin{array}{c}\text { Capacity } \\
\text { MW }\end{array}$ & $\begin{array}{c}\text { Energy } \\
\text { GWh }\end{array}$ & \multicolumn{1}{c}{$\begin{array}{c}\text { Probability } \\
\text { Events/Year }\end{array}$} \\
\cline { 2 - 2 } & 250 & $\frac{0.011}{24}$ \\
8 & 1,000 & 0.0016 \\
16 & 1,700 & 0.0087 \\
24 & 2,400 & 0.0043 \\
24 & 20,000 & 0.0016 \\
& 50,000 & 0.0016
\end{tabular}




\section{SIMULTANEOUS LOSS OF THERMAL AND HYDROELECTRIC CAPACITY}

INTRODUCTION

In an investigation of risk of loss of generation at an HNEC vs that at dispersed sites, the questions arises, would an HNEC entail risk of greater loss of regional generation in the event of catastrophic conditions on the Columbia River than the loss that would be experienced with dispersed sites? This question is discussed below.

Simultaneous loss of thermal and hydroelectric capacity could occur 1) if a flood were great enough to incapacitate downstream hydroelectric dams and at the same time, immerse the river pump houses supplying coolant makeup to thermal plants, or 2) if a drought were sufficiently severe and prolonged to reduce the capacity of hydrogeneration and also starve the thermal plants of coolant makeup.

If either a severe flood or drought were to occur, the amount of hydro capacity that would be affected would, of course, be the same for the HNEC and DS cases. The amount of thermal capacity that would be affected in addition would depend on the flood or drought. For example, if the Columbia at HNEC were affected but not all tributaries, only a portion of the DS case capacity may be flooded or starved, while the remaining portion stays in service. Drought

After consideration of the risk of a widespread and prolonged drought affecting both hydro and thermal generation coincidentally, it was concluded that there would be no substantial difference in the magnitude of the resulting outage between the HNEC and DS cases. The reason is contained in the discussion on extremely low river flow in Appendix A. Briefly, in a prolonged drought, time would be available to take emergency measures to provide coolant makeup to thermal plants in low-flow portions of the river system, whether they be at HNEC or at DS sites.

River Blockage or Diversion

Other events such as river blockage or diversion occurring in the middle or lower reaches of the columbia conceivably could affect some thermal and 
hydroelectric capacity, and the effects of such events on thermal plants of the HNEC and DS cases are reviewed in Appendix A. Effects on hydroelectric plants could include possible flooding of hydro plants upstream from the point of blockage, and temporary interruption of generation at plants downstream. In event of a blockage, the downstream hydro plants would not be damaged immediately but could be damaged later by flood waters resulting from overtopping and disintegration of the blockage.

The probabilities of occurrence of such blockages are discussed in Appendix A. Although there are no accurate bases available to evaluate this probability, one may suppose that it could be of the same general order as that of an Artificial Flood No. 1 .

The consequences of blockage, again with the exception of a major change of channel that could bypass some of the downstream dams, would be less than those of an Artificial Flood No. 1. Fewer plants would be affected and with less damage occurring. For these reasons, this section considers floods from dam failure rather than river blockage as the events that could have the greatest effect on simultaneous loss of thermal and hydro generation.

Floods

Artificial Flood No. 1 would incapacitate many plants, both thermal and hydro, and inflict much damage, causing long generator outages. The natural river floods discussed in the section on Floods, that affect river pump houses of thermal plants primarily, are not considered, as the hydroelectric generation would not be seriously affected. The hydroelectric generating resources that would be affected by a Artificial Flood No. 1 in 1977, and estimated for 1987, are given in Table 16.

From an Artificial Flood No. 1 in the year 2005, 1) al1 hydro capacity on the Columbia below Grand Coulee would be forced out of service, and 2) 100\% of the thermal capacity at HNEC or $50 \%$ of the DS case capacity would be shut down for lack of coolant makeup.

The severity of damage at the dams downstream of Grand Coulee Dam would probably be such that comparatively long periods would be required for rebuilding. Since the major facilities of the thermal plants are above this flood level, their operation could be restored much more rapidly. 
TABLE 16. Hydroelectric Capacity on the Columbia River from Grand Coulee to the River Mouth, GW

\begin{tabular}{|c|c|c|}
\hline & 1977 & $1987^{(1)}$ \\
\hline anuary Peaking Capability, (a) GW & 16 & 20.5 \\
\hline $\begin{array}{l}\text { Critical Period(b) Energy Produc- } \\
\text { tion Capacity, Average GW }\end{array}$ & 8.3 & 8.4 \\
\hline
\end{tabular}

a. Peaking capability, the maximum ability of firm resources of the system to carry a peak load.

b. Critical period, that multimonth period, determined for the Coordinated System under adverse stream flows of historical record, during which the least amount of estimated firm energy load can be served from firm resources.

Risk of Forced Outage

Regional generation that would be affected by an Artificial Flood No. 1 in 1977, and by the same flood in 2005 with HNEC or DS in place, are given in Tables 17 and 18 respectively. Assumptions used in the preparation of these tables are 1) new hydro power developed after 1987 will be insignificant, 2) data on resources include all peaking and reserve generating facilities in the region, 3) by 2005 the regional capacity reserves will be $20 \%$ of January peak load, 4) peak generating capacity will total about 84 GW in 2005, 5) a $75 \%$ average plant factor of thermal units, for computation of energy production capability, and 6) average system load factor will remain at about $63 \%$.

TABLE 17. Generation Affected by an Artificial

Flood No. 1 in 1977

January Peaking Capacity, GW

Hydroelectric plants on Columbia, Grand Coulee to the mouth 16

Thermal plants on the Columbia

other hydro and thermal plants

9.9

27.1

Critical Period Energy Production

Capability, average GW

Hydroelectric plants on Columbia 8.3

Thermal plants on Columbia $\quad 1.6$

other hydro and thermal plants $\frac{5.5}{15.4}$ 
TABLE 18. Generation Affected by an Artificial Flood No. 1 in 2005

\begin{tabular}{|c|c|c|}
\hline \multicolumn{3}{|l|}{ January Peaking Capacity, GW } \\
\hline $\begin{array}{l}\text { Hydroelectric plants on the } \\
\text { Columbia, Grand Coulee to } \\
\text { the mouth }\end{array}$ & 20.5 & 20.5 \\
\hline $\begin{array}{l}\text { Thermal plants on the colum- } \\
\text { bia }\end{array}$ & 24.0 & 12.0 \\
\hline $\begin{array}{l}\text { Other hydro and thermal } \\
\text { plants }\end{array}$ & 25.5 & 37.5 \\
\hline & 70.0 & 70.0 \\
\hline \multicolumn{3}{|l|}{$\begin{array}{l}\text { Critical Period Energy Produc- } \\
\text { tion Capability, Average GW }\end{array}$} \\
\hline $\begin{array}{l}\text { Hydroelectric plants on the } \\
\text { Columbia }\end{array}$ & 8.4 & 8.4 \\
\hline $\begin{array}{l}\text { Thermal plants on the Colum- } \\
\text { bia }\end{array}$ & 18.0 & 9.0 \\
\hline $\begin{array}{l}\text { Other hydro and thermal } \\
\text { plants }\end{array}$ & 12.6 & 21.6 \\
\hline & 39.0 & 39.0 \\
\hline
\end{tabular}

The percentage of total regional resources affected by the flood would be:

\begin{tabular}{lll} 
& \multicolumn{2}{c}{ Percent } \\
\cline { 2 - 3 } Capacity & $\frac{\text { HNEC }}{64}$ & $\frac{\text { DS }}{46}$ \\
Energy & 68 & 45
\end{tabular}

From information in the preceding tables:

1) In the year 2005 with the DS case the hydroelectric and thermal energy resources that would be affected by Artificial Flood No. 1 would be $45 \%$ of the total resources in the region.

2) In the year 2005 with the HNEC case the hydroelectric and thermal resources affected would be $68 \%$ of the total resources in the region, as determined by energy production capability loss. The DS case, therefore, has a marked advantage in potential for retaining a greater percentage of both capacity and energy generating resources in service following such a flood. 
3) From Table 17, in the year 1977 such a flood would affect $64 \%$ of system resources, as determined by energy production loss. This may be compared with the $68 \%$ that would be affected with HNEC in 2005 . The risk corresponding to $64 \%$ loss of generating capacity has societal acceptance; acceptance of a risk corresponding to $68 \%$ loss of generating capacity with HNEC is only slightly greater and with a probability of occurrence estimated at less than $10^{-7} / \mathrm{yr}$.

In the comparison, the HNEC case has benefited by the assumption that capacity reserves would have increased to $20 \%$ of peak load by 2005 . If they had not increased to that extent the $68 \%$ figure for HNEC would be somewhat greater.

In conclusion, an Artificial flood No. 1 is the only event for which the dependence on energy in the Pacific Northwest from an HNEC would cause a substantially greater simultaneous loss of hydro and thermal energy resources than would the Flood with a DS case $(68 \%$ vs $45 \%)$. The probability of occurrence of such a flood is extremely low. The loss of generation with HNEC would be $68 \%$ of regional generating resources, as compared with $64 \%$ if the flood were to occur at the present time. The thermal portion of lost resources could be restored to service in perhaps two to three weeks; but the hydro portions would require dam and station repairs over many months to restore them to service.

These cases of combined hydro and thermal capacity loss are not included in the following section on Impact of Forced Outages since the comparison is limited to the reliability of nuclear generation, not hydroelectric.

\section{REFERENCES - SIMULTANEOUS LOSS OF THERMAL}

\section{AND HYDROELECTRIC CAPACITY}

1. Pacific Northwest Utilities Conference Committee, West Group Forecast of Power Loads and Resources, July 1976-June 1987, March 1, 1976. (Reviewed with issue for Juty 1977-June 1988, February 15, 1977) 
VII. IMPACT OF HNEC OUTAGES ON SYSTEM OPERATION

INTRODUCTION

The impact of possible loss of generation due to HNEC outages is discussed with respect to a) sudden capacity loss and its short-term effects, and b) loss of energy production capability with its longer-term effects. In extreme cases, the effects of capacity loss could resemble those of the northeastern blackout of 1965 and the New York City blackout of 1977 with their temporary disruption of normal activities in the blackout areas. The effects of energy shortage have not been experienced on a comparative scale, but plans are being made for coping with such shortages. For small shortages in which the reserves on the system are capable of meeting generation deficiencies, there would be no immediate impact on the power user, although if prolonged, there might be some impact on power costs. These possible impacts are considered in relation to probability of occurrence.

In this discussion capacity or capacity loss means the total capacity of a11 units affected by an event, independent of their operating status at the time of the event, for example, the capacity of 20 HNEC units is 1.2 GW/unit $x$ 20 units $=24 \mathrm{GW}$.

Generation loss means energy production capability that is not available to the system because of the loss of capacity over a period of time due to an event. It is assumed that the lost capacity would have operated at an average plant factor of 0.87 during the outage period. This is greater than the 0.75 assumed annual plant factor, but it is used to take a conservative position with respect to the possible impact of an outage that occurred in winter months when the loads on thermal plants may be greater than the annual average. For example, generation loss in the event of a loss of $24 \mathrm{GW}$ of capacity for 60 days would be $24 \mathrm{GW} \times 60$ days $\times 24 \mathrm{hr} \times 0.87 \mathrm{PF}=\sim 30,000$ GWh.

Energy shortage means the amount of normal system loads curtailed (dropped) mandatorily because of insufficient energy resources. They are shown on Reserve Energy Planning Model runs as "negative energy surplus", i.e., as an 
energy deficit. They bear a statistical relationship to the generation loss associated with the events being studied. System reserve energy would take the place of HNEC generation loss in varying degrees, as shown later.

Loads assumed to be on the system in 2004-2005 for purposes of this report are:

$\begin{array}{lcc}\frac{\text { Load }}{\text { Average }} & \text { January to April } & 45,600 \mathrm{MW} \\ \text { Average } & \text { Annual } & 42,125 \mathrm{MW} \\ \text { Peak } & & 70,000 \mathrm{MW}\end{array}$

Peak load estimated for 1986-87 in Reference 4 is 37,896 MW. The above $70 \mathrm{GW}$ estimate represents an annual increase of about 3.5\% between 1987 and 2005 as compared with the West Group Forecast increase at a $5.1 \% / \mathrm{yr}$ rate from 1977 to 1987.

System resources assumed for 2005 including miscellaneous peaking facilities are:

$\begin{array}{ll}\text { Total peak resources } & \\ \text { (other than HNEC) } & 60,000 \mathrm{MW} \\ \text { HNEC } & \frac{24,000 \mathrm{MW}}{84,000 \mathrm{MW}} \\ \text { Total } & \end{array}$

Energy resources, with the addition of the thermal units, are assumed to be such as to provide an adequate margin over the 42,125 average MW load estimate. The relative energy resources in 2005 are reflected in the data from the Energy Reserve Planning Model to follow in this section.

The resource estimates affect the results of this study in that they determine how much system generating capacity remains in the system after the hypothetical HNEC outage has occurred, i.e., the percentage of system generating capacity that remains after up to 24 GW of capacity has been forced out of service. The foregoing estimates are considered to be middle-of-the-road, and therefore appropriate for the purpose of demonstrating the impact of the postulated generating outages. 
In 2005, with the assumptions used in the HNEC case for purposes of this study, the status of generating resources would be:

\begin{tabular}{|c|c|c|}
\hline & 2005 Gener & sources \\
\hline & Capacity, GW & $\begin{array}{c}\text { Energy, } \\
\text { Average GW }\end{array}$ \\
\hline Total & 84 & 45 \\
\hline $\begin{array}{l}\text { HNEC (percent of } \\
\text { tota } 1\end{array}$ & $24 \quad(29 \%)$ & $18(40 \%)$ \\
\hline $\begin{array}{l}\text { DS 4-unit cluster } \\
\text { (percent of total) }\end{array}$ & $4.8(5.7 \%)$ & $3.6(8 \%)$ \\
\hline
\end{tabular}

As noted previously, the outage cases of the HNEC study start with four units affected, and range up to the ful1 20 units. DS case outages range from 3 to 10 units.

Most of the causes of forced outages of interest were assumed to occur randomly throughout the year.

The number of generating plants that would be operating at the time of an event, and their loading, would depend on the season of the year, how much reserve is assigned to thermal units, refueling schedules, and conditions on other parts of the system. Operating policy as envisioned for 2005 governed the inputs to the simulations of the thermal generation portions of the system. The outage probabilities computed in prior sections of the report were inserted into the simulations of thermal plant operation as perturbations of normal operations.

A necessary assumption in describing the effects of reduced energy production capability is that system loads as influenced by the severity of winter weather be normal or near normal. In the winter of 1976-77 in the New YorkNew Jersey area, space heating requirements were $30 \%$ above normal, whereas the fuel suppliers (fossil fuels in that case) had made provisions for only an $8 \%$ margin. If a major outage of the type to be described were to occur during an extremely hard winter in the Pacific Northwest the electric energy shortage effects (where much of space heating is electrical) would be exacerbated.

There are numerous points on Figure 28 of the section on Composite Risk, the curve of capacity and energy loss versus probability of occurrence, that 
could be used to illustrate the reliability risk of an HNEC. In discussion to follow, emphasis is placed on the maximum possible capacity loss, $24 \mathrm{GW}$, and a generation loss of 30,000 GWh ( 1.5 times the probable maximum). The impact of intermediate values of capacity and energy generation losses are also discussed.

IMMEDIATE IMPACT OF FORCED OUTAGE

Many factors would contribute to the impact of a catastrophic event at HNEC on the PNW system in the first hours following the event. The following analysis relates to system conditions anticipated for the year 2005.

Outage Magnitude

The number of generators operating at the time, and their loading, will vary with the seasons. In the winter months, at times of peak system loads, most of the HNEC units would be operating; in spring and summer months many units would be down for refueling and scheduled maintenance, with a greater percentage of the system load then being carried by hydro plants. An example of how such outages may be scheduled is:

\begin{tabular}{lcc} 
Season & $\begin{array}{l}\text { Number of units } \\
\text { Shut down for 2 months }\end{array}$ & $\begin{array}{c}\text { Avg } \% \text { of total HNEC } \\
\text { Capacity Available }\end{array}$ \\
\cline { 2 - 3 } Aug - Nov. & 4 & 90 \\
Dec - Mar. & 2 & 95 \\
April - July & 14 & 65
\end{tabular}

Assuming that available generators are loaded to 87 percent of capacity at the time of the event, the loss of generation would be:

Number of Units

Affected by an Event

8

14

20
Probable Interrupted Power Generation GW

\begin{tabular}{ccc}
\hline Aug-Nov & Dec-Mar & Apr-July \\
7.4 & 7.9 & 5.4 \\
13.0 & 13.9 & 9.5 \\
18.6 & 19.8 & 13.5
\end{tabular}


Onset of the Outage

The immediate impact of an HNEC outage on the system would depend to some extent on the amount of advance notice of shutdown, if any, and on the intervals between successive losses of power from affected generating units. Some of the outage causes would permit advance notice, for example, floods, ashfall, and radioactive release. Others would take place without notice, for example, earthquake, the first cluster hit by a tornado, and an aircraft crash into a switching station. Since earthquake is the most probable cause of outage, and since it would occur without notice, it is assumed in this discussion that no notice is given before the first generating units are forced out of service.

The shutdown of units subsequent to the first unit or group may span periods of one or two hours, for example:

- An earthquake may cause failure of essential equipment that would cause simultaneous shutdown of eight units, followed within an hour or several hours by manual shutdown of perhaps another eight units which had been subjected to OBE conditions as verified by analysis of instrument records.

- Ashfall accumulations rates would probably be such as to permit at least 30 minutes between the shutdown of successive clusters.

- A tornado may require tens of minutes to travel the distance between adjacent clusters.

- Flood crests may take minutes or tens of minutes to travel the distance between adjacent pump houses.

- Radioactive plumes may take tens of minutes to travel between clusters, the time depending on wind velocities.

In all probability the initial loss of generation would not exceed the equivalent of that from two clusters, 9 to $10 \mathrm{GW}$, possibly followed by additional amounts within tens of minutes, and with all units involved in the outage dropping off or being shut down normally within an hour or two.

The only incident visualized that could instantaneously affect more than $10 \mathrm{GW}$ is an earthquake with a probability of $4 \times 10^{-4}$ events per year. 
The distinction between capacity dropped instantaneously and that dropped over following minutes or hours is important with respect to the ability of the system to respond without instability and consequent separation of parts of the system.

\section{Capacity Reserves}

Capacity reserves in the Pacific Northwest are presently calculated at $12 \%$ of the estimated system peak load. In the near future, this may be raised to $15 \%$. Operating reserves normally are $7 \%$ of the peak thermal resources and $5 \%$ of the peak hydro resources. One-half of the reserves are spinning, available immediately, and one-half are available within 10 minutes.

For planning purposes, reserves for unforeseen load growth are set at one half of a year's load growth for utility type loads. Utility type loads are those in commercial and residential categories which cannot be estimated as accurately as heavy industrial loads. Reserves for new resources that may not come into service as scheduled are called planning reserves, and represent the amount left over after Federal, Public, and Private system reserves have been determined under present methods. If reserves planned for these purposes are not yet in service, or if they are installed but already loaded at the time of an event, the effective reserves would be:

$\begin{array}{lcr}\frac{\text { Reserves }}{\text { "Spinning" }} & \frac{\text { GW }}{4.2} \\ \text { Available in 10 min } & \frac{6}{12} & \frac{4.2}{8.4}\end{array}$

If reserves planned for unforeseen load growth and possible delays in new generating capacity have not been absorbed, some reserves in addition to those listed above may be available. These would require substantial time periods to bring into service.

Role of the Hydro System in Providing Capacity Reserves

The hydro system can provide capacity reserves beyond those described above, for short periods, during certain times of the year, summer for example. Stored water can be released through surplus capacity in turbine generators 
to provide power on short notice. The degree to which this emergency resource can be utilized is limited by available water, and by the effects of rapid water release on river elevations below the dams and the consequent effects of high elevations. The curve in Figure 29 prepared by BPA, indicates the allowable duration of such usage. The $100 \%$ point on the ordinate corresponds to a system peak capacity, in 2005, of from 31 to 37 GW depending on reservoir elevations. The upper end of the curve is of principal interest here, i.e., the capability over the first few hours.

Storage water withdrawals from the system for peaking in an emergency cannot exceed those defined by the curve; without significant spilling, nor extend beyond the 12-hour point. For example, with reservoir and river flow conditions corresponding to $32 \mathrm{GW}$ at $100 \%$, the normal use of the hydro system would be below $80 \%$, or $26 \mathrm{GH}$. Ninety-two percent, or $29 \mathrm{GW}$, about $3 \mathrm{GW}$ above normal maximum, could be taken for four hours.

Role of Pumped Storage in Providing Capacity Reserve

By 2005 there may be some 5 GW in pumped stotage on the system. Water in these reservoirs would also be available on short notice for emergency generation, if not already in service at the time of the outage. The duration of such generation could be for a few hours up to 40 hours depending on reservoir fill at the time of the incident. Such capacity serves as part of the forced outage reserve in the hydro system.

Role of Thermal Plants in Providing Capacity Reserve

Gas turbine driven generators are beginning to appear on the system, and may add a few GW to the peaking capacity of pumped storage units in 2005 . The advantage of the gas turbines in an emergency as compared with pumped storage is that they can supply power for relatively long periods, (although the power would be costly).

Some of the planned system capacity reserves, perhaps up to $55 \%$ of operating reserves, may be in nuclear plants at that time. Ail or part of the reserves allocated to HNEC would be negated with the HNEC outage. The distribution of thermal reserves would recognize such a possibility. 


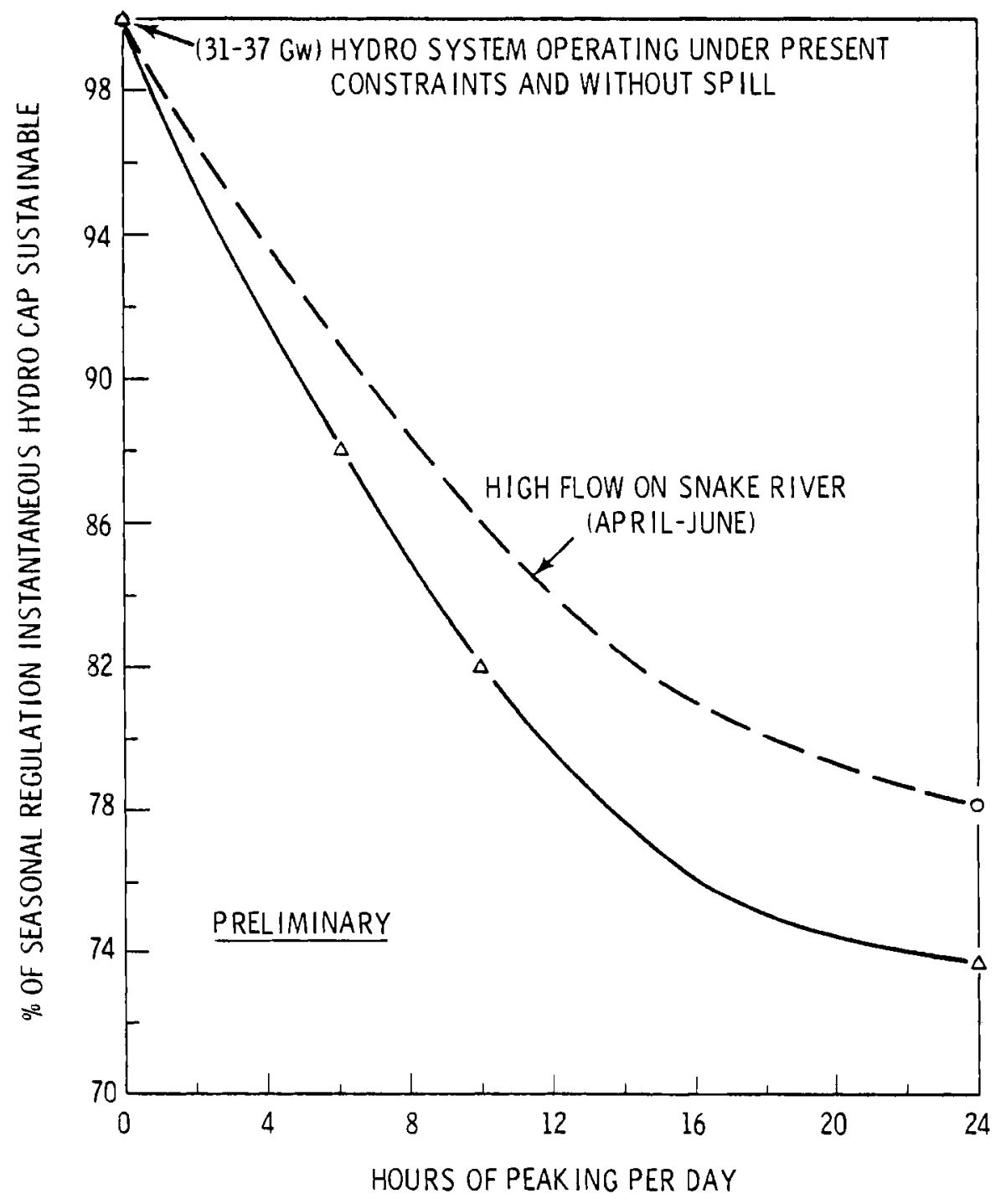

FIGURE 29. Percent of Seasonal Instantaneous Peak Sustainable Hydro MW vs Number of Hours Per Day of Peaking 
Other thermal plants on the system partially loaded or in hot standby could provide energy capacity rather quickly, but in cold standby would require about 10 hours.

Emergency Power Inflow Over Tie Lines

In the event of a sudden major deficiency in generation in the PNW system, power may be available from tie lines, provided that the effect of power withdrawals from the other systems does not affect them to the extent that the operators would disconnect the ties.

The one DC and two AC lines to the southwest have a total capacity of about four GW.

The pattern of diversity capacity exchange, if contracted between the regions, would be power flowing south from May through September, and north from November through March. Any capacity available to the PNW over these lines in an emergency would be additive to the reserve capacity within the PNW system if covered under contracted agreements. If a catastrophic event were to take place in the summer months when power is normaliy flowing south, the reversal of that flow could make a net 4 to $8 \mathrm{GW}$ available to the PNW. How long that flow could be sustained would depend on energy conditions in the Cal ifornia and Arizona systems.

If the event took place in the winter months when power is flowing north, no change would take place if the lines are already loaded to capacity and if the line connections remain intact. If the lines were inadvertently opened, the PNW capacity deficit would be increased by 4 GW or whatever the power flow was at the time. If the outage occurred at an off peak point in the daily or weekly transmission load curves, some relief may be available even in winter months.

A review of the month-by-month capacity exchange shows that these tie lines could make additional capacity contribution in an emergency as follows. For example, in the summer months of June, July or August, the 8 GW is obtained by a reversal of $4 \mathrm{GW}$ flow out to $4 \mathrm{GW}$ flow into the PNW system. 


$\begin{array}{cl}\text { Jan and Feb } & \frac{G W}{0 \star} \\ \text { March } & 2 \star \\ \text { April } & 4 \\ \text { May } & 6 \\ \text { June, July, Aug } & 8 \text { (if available) } \\ \text { Sept } & 6 \\ \text { Oct } & 4 \\ \text { Nov } & 2 * \\ \text { Dec } & 0 *\end{array}$

*With additional capacity contribution if the event occurred in daily or weekly transmission light-load periods.

Generation outages of the magnitude discussed here would be very rare, and it is assumed that the inter-regional agreements would allow adjacent regions to make exceptional contributions to the stricken area in such an emergency, to the extent of their capability without undue hazard to their own operations.

Ties with Canadian generating resources may permit a power flow of some three GW by 2005. Without a pattern of normal power flow, no emergency relief from this tie line can be assumed.

Available generating capacity in Idaho and Utah would be relatively small; help in an emergency is expected to be insignificant.

\section{Load Shedding}

The immediate effect of a large loss of generating capacity may be a drop in system frequency below the level at which certain loads are shed to maintain system integrity. The first loads to be shed would be industrial loads totalling about four GW. An effort would be made to restore service to the noninterruptible portions of this load, three GW, within ten minutes or as soon as possible. If the frequency dropped further, additional loads would be dropped according to contingency plans. 
Transmission System

System integration is maintained through the transmission system. That system must have sufficient capacity and stability to accommodate the shift to reserve generating capacity wherever it is on the system. The ability of the PNW transmission system to respond to changes of the magnitude discussed here has not been substantiated by studies, but is assumed for purposes of this report. The scope of this report is 1 imited to generation at an HNEC, and power flow through adjacent switching stations. The effect of losing substantial amounts of transmission capacity generating from HNEC may be equivalent to loss of substantial portions of HNEC generation, but should be evaluated separately. (1)

Communications and Pianning

If an HNEC were to develop, there would be concomitant development of communications systems and planning procedures to appropriately handle major outages, however remote the probabilities of such outages. The costs associated with communications, monitoring, relaying, and load shedding systems would not be expected to be prohibitive. The objective would be to manage the system so that, with normal reserves, due operating reliability could be achieved, by judicious load shedding if necessary--not by providing additional costly reserves.

Summary of System Responses to Large Outages

In summary, immediate system relief in the event of large outage in the year 2005 would be provided by reserves, tie line transfers, and load shedding as in Table 19.

Restoration Period

The restoration of at least partial service to shed loads would follow the onset of the outage. It is estimated that steps taken to restore the system to a state of managed energy shortage could be accomplished within six hours in most situations, and within 12 hours in the worst situation, one in which some system breakup did occur in spite of load shedding and other measures to maintain stability and tie line connections. 
TABLE 19. Summary of Generating Outage Relief Capabilities, Without Shedding of Commercial and Residential Loads

GW

Immediate Response

Spinning reserves

4.2

Transfer over tie lines

$275 \%$ of the time

4 to 8

$225 \%$ of the time

0 to 4

Shedding industrial loads

4

Subtotal

8.1 to 16.1

Response after tens of minutes

Operating reserves

4.2

Additional temporary power

from reservoir withdrawals,

$250 \%$ of the time

Pumped storage installations (3)

Gas Turbines (3)

0 to 5

0 to 2

4.2 to 15.2

Response after hours

Planned reserves for unforeseen

loads and late new generating

resources, not aiready absorbed

Total

0 to 5.6

$\%$ of Total system capacity

(84 GW)

12.3 to 36.9

$15 \%^{(1)}$ to $44 \%^{(2)}$

(1) Consistent with $12 \%$ operating reserves, and some additional relief from tie lines and load shedding.

(2) Compare with ratio of excess capacity at average load, to total capacity $48 \%$

(3) Part of this capacity may be in Operating Reserves. 
The amounts in Table 19 would be reduced by the amount of operating reserves that may have been assigned to the HNEC thermal units affected by the outage.

From the table:

- Instantaneous loss of $8 \mathrm{GW}$ could be accommodated, with 75 percent probability that $12 \mathrm{GW}$ could also be accommodated without commercial and residential load shedding.

- Instantaneous loss of $8 \mathrm{GW}$, followed in tens of minutes by additional loss of $4 \mathrm{GW}$, for a total of $12 \mathrm{GW}$, could be accommodated.

- Instantaneous loss of $12 \mathrm{GW}$, followed in tens of minutes by additional loss of $8 \mathrm{GW}$ (the maximum probable HNEC outage) would have a 50 to 75 percent probability of accommodation without additional load shedding.

- Instantaneous loss of 12 to $20 \mathrm{GW}$ (the maximum possible HNEC outage) would require automatic or emergency manual shedding of substantial amounts of mixed loads beyond the $4 \mathrm{GW}$ industrial block. There would be a risk of system breakup, i.e., segregation of portions of the system. The segregated protions would have disproportionate loads and generation--some would continue in service and some would black out. The aim of the system operations would be to prevent such a breakup by widespread load shedding, either automatically or manually, since it is easier and quicker to restore shed load than to resynchronize a system from separate pieces. The duration of outages on the shed load portions of the system would depend on the ensuing events, i.e., the additional generation that may be lost in minutes or hours after the original instantaneous loss, and progress in bringing up operating and energy resources.

To sum up this section concerning the immediate effects of HNEC forced outages:

- Capacity losses could range up to $20 \mathrm{GW}$ in period of high load on the PNW system ( $70 \mathrm{GW}$ load) or to $14 \mathrm{GW}$ in low load periods ( $<44 \mathrm{GW}$ load), i.e., to about 30 percent of generating capacity then on 1 ine. 
- Instantaneous capacity losses of 12 Gi' and staged losses totalling up to 20 GW could be accommodated without impact on the public at most times of the year. At the most adverse times (25 percent of total time) these losses would entail temporary shedding of perhaps 10 percent of commercial and residential loads. The probability of such loss is about $9 \times 10^{-4}$ events per year, or once in 1100 years.

- Instantaneous capacity losses of more than 12 GW would entail greater amounts of load shedding, to keep the system intact, perhaps 20 percent of the commercial and residential load on the system. The probability of such loss is about $1 \times 10^{-4}$ events per year, or once in 10,000 years.

- It is believed that adequate communications, control systems, and operating procedures can be developed to cope with the largest outage without system breakup or collapse, even though it might require load shedding of the proportions indicated above. Restoration to normal or to a managed energy shortage could be accomplished within six hours. However, if system breakup should occur, reintegration could be accomplished within 12 hours.

- Following the first few hours, the management of the system would follow contingency plant for allocation of energy in a period of energy shortage.

The impact on the system in the days and weeks following such an impact incident are discussed in the following section.

FOLLOW-ON IMPACT OF FORCED OUTAGE

A loss of energy production capability caused by events such as those discussed previously resulting in capacity loss would affect the capability of the system to meet its firm and interruptible loads.

This capability projected to the year 2005 has been estimated by the Northwest Power Pool Coordinating Group's Energy Reserve Planning Model described in Reference 2. This mode1, with minor changes to accommodate this study, was used to simulate the system when the HNEC is assumed to reach maturity.

Normally, the model is used for examining the capability of the Northwest Power Pool to meet growing loads as projected in and beyond the West Group forecast. For this study the model was used to estimate the effects of loss 
of large blocks of generation. No load growth was assumed by this model for the years of interest: namely, those typical of the period following HNEC maturity. System resources were essentially those projected by the same forecast with $24 \mathrm{GW}$ of this resource at either dispersed sites or at an HNEC. The program examined the system's ability to meet firm load over a 16-yr period using randomly selected parameters such as reservoir storage, snowpack, rainfall, expected runoff, state of other thermal reserves, etc.

Each year was divided into three 4-month periods; namely, hydro system early drawdown, August through November; late drawdown season, December through March; and system refill-hold, April through July. Five hundred trials (games) per case were run with data points summarized at each 4 -month period. The period of interest contained 6000 data points; namely, 4 yr $\times 3$ periods/yr $\times 500$ trials/yr. It was estimated that any simulation by this model using different combinations of the randomly selected parameters would be within $2 \%$ of others. For insights useful in the analyses here, a single run accumulating 6000 data points was judged sufficient.

The simulation of forced outages resulted from assuming that 30,000 gigawatt hours (GW-hr) of energy was not available from an HNEC during the 4-month periods, assuming the HNEC had a capacity to generate $24 \mathrm{GW}$. An annual plant availability factor of 0.75 was assumed with availability factors in each 4-month interval varying over a rather wide range, depending upon the chance combinations of the variable parameters. Outage cases less than 30,000 GW-hr were not separately analyzed in this model since their effects could not be clearly distinguished from the effects of other perhaps unexpected variations in the system operation not assessed here. Also, a review of the individual games indicated that on a number of occasions, an outage of 30,000 GW-hr could be absorbed with no system energy deficit (user energy shortage) while lesser outages sometimes resulted in deficits.

Five Dispersed Sites were assumed, each with $4.8 \mathrm{GW}$ capacity. The outages simulated for these clusters were for the full capacity of the cluster being down for 2 months out of any 4-month period; i.e., $6000 \mathrm{GW}$-hr. In most cases, the initiating events of concern would affect only one cluster of four generating units at a time. In a few trials, an event being widespread could affect more 
than one Dispersed Site. These did not occur frequently enough to justify added simulation to identify their effect.

The comparative numbers of periods in which deficits of different magnitudes occurred are listed in Table 20.

From the mode1, energy deficits from HNEC occurred in 696 four-month periods (out of a 6000 four-month period population sample). Detailed examination indicated that 624 of the 696 were due to the $30,000 \mathrm{GW}-\mathrm{hr}$ loss at the HNEC.

From a detailed analysis of the computer runs, the numbers of periods in which deficits among the 6000 game periods appear are:

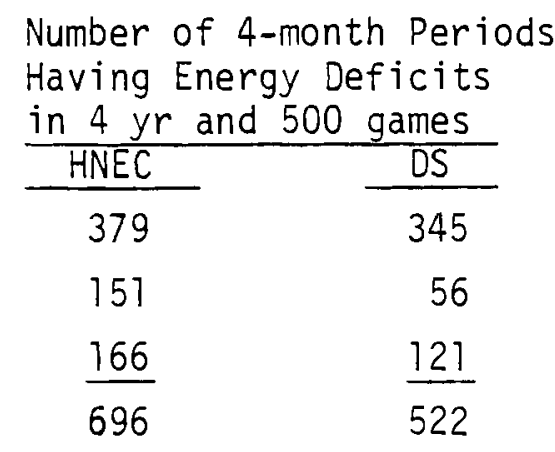

1. September through December

2. January through Apri1

3. May through August

Number of 4-month Periods Having Energy Deficits in $4 \mathrm{yr}$ and 500 games

3. May through August

$\begin{array}{ll}151 & 56 \\ \frac{166}{696} & \frac{121}{522}\end{array}$

TABLE 20. Number of Load-Loss Events Due to Generation Outages

Load Loss, Average MW Over a 4-month Period $0-1,000$

$1,000-2,000$

$2,000-3,000$

$3,000-4,000$

$4,000-5,000$

$5,000-6,000$

$6,000-7,000$

$7,000-8,000$

$8,000-9,000$

$9,000-10,000$
Number of Energy Deficit Periods

\begin{tabular}{|c|c|c|c|}
\hline HNEC & DS & $\begin{array}{c}\mathrm{DS}(\mathrm{a}) \\
\text { Adjusted }\end{array}$ & $\begin{array}{l}\text { Difference } \\
\text { (HNEC-DS) }\end{array}$ \\
\hline 201 & 244 & 244 & -42 \\
\hline 132 & 185 & 185 & -53 \\
\hline 70 & 63 & 54 & 16 \\
\hline 51 & 19 & 0 & 51 \\
\hline 53 & 8 & 0 & 53 \\
\hline 39 & 3 & 0 & 39 \\
\hline 41 & & & 41 \\
\hline 74 & & & 74 \\
\hline 29 & & & 29 \\
\hline 6 & & & 6 \\
\hline 696 & 522 & & \\
\hline
\end{tabular}

(a) Explained in Appendix $C$. 
Most of the deficits occur in the early winter months when loads are fairly high and when information on snowpack to replenish stored water in the hydro system is not yet available. Since the forced outages occur at random, it would be expected that their occurrence would be almost equally shared by the three periods. The inequities in the number of deficit periods are due, therefore, to system conditions and response rather than to incidence of the outages. These observations apply to both the HNEC and DS cases. The greater numbers of HNEC deficit periods relative to DS in the second and third periods are to be expected. Even though conditions are more favorable in those periods with respect to response to outages (in spite of the fact that many refueling outages for thermal plants are in the third period), the greater magnitude of the HNEC outages will result in more load-loss situations.

An analysis of the information shown in part in the foregoing tables reveals that for a 30,000 GW-hr HNEC outage:

1) Of the 624 incidents of HNEC outages out of the 6000 trials in the sampling by the mode1, in 315 of these, the system effects in terms of system energy deficits were no worse than those of the DS case, i.e., the probability that a load loss would be no greater than in the DS case is $50 \%$.

2) In 120 trials the additional deficits caused by outages at HNEC were in the 2000 to $5000 \mathrm{MW}$ range, i.e., a probability of $19 \%$ of causing a 1 oad loss of 5760 to $14,400 \mathrm{GW}-\mathrm{hr}$.

3) In 154 trials HNEC caused deficits in the 5000 to 8000 MW range, i.e., the outage would have a probability of $25 \%$ of causing a load loss of 14,400 to $23,230 \mathrm{GW}-\mathrm{hr}$.

4) In 35 trials HNEC caused deficit periods in the 8000 to 10,000 MW range, i.e., an outage would have a $5.6 \%$ probability of causing a load loss of 23,230 to $29,000 \mathrm{GW}-\mathrm{hr}$.

In effect, system reserves offset generation losses to the extent that curtailment of service to power users approximating the HNEC generation loss seldom occurred among the many trial situations of this study. 
Load loss effects between the $6000 \mathrm{GW}-\mathrm{hr}$ and $30,000 \mathrm{GW}-\mathrm{hr}$ energy $10 \mathrm{ss}$ points are not identified by the available data from the simulation but are estimated by interpolation.

Figure 30 is a plot of the cumulative annual probability of load loss in GW-hr, for the greatest probable generation losses of HNEC and DS. The curves were obtained by multiplying the probabilities of occurrence of the generation loss, as developed in prior sections, by the probabilities of system response as developed in this section, as explained in Appendix $C$.

The area between the maximum probable DS and HNEC curves represents the added risk of HNEC. Curves for lesser amounts of capacity loss, and for lesser outage periods, at an HNEC would lie within this area. An earthquake outage of a11 20 units for which the repair time is the maximum rather than the probable repair time would be represented by points outside of the shaded area of Figure 30 .

It will be noted that a major energy shortage, 20,000 GW-hr, would have a maximum probability of $10^{-4}$ events per year. On the low end, an energy shortage of $6000 \mathrm{GW}-\mathrm{hr}$ would have a maximum probability of $3 \times 10^{-3}$ events per year, depending on the character of the generation outage. Intermediate load loss levels would have probability ranges as shown in Figure 30 . For example, a $15,000 \mathrm{GW}-\mathrm{hr}$ load loss would have a maximum probability of $3 \times 10^{-4}$ events per year.

The shaded area of Figure 30 showing the difference in risk is the overal1 measure of added user risk from HNEC, as compared to DS.

The results of the study emphasize the fact that the Pacific Northwest power pool is able to supply reserve energy in large amounts if the outage occurs at a time of favorable circumstances in the hydro system. Further, there are more years in which circumstances are favorable than when they are unfavorable. By simulating a large number of events, occurring at times when changing circumstances in the hydro system are encountered, the system capability can be illustrated as in the foregoing tables and figures. In considering the effects of large numbers of trials or games, the reader must remember that the use of such numbers is for statistical purposes only. As noted in 


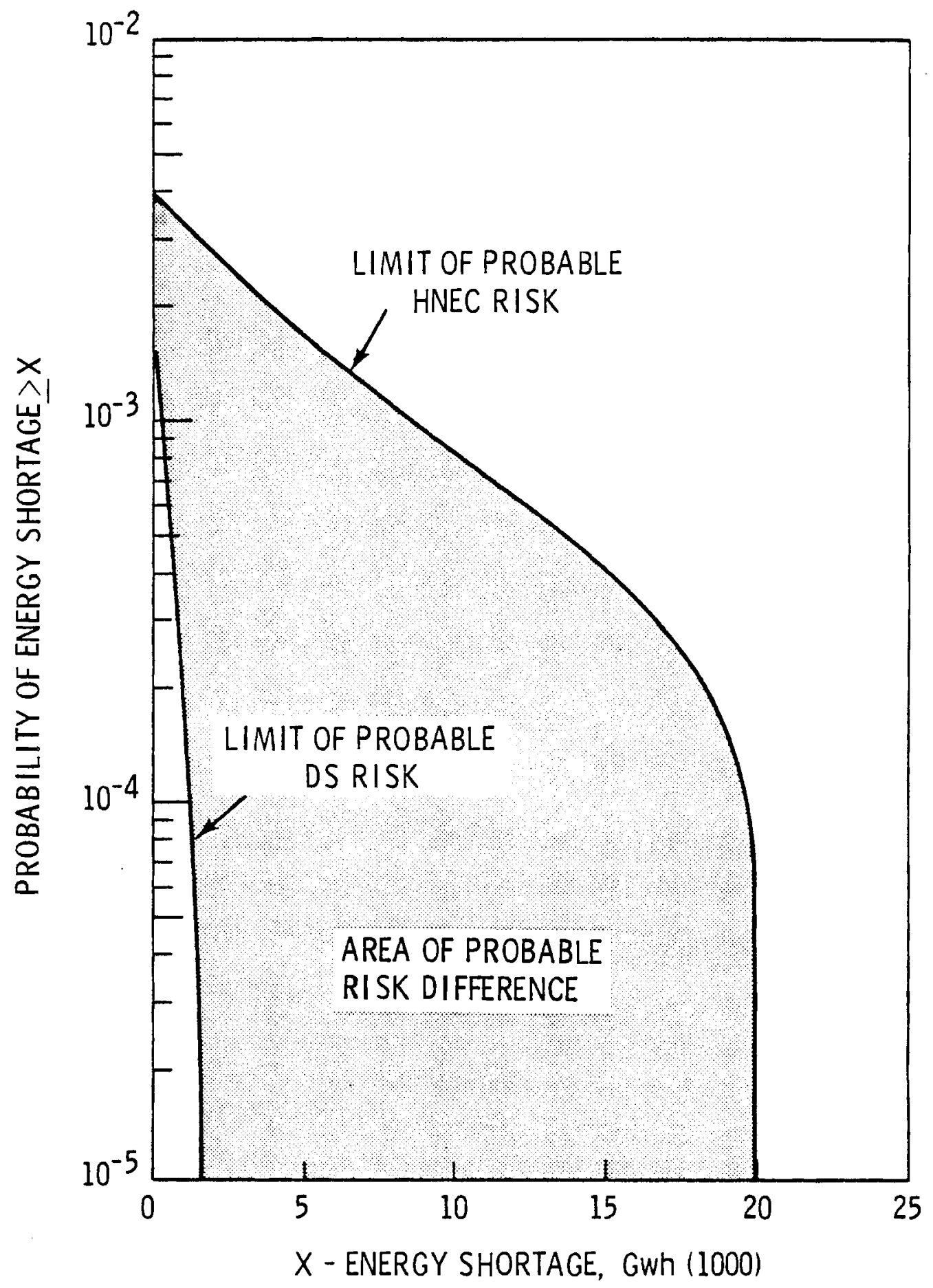

FIGURE 30. A Comparison of Risk of Energy Shortages Resulting from HNEC and DS Outages 
previous sections, the probabilities of occurrence of major energy shortages are of the order of 0.0001 events per year. It is unlikely that one such event would occur in an HNEC lifetime.

The results of several individual games, in which varying amounts of negative and positive surplus energy occur, are given in Appendix $C$. The simulated performance of the system can be better understood from a review of these game results and the accompanying discussion in Appendix $C$.

\section{REFERENCES - IMPACT OF HNEC OUTAGES ON SYSTEM OPERATION}

1. Electric Power Transmission from a Hanford Nuclear Energy Center, BNWL-B-426, Battelle, Pacific Northwest Laboratories, Richland, WA 99352, September 1975.

2. Technical Coordinating Group Energy Reserve Planning Model Progress Report, Northwest Power Pool Coordinating Group, January 21, 1975. 


\section{SOCIETAL IMPACT}

Power outages of the type described herein could have adverse societal effects in the categories of health and safety, economics, and disturbance of lifestyle.

HEALTH AND SAFETY

The health and safety of the public are more likely to be affected by complete loss of service than by the longer term periods of managed reduction of energy consumption. Building elevators, water and sewage systems, rail transportation, traffic signals, lighting of public streets and many other necessities are dependent on electric power supply. The 1965 power blackout in the Northeast and the 1977 blackout in New York City are examples of power outages that have affected the health and safety of the public to some degree. The adverse health and safety effects of the 1965 event were minimal, while the 1977 were considerably worse because of looting and deliberate setting of fires in ghetto areas. Those incidents serve to warn of some consequences that could follow sudden power interruptions, but also to demonstrate that the reaction of the public can be salutary and that great hazards to health and safety do not necessarily accompany such an incident.

The 1965 event affected some 25 million people, and the 1977 event $10 \mathrm{mil}$ lion. A 2005 forced outage involving more than 12 GW or 15,000 GWh could affect perhaps 15 million people over a much wider geographical area in the Pacific Northwest.

In the 1965 blackout, power was restored to most of the affected urban areas in about $12 \mathrm{hr}$, and in the 1977 event in about $25 \mathrm{hr}$. Had complete loss of service persisted, more serious health and safety consequences may have followed. Assurance of ability to restore service within a reasonable period is important to the acceptance of such risk.

The short term effects of major HNEC outages could resemble those of the 1965 and 1977 events, if the instantaneous loss of HNEC power exceeded 12 GW. 
As noted previously, an intense earthquake is the only event that could cause such a loss. Its frequency of occurrence is estimated at once per 10,000 years. All other events would entail some time delay between the dropping of generating units at different clusters, with good prospects for avoiding any prolonged area blackouts, al though mixed residential and commercial loads as well as industrial loads might be shed in certain areas until other reserves could be brought on line. Such shed loads would not exceed 25 percent of the total; and outages would not last more than six hours.

In view of the rarity of all events involving more than one cluster at HNEC, and expectations for early return of electrical services to near normal, the risk to public health and safety is considered low.

\section{Economic Effects}

In the Pacific Northwest there is a strong linkage between the region's economy and the region's usage of electricity. Energy shortages for any reason for an extended period of time possibly would create considerable economic loss. Specific allocation of energy shortages has not been investigated as part of this analysis. Additional study is required to quantify the resulting economic consequences. Fortunately, there is only an estimated 0.0001 probability that severe energy shortages will result from HNEC shortages.

The shortage of energy in an incident of the type being discussed is temporary and would be felt mainly in then-existing industries. The situation should not be seen as one of chronic power shortage that would discourage new industry from locating in the area. Prospective owners and investors would identify a shortage resulting from a rare incident as a freak occurrence, one that would not deter them from choosing what might otherwise be an attractive location.

Economic losses would be suffered by 1) the industries and communities directly affected, 2) secondary support activities, and 3) indirectly by the general public. The public may be affected in a general way by suspended activity in industry, and the corresponding reduction in taxes paid into state and local governments; but also in any power rate increases or surcharges that may come as a result of the use of high-cost emergency generating resources or 
through the effects of continuing fixed charges on plants that are not in use temporarily.

Under regional conditions where water reserves and alternative fuel supplies are at normal levels the economic impact of a 20,000 GW-hr loss from HNEC could be considerably moderated through voluntary conservation and voluntary implementation of contingency plans. In addition, arrangements may be made for the import of electricity from outside the region, arrangements not included in the system simulations of this study.

In addition to voluntary exchange of electrical energy between regions, some of which has been assumed in the system simulation, the Federal Power Commission has asserted that it:

"...enjoys very broad emergency power to deal with an electric energy shortage. These powers extend to all generation of electricity throughout the United States, including federal agencies generating electricity. The FPC claims it has power to compel any generator of electricity to transfer power to a utility experiencing a deficiency of electric energy. It can control the terms of compensation to be paid for such transfer. It has served notice by Orders 520 and $520 \mathrm{~A}$ that it wi 11 compe 1 such transfers wherever excess power exists anywhere in the United States which can be practicably used to cure a deficiency. It has also indicated by implication, but refrained from stating outright, that it may order a transfer of power from one utility to another even if to do so will render the first utility unable to satisfy the requirements of its consumers."(1)

The primary economic impact of increasing the region's electrical supply by fuel switching, extending fossit unit operation, and by purchasing electricity from outside the region will most likely be an increase in cost of electricity for that period.

Measures such as these for increasing supply, and conservation, may serve to satisfy individual and commercial requirements with little reduction in employment and production when eneray deficits are of the order of $10 \%$. Greater deficits, for example the 15\% deficit (for four months) of the maximum probable outage may result in some economic loss other than increased electricity cost. The amount of possible loss has not been estimated. 
Life Style

This discussion on life style, as for economic effects, refers to the effects of an energy shortage over weeks or months rather than the short term disturbance of a 6 - to $12-\mathrm{hr}$ complete outage.

The use of electricity pervades the home and working environment of most Americans, such as refrigeration, cooking ranges, water heaters, television, clothes washers and dryers, lighting, and for many, space heating and cooling. In office and commercial establishments are typewriters, copy machines, computers, lighting, ventilation, and communications. In terms of life style a shortage of energy for any length of time means curtailment of these uses, or a periodic interruption of use.

This type of societal impact is of less importance than that of health and safety and economics, but it could have political repercussions, especially if prolonged more than a few weeks. Much of the public would not comprehend the logic of a very-low-probability event that had actually taken place. They would tend to criticize the utility and the local government.

The excellent reliability records of the U.S. utilities has conditioned the populace to near-perfect service. However, "questions are being raised about the cost of very high reliability. Regulatory bodies essentially have left reliability standards to the judgment of utilities. Customers have little or no input. An important factor is that the cost of outages to consumers and the economy in general is very difficult to determine. Another problem is that the actual and planned levels of reliability are hard to determine for any given utility or to compare among utilities because of inconsistent data. What is needed is a much more complex and dynamic examination of optional reliability than has been done." $(2)$ This includes the costs associated with the levels of reliability.

By the year 2005, in an era of higher energy cost the public may better understand the tradeoff between cost and reliability, and better accept temporary inconvenience if they are convinced that merits of energy centers can compensate for a very small degree of added reliability risk. If there are 
benefits, they will accrue to the public throughout the life of the project, whereas incidents of the type described herein would have only a small chance of occurring during the project's lifetime.

The degree to which the economic and life style effects noted above may be felt in the event of an HNEC outage would depend on the size of the energy deficit. The maximum probable deficit arrived at in Section VII is 20,000 GWh, about $5.3 \%$ of the prospective total annual energy production in 2005 , or about $16 \%$ of the average production over a 4 -month period. In the Energy Reserve Planning Program simulations very few cases occurred in which system energy deficits due to an HNEC outage of 30,000 GWh are carried over into a following 4-month period. It can be assumed therefore that the effects of an outage would be felt over a 4 -month period, and that an approximate $20 \%$ shortage is the maximum that might be expected.

When impacts of such outages were sustained over weeks or months, the necessary load reductions would be accomplished by managed curtailment of various uses as discussed previously. Plans for mandatory curtailment are taking form in northwestern states. $(3,4)$ For example, in Washington the Emergency Power Bill was signed into law in June 1977. The law provides for two phases of effort to meet energy shortages, 1) an energy supply "alert", and 2) an energy supply "emergency". An alert, which can be declared by the governor for 90 days, and extended with certain approvals, would affect mainly the public sector. An energy supply emergency can be declared for 30 days and extended with the concurrence of the state legislature, and can affect both the public and private sectors.

Examples of the kinds of action that can be taken are:

- Alert

Appeal for voluntary reduction

Suspend environmental standards

Reduce consumption by state or civic entities

Curtail school hours

- Emergency

Implement mandatory curtailment plans of utilities 
Impose surcharges and fines

Curtail outdoor lighting

Allow only part time operation of certain commercial establishments

Impose restrictions on comfort cooling

Apply percentage cuts for a 11 consumers

Impose severe restrictions on a 11 operations

Authorize service interruptions or voltage reductions

Some of these measures would reduce both peak and average loads. Rotating blackouts would reduce peaks, and perhaps to a lesser extent the average loads. Some steps would be more effective in different seasons.

\section{Summary}

The societal effects of shortages are estimated in Table 21 along with probabilities of being experienced as taken from Figure 30 page 113.

\section{TABLE 21. Societal Impact of Energy Deficits}

\begin{tabular}{|c|c|c|}
\hline$\frac{\text { Energy Deficit }}{\text { GWh }(1000)}$ & Societal Impact & $\begin{array}{l}\text { robabilities, } \\
\text { Events/Year }\end{array}$ \\
\hline 2.5 & $\begin{array}{l}\text { A Tert declared, generation loss } \\
\text { probably offset by voluntary con- } \\
\text { servation at behest of government } \\
\text { and utilities }\end{array}$ & 0.0045 \\
\hline 5 & $\begin{array}{l}\text { Conservation, plus cutoff or inter- } \\
\text { ruptible loads. Some economic loss } \\
\text { entailed }\end{array}$ & 0.0035 \\
\hline 10 & $\begin{array}{l}\text { Emergency declared. Above steps } \\
\text { taken, plus governmental restric- } \\
\text { tions on public, commercial and } \\
\text { industrial use. Appreciable econo- } \\
\text { mic loss }\end{array}$ & 0.001 \\
\hline 15 & $\begin{array}{l}\text { Further governmental restrictions on } \\
\text { nonessential uses as per emergency } \\
\text { plan. Substantial economic loss }\end{array}$ & 0.00035 \\
\hline 15 to 20 & $\begin{array}{l}\text { Implementation of full powers of the } \\
\text { emergency legislation, including } \\
\text { some or all of the measures } 1 \text { isted } \\
\text { under "Emergency" on page } 133 \text {, econo- } \\
\text { mic loss, and appreciable effect on } \\
\text { lifestyle. }\end{array}$ & 0.0001 \\
\hline
\end{tabular}


The table indicates that the maximum probability of substantial economic loss is no greater than 0.00035 events/yr once in 2850 years, and for substantial curtailment of power to residential users no greater than 0.0001 events/yr (once in 10,000 years).

In searching for an historical event that had a comparable effect on the public as power consumers, the authors considered the drought of 1976-77. The actual consumption of energy with relation to the forecast, or to the norm, is influenced by both supply and demand. The supply of energy was affected by the drought, but also by water conditions in periods preceding and following the drought. The demand could be affected by temperatures, by voluntary conservation effects releated or not related directly to the drought, and by keeping interruptible loads off line.

These combined effects resulted in the firm power energy consumption in that year being $4.6 \%$ below the forecast; and total consumption, including interruptible industrial load, being $6.8 \%$ below forecast. The $4.6 \%$ energy use reduction for one year, may be compared with the $16 \%$ reduction risk, from the maximum HNEC outage, for four months. Al though no mandatory reductions were imposed on the public consumer during the drought, a $16 \%$ reduction may require mandatory reductions for a four month period.

\section{REFERENCES - SOCIETAL ASPECTS}

1. Emergency Contingency Planning, Northwest Energy Policy Projects, page II-24, Portland, Oregon 1977.

2. Electrical Week, p. 5, February 7, 1977.

3. Plans for Mandatory Curtailment Taking Final Form in States, Northwest Public Power Butletin, No. 5, 1977.

4. Proposed Regional Guidelines for Curtailment Planning, July 20, 1977, Pacific Northwest Regional Commission. 


\section{CONSIDERATION OF REDUCTIONS IN THE RISK OF HNEC FORCED OUTAGES}

The probability of forced outage of HNEC has been indicated to be very low from all events except earthquakes. Because the subsequent consequences of large outages to the region can be substantial however, the potentials for some reduction of the risk (lower probability of occurrence and/or lesser consequences) are briefly considered.

Figures 25 and 26 show the ranking of HNEC and DS risks, i.e., the ranking indicates for example that earthquakes result in higher risks of loss of loads than all others combined. The following gives the ranking:

1. Earthquake (inspection requirement)

2. Earthquake (repair requirement)

3. Ashfall

4. Radiation release

5. Switching station (a11 causes)

6. Flood

7. Tornado

\section{EARTHQUAKE}

Administrative Considerations

The NRC regulation requires shutdown for inspection of nuclear-safetyrelated portions of the plant following any earthquake at or above the OBE intensity and less than the SSE. This is a mandatory requirement even if the plant continues in operation during the quake and has received no apparent damage.

If essential facilities have not been damaged, shutdown of the plants can be reasonably orderly under emergency shutdown and load-shedding procedures.

The time required for the subsequent mandatory inspection in this study was estimated to be a week. The HNEC concept would be adversely affected. Note that the risk from an earthquake on HNEC or a DS could be reduced by a factor of 10 in most cases and 4 for this instance of the SSE if the inspection 
requirements were eased. Shutdowns with subsequent long delays for inspection could be avoided wherever earthquakes less than an SSE occurred.

Design Consideration

Seismic instrumentation properly located may be or become adequate to give reliable assurances that the earthquake was less than the SSE and that the design has been adequate. Such instrumentation may supplement or even replace the extended mandatory inspection. A substantial reduction in the risks of HNEC and DS outages from earthquakes would result.

Risk of earthquake damage to the Code-design portions(a) of the plant would be reduced, of course, if those portions were designed to a horizontal acceleration greater than $0.125 \mathrm{~g}$, closer to the associated criteria of the Category I portions of the plant. Whether the added cost would be justified would depend on the added values attached to the use of such a Center, along with the assessment of the risk that can reasonably be taken with respect to earthquake effects.

A somewhat greater spacing between clusters, or three units per cluster instead of four or five, would reduce the risk of earthquake effects somewhat, but the beneficial effect would be small and probably would not justify added costs.

ASHFALL

Knowledge of the possible effects of ashfall on plant operations is so meager that the quality of the assessment is highly uncertain. Further study analysis and experimentation on the effects could move the zone shown in Figure 30 in either direction. The dust storms occasionally experienced in the Hanford area are good indicators of where trouble might be experienced with the much more voluminous mass of a two- to six-in. ashfall. Such studies would be recommended before any design changes to reduce risk be considered.

(a) Code-design portions refers to facilities other than Category I features essential to power generation. 
Following that, measures might be considered that would:

- permit quick filter changes,

- cover exposed water pools,

- control possible ash drifts,

- seal instruments and machines that could be damaged by ash infiltration, and

- make provisions for insulator washing if the anticipated effects of acid deposits are adverse.

If it can be shown that with certain economical preventative measures a nuclear plant would have a better probability of remaining operational under a 6-in. average ashfall deposited over a 3 to 7 day period, the perceived risk would decrease in importance.

FLOOD

The vulnerable point of the HNEC plants to flood is their river pumping plants. The vulnerability of a Pebble Springs plant would be greatly reduced by the availability of stored water in the planned reservoir. An obvious way to reduce the effect of flood on HNEC plant operability is to provide a backup source of coolant makeup in the form of a pond, reservoir or well system that could serve a cluster of plants. This backup source need have only sufficient capacity to serve the plants until the river pump houses be restored, or temporary pumping facilities be provided to deliver makeup water from the river after the flood had subsided.

The above pertains to natural floods that could incapacitate river pump houses. It could pertain also to Artificial Flood No. 1, but first, one would have to make a more careful study to ascertain that in the event of such a flood, other impediments to continued delivery of power are not likely to appear, such as washed-out transmission line towers and consequent cutting of vital system connections.

OTHER CAUSES

Of the remaining causes, only two opportunities for risk reduction are worthy of mention: 
1) Switching stations could be designed to handle the output of only one cluster, and

2) Structures vulnerable to tornadoes, particularly vital overhead cluster lines, and cooling towers, could be designed to reduce the risks, i.e., by placing critical lines underground and by orienting lines of towers at right angles to prevailing tornado travel directions.

An option that must be addressed is that of providing additional reserve capacity to the added reliability risk at a center. This alternative does not appear to be feasible because such a large amount of reserve capacity would be needed to make any appreciable reduction in the risk that it would be uneconomical. The preferred course would be to improve reliability at the Center via reduction of effects of earthquake.

In enumerating the possibilities for reliability improvement over that of the model used for this study, no inference is made regarding justification, or regarding the need for improvement. If improvement is needed, efforts should be directed to the effects of earthquake, since a substantial improvement in the effect from other causes would make little change in the overal1 risk. 



\author{
APPENDIX A \\ TYPES OF DISRUPTIVE EVENTS EXCLUDED \\ FROM COMPARATIVE ANALYSIS OF RELIABILITY
}




\section{TYPES OF DISRUPTIVE EVENTS EXCLUDED \\ FROM COMPARATIVE ANALYSIS OF RELIABILITY}

\section{TYPES OF EVENTS EXCLUDED}

\section{NEW VOLCANOES}

Eleven new volcanoes have formed on the earth since 1750 A.D. The probability of occurrence of a new volcano that would affect a generating plant cluster would be of the order of $10^{-9}$ to $10^{-11}$ events per year. Its estimated value within this range would depend on whether new volcanoes would appear at random over the entire face of the earth, or would tend to appear in locations which are presently active or contain recently extinct volcanoes. While the latter is the more reasonable, the probability of occurrence under either assumption is too low to be of interest in this comparison. Activity from existing volcanoes has been covered in the section on Ashfall Effects.

\section{METEORITES}

Data have been gathered on meteorite impact frequency. (1) Meteorites of iron and stone of a size of interest here range from 10 to $10^{13}$ tons in weight. The combined probability of meteorites striking a site would be of the order of $10^{-9}$ to $10^{-10}$ events per year. The chance of a meteorite having a destructive area of impact large enough to involve more than one cluster would be even less. (The probability of occurrence of 10 to $10^{4}$ fatalities from a meteorite would be in the $10^{-4}$ to $10^{-7}$ range. (6) The probability of striking inhabited areas is greater than the probability of striking the much smaller land area occupied by power plants).

A meteorite estimated to have had a weight of about 2.7 metric tons fell in Kirin province, China, on March 8, 1976. The meteorite broke into three major fragments weighing $1.7,0.4$ and 0.12 metric tons. (3) The largest fragment left a pit in frozen ground measuring about $2 \mathrm{~m}$ wide and $6.5 \mathrm{~m}$ deep.

- Smaller fragments were scattered over an area of $500 \mathrm{~km}^{2}$. This example has a meteorite weight below the range indicated above, but serves to indicate that for stony meteorite types: 
1) The area over which fragments can be strewn may be quite large and could involve more than one cluster, but

2) The area of severe damage by each major fragment would probably be relatively small. Within each cluster, a major fragment striking critical plant facilities would probably involve only one unit rather than all units. A very large meteorite conceivably could affect other clusters through ground shaking.

Iron type meteorites would be expected to have less fragmentation and less probability of involving more than one cluster.

Although HNEC may have slightly greater exposure than DS for the reasons given above, the probabilities are so low, and the possible number of units involved so small, that meteorite strikes were eliminated from the comparison.

\section{FLOODS OR LOW WATER LEVELS FROM RIVER CHANNEL DIVERSION OR BLOCKAGE}

A blockage of the Columbia or its tributaries in the past has occurred in these ways:

1) Following an earthquake on December 14, 1872, "The most important slide reportedly occurred just north of Entiat where a section of 01d Broken Mountain fell into the Columbia River and completely blocked the flow of water for about $12 \mathrm{hr}$. The slide area is just above Entiat Rapids at what is now referred to as Earthquake Point. The section of mountain exposed by this slide is now called Ribbon Cliffs because of prominent Dasalt dikes in the crystalline rock face." ${ }^{(13)}$

2) "In historic times, no more than a few hundred years ago, a large landslide occurred on the southeast face of Table Mountain near the site of Bonneville Dam. The river was completely blocked for a short period of time, raising the water about $200 \mathrm{ft}$ above normal stream level, before overtopping the natural dam. "(14)

3) "During the last glacial period, about 15,000 yr ago, Clark Fork was blocked by ice in northern Idaho forming Lake Missoula extending into Montana. At about the same period, ancient Lake Lewis 
was formed by a blockage of the Columbia River near the present community of Hood River, downstream from the site (Pebble Springs). The cause of this blockage is not established, but may have been either ice, landslide or Tava flow. "(13)

4) "The Clark Fork was blocked at least twice in the last 20,000 yr, resulting in floods between 18,000 and $20,000 \mathrm{yr}$ ago, and 13,000 $\mathrm{yr}$ ago." ${ }^{(7)}$

5) "Ancient Lake Lewis formed most likely as a result of hydraulic dariming of the Columbia at three restrictions. Those are: 1) the Columbia Gorge downstream from Portland, 2) the gorge at Hood River, and 3) Wallula Gap. If landslides, lava flows or ice jams were significant there should be some scars left. None have been reported. Instead, calculations show that the gorge could not pass water through those restrictions at the rate it was moving downstream. Hence, water was backed up at the three sites. Significartly the last flood (13,000 yr ago) appears to have been of the same magnitude as the earlier one, based on the nature of the deposits, but rose to only about $900 \mathrm{ft}$ in the Pasco Basin versus 1150 for the earlier one. The reason is probably that the constrictions were reamed out by the earlier flood."

The following opinions regarding the danger of diversion or blockage of the Columbia in the vicinity of Hanford and Pebble Springs are found in safety analysis reports.

"--The Columbia River is deeply incised and does not meander so that cutoffs above the site are not possible. Ice formation is not of sufficient thickness to cause ice jams. There are no topographic conditions upstream of the site that would provide complete blockage of the river by lands lide." 13 )

"In the vicinity of the site the river bed is well defined, and it is very unlikely that the river would be diverted from the present location by natural causes. Any possible effect on water supply to the makeup water pump house from river bed changes should come from extremely slow changes which can be corrected as they occur. The river has not 
frozen over in the Hanford reach during the past twenty-five (25) yr, and icing on the river has not been a problem at pump houses or outfall structures associated with the Hanford plutonium production plants." (14)

The historical and prehistorical river blockages have been attributed to ice, lava flow, and landslides or, for Lake Lewis, hydraulic damming at river flow restrictions. No evidence was found to indicate a significant risk of ice blockage in the river either in reaches of interest here or in upstream areas. Similar risks would result from lava flow. Lava flow conceivably could occur near the river in the vicinity of Mount Hood. Blockage at this point, however, would affect only the Portland site of the DS case, and would have no effect insofar as multiple-cluster outages are concerned.

Lands 1ides can occur 1) from earthquakes in either rock or soil formations near the river, 2) from undercutting soil bluffs by river flow, and 3) from possible effects of irrigation water on soil shear strength, weight, and stability.

North of the HNEC site as far as Grand Coulee the river bank formations are mostly rocky. Earthquake-induced slides from these rock formations could occur in this portion of the river. The slide at Ribbon Cliffs noted above is an example of an earthquake-induced rock slide. Complete blockages in this portion of the river could reduce river water elevations at a11 of the HNEC sites and some of the DS sites in this study. Partial river blockage above any of the storage dams upstream of the sites would not seriously affect either HNEC or DS.

White Bluffs on the eastern side of the Columbia River opposite HNEC are Ringold Formation sediments that are subject to some undercutting, and, more importantiy, to the effects of irrigation. In recent years perched water in the bluffs along the river edge has developed from irrigation and is appreciably above the river level. The loss of shear strength in the clay-rich sediments, and added weight of the water, and their effect on the stability of the soil, are factors in studies of possible soil movement. If portions of these bluffs should slump into the river, blockage may occur. 
In documentation in support of safety studies for the Fast Flux Test Facility (FFTF) near HNEC the conclusion is reached that "Geologic evidence indicates that the FFTF site has not been inundated for perhaps several thousand to many thousands of years (by large earth avalanches or landslides). No evidence indicates that even the largest slides that have occurred in the White Bluffs area have had more than relatively local impact on the area." (8)

After a brief investigation of the White Bluff condition a soil mechanics firm noted that "There are two possible modes for landslides, i.e., 1) a series of shallow steep slides which would cascade into the river with the material pulverized and rapidly eroded by the river, or 2) a few very large, massive and slow moving slides which would move into the river diverting it away from its east bank and which because of the mass would require some time for erosion by the river to restore its original channel. With the advent of irrigation we believe the second mode of landslides is the more critical and based on limited information the more likely." (9)

Although the historical evidence indicates that any slides that have occurred have not been large enough to have had widespread effects, the new factor--irrigation on the Bluffs--may increase the probability of large slides. The tendency to slides in the White Bluffs area can be monitored. (9) Possibly, irrigation practices could be modified to limit excess drainage, or be curtailed if the potential risks were great enough.

In the event of a major slide, the extent of blockage would depend on the amount of material dislodged, how quickly the temporary dam breaks after overtopping, and the river flow at the time. During concurrent high-river flows, large amounts of soil could be washed downstream with no effective blockage of river flow. During concurrent low flows, the river run may be completely blocked. The blockage may occur below some HNEC sites and above others. River bed contours in the White Bluffs area indicate that slides from the bluffs would be more likely to block and be overtopped than to divert the river flow to a permanent channel west of the slide.

The possible effects of a White Bluffs landslide of approximately one milition cu yd on river flow and elevations were considered, with given assumptions 
as to the time for the earthdam to fail after it was overtopped, and the river flow rates. (The effects of wave action from downstream backwater flow were ignored.) For example, if flooding occurred simultaneously with a bluff slumping into the river, the approximate elevation of the flood wave crest in the vicinity of the southern HNEC cluster would be about $400 \mathrm{ft}$ above Mean Sea Level (MSL), for a river flow of 600,000 cfs, (1 in 200-yr flood) and about $410 \mathrm{ft}$ for a river flow of 1,400,000 cfs [the Probable Maximum Flood (PMF)]. These elevations of flood waters would be above the Probable Maximum Flood elevation, $389 \mathrm{ft}$, and below the Limiting Case Flood elevation, $424 \mathrm{ft}$. They would flood the river pump houses but not the major plant facilities. Water elevations upstream from the blockage would rise gradually until the dam is overtopped. At the 1,440,000 cfs flow these levels would already be close to the maximum tolerated at the river pump houses. At this extreme flow the river pump house at both upstream and downstream plants would be affected by the slide.

For these assumptions and flood conditions to occur, the drainage area for the Columbia would have to produce a river flow close to or exceeding the historical maximum, and, in addition, the conditions at white Bluffs would have to be such as to induce the slide.

The probabilities of occurrence of such a combination of conditions have not been estimated. The combination would include the probability of high river flow with recently completed or projected large flood control projects on the river, that of conditions at white Bluffs to induce a siide, and that of the slide being of sufficient volume to completely block the channel. The probability of the occurrence of a $600,000 \mathrm{cfs}$ flow has been estimated at once/700 yr, and that of a Probable Maximum Flood has been estimated at once per $10^{7} \mathrm{yr}$. Since other factors in the probability equation would also have low values, it would appear that the combination may be below the area of interest. This assumption is necessarily conjectural lacking further information on the likelihood of collapse under the conditions at white Bluffs.

The probabilities of a slide occurring at low flow may be much higher but for equal dam height the elevation of the flood crest above and below the blockage would be less than for high flow, with less chance of flooding the river pump houses. 
Returning to the earthquake-induced rock or earth slide, historical events indicate that three changes of major features on the Columbia River may have been from landslides, which may have been induced by earthquake (one is known to have been earthquake-induced) during the last 15,000 yr. These occurred at

- different points and would not have affected the entire river. For example, the Ribbon Cliffs slide was above the confluence of the Snake and would not have seriously affected the lower Columbia; and the Table Mountain event would not have affected upper portions of the mid Columbia.

The probability of three such events occurring where the same portion of the river would be affected, based on these data, would therefore be much less than $3 / 15,000$, i.e., much 1 ess than $2 \times 10^{-4}$ events per year.

Although this analysis of river blockage probabilities and consequences is very rough and preliminary, it indicates that the risk may be less than others analyzed in the report, and need not be included in the quantitative evaluation.

\section{EXTREMELY LOW RIVER FLOW}

Lack of available makeup cooling water at the river pump suction intake point could occur in the event of very low flow in the river because of freak weather conditions in the drainage area, or in the event of blockage or diversion of the channel as discussed above. Extremely low precipitation would affect these river systems supplying cooling water for these sites:

\begin{tabular}{ll}
\multicolumn{1}{c}{ Site } & \multicolumn{1}{c}{ River } \\
$\begin{array}{l}\text { HNEC } \\
\text { DS }\end{array}$ & Columbia River \\
Hanford & Columbia River \\
Pebble Springs & Columbia River \\
Portland area & Columbia River (or \\
& possibly Cowlitz or \\
Kalama) \\
Oregon & Willamette River or \\
& tributaries
\end{tabular}

Some $70 \%$ of the DS Case generating capacity and 100\% of the HNEC Case capacity would depend on Columbia River water. 
The HNEC points of withdrawal of river water are above the confluence of the Columbia and Snake Rivers, while Pebble Springs is below it. The Portland area site is near the mouth of the Columbia and the Oregon sites are on a Columbia River tributary, the Willamette. Even though HNEC is upstream of some of the major tributaries flowing into the lower river, it is on a reach of the river carrying drainage from large areas in the northwestern U.S. and Canada and furthermore, it is downstream of the major storage dams.

River surface elevation necessary for reliable pumping opposite the WPPSS plants under construction is $343 \mathrm{ft} \mathrm{MSL} \mathrm{(river} \mathrm{mile} \mathrm{352).} \mathrm{The} \mathrm{flow} \mathrm{here} \mathrm{corre-}$ sponding to that level is $36,000 \mathrm{cfs}$. If river flow dropped much below that amount, the HNEC plants would be incapable of sustained operation.

Flow is now regulated by Grant County PUD at their Priest Rapids Dam so that "it will not result in flows of less than 36,000 cfs of water at the Hanford Works of the Atomic Energy Commission except when conditions are beyond the licensee's control". (15)

Historical records of the USGS gauging station (R.M. 394.5) located 2.6 mi downstream from Priest Rapids Dam show low daily average flows of 20,000 cfs in January 1937. At that time there were only 1.19 million acre-ft of upstream storage on the river as compared with 38.2 million acre-ft at present, and 51 million potential. (16) The 20,000 cfs flow in 1937 may be considered as a historical low in natural river flow in the Hanford reach prior to the building of the major upstream storage dams. This flow may be considered as having a probability of $1 / 75$ or 0.013 events per yr. A 14,800 cfs natural flow would have a probability of 0.001 events per $y r$, again without use of stored water as indicated in Reference 13.

The total usable storage of dams from Grand Coulee Dam to the Columbia River headwaters now totals about 38.2 million usable acre-ft. Some additional storage below Grand Coulee would bring the total to around 40 million acre-ft. Disregarding withdrawals above Hanford this amount of storage would sustain a flow of $36,000 \mathrm{cfs}$ for 559 days. From full reservoirs the release of stored water could supplement the 1000-yr low flow of 14,800 cfs, to achieve a level of 36,000 cfs at Hanford, for 947 days if used for that purpose alone. 
The above statistics are presented only to place the amount of storage in perspective. There would be competing uses for stored water that may or may not be compatible with maintaining a 36,000 cfs minimum flow at HNEC. These uses include irrigation, power at hydroelectric dams, navigation and fisheries accommodations. The water consumption for 20 operating plants with wet cooling towers would be about $1100 \mathrm{cfs}$. If an HNEC were in place its importance to the region would justify a high priority in the scheduling of use of the water. It is evident that the upstream reservoirs provide the means of sustaining adequate flow during a substantial drought period. Starting full, and with no other withdrawals, they can sustain a 36,000 cfs flow for 947 days. Starting partially full, and with other withdrawals, they could probably sustain minimum flows through at least a one-yr drought.

Plants with reservoirs of their own, such as the cooling pond and irrigation reservoir proposed for Pebble Springs, could tolerate low water periods of many weeks duration in which makeup water from the river were cut off. The length of the period would depend on irrigation withdrawals.

Finally, if a prolonged drought should empty the upstream reservoirs and drop the natural flow below the point at which suction can be maintained on the river pump intakes, the time taken to reach that stage would be sufficient for other emergency measures to be taken. These could take the form of extensions to intake pipes, temporary booster pumping stations, or drilling of wells to provide makeup water.

In summary,

1) The Columbia River could supply makeup coolant to $100 \%$ of the HNEC capacity and $70 \%$ of the DS capacity; $30 \%$ of the DS Case capacity takes makeup from the Willamette River which may or may not be affected by drought at the same time,

2) In view of the nature of the river system, and the stored water at upstream dams, the probabilities of flows dropping to critical levels are extremely low. However, if flows were to drop to that degree, the progression to that stage would take enough time that contingency plans to provide makeup water could be implemented at either the HNEC or the DS sites. 
For these reasons the difference in risk from this cause is considered too low to be included in these comparisons.

\section{AIRCRAFT CRASH}

The annual probability of an aircraft striking a nuclear power plant is estimated to be: (2)

\begin{tabular}{|c|c|c|}
\hline \multirow[b]{2}{*}{ Aircraft Size } & \multicolumn{2}{|c|}{ Location of Plant } \\
\hline & $\begin{array}{l}\text { Beyond } 5 \mathrm{mi} \\
\text { of Airport }\end{array}$ & $\begin{array}{l}\text { Within } 5 \mathrm{mi} \\
\text { of Airport }\end{array}$ \\
\hline Sma 11, <12,500 1b & $1.4 \times 10^{-5}$ & $3.3 \times 10^{-5}$ \\
\hline Large, $>12,5001 \mathrm{~b}$ & $4.6 \times 10^{-7}$ & $1.1 \times 10^{-6}$ \\
\hline
\end{tabular}

These probabilities would apply whether the plant were part of a cluster or sited alone.

Since HNEC sites would be more than $5 \mathrm{mi}$ from an airport, and presumably the DS sites would also, the $4.6 \times 10^{-7}$ probability would apply. Furthermore, in view of the limited impact area, no mechanism can be visualized whereby more than one cluster could be affected by an aircraft crash other than by a crash into a switching station carrying the output of multiple generating units (previousty discussed).

The extremely low probability of affecting more than one cluster is the reason for exclusion of aircraft crash at the generation plant from the study.

\section{EXPLOSIONS}

Explosions can occur at tanks at industrial complexes, tank cars or trucks on rail or highway, on tanker ships on waterways, or bombs from military or saboteur operations. Tanker ships can be excluded since explosive cargo is not carried on the Columbia River at the plant sites and, if it were, the distances would provide adequate protection except for river bank pumping or outfall facilities. Military explosives are excluded as a matter of policy.

Conceivably, industrial complexes could be attracted to a nuclear center. Since there are none now, and since any that may be placed in the Center in the future would be sited so as to be compatible with the generating plants, 
exposure of multiple clusters to possibie explosions can be avoided. NRC criteria would ensure that the safety of the nuclear plants is maintained.

A nuclear plant is considered safe at a distance of 8 to $10 \mathrm{~km}$ from an explosion. (4) It would be feasible to maintain such distance from possible explosive sources in the Hanford reservation. The chance of more than one cluster being affected under the controls which are both necessary and feasible would be extremely remote.

The same precautions could and would be taken with respect to potentially explosive materials transported in the plant vicinity by rail or over highways.

As for DS sites, it is assumed that whether industrial plants existed in the vicinity of the site before its development, or were planned after the generating plant came into service, adequate controls would be exercised there also. There may or may not be the flexibility of siting that exists at Hanford. In any case, it was concluded that no discernible difference in risk from industrial explosions existed between the HNEC and DS cases.

With respect to bombs placed by saboteurs, certain conclusions were reached by the authors of References 5 and 6 which are significant:

"Protection of nuclear power reactors against sabotage is provided both by the nature of the nuclear process and by explicit protective actions of 1 icensees in accordance with AEC regulations." ${ }^{(5)}$

The massive shielding, radioactivity of the process, sealed containment vessel, and redundant safety systems are noted, along with deterrents to unauthorized entry.

"Successful sabotage of a reactor at an NEC or Dispersed quad would require a sequence of several events, each of them quite improbable, and even then the severity of the results would depend on the state of the reactor core and cooling systems as well as the weather at the time." (5)

"With the implementation of current security measures it appears that the probability of successful sabotage is low, and further reductions in probability can be anticipated in the future. "( 6 ) 
Our study is concerned with the probabilities of success of sabotage of all generating units at one cluster plus one or more units at another cluster, at the same time. A sabotage plan conceivably could include two clusters at an HNEC or two at distant DS sites. Tactics for carrying out such a plan might differ for the two cases, but there is no fundamental reason why the prospects of success should be much different. The prospects of success would be extremely low, given that the successful sabotage of even one generating unit would be as difficult as indicated above. These statements were oriented primarily to the reactor and its safety systems, and perhaps less so to the non-nuclear facilities. However, the security measures apply to both.

If sabotage of a single generating unit were successful to the point that radioactive contaminants were released, the effects on other units would be the same as though the release were caused by equipment failure. Those effects are included in the comparative analysis.

For those reasons, bomb blast sabotage has been excluded from detailed comparison, except for the possibilities at switching stations, which are discussed in another section.

\section{TOXIC GASES}

The danger from toxic gases from nearby industrial plants cannot be evaluated without knowledge of the industrial process. However, since power generation would be the principal activity at a nuclear energy center, it can be assumed that controls would be exercised to limit this risk to very low levels.

At LWR and LMFBR generating plants, the only source of toxic gases other than radioactive releases and sodium fires discussed elsewhere is stored chlorine for water treatment. The amounts of chlorine stored and the separation of clusters at HNEC is such that a chlorine release at one cluster would be greatly diluted if carried by wind to an adjacent cluster.

\section{FIRES}

For multiple clusters to be affected, a fire would have to be widespread and difficult to control, such as a major forest fire. HNEC has minimum 
exposure in this sense. No industrial fire within the plants can be visualized that would extend to other clusters.

A sodium fire at an LMFBR is a special case in which the fire itself would not involve other clusters, but the airborne products from the fire might affect them.

\section{SODIUM FIRES}

Since LMFBRs may supplement LWRs in the 1990s, at the HNEC or DS sites, the possible effect of sodium fires on generating units in an adjacent HNEC cluster was considered. This discussion is limited to the burning of sodium that would come from the primary or secondary coolant circuits in its normal operating condition, i.e., not following a fuel melt accident. The latter type of accident is discussed in another section of the report.

Some radioactivity will be present in the sodium. "The principal source of activity in the primary sodium is from neutron activation in the primary sodium itself. Neutron capture in ${ }^{23} \mathrm{Na}$ forms ${ }^{24} \mathrm{Na}$ (15 hr half-life). Smaller concentrations of ${ }^{22} \mathrm{Na}\left(2.6 \mathrm{yr}\right.$ half-life) are formed by $\left(n,{ }^{2} n\right)$ reactions with ${ }^{23} \mathrm{Na}$. Depending on the number of fuel failures that may have occurred during prior plant operations and on the amount of corrosion of irradiated cores structural members, other radioactive species may also be present." "The sodium in the secondary coolant circuit is not normally radioactive except for tritium that has diffused through the intermediate heat exchanger tubing. "(11)

Reference 12 contains the results of analyses of a) releases of sodium from the primary system, into an inert atmosphere, and b) releases of sodium from the secondary system into air-filled spaces. With reference to the latter, "release of sodium and of its oxides to the environment is a relatively minor consideration due to its low chemical toxicity." In the section describing tests, "0.5\% of the spill mass was released from the cell as aerosol parti- cles", and when a coverplate was used, "Smoke release from the cell was $0.03 \%$ of the spill mass...."

These references describe the measures that can be taken to limit the rate of combustion, confine the combustion products, and extinguish fires that may 
occur. The possibility of a sodium fire in the waste heat exchangers of FFTF, which was assessed in connection with the 1icensing of WPPSS plants at Hanford, would not exist in a commercial LMFBR since the sodium coolant circuit would a11 be within the confinement vessel.

The response of such containment systems is expected to limit releases to the extent that radiation levels beyond the site boundary for a 1000 MW LMFBR would be a 2-hr, whole-body dose of 12 mrem at a distance of $2000 \mathrm{ft}$, and a 30-day whole-body dose of $4.5 \mathrm{mrem}$ at $2 \mathrm{mi}$. (11)

The releases of radioactivity would be greater in the event that primary sodium burns and the containment systems fail. No estimate is available presently as to the plume characteristics for a commercial LMFBR. A calculation has been made for FFTF. (12) Although the primary sodium inventory at a $1000 \mathrm{MW}$ LMFBR would be greater than at FFTF, the amount of the release would not be proportionately greater because of plant design features to limit the size of possible pools.

To summarize, in the rare event of accidental release of the combustion products of a large sodium fire:

- If the burning sodium were from the primary circuit, and if all fire control and containment features failed, there could be a radioactive plume which, if the wind conditions were right, could be carried to adjacent clusters. A quantitative assessment has not been made. The effects can be judged by studies of FFTF potential releases. The radioactive sodium deposition in the $1000 \mathrm{MW}$ plant case is estimated to be no greater than that computed for FFTF, and is of course, much less than the total radioactive deposits that would result from LWR releases following a fuel melt. In the unlikely event that some radioactivity were deposited, continued operation of adjacent clusters is believed to be possible if operating personnel have available air packs for outside operations if needed until the plant could be decontaminated.

- No problems would be created at adjacent clusters if the sodium were from the secondary circuit since little or no radioactivity would be present in the combustion products. 
For these reasons sodium fires were excluded for consideration as an added risk at HNEC.

\section{LOSS OF OFFSITE STATION SERVICE POWER}

Loss of offsite station service power would force shutdown of a plant within $72 \mathrm{hr}$ for safety reasons. The probability of occurrence of such loss was assessed for the HNEC and DS cases.

Several possible ways in which HNEC could receive offsite station service power from the network in the vicinity were explored in Reference 17. These included the $220 \mathrm{kV}$ system as a source, as for the WPPSS plants under construction, and the $500 \mathrm{kV}$ system over which the output of the center would be fed into the bulk power network. Similar alternatives would exist at most of the dispersed sites.

The reliability of offsite power supply would depend on that of 1) the network from which the power is drawn, and 2). the circuits carrying power from the network to the station service transformers. The reliability of the network is a function of the number of independent sources of power on the network that would have a good chance of remaining connected to the HNEC switchyards in the event of system faults or disturbances. The greater the number of generating stations in the vicinity of each cluster, and the shorter the interconnecting transmission lines, the greater will be the reliability of the network as far as that one particular cluster is concerned (assuming that relaying on all lines and in all situations is equally dependable, and that the lines and terminals are constructed to the same standards). From this standpoint, the reliability of the network source to HNEC should be greater than that to isolated clusters if the $500 \mathrm{kV}$ system is used as the source of power. If the $220 \mathrm{kV}$ system is used as the source, the reliability of service to HNEC should be equal to or better than that to the typical isolated cluster.

Turning to the second element, the circuits connecting the network with the station service transformers, the most significant fact is that failure of a circuit or piece of equipment could not involve more than three or four generating units. Any event, such as a severe earthquake, that could affect more than one circuit or one transformer would also act to shut down plants in 
other ways--ways that are discussed in the sections of the report concerned with switching stations and overhead lines from the switching stations to the station service transformers at the operating plants.

It was concluded that:

1) with offsite power supply from the $500 \mathrm{kV}$ system there is no way in which more than one cluster could be affected at HNEC other than collapse of the network in eastern washington. If that should occur, the operation of the plants would be interrupted anyway. The effect of loss of offsite power is additive to the risk of loss of generation at a Center only if the cause of the trouble is apart from causes that can force shutdown in other ways,

2) with offsite power supply from the $220 \mathrm{kV}$ system, the reliability of service would be equal to or better than that to the typical isolated cluster,

3) the prospects of having offsite power available for restarting from the hot or cold state are approximatley equal for the HNEC and DS cases,

4) failure in a circuit from the network to a station service system could in no case affect more than four generating units.

For these reasons loss of offsite power was not quantitatively assessed as a source of differences in risk between the HNEC and DS cases. HNEC is considered to be in an advantageous position with respect to reliability of station service power.

\section{FAULT CLEARING}

One of the characteristics of an energy center is that currents would be greater for faults on the transmission system near a center than for faults near a dispersed site, requiring power circuit breakers of greater interrupting capacity than are now available. The problem of reliable clearing of faults has been considered in prior studies of transmission from energy centers. (5,6) Although the problem may be properly categorized as one of transmission rather than generation, it concerns generator protection and access of 
generation to the transmission system as well as its impact on system stability and reliability; and it should be included in an investigation of generation reliability differences between DS and an HNEC.

The state-of-the-art with respect to such devices is summed up as follows:

Certain cases examined in regional studies (of energy centers) would have an available fault current of up to 86 kVA which is in excess of interrupting capacity of available circuit breakers. Within the last two decades the interrupting time of circuit breakers has been reduced from eight cycles of the power frequency to two cycles, and at $500 \mathrm{kV}$ the standard rating is $40 \mathrm{kVA}$ and two cycles. Breakers capable of interrupting up to $63 \mathrm{kVA}$ in two cycles at voltages up to $800 \mathrm{kV}$ are being developed and should be available within the next few years. Development of a synchronous interruping device capable of interrupting faults at the first current zero is proceeding. Further research is expected to extend interrupting capacities and shorten fault clearing times. However, when designing for interruption of extremely large fault currents, additional strengthening of many associated equipment components to withstand very large mechanical stresses may also be required. Other approaches may be less costly.

Another ac circuit breaker development which could benefit NECS is the current limiting breaker. It or an extremely fast (one cycle) relay and circuit breaker system could provide a way to mitigate many of the extremely high fault current difficulties. More generators could thus be tied together normally at an NEC switchyard. This could reduce the number of transmission lines required for reliability purposes. (17)

Among the alternatives open to the designer in the 1990s will be 1) to apply adequate interrupting capacity breakers if these have been developed by that time, 2) to use current limiting breakers, 3) to install extremely fast sectionalizing breakers to reduce fault levels, or 4) to design generating stations and their interconnecting transmission lines so as to limit fault currents to the interrupting capacity of equipment then available. The choices will take into account economics, reliability, and environmental impact. 
The question is--would the higher fault currents, with the equipment and system design that would be used to interrupt the current and isolate the fault, be likely to cause greater generating outages than the lesser fault currents with the conventional equipment of the DS case? In the HNEC case the designer would aim for the same level of reliability as in the DS case, and only if equal protection became economically prohibitive would the aim be lowered and the reliability consequences accepted. With the alternatives expected to be then available it is considered likely that an equal level of reliability could be achieved economically.

However, if there were some doubt as to the level of reliability that could be achieved, the consequences of breaker failure should be evaluated.

A fault on a transmission line near a HNEC switching station would be cleared at the switching station end by two circuit breakers in a breaker-anda-half bus arrangement. If one of them failed it would be backed by a breaker or by a group of breakers in parallel. In this sequence not more than one generator would be dropped. If a failure occurs in the backup, a third line of breaker protection is available, but by that time the stability of the system could be threatened, with possible outage of all generating capacity at the station. The difference in probability of such an outage at HNEC versus that at $D S$ is a function of the product of the probabilities of successive failure of two circuit breakers in each case, or of one circuit breaker and one in a group of six parallel breakers.

Modern $500 \mathrm{kV}$ heavy duty circuit breakers have a failure rate of about one failure in 200 attempts, a probability of failure of 0.005 . The probability of successive failure of two breakers would be $(0.005)^{2}$, or $2.5 \times 10^{-5}$, and that of one breaker and six in parallel, $1.5 \times 10^{-4}$. The probability of an outage of up to 20 generating units because of such a sequence of failures would be the product of a) the annual occurrence rate for transmission system faults near the station, b) the factor $2.5 \times 10^{-5}$ or $1.5 \times 10^{-4}$, and $c$ ) the probability that the system would become unstable under the circumstances, and that $x$ generators would separate from the system. Good estimates of factors a) and c) are not available, but the presence of the $2.5 \times 10^{-5}$ or $1.5 \times 10^{-4}$ 
factor ensures that the probability of occurrence of such events per year would be low enough that overall reliability of generation would not be affected significantly. If the probability of failure of a higher capacity breaker were greater than 0.005 its square would be greater than $2.5 \times 10^{-5}$, but the increase in probability of failure would have to be substantial to change the general conclusion.

The additional question can be asked--if the fault occurred on a tie line between two HNEC switching stations, and if the system did not become unstable, could outage of generators occur at both stations? In that event both stations would be affected in the same way at the same time, the probability of double circuit breaker failures occurring at both ends is the square of that of occurrence at one end, placing this risk below the area of interest.

For the reasons given above the high-fault-current characteristic of the Center is deemed a reliability risk that would not significantly alter the risk level set by other contingent events.

SUMMARY

A summation of all of the exclusions discussed above follows in Table A-1.

Finally, although an effort was made to anticipate all the sorts of risks that may enter into a comparison of Centers and Dispersed Sites, some generic problem not now foreseen could arise in future years to affect the risks of plant outages in any one area. This is an intangible risk difference, which diminishes as more experience is gained with nuclear plants, and as the seismic, hydrological, meteorological and other characteristics of the area become better understood. There has been $34 \mathrm{yr}$ of operation of noncommercial nuclear facilities at Hanford, and considerable experience has been gained elsewhere in the operation of light-water reactor commercial plants, so the intangible risk of unforeseen generic problems in the HNEC model is believed to be - acceptably low. 
TABLE A-1. Summary of Effects of Miscellaneous Outage Causes

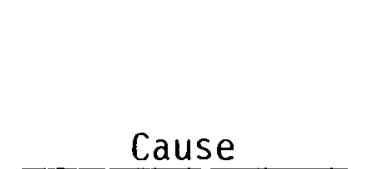

New volcano

Meteorite

River channel

blockage

Extremely low

river runoff

\begin{abstract}
Aircraft crash
\end{abstract}
Explosions

Toxic gases

Fires-general

Fire-sodium

Offsite station service failure

Fault clearing
Probability of 0ccurrence, $\frac{\text { Events per Year }}{10^{-9} \text { to } 10^{-11}}$ $10^{-9}$ to $10^{-10}$

$$
\text { low }
$$

low

$$
\begin{gathered}
10^{-6} \text { to } 10^{-10} \\
\text { control to low } \\
\text { level }
\end{gathered}
$$

control to low level

high at one

$$
\text { cluster }
$$

intermediate

intermediate

low
Probability That an
Event That 0ccurred
Would Affect More

Than One HNEC Cluster

high

intermediate

high

high

zero

low

low

zero

low

low

high (if incident triggers instability)
Comment

Highly improbable

Even if one more than one cluster were affected, probably not all units in each cluster

Insufficient data to quantify

Large upstream storage protects minimum flow, and there would be time to take emergency measures Applies equally to HNEC and DS Risk can be controlled at Center

Risk can be controlled at Center

Absence of combustibles between clusters

Reduce hazard by control of pool size

If it occurred, could affect only a few units immediately; $72 \mathrm{hr}$ wait for repair. Risk difference small but in favor of HNEC

Depends partially on improved equipment development, or greater expenditures to gain reliability 


\section{REFERENCES - APPENDIX A}

1. V. E. Blake, A Prediction of the Hazards from the Random Impact of Meteorites in the Earth's Surface. Scandia Labs, Aerospace Nuclear Safety, SC-RR-68-388, December 1968.

2. C. V. Chelapatieta1, "Probabilistic Assessment of Aircraft Hazard for Nuclear Power Plants." Nuclear Engineering and Design, 19:333-364, 1972.

3. "Kirin Meteorites." Science News, February 6, 1977.

4. International Atomic Energy Agency, Safety Guide on Man-Induced Events Related to Nuclear Power Plant Safety, draft, November 19, 1976.

5. USNRC, Nuclear Energy Center Site Survey - 1975, Part IV of V, NUREG-0001, P. IV 6-27, January 1976.

6. USNRC, Reactor Safety Study, October 1975, WASH-1400.

7. R. E. Brown, Greasewood in Ancient Playa Lake Deposits in the Pasco Basin, and Geologic Causes of Its Presence, Proc. of the Symposium on Terrestrial and Aquatic Ecological Studies of the Northwest, Northwest Scientific Assoc., p. 39-45, March 26-27.

8. J. C. Senniclsen and R. E. Brown, Evaluation of Seismically-Induced Flooding at FFTF Site, BNW 1465, (WADCO L-1465), JuTy 1970.

9. Allen S. Cary and William L. Shannon, Reconnaisance of the Walluke Slope, Letter to J.W. Ballowe of Douglas United Nuclear, Inc., April 15, 1968.

10. R. E. Brown, Personal Communication, November 1977.

11. WASH-1535, Proposed Final Environmental Statement, Liquid Metal Fast Breeder Reactor Program, Vo1. II. December 1974.

12. Sodium Spil1 and Fire Evaluation Report for the Fast Flux Test Facility, Hanford Engineering Development Laboratory, HEDL-TME 75-122, Apri1 1976.

13. Preliminary Safety Analys is Report, Pebble Springs.

14. Preliminary Safety Analys is Report, Hanford WNP 1-4.

15. FDC License for Grant County P.U.D.

16. Fred Meyer, Storage Capacity of Dams on the Columbia River and Its Tributaries from the Grand Coulee Dam to Its Headwaters. Bureau of Reclamation, February 2, 1976.

17. R. L. Richardson and W. J. Dowis, Station Service Power Supply for a Hanford Nuclear Energy Center (HNEC). Battelle, Pacific Northwest Laboratories, December 1976. 

APPENDIX B

COMPUTATION OF PROBABILITIES OF HNEC AND DS OUTAGES

This appendix contains computations of probabilities of $x$ generating units being affected by one event. Computations for earthquake, tornado, release of radioactive contaminants, and volcanic ashfall are included.

\section{EARTHQUAKE}

Earthquake effects were analyzed as follows:

1) Circles were drawn around each cluster site on a map, the radius being the computed distance at which an earthquake of magnitude $M$ would produce a free field horizontal acceleration of $0.125 \mathrm{~g}$. Quakes of magnitude $M$ with epicenters lying within the circle would cause a shutdown of the plant, while those outside the circle may be felt but would not affect plant operations.

2) In areas where circles overlap, an earthquake of magnitude $M$ would affect two or more clusters (Overlap Areas).

3) When this area is multiplied by the probability of occurrence of quakes of magnitude $M$ per unit area (including an adjustment for proximity to active earthquake areas), it represents the probability of forced shutdown of $x$ generating units.

4) The above procedure, carried out for the ful1 range of magnitudes applicable to this region, accumulated and plotted, generates a curve of annual probability of $x$ generating units being subjected to accelerations in excess of the OBE.

5) The probable horizontal acceleration resulting from earthquakes in the overlap areas was calculated, using distances from the site center.

6) Another factor was applied to account for the probability of failure of essential facilities if the structure were subjected to accelerations at and above their code design. 
7) The time required to inspect the plant and, if necessary, to repair damage following the incident (caused by the probable acceleration) was estimated.

8) A curve of probable generation loss as a result of the forced outage was prepared from the information obtained.

Figures B-1 through B-4 are maps of the critical (overlap) areas for magnitudes Richter $7.6,6.6,5.5$, and 5.2 , respectively. These maps also indicate the boundaries of the most active earthquake areas in the Pacific Northwest as reported in Reference 14 in the Earthquake section.

Table B-l contains data for calculation of probabilities of $x$ generating units being affected by an earthquake of given magnitude occurring in the overlap areas. In Table B-2 the probabilities of $n, n+1$, etc. units are grouped and added, and cumulative probabilities derived. These are probabilities of outages as required by current inspection requirements.

Table B-3 contains calculations for probability of outages as forced by failure of essential plant equipment. 


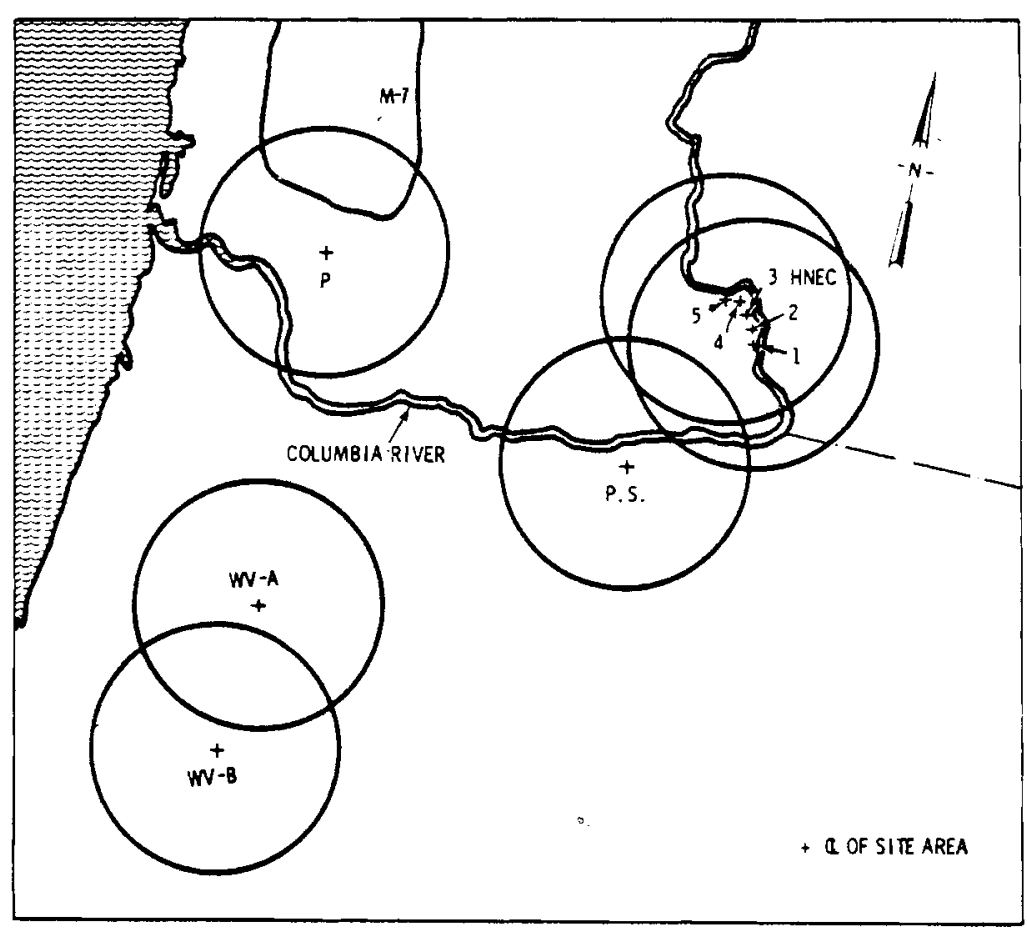

FIGURE B-1. Circular Areas within which an Occurrence of an Earthquake of Richter 7.6 Cause Horizonta 1 Accleration $\geq 0.125 \mathrm{~g}$ at the Center

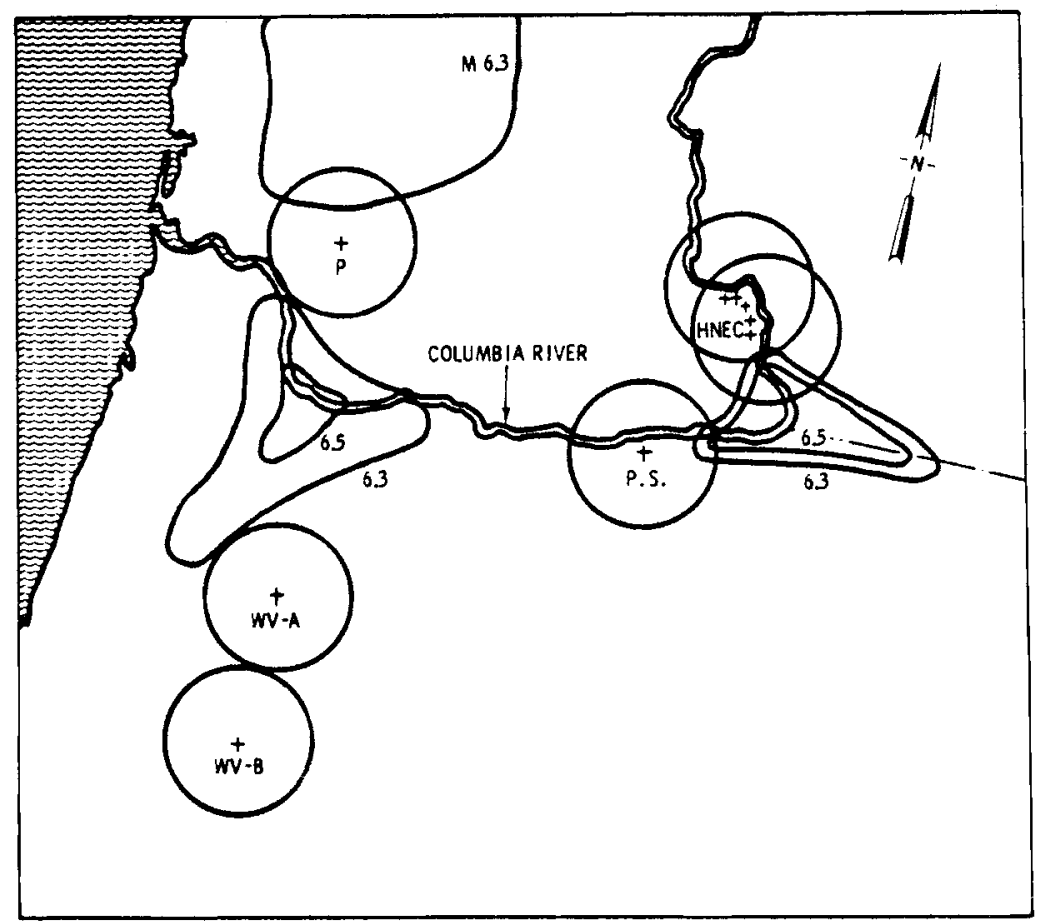

FIGURE B-2. Circular Areas Within Which an Occurrence of Earthquakes of Richter 6.6 Cause Horizonta? Acceleration $\geq 0.125 \mathrm{~g}$ at the Center 


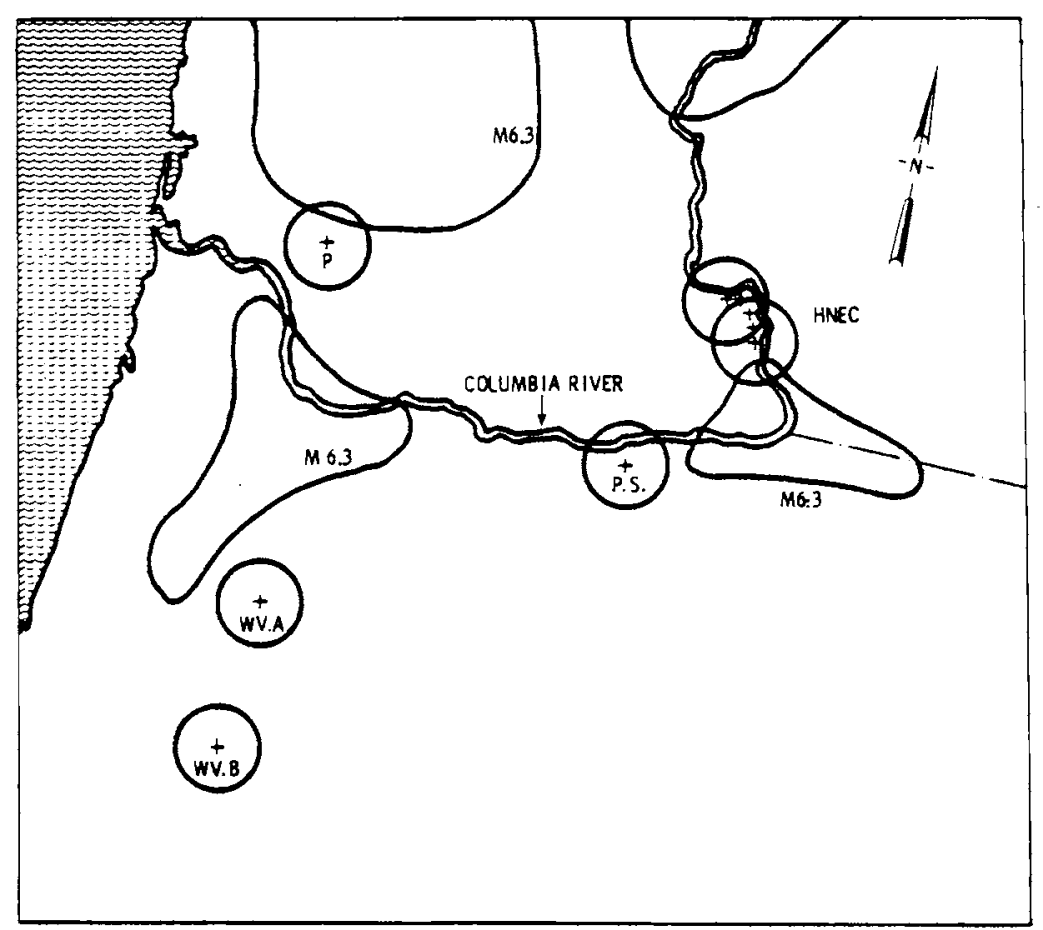

FIGURE B-3. Circular Areas within Which an Occurrence of Earthquakes of Richter 5.6 Cause Horizontal Acceleration $\geq 0.125 \mathrm{~g}$ at the Center

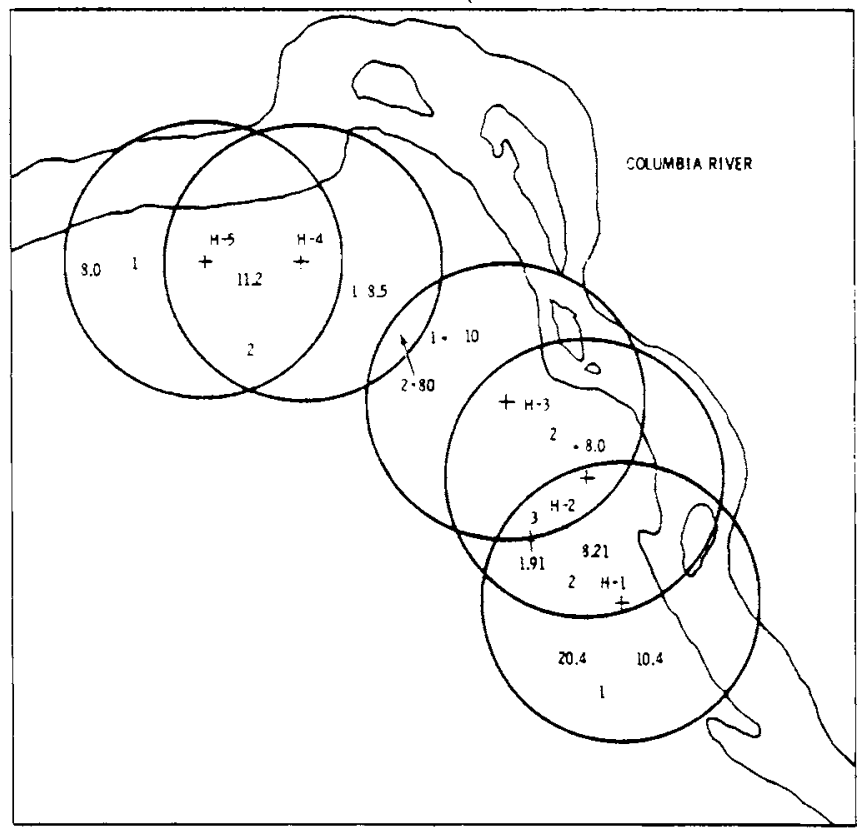

FIGURE B-4. Circular Areas Within Which an Occurrence of Earthquakes of Richter 5.2 Cause Horizontal Acceleration $\geq 0.125 \mathrm{~g}$ at the Center 
TABLE B-1. Calculation - Outage Probabilities, Earthquake, HNEC

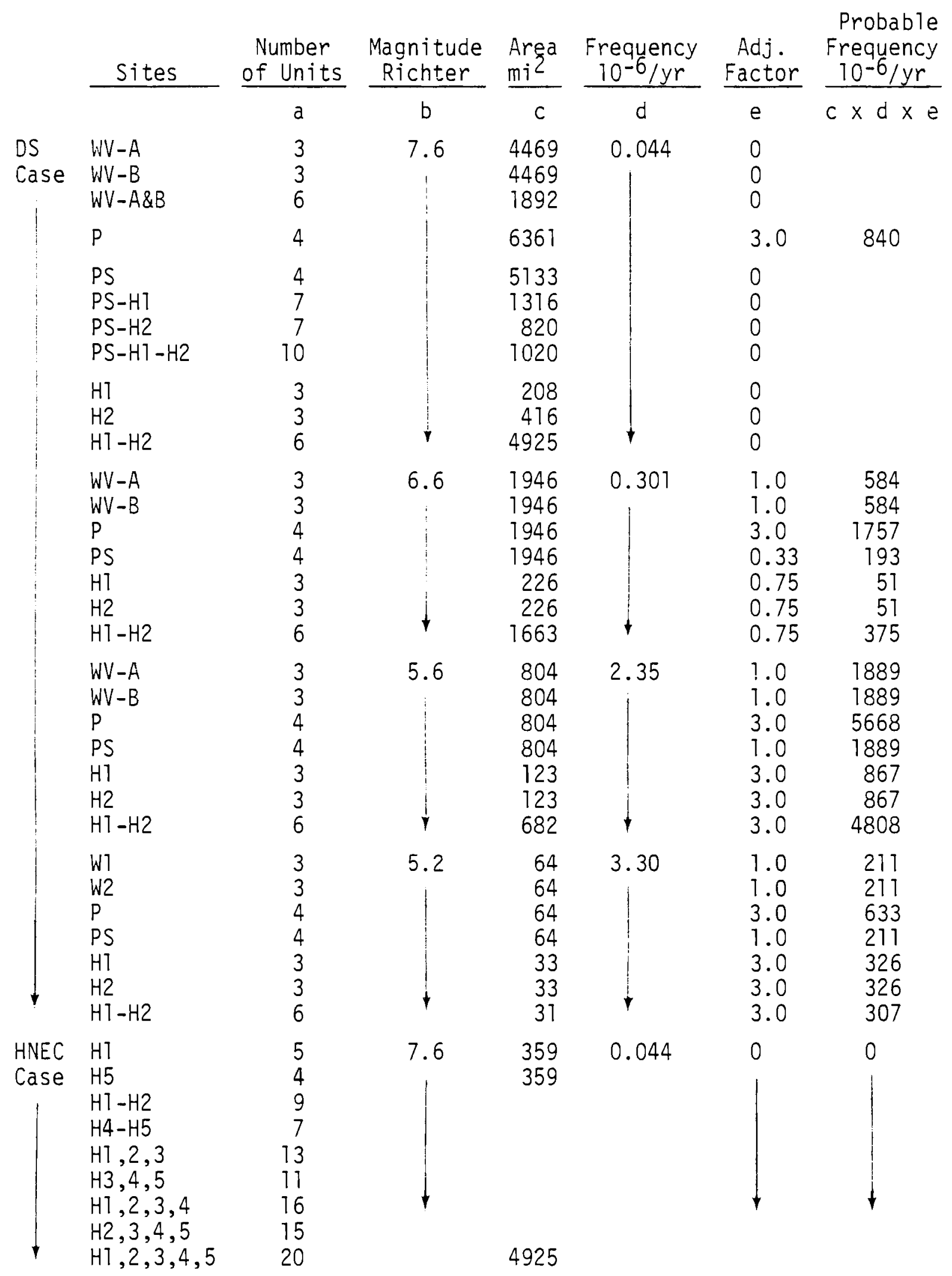


TABLE B-1. (contd)

\begin{tabular}{|c|c|c|c|c|c|c|c|}
\hline \multicolumn{2}{|r|}{ Sites } & $\begin{array}{c}\text { Number } \\
\text { of Units }\end{array}$ & $\begin{array}{l}\text { Magnitude } \\
\text { Richter } \\
\end{array}$ & $\begin{array}{l}\text { Area } \\
m i^{2}\end{array}$ & $\begin{array}{l}\text { Frequency } \\
10^{-6} / \mathrm{yr}\end{array}$ & $\begin{array}{c}\text { Adj. } \\
\text { Factor }\end{array}$ & $\begin{array}{c}\text { Probable } \\
\text { Frequency } \\
10^{-6} / \mathrm{yr} \\
\end{array}$ \\
\hline \multirow[b]{2}{*}{$\begin{array}{c}\text { HNEC } \\
\text { Case } \\
\text { (contd) }\end{array}$} & & $a$ & b & c & $d$ & e & $c \times d \times e$ \\
\hline & $\begin{array}{l}\text { H1 } \\
\text { H5 } \\
\text { H1-2 } \\
\text { H4-5 } \\
\text { H1-2-3 } \\
\text { H3,4,5 } \\
\text { H1, 2,3,4 } \\
\text { H2-3,4,5 } \\
\text { H1, } 2,3,4,5\end{array}$ & $\begin{array}{r}5 \\
4 \\
9 \\
7 \\
13 \\
11 \\
16 \\
15 \\
20\end{array}$ & $\begin{array}{c}6.6 \\
1\end{array}$ & $\begin{array}{c}208 \\
208 \\
1\end{array}$ & 0.301 & 0.75 & $\begin{array}{l}47 \\
47 \\
1 \\
+ \\
251\end{array}$ \\
\hline & $\begin{array}{l}H 1 \\
H 5 \\
H 1-2 \\
H 4-5 \\
H 1-2-3 \\
H 3-4-5 \\
H 1-2-3-4 \\
H 2-3-4-5 \\
H 1-2-3-4-5\end{array}$ & $\begin{array}{r}5 \\
4 \\
9 \\
7 \\
13 \\
11 \\
16 \\
15 \\
20\end{array}$ & 5.6 & $\begin{array}{l}124 \\
124 \\
124 \\
124 \\
151 \\
151 \\
124 \\
124 \\
198\end{array}$ & 2.35 & 3.0 & $\begin{array}{l}874 \\
+ \\
1 \\
1064 \\
1064 \\
874 \\
874 \\
1395\end{array}$ \\
\hline$\downarrow$ & $\begin{array}{l}\text { H1 } \\
\text { H1-2 } \\
\text { H1-2-3 } \\
\text { H2-3 } \\
\text { H2 } \\
\text { H3-4 } \\
\text { H4 } \\
\text { H4-5 } \\
\text { H5 }\end{array}$ & $\begin{array}{r}5 \\
9 \\
13 \\
8 \\
4 \\
7 \\
3 \\
7 \\
4\end{array}$ & 5.2 & $\begin{array}{r}33 \\
26 \\
6 \\
25 \\
32 \\
3 \\
3 \\
27 \\
36 \\
27\end{array}$ & 3.30 & 3.0 & $\begin{array}{r}326 \\
257 \\
59 \\
247 \\
317 \\
30 \\
267 \\
356 \\
267\end{array}$ \\
\hline
\end{tabular}


TABLE B-2. Probabilities of OBE Accelerations Being Exceeded at $n, n+1$, etc. Generating linits

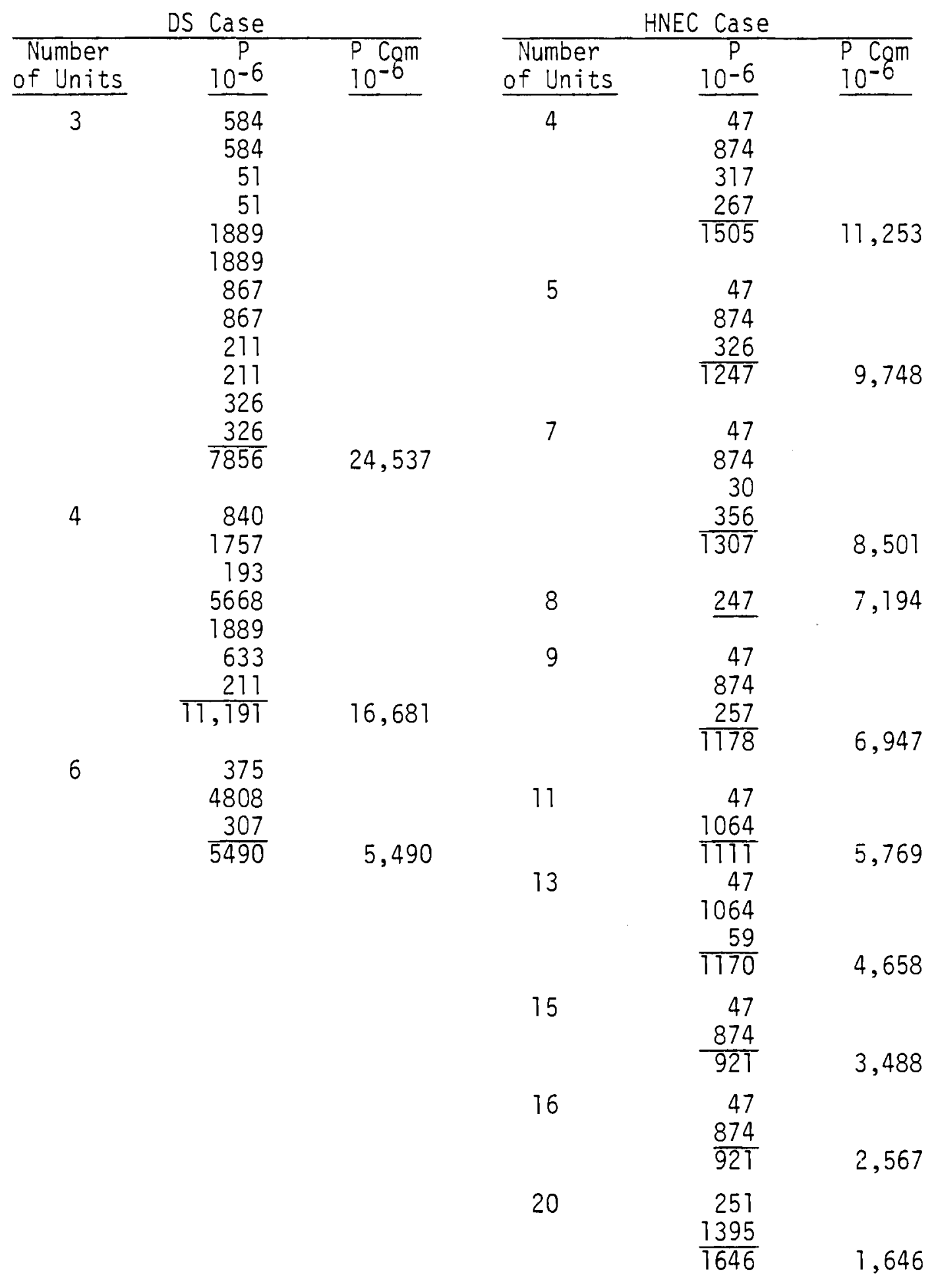


TABLE B-3. Probabilities of Outages Forced

by Failure of Essential Facilities

\begin{tabular}{|c|c|c|c|c|}
\hline $\begin{array}{l}\text { No. of } \\
\text { Units }\end{array}$ & $\begin{array}{c}\text { Total } \\
\mathrm{P} \\
10-6 \\
\end{array}$ & Factor & $\begin{array}{c}\mathrm{P} \\
10^{-6} \\
\end{array}$ & $\begin{array}{c}P \\
\text { Cum. } \\
10^{-6}\end{array}$ \\
\hline & & $\underline{D S}$ & & \\
\hline 3 & 7856 & 0.1 & 786 & 2454 \\
\hline 4 & 11,191 & 0.1 & 1119 & 1668 \\
\hline \multirow[t]{2}{*}{6} & 5490 & 0.1 & 549 & 549 \\
\hline & & HNEC & & \\
\hline 4 & 1505 & 0.1 & 151 & 1372 \\
\hline 5 & 1247 & & 125 & 1221 \\
\hline 7 & 1307 & & 131 & 1096 \\
\hline 8 & 247 & & 25 & 965 \\
\hline 9 & 1178 & & 118 & 940 \\
\hline 11 & 1111 & & 111 & 823 \\
\hline 13 & 1170 & & 117 & 712 \\
\hline 15 & 921 & & 92 & 595 \\
\hline 16 & 921 & $t$ & 92 & 503 \\
\hline 20 & 1646 & 0.25 & 411 & 411 \\
\hline
\end{tabular}

TORNADO

Exposure probability was computed in the following way:

1) On an HNEC map, slots were drawn enclosing vulnerable facilities for each pair of clusters as in Figure 2 of the Tornado section. A tornado that would affect two or more clusters would be confined in the slot.

2) The angles that tornado paths would take within the slot boundaries were measured, and the percentage of tornadoes traveling in those directions were noted.

3) The number of generating units that would be forced out of service by tornadoes moving through a cluster having one of the standard plot plans was estimated. The estimate was based on typical plot plans 
for 3,4 and 5 unit clusters. The orientations chosen for clusters other than No. 1 in Figure 11 were with the long axis of the cluster lying generally northwest-southeast. Cluster No. 1 has no predominant axis.

4) The distances that a tornado would have to travel to strike a second or third cluster after it had struck any one of the five clusters were measured. The percentage of tornadoes moving in given directions, and numbers of units affected in all possible combinations of direction, length and cluster configuration were arranged in descending order of distance. This provided the combination of generating units that would be affected by a tornado having a given effective path length. The probabilities of occurrence of tornadoes of given path length were then applied to the generating unit combinations to obtain the probabilities of a given number of units being forced out of service by tornadoes.

TABLE B-4. Possible Paths in which a Tornado Could Affect Two or More Clusters

\begin{tabular}{|c|c|c|c|c|c|c|}
\hline$\frac{\text { Cluster }}{\text { To }}$ & $\begin{array}{l}\text { Number } \\
\text { From }\end{array}$ & $\begin{array}{c}\text { Distance, } \\
\text { Miles } \\
\end{array}$ & $\begin{array}{l}\text { Direction } \\
\text { Tornadoes } \\
\text { Head Toward } \\
\end{array}$ & $\begin{array}{c}\text { Percent of } \\
\text { Tornadoes in } \\
\text { This Direction } \\
\end{array}$ & $\begin{array}{l}\text { Reverse } \\
\text { Direction }\end{array}$ & $\begin{array}{l}\text { Percent of } \\
\text { Tornadoes in } \\
\text { the Reverse } \\
\text { Direction }\end{array}$ \\
\hline 1 & 5 & 17.54 & SE & 4.5 & $N W$ & 13.6 \\
\hline 1 & 4 & 15.72 & $S E$ & 4.5 & $N W$ & 13.6 \\
\hline 1 & 3 & 7.86 & SSE & 0 & NNW & 4.5 \\
\hline 1 & 2 & 4.83 & SSE & 0 & NNW & 4.5 \\
\hline 2 & 3 & 4.23 & SE & 4.5 & NW & 13.6 \\
\hline 2 & 4 & 12.34 & $S E$ & 4.5 & $N W$ & 13.6 \\
\hline 2 & 5 & 14.88 & ESE & 4.5 & WNW & 0 \\
\hline 3 & 4 & 8.83 & $S E$ & 4.5 & $N W$ & 13.6 \\
\hline 3 & 5 & 11.49 & ESE & 4.5 & WNW & 0 \\
\hline 4 & 5 & 3.75 & $E$ & 4.5 & W & 0 \\
\hline
\end{tabular}


TABLE B-5. Arrangement of Numbers of Units Affected, in Descending Order of Distance(a)

\begin{tabular}{|c|c|c|c|c|}
\hline From & To & $\begin{array}{l}\text { Distance, } \\
\text { Miles } \\
\end{array}$ & $\begin{array}{l}\text { Number of } \\
\text { Units }(b)^{f}\end{array}$ & $\begin{array}{l}\text { Percent of } \\
\text { Tornadoes } \\
\text { Involved in } \\
\text { This Length } \\
\text { and Direction }\end{array}$ \\
\hline 1 & 5 & 17.54 & 4 & 13.6 \\
\hline 5 & 1 & 17.54 & 2 & 4.5 \\
\hline 1 & 4 & 15.72 & 2 & 13.6 \\
\hline 4 & 1 & 15.72 & 1 & 4.5 \\
\hline 2 & 5 & 14.88 & 2 & 0 \\
\hline 5 & 2 & 14.88 & 2 & 4.5 \\
\hline 2 & 4 & 12.74 & 2 & 13.6 \\
\hline 4 & 2 & 12.74 & 4 & 4.5 \\
\hline 3 & 5 & 11.49 & 2 & 0 \\
\hline 5 & 3 & 11.49 & 2 & 4.5 \\
\hline 3 & 4 & 8.83 & 2 & 13.6 \\
\hline 4 & 3 & 8.83 & 2 & 4.5 \\
\hline 1 & 3 & 7.86 & 4 & 4.5 \\
\hline 3 & 1 & 7.86 & 2 & 0 \\
\hline 1 & 2 & 4.83 & 4 & 4.5 \\
\hline 2 & 1 & 4.83 & 2 & 0 \\
\hline 2 & 3 & 4.23 & 2 & 13.6 \\
\hline 3 & 2 & 4.23 & 2 & 4.5 \\
\hline 4 & 5 & 3.75 & 2 & 0 \\
\hline 5 & 4 & 3.75 & 1 & 4.5 \\
\hline
\end{tabular}

(a) Tornado of effective length $x$ will have a probability of reaching all combinations below $x$ in the table.

(b) Beyond first cluster. 
TABLE B-6. Event Probability (a)

\begin{tabular}{|c|c|c|c|c|c|}
\hline $\begin{array}{l}\text { Path Area } \\
\text { Miles? } \\
\end{array}$ & $\begin{array}{l}\text { Path width } \\
\text { Yards } \\
\end{array}$ & $\begin{array}{l}\text { Path Length } \\
\text { Miles } \\
\end{array}$ & $\begin{array}{l}\text { Random } \\
\text { Percent }\end{array}$ & $\begin{array}{l}\text { Effective } \\
\text { Path Length } \\
\text { Miles(b) } \\
\end{array}$ & $\begin{array}{l}\text { Probability } \\
\text { of 0ccurrence } \\
10^{-7 / y r}(\mathrm{c}) \\
\end{array}$ \\
\hline 0.44 & 165 & 4.69 & 0.90 & 4.22 & 0.7 \\
\hline 1.70 & 325 & 9.22 & 0.90 & 8.30 & 2.71 \\
\hline 7.80 & 695 & 19.74 & 0.20 & 3.95 & 12.41 \\
\hline 0.82 & 225 & 6.40 & 1.00 & 6.40 & 1.31 \\
\hline 2.60 & 401 & 11.40 & 0.40 & 4.56 & 4.13 \\
\hline 4.50 & 528 & 15.00 & 0.90 & 13.50 & 7.16 \\
\hline 3.80 & 485 & 13.78 & 1.00 & 13.78 & 6.05 \\
\hline
\end{tabular}

(a) For tornadoes from Jaech 200-yr simulation having sufficient path area for a path length of $3.75 \mathrm{mi}$ or more, using a length/width ratio of 50 , compute effective path length and event probability.

(b) Remaining length after striking first cluster, path length multiplied by random number.

(c) $\frac{\text { Path Area }\left(m i^{2}\right)}{100 m i^{2} \times 200 \mathrm{yr}}$. 
TABLE B-7. Combined Probabilities

Tornado

\begin{tabular}{|c|c|c|c|c|c|c|}
\hline $\begin{array}{c}\text { Path Area } \\
\mathrm{mi}^{2} \\
\end{array}$ & $\begin{array}{l}\text { Effected } \\
\text { Length } \\
\text { Miles } \\
\end{array}$ & $\begin{array}{r}\text { Exp } \\
\text { Proba } \\
\text { Units } \\
\end{array}$ & $\begin{array}{l}\text { ure } \\
\frac{1 \text { ity }}{\text { P1 }}\end{array}$ & $\begin{array}{c}\text { Event } \\
\text { Probability } \\
\text { PN 10-8 } \\
\end{array}$ & $\begin{array}{c}\text { Outage } \\
\text { Probabi } 1 \text { ity } \\
10^{-8} \\
\end{array}$ & ' \\
\hline 0.44 & 4.22 & $\begin{array}{l}2 \\
2 \\
1\end{array}$ & $\begin{array}{l}0.136 \\
0.045 \\
0.045\end{array}$ & $i$ & $\begin{array}{l}0.952 \\
0.315 \\
0.315\end{array}$ & \\
\hline 1.70 & 8.30 & $\begin{array}{l}4 \\
4 \\
2 \\
2 \\
1\end{array}$ & $\begin{array}{l}0.045 \\
0.045 \\
0.136 \\
0.045 \\
0.045\end{array}$ & $\begin{array}{c}27.1 \\
t\end{array}$ & $\begin{array}{l}1.220 \\
1.220 \\
3.685 \\
1.220 \\
1.220\end{array}$ & \\
\hline 7.80 & 3.95 & 1 & 0.045 & 124.1 & 5.584 & \\
\hline 0.82 & 6.40 & $\begin{array}{l}4 \\
2 \\
2 \\
1\end{array}$ & $\begin{array}{l}0.045 \\
0.136 \\
0.045 \\
0.045\end{array}$ & 13.1 & $\begin{array}{l}0.589 \\
1.782 \\
0.589 \\
0.589\end{array}$ & \\
\hline 2.60 & 4.56 & $\begin{array}{l}2 \\
2 \\
1\end{array}$ & $\begin{array}{l}0.136 \\
0.045 \\
0.045\end{array}$ & 41.3 & $\begin{array}{l}5.617 \\
1.858 \\
1.858\end{array}$ & - \\
\hline 4.50 & 13.5 & $\begin{array}{l}2 \\
4 \\
2 \\
2 \\
2 \\
4 \\
4 \\
2 \\
2 \\
1\end{array}$ & $\begin{array}{l}0.136 \\
0.045 \\
0.045 \\
0.136 \\
0.045 \\
0.045 \\
0.045 \\
0.136 \\
0.045 \\
0.045\end{array}$ & + & $\begin{array}{l}9.737 \\
3.222 \\
3.222 \\
9.737 \\
3.222 \\
3.222 \\
3.222 \\
9.737 \\
3.222 \\
3.222\end{array}$ & \\
\hline 3.8 & 13.78 & $\begin{array}{l}2 \\
4 \\
2 \\
2 \\
2 \\
4 \\
4 \\
2 \\
2 \\
1\end{array}$ & $\begin{array}{l}0.136 \\
0.045 \\
0.045 \\
0.136 \\
0.045 \\
0.045 \\
0.045 \\
0.136 \\
0.045 \\
0.045\end{array}$ & $\begin{array}{r}60.46 \\
1\end{array}$ & $\begin{array}{l}8.222 \\
2.721 \\
2.727 \\
8.222 \\
2.721 \\
2.721 \\
2.721 \\
8.222 \\
2.721 \\
2.721\end{array}$ & t \\
\hline
\end{tabular}


TABLE B-8. Collection of Like Numbers of Units Affected, HNEC

\begin{tabular}{|c|c|c|c|}
\hline \multicolumn{4}{|c|}{$\times 10^{-8}$} \\
\hline Unit & 2 Units & 3 Units & 4 Units \\
\hline 0.315 & 0.952 & 0 & 1.220 \\
\hline 1.220 & 0.315 & & 1.220 \\
\hline 5.584 & 3.685 & & 0.589 \\
\hline 0.589 & 1.220 & & 3.222 \\
\hline 1.850 & 1.782 & & 3.222 \\
\hline 3.222 & 0.589 & & 3.222 \\
\hline 2.721 & 5.617 & & 2.721 \\
\hline \multirow[t]{14}{*}{15.509} & 1.858 & & 2.721 \\
\hline & 9.737 & & 2.721 \\
\hline & 3.222 & & 20.858 \\
\hline & 9.737 & & \\
\hline & 3.222 & & \\
\hline & 9.737 & & \\
\hline & 3.222 & & \\
\hline & 8.222 & & \\
\hline & 2.721 & & \\
\hline & 8.222 & & \\
\hline & 2.721 & & \\
\hline & 8.222 & & \\
\hline & 2.721 & & \\
\hline & 87.724 & & \\
\hline
\end{tabular}

(5) Cumulative Probability:
3.101
17.54
4.17
24.811
21.71
4.17 


\section{RADIOACTIVE RELEASE}

1) Air Submersion Case - (Passing Cloud)

a) Selection of Radionuclides - The radionuclides used were those selected for the reference report, Reference 2 of the text and Table VI 3-1 of that report. The tabulation is repeated below as Table B-9. The model used to convert these radioactive species into external body dose was SUBDOSA. (4, Text) The results are given in the following table, Table B-10, where body dose is given as a function of time after release Note that for the times shown, to $20,000 \mathrm{sec}$, the external body dose does not vary significantly.

b) Dose Calculation - The external total-body dose for this accident in $\mathrm{rem} /\left(\mathrm{s} / \mathrm{m}^{3}\right)$ was converted to a radiation dose in rem as a function of a probability by using data in Table 4 , Reference 3 of the text. For example, for the first 1000 seconds following a release, the radiation dose factor is a constant; namely, $1.4 \times 10^{-8} \mathrm{rem} /\left(\mathrm{s} / \mathrm{m}^{-3}\right)$. The associated normalized concentrations $(x / Q)$ that range from $1 \times 10^{-5}\left(\mathrm{~s} \mathrm{~m}^{-3}\right)$ to $1 \times 10^{-8} \mathrm{~s} \mathrm{~m}^{-3}$ :ave varying conditional probabilities of involving three or more reactions as shown in Table 4, Reference 3 . The radiation level inside a facility associated with a $\times / Q$ of $1 \times 10^{-5} \mathrm{~s} \mathrm{~m}^{-3}$ during the first 1000 seconds for example, is $1.4 \times 10^{-8} \mathrm{rem} /\left(\mathrm{s} / \mathrm{m}^{3}\right) \times 1 \times 10^{-5} \mathrm{sec} \mathrm{m}^{-3}$ and including a shielding factor of 0.2 yields 280 rem. These conversions for several values of $x / Q$ for the first 1000 seconds are given in Table B-12, following. During the first 1000 seconds, units in only the same cluster as the accident would likely be affected. Thus, from Table B-12, the probability of personnel at three or more reactors receiving a radiation dose of at least 280 rem say in their control room is 1.00 . From the same data, the probability of five or more having this radiation level is at least 0.25 . Five or more assumes that the single cluster with five units was involved. Similar calculations can be for other concentrations in the air as a function of meteorology and distances, and are summarized in Table $B-11$. (5) 
TABLE B-9. Initial Activity of Radionuclides in the Nuclear Reactor Core at the Time of the Hypothetical Accident (Reference 2)

\begin{tabular}{r} 
\\
\\
No. \\
\hline 1 \\
2 \\
3 \\
4 \\
5 \\
6 \\
7 \\
8 \\
9 \\
10 \\
11 \\
12 \\
13 \\
14 \\
15 \\
16 \\
17 \\
18 \\
19 \\
20 \\
21 \\
22 \\
23 \\
24 \\
25 \\
26 \\
27 \\
28 \\
29 \\
30 \\
31 \\
32 \\
33 \\
34 \\
35 \\
36 \\
37 \\
38 \\
39 \\
40 \\
41 \\
42 \\
43 \\
44 \\
45 \\
46 \\
47 \\
48 \\
49 \\
50 \\
51 \\
52 \\
53 \\
54 \\
\end{tabular}

\begin{tabular}{l}
\multicolumn{1}{c}{ Radionuclide } \\
\hline Cobalt-58 \\
Cobalt-60 \\
Krypton-85 \\
Krypton-85m \\
Krypton-87 \\
Krypton-88 \\
Rubidium-86 \\
Strontium-89 \\
Strontium-90 \\
Strontium-91 \\
Yttrium-90 \\
Yttrium-91 \\
2irconium-95 \\
Zirconium-97 \\
Niobium-95 \\
Molvbdenum-99 \\
Technetium-99m \\
Ruthenium-103 \\
Ruthenium-105 \\
Ruthenium-106 \\
Rhodium-105 \\
Tellurium-127 \\
Tel lurium-127m \\
Tellurium-129 \\
Tellurium-129m \\
Tellurium-131m \\
Tel lurium-132 \\
Antimony-127 \\
Antimony-129 \\
Iodine-131 \\
Iodine-132 \\
Iodine-133 \\
Iodine-134 \\
Iodine-135 \\
Xenon-133 \\
Xenon-135 \\
Cesium-134 \\
Cesium-136 \\
Cesium-137 \\
Barium-140 \\
Lanthanum-140 \\
Cerium-141 \\
Cerium-143 \\
Cerium-144 \\
Praseodymium-143 \\
Neodymium-147 \\
Neptunium-239 \\
Plutonium-238 \\
Plutonium-239 \\
Plutonium-240 \\
Plutonium-241 \\
Americium-241 \\
Curium-242 \\
Curium-244 \\
\end{tabular}

Radioactive Inventory

Source (curies $\times 10-8$ )

0.0078

0.0029

0.0056

0.24

0.47

0.68

0.00026

0.94

0.037

1.1

0.039

1.2

1.5

1.5

1.5

1.6

1.4

1.1

0.72

0.25

0.49

0.059

0.011

0.31

0.053

0.13

1.2

0.061

0.33

0.85

1.2

1.7

1.9

1.5

1.7

0.34

0.075

0.030

.0 .047

1.6

1.6

1.5

1.3

0.85

1.3

0.60

16.4

0.00057

0.00021

0.00021

0.034

0.000017

0.0050

0.00023
Half-Life (days)

71.0

1,920

3,950

0.183

0.0528

0.117

18.7

52.1

11,030

0.403

2.67

59.0

65.2

0.71

35.0

2.8

0.25

39.5

0.185

366

1.50

0.391

109

0.048

0.340

1.25

3.25

3.88

0.179

8.05

0.0958

0.875

0.0366

0.280

5.28

0.384

750

13.0

11,000

12.8

1.67

32.3

1.38

284

13.7

11.1

32,500

2.35

$8.9 \times 106$

$2.4 \times 106$

5,350

$1.5 \times 10^{5}$

163

B. 15 
EXTERNAL TOTAL-BODY DOSE FROM RSS ACCIDENT PWR-2

The external total-body dose has been calculated for the release inventory of the Reactor Safety Study (WASH-1400) accident PWR-2. The calculated dose is normalized to a time-integrated air concentration of $1.0 \mathrm{sec} / \mathrm{m}^{3}$. The dose is presented as a function of time after release in the table below.

TABLE B-10. External Total-Body Dose for Accident PWR-2

Time, Seconds

0

100

200

500

1,000

2,000

5,000

10,000

20,000
Tota 1-Body Dose $\mathrm{rem} /\left(\mathrm{sec} / \mathrm{m}^{3}\right)$

$1.4 \times 10^{8}$

$1.4 \times 10^{8}$

$1.4 \times 10^{8}$

$1.4 \times 10^{8}$

$1.4 \times 10^{8}$

$1.3 \times 10^{8}$

$1.2 \times 10^{8}$

$1.0 \times 10^{8}$

$8.0 \times 10^{7}$ 
TABLE B-11. Conditional Probability that Personnel in at Least 3 or 4 or 5 Reactors Would Experience the Stated Radiation Doses from the Possing Cloud Following a Release from a Reactor Accident at an HNEC

\begin{tabular}{ccccc}
$\begin{array}{c}\text { Radiation Dose } \\
\text { Assuming Shielding } \\
\text { Factor of } 0.2\end{array}$ & \multicolumn{3}{c}{$\begin{array}{c}\text { Conditional Probabilities } \\
\text { for Numbers of Reactors }\end{array}$} \\
\cline { 2 - 2 } 280 & $\frac{3}{1.000}$ & .850 & $\frac{5}{.250}$ \\
130 & 1.000 & .852 & .256 \\
60 & 1.000 & .853 & .268 \\
28 & 1.000 & .853 & .290 \\
13 & 1.000 & .865 & .313 \\
6 & 1.000 & .876 & .369 \\
2.8 & 1.000 & .878 & .397 \\
1.3 & 1.000 & .881 & .409 \\
0.6 & 1.000 & .884 & .417 \\
0.28 & 1.000 & .884 & .421 \\
0.13 & 1.000 & .884 & .427
\end{tabular}

2) Ground Contamination

a) Selection of Radionuclides - The radionuclides used were also those selected in the reference study. (4) This selection, important to external exposure from ground deposition, was based on the radioactive half-life and the type and the energy of the emitted radiation. For purposes of this study, the selected nuclides were divided into two groups according to half-life as shown in the following table, Table B-12. Section of the table lists the relatively long-lived species whose contribution to the radiation level is essentially constant over the time period of interest here; namely, 60 days. Section II contains the short-lived species whose contribution will decrease over the times of interest, some very rapidly. 
TABLE B-12. Ground Leve1 Summation

Section I

\begin{tabular}{|c|c|c|c|}
\hline Species & $\begin{array}{c}\text { Ha } 1 \mathrm{f}-\mathrm{L} \text { ife } \\
\text { Days } \\
\end{array}$ & $\begin{array}{l}\text { Conversion Factor } \\
\times 10^{9} \frac{\mathrm{m} \mathrm{rem}}{\mathrm{hr}} / 1 / \mathrm{m}^{2} \\
\end{array}$ & $\begin{array}{l}\begin{array}{l}\sum \times 10^{9} \\
\mathrm{~m} r \mathrm{rem}\end{array} / 1 / \mathrm{m}^{2} \\
\mathrm{hr}\end{array}$ \\
\hline $\mathrm{Cs}^{137}$ & 1100 & 9.87 & \\
\hline $\mathrm{Cs}^{134}$ & 750 & 67.5 & 77.35 \\
\hline $\mathrm{Ru}^{106}$ & 366 & 0.75 & $78.10 \times 10$ \\
\hline $\mathrm{Co}^{60}$ & 1920 & 0.1 & 78.2 \\
\hline $\mathrm{Co}^{58}$ & 71 & 0.1 & 78.3 \\
\hline
\end{tabular}

Section II

Shorter Term Isotopes at Time Zero

\begin{tabular}{|c|c|c|c|}
\hline Species & $\begin{array}{c}\text { Ha If }- \text { Life } \\
\text { Days } \\
\end{array}$ & $\begin{array}{l}\text { Conversion Factor } \\
\times 10^{9} \frac{\mathrm{m} \mathrm{rem}}{\mathrm{hr}} / 1 / \mathrm{m}^{2} \\
\end{array}$ & $\begin{array}{l}\sum \times 10^{9} \\
\frac{\mathrm{m} r \mathrm{~m}}{\mathrm{hr}} / 1 / \mathrm{m}^{2}\end{array}$ \\
\hline $\mathrm{Cs}^{136}$ & 13 & 22.5 & \\
\hline$I^{131}$ & 8.05 & 166.6 & 189.1 \\
\hline $\mathrm{Ru}^{103}$ & 39.5 & 39.5 & 228.6 \\
\hline$Z r^{97}$ & 0.71 & 3 & 231.6 \\
\hline$Z r^{95}$ & 65 & 3 & 234.6 \\
\hline $\mathrm{Hb}^{95}$ & 35 & 3.1 & 237.7 \\
\hline
\end{tabular}


b) Dose Calculations - The External Dose Conversion Factor as shown in Column 3 was developed for each isotope used in this analysis as follows. DR is derived from the Conversion Factor as follows.

$$
D R=D F \times D / Q \times S \times e^{-\lambda t}
$$

where

$$
\begin{aligned}
& D R=\text { Dose Rate, } \mathrm{m} \mathrm{rem} / \mathrm{hr} \\
& D F=\text { Dose Factor, a value in } \mathrm{m} \mathrm{rem} / \mathrm{hr} / \mathrm{p} \mathrm{Ci} / \mathrm{m}^{2}
\end{aligned}
$$

see

$$
\begin{aligned}
D / Q= & \text { Normalized surface concentration }\left(1 / \mathrm{m}^{2}\right) \text { as a function of } \\
& \text { Hanford meteorology--Reference } 3 \text {, Table } 5 \\
S= & \text { Source Term, given in } \mathrm{P} C i \text { for each isotope--Reference } \\
& \text { Table VI, } 3-1 \text { as modified by Table } I, 5-i \\
e^{-\lambda t}= & \text { Correction for radioactive decay. }
\end{aligned}
$$

The $D R$ as a function of $D / Q$ are given in Column 3 for time equal to zero, and summed in Column 4. The long-lived component is essentially constant and can be summed with the short-lived component at the times of interest. For these studies, the times are shown in the following table with the corresponding conversion dose. For example, at 120 days, the total conversion dose of $84 \mathrm{~m} \mathrm{rem} / \mathrm{hr} / \mathrm{m}^{2}$ consists of the long-1ived component $78.3 \mathrm{~m} \mathrm{rem} / \mathrm{hr} / \mathrm{m}^{2}$ plus the short-lived component $5.91 \mathrm{~m} \mathrm{rem} / \mathrm{hr} / \mathrm{m}^{2}$. (5)

TABLE B-13. External Dose Conversion Factor vs. Time

ersion

Dose

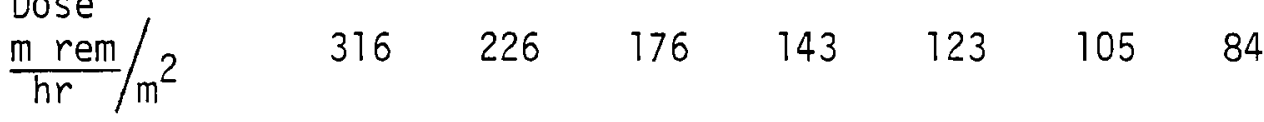

$$
\begin{array}{llllll}
\text { Days After Event } \\
0 \quad 1 & 14 & 30 & \mathbf{4 5} & \mathbf{6 0} & 120
\end{array}
$$


At the times shown, these Dose Conversion Factors, when related to the normalized concentrations, Table 5 (Reference 3 of the text) yield the radiation. doses from ground contamination and the associated probability that a given number of reactors will be affected. These values modified by shielding factors resulting from the deposition is on uneven surfaces (Reference 2, Vol. VI, Tables $11-7,-8)$ and afforded by the building are given in the left column of Table B-14. This table depicts radiation levels inside a facility and the probability that three or four or five, etc. facilities may be involved. From this table, it can be seen that the probability that nine or more reactors have a radiation level of at least $2 \mathrm{~m} \mathrm{rem} / \mathrm{hr}(.002) / \mathrm{hr}$ is 0.08 . Similar tables were developed for $0,7,30,45$ and 60 days following a radionuclide release. These in turn were the basis for the development of the probability of loss of electrical energy in GWh from a release of radioactive material. 
TABLE B-14. Probabilities of 11 or More Reactors Having Different Radiation Levels 14 Days Following an Accident Assuming Preliminary Decontamination Efforts Have Reduced Radiation Levels by a Factor of 10

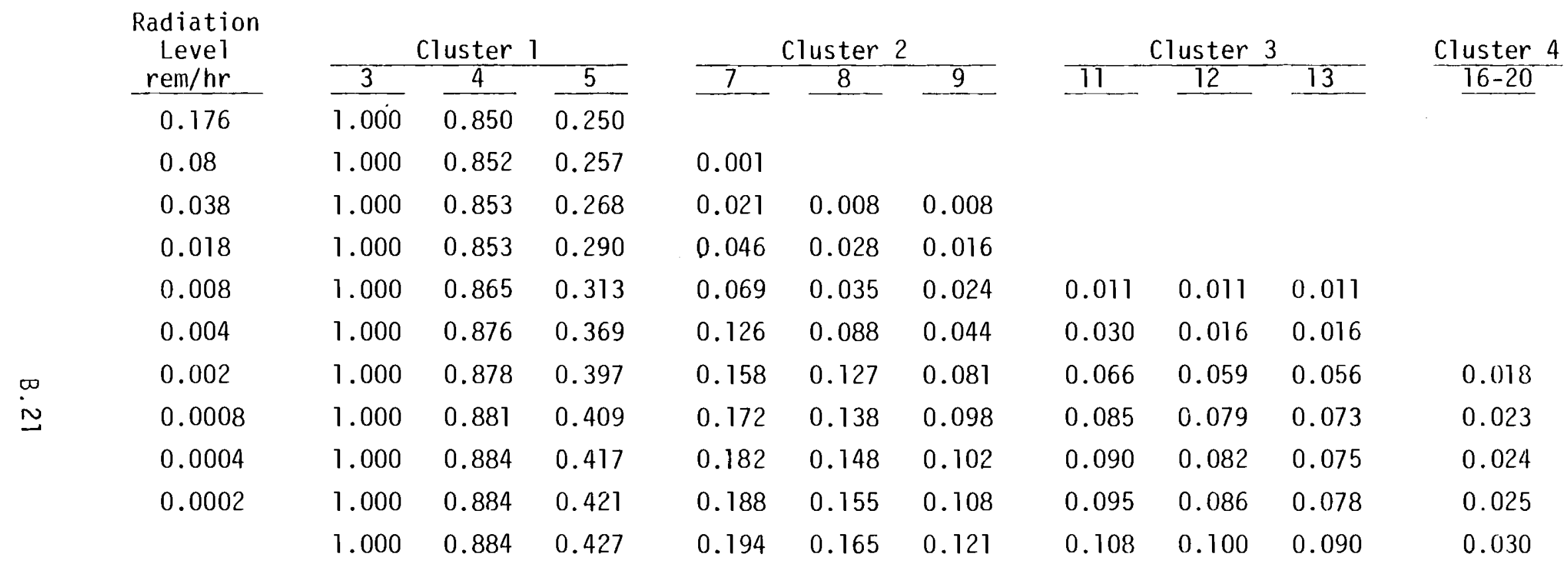


$\underline{\text { ASHFALL }}$

The estimation of probabilities of ashfall at the plant sites was made without explicit information on the volume of ash discharged from volcanoes in historic events. A relative index of volume was used in the following way. A family of curves was prepared that conformed as closely as possible with observed deposition of ash in the Hanford vicinity from the three eruptions noted in the body of the report. It is assumed that an average deposition of less than about 2 in. in one event would not force shutdown or would be compatible with staggered outages one at a time for corrective action. Since the historical data are very sparse, the curves are based mainly on hypothetical relationships between the volume of ash expelled, the mean wind velocity off the coast and the distance of the nuclear plant site from the volcano.

The curves of Figure B-5 indicate that for a cluster having a distance from a volcano equal to or greater than that shown on one of the family of curves, a combination of $x$ wind velocity and $y$ relative volume of ash discharged would cause a shutdown if the corresponding point lies to the right of the curve, but would not do so if it lies to the left of the curve.

To assess the probability of forced outage:

1) A $30^{\circ}$ sector centered at a volcanic peak was drawn on a map of the area with the centerline of the angle on one site (HNEC or DS). If more than one DS site is within the sector all are included in the effects of one eruption. (It is assumed that an ashfall at HNEC would have the same effect on all clusters).

2) The compass directions enclosed by the sector were noted, and from Figure B-6 the enclosed wind vectors and their corresponding mean wind speeds were recorded.

3) The distances between the volcano and the enclosed sites were measured.

4) From Figure B-5, the index of magnitude of ash released to the atmosphere required to force shutdown at the site under the wind and distance conditions was found, together with its probable occurrence frequency (from Figure 27 in the Ashfall section). 


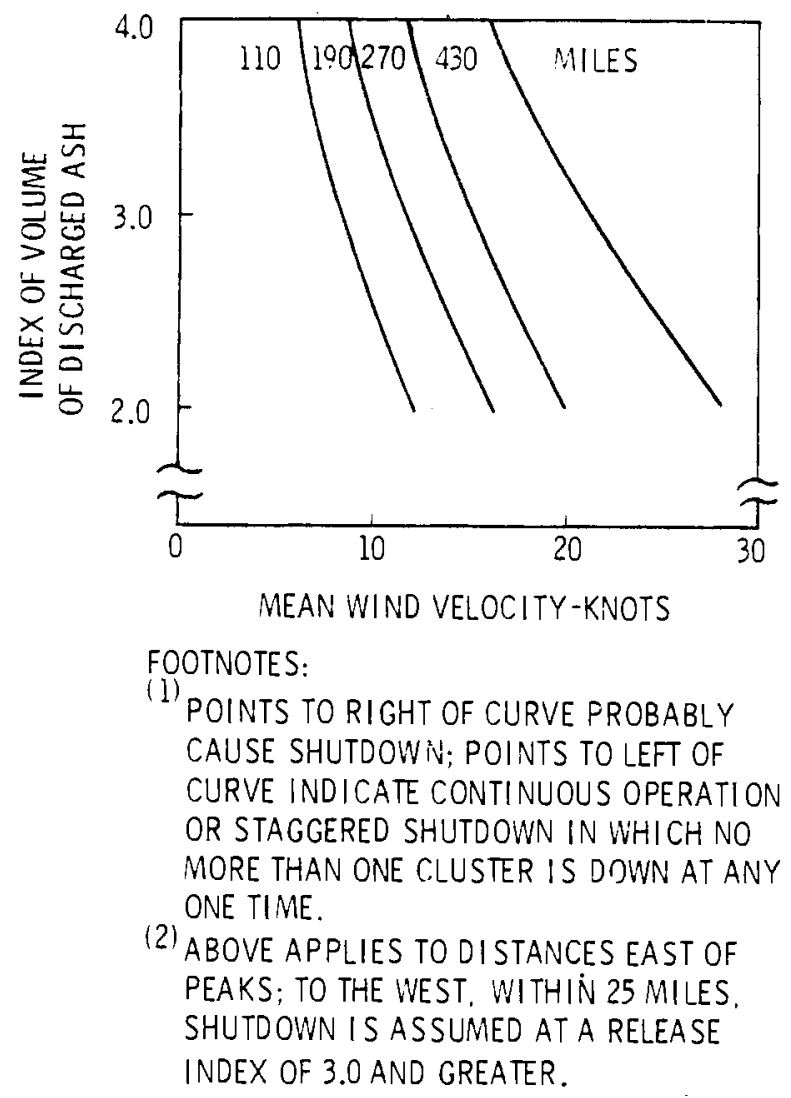

FIGURE B-5. Threshold Conditions for Forced Outage from Ashfal1

5) This procedure was carried out for each volcanic peak in succession. The probabilities of occurrence and exposure and the number of units affected were listed for each possible source and wind direction.

6) Probabilities for each set of $x$ units were summed up, and cumulative probability curves constructed.

Tables B-15, B-16 and B-17 contain probability computations for Figure 28 in the section on Ashfal1. 


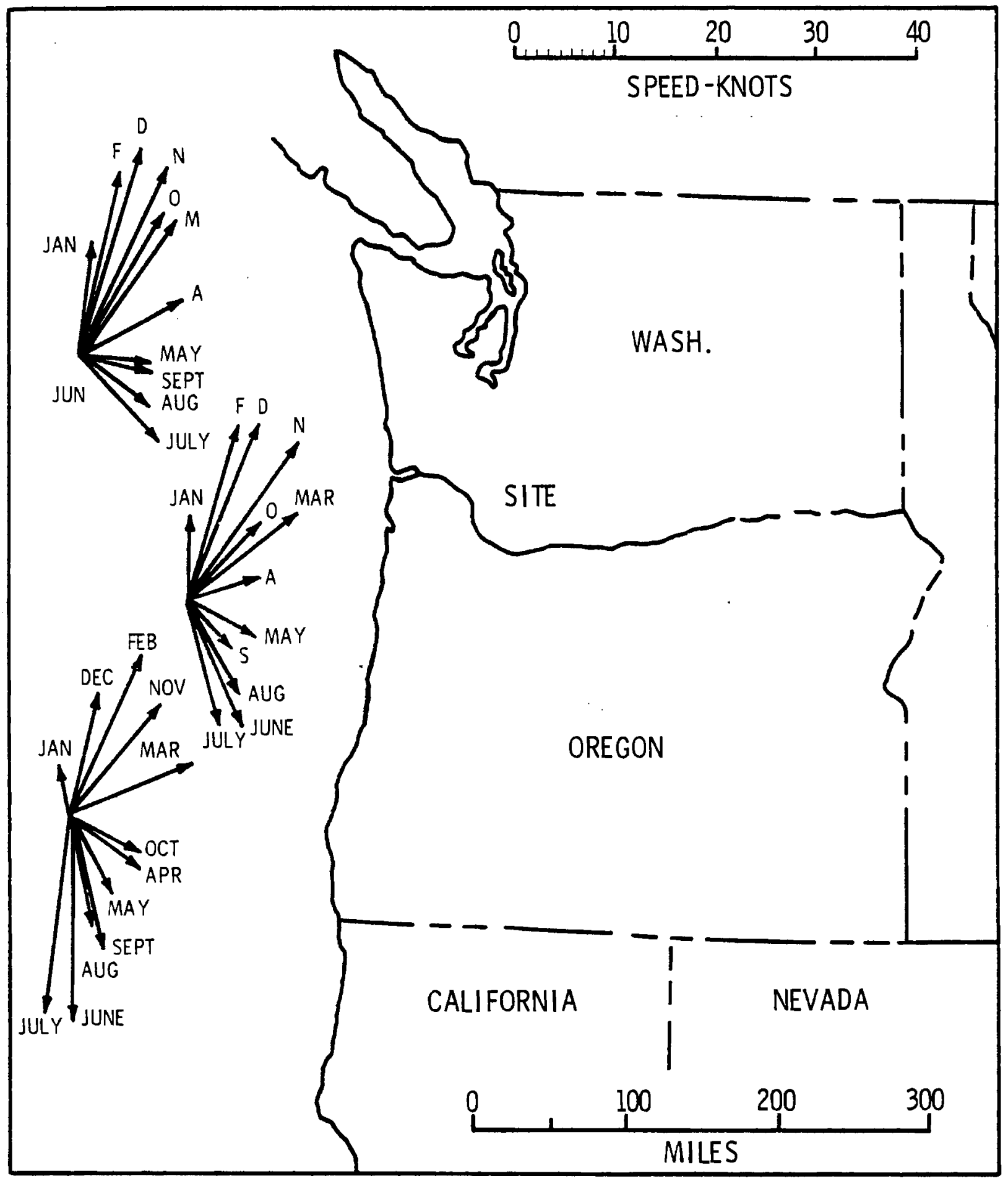

FIGURE B-6. Seasonal Migration of the Mean Wind Direction off the Coasts of Washington and Oregon 
TABLE B-15. Probability of Outage from Ashfal1, HNEC

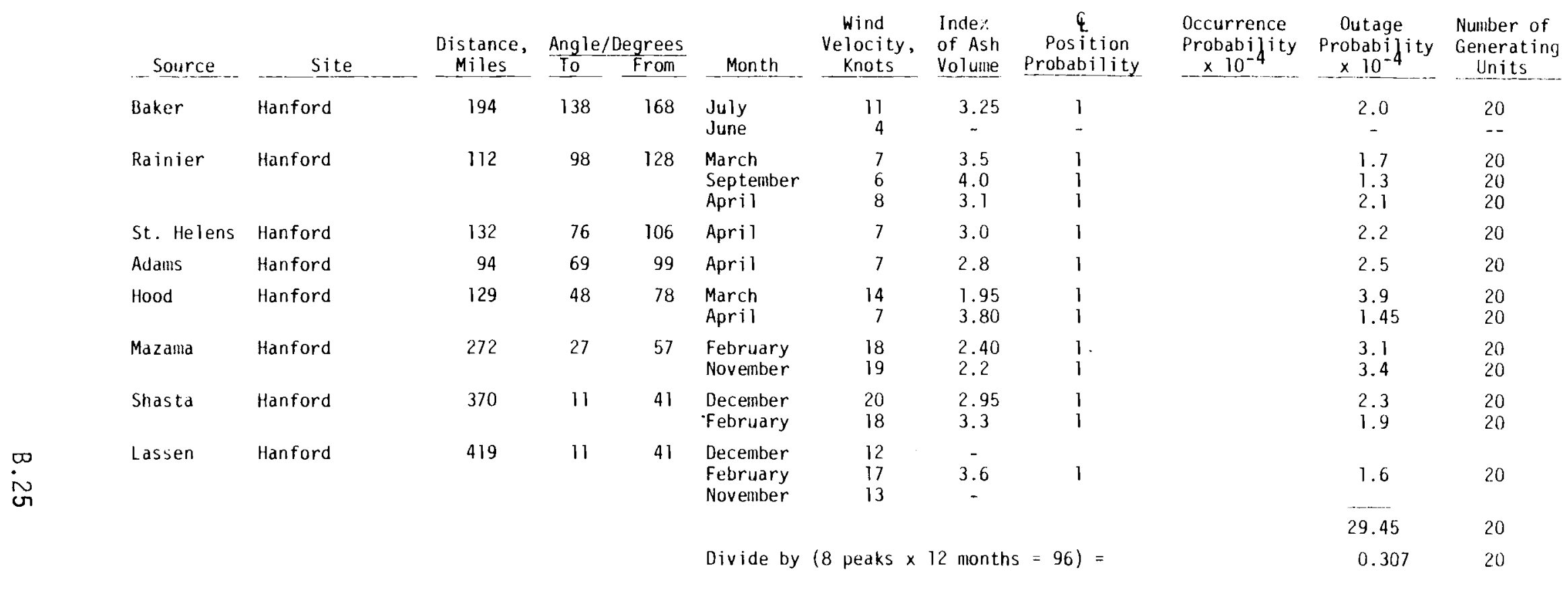


TABLE B-16. Probability of Outage from Ashfa11, DS Case

on

\begin{tabular}{|c|c|c|c|c|c|c|c|c|c|c|c|}
\hline Source & Site & $\begin{array}{c}\text { Distance, } \\
\text { Miles } \\
\end{array}$ & $\frac{\text { Angle }}{\text { To }}$ & $\begin{array}{l}\text { Degrees } \\
\text { From }\end{array}$ & Month & $\begin{array}{l}\text { Wind } \\
\text { Velocity, } \\
\text { Knots } \\
\end{array}$ & $\begin{array}{l}\text { Index } \\
\text { of Ash } \\
\text { Volume }\end{array}$ & $\begin{array}{c}\mathbb{4} \\
\text { Position }(a) \\
\text { Probability }\end{array}$ & $\begin{array}{l}\text { Occurrence } \\
\text { Probabifity } \\
\times 10^{-4} \\
\end{array}$ & $\begin{array}{c}\text { Outage } \\
\text { Probabijity } \\
\times 10^{-4} \\
\end{array}$ & $\begin{array}{l}\text { Number of } \\
\text { Generating } \\
\text { Units }\end{array}$ \\
\hline Baker & $\begin{array}{l}\text { Hanford } \\
\text { Pebble Springs } \\
\text { Portland } \\
\text { WV-1 } \\
\text { WV-2 }\end{array}$ & $\begin{array}{l}194 \\
228 \\
194 \\
228 \\
228 \\
177 \\
282 \\
337\end{array}$ & $\begin{array}{l}138 \\
138 \\
138 \\
138 \\
151 \\
188 \\
188 \\
188\end{array}$ & $\begin{array}{l}168 \\
168 \\
168 \\
168 \\
181 \\
218 \\
218 \\
218\end{array}$ & $\begin{array}{c}\text { July } \\
- \\
\text { June } \\
\text { June } \\
- \\
- \\
-\end{array}$ & $\begin{array}{r}11 \\
4 \\
4\end{array}$ & $\begin{array}{c}2.5 \\
- \\
-\end{array}$ & 1 & 2.9 & 2.9 & 6 \\
\hline Rainier & $\begin{array}{l}\text { Hanford } \\
\text { Pebble Springs } \\
\text { Pebble Springs } \\
\text { Portland } \\
\text { WV-1 } \\
\text { WV-2 }\end{array}$ & $\begin{array}{r}112 \\
116 \\
61 \\
163 \\
214\end{array}$ & $\begin{array}{r}98 \\
128 \\
220 \\
200 \\
200\end{array}$ & $\begin{array}{l}128 \\
158 \\
250 \\
230 \\
230\end{array}$ & $\begin{array}{l}\text { March } \\
\text { March } \\
\text { September } \\
- \\
- \\
-\end{array}$ & $\begin{array}{l}7 \\
7 \\
6\end{array}$ & $\begin{array}{l}3.5 \\
3.5 \\
4.0\end{array}$ & $\begin{array}{l}0.5 \\
0.5 \\
1\end{array}$ & $\begin{array}{l}1.7 \\
1.7\end{array}$ & $\begin{array}{l}0.85 \\
0.85 \\
1.3\end{array}$ & $\begin{array}{l}6 \\
4 \\
4\end{array}$ \\
\hline St. Helens & $\begin{array}{l}\text { Hariford } \\
\text { Pebtle Springs } \\
\text { Portland } \\
\text { WV- } 1 \\
\text { WV-2 }\end{array}$ & $\begin{array}{r}136 \\
112 \\
24 \\
109 \\
160\end{array}$ & $\begin{array}{r}76 \\
100 \\
180 \\
200 \\
200\end{array}$ & $\begin{array}{l}106 \\
130 \\
210 \\
230 \\
230\end{array}$ & $\begin{array}{l}\text { April } \\
\text { March } \\
- \\
- \\
-\end{array}$ & $\begin{array}{l}7 \\
7\end{array}$ & $\begin{array}{l}3.9 \\
3.5\end{array}$ & $\begin{array}{l}1 \\
1\end{array}$ & & $\begin{array}{l}1.4 \\
1.7\end{array}$ & $\begin{array}{l}6 \\
4\end{array}$ \\
\hline Adams & $\begin{array}{l}\text { Hanford } \\
\text { Pebble Springs } \\
\text { Pebble Springs } \\
\text { Portland } \\
\text { WV-1 } \\
\text { WV-2 }\end{array}$ & $\begin{array}{r}94 \\
75 \\
75 \\
61 \\
129 \\
180\end{array}$ & $\begin{array}{r}69 \\
108 \\
108 \\
272 \\
213 \\
213\end{array}$ & $\begin{array}{r}99 \\
138 \\
138 \\
302 \\
243 \\
243\end{array}$ & $\begin{array}{l}\text { April } \\
\text { March } \\
\text { September } \\
- \\
- \\
-\end{array}$ & $\begin{array}{l}7 \\
7 \\
6\end{array}$ & $\begin{array}{l}3.0 \\
3.3 \\
3.8\end{array}$ & $\begin{array}{l}1 \\
1 \\
1\end{array}$ & & $\begin{array}{l}2.2 \\
1.9 \\
1.5\end{array}$ & $\begin{array}{l}6 \\
4 \\
4\end{array}$ \\
\hline Hocd & $\begin{array}{l}\text { Hanford } \\
\text { Hanford } \\
\text { Pebble Springs } \\
\text { PS + H }\end{array}$ & $\begin{array}{r}129 \\
81 \\
129\end{array}$ & $\begin{array}{l}48 \\
48 \\
73 \\
63\end{array}$ & $\begin{array}{r}78 \\
78 \\
103 \\
93\end{array}$ & $\begin{array}{l}\text { March } \\
\text { Aprii } \\
\text { Appii } \\
\text { Apri }\end{array}$ & $\begin{array}{r}14 \\
7 \\
7 \\
7\end{array}$ & $\begin{array}{l}1.95 \\
3.8 \\
3.0 \\
3.8\end{array}$ & $\begin{array}{l}1 \\
0.33 \\
0.33 \\
0.33\end{array}$ & $\begin{array}{l}1.45 \\
2.2 \\
1.45\end{array}$ & $\begin{array}{l}3.9 \\
0.48 \\
0.73 \\
0.48\end{array}$ & $\begin{array}{r}4 \\
4 \\
4 \\
10\end{array}$ \\
\hline Mazama & $\begin{array}{l}H+\text { PS } \\
\text { Pebble Springs } \\
\text { Portland } \\
\text { Portland } \\
\text { WV-1 } \\
\text { WV-2 } \\
W V-1+W V-2\end{array}$ & $\begin{array}{r}272 \\
215 \\
228 \\
\\
133 \\
94 \\
133\end{array}$ & $\begin{array}{r}27 \\
27 \\
350 \\
\\
333 \\
310 \\
320\end{array}$ & $\begin{array}{r}57 \\
57 \\
20 \\
\\
3 \\
340 \\
350\end{array}$ & $\begin{array}{l}\text { February } \\
\text { November } \\
\text { January } \\
\text { December } \\
\text { January } \\
\text { - } \\
\text { January }\end{array}$ & $\begin{array}{r}18 \\
19 \\
9 \\
20 \\
9 \\
9\end{array}$ & $\begin{array}{l}2.4 \\
1.8 \\
- \\
1.8 \\
3.3 \\
- \\
3.3\end{array}$ & $\begin{array}{l}1.0 \\
1.0 \\
0.33 \\
1.0 \\
0.33 \\
0.33\end{array}$ & $\begin{array}{l}3.1 \\
4.2 \\
- \\
1.8 \\
1.9 \\
1.9\end{array}$ & $\begin{array}{l}3.1 \\
4.2 \\
1.8 \\
0.63 \\
0.63\end{array}$ & $\begin{array}{r}10 \\
4 \\
4 \\
4 \\
3 \\
6\end{array}$ \\
\hline
\end{tabular}


TABLE B-16. (contd)

\begin{tabular}{|c|c|c|c|c|c|c|c|c|c|c|c|}
\hline Source & Site & $\begin{array}{c}\text { Distance, } \\
\text { Miles }\end{array}$ & $\frac{\text { Angle/ }}{\text { To }}$ & $\begin{array}{l}\text { egrees } \\
\text { From }\end{array}$ & Month & $\begin{array}{l}\text { Wind } \\
\text { Velocity, } \\
\text { Knots }\end{array}$ & $\begin{array}{l}\text { Index } \\
\text { of Ash } \\
\text { Volume }\end{array}$ & $\begin{array}{c}G \\
\text { Position }(a) \\
\text { Probability }\end{array}$ & $\begin{array}{l}\text { Occurrence } \\
\text { Probabi]ity } \\
\quad \times 10^{-4}\end{array}$ & $\begin{array}{c}\text { Outage } \\
\text { Probabi]ity } \\
\times 10^{-4}\end{array}$ & $\begin{array}{l}\text { Number of } \\
\text { Generating } \\
\text { Units }\end{array}$ \\
\hline $\begin{array}{l}\text { Shasta } \\
\text { Shasta }\end{array}$ & $\begin{array}{l}\text { Pebble Springs } \\
H+D S \\
\text { Pebble Springs } \\
H+D S \\
W V-1 \\
\text { Po. + WV-1 } \\
W V-1 \\
\text { Po. + WV-1 } \\
W V-2 \\
W V-1+W V-2 \\
W V-2 \\
W V-1+2 \\
\text { Po. WV } 1 \& 2 \\
W V-2 \\
W V-1+2 \\
\text { Po. + WV-1 \& } 2\end{array}$ & $\begin{array}{l}313 \\
370 \\
313 \\
370 \\
230 \\
328 \\
230 \\
328 \\
182 \\
230 \\
182 \\
230 \\
328 \\
182 \\
230 \\
328\end{array}$ & $\begin{array}{l}18 \\
18 \\
18 \\
18 \\
355 \\
355 \\
355 \\
355 \\
337 \\
337 \\
345 \\
345 \\
345 \\
345 \\
345 \\
345\end{array}$ & $\begin{array}{r}48 \\
48 \\
48 \\
48 \\
25 \\
25 \\
25 \\
25 \\
7 \\
7 \\
15 \\
15 \\
15 \\
15 \\
15 \\
15\end{array}$ & $\begin{array}{l}\text { February } \\
\text { February } \\
\text { November } \\
\text { Novenber } \\
\text { December } \\
\text { December } \\
\text { February } \\
\text { February } \\
\text { January } \\
\text { January } \\
\text { January } \\
\text { January } \\
\text { January } \\
\text { December } \\
\text { December } \\
\text { December }\end{array}$ & $\begin{array}{l}18 \\
18 \\
19 \\
\\
20 \\
18 \\
\\
9\end{array}$ & $\begin{array}{l}2.7 \\
3.3 \\
2.5 \\
3.1 \\
1.7 \\
2.4 \\
2.3 \\
2.75 \\
4.0 \\
- \\
3.8 \\
- \\
- \\
1.5 \\
1.8 \\
2.5\end{array}$ & $\begin{array}{l}1 \\
1 \\
1 \\
1 \\
0.5 \\
0.5 \\
1 \\
1 \\
0.5 \\
0.5\end{array}$ & $\begin{array}{l}4.5 \\
3.1 \\
1.3 \\
1.45\end{array}$ & $\begin{array}{l}2.65 \\
1.9 \\
2.7 \\
2.1 \\
2.25 \\
1.55 \\
3.25 \\
2.5 \\
0.65 \\
0.73\end{array}$ & $\begin{array}{r}4 \\
10 \\
4 \\
10 \\
3 \\
7 \\
3 \\
7 \\
3 \\
\\
3\end{array}$ \\
\hline Lassen & $\begin{array}{l}\text { Pebble Springs } \\
H+P S \\
W V-2 \\
W V-1+2\end{array}$ & $\begin{array}{l}360 \\
419 \\
251 \\
345\end{array}$ & $\begin{array}{l}11 \\
11 \\
15 \\
15\end{array}$ & $\begin{array}{l}41 \\
41 \\
45 \\
45\end{array}$ & $\begin{array}{l}\text { February } \\
\text { February } \\
\text { December } \\
\text { December }\end{array}$ & $\begin{array}{l}17 \\
17 \\
12 \\
12\end{array}$ & $\begin{array}{l}3.2 \\
3.7 \\
3.8 \\
4.0\end{array}$ & $\begin{array}{l}1 \\
1 \\
1 \\
1\end{array}$ & $\begin{array}{l}2.0 \\
1.55 \\
1.45 \\
1.3\end{array}$ & $\begin{array}{l}2.0 \\
1.55 \\
1.45 \\
1.3\end{array}$ & $\begin{array}{r}4 \\
10 \\
3 \\
6\end{array}$ \\
\hline
\end{tabular}

(a) Probability of angular orientation occurring within one month. 
TABLE B-17. Sum of Probabilities for $n$ Units Affected,
DS Case, Probabilities, $10^{-4}$

\begin{tabular}{|c|c|c|c|c|c|}
\hline \multirow[t]{15}{*}{ Generating Units } & 3 & 4 & 6 & 7 & 10 \\
\hline & 0.63 & 0.85 & 2.90 & 2.55 & 0.48 \\
\hline & 2.25 & 1.30 & 0.85 & 2.50 & 3.10 \\
\hline & 3.25 & 1.70 & 1.40 & & 1.90 \\
\hline & 0.65 & 1.90 & 2.20 & & 2.10 \\
\hline & 0.73 & 1.50 & 0.63 & & 1.55 \\
\hline & 2.50 & 3.90 & 2.10 & & 1.35 \\
\hline & 1.45 & 0.48 & 1.30 & & \\
\hline & & 4.20 & & & \\
\hline & & 1.80 & & & \\
\hline & & 2.65 & & & \\
\hline & & 2.70 & & & \\
\hline & & 2.00 & & & \\
\hline & 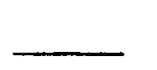 & 0.73 & & 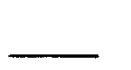 & \\
\hline & 11.46 & 25.71 & 11.38 & 4.05 & 10.48 \\
\hline Divide by $8 \times 12=96$ & 0.119 & 0.268 & 0.118 & 0.042 & 0.109 \\
\hline Cumulative & 0.656 & 0.537 & 0.269 & 0.151 & 0.109 \\
\hline
\end{tabular}




\author{
APPENDIX C \\ EXAMPLES OF PACIFIC NORTHWEST SYSTEM RESPONSE \\ TO HNEC AND DS OUTAGES
}




\section{APPENDIX C}

\section{EXAMPLES OF PACIFIC NORTHWEST SYSTEM RESPONSE TO HNEC AND DS OUTAGES}

This appendix contains descriptions of example "games" taken from computer runs of the Energy Reserve Planning Model. The "games" are intended to explain why the system visualized for the period of interest could sometimes provide reserve energy for the maximum postulated HNEC outage without any load being dropped, while at other times with a DS outage of much lesser magnitude would be unable to supply all loads.

Examples 1 and 2 are for 30,000 GWh outages at HNEC that result in large energy deficits (load dropping); examples 3 and 4 are for 30,000 GWh outages at HNEC that are absorbed without any effect on loads; and examples 5 and 6 are for 6,000 GWh outages at DS that result in dropping of some load.

\section{EXAMPLE 1 - HNEC, 7161 AVERAGE MW DEFICIT PER (OVER FOUR MONTHS)}

Period 1, September to December:

\begin{tabular}{lc} 
& $\begin{array}{c}\text { Generation (Deficits) } \\
\text { MW, Average }\end{array}$ \\
\cline { 2 - 2 } Run of river & 5,638 \\
Draft & $\frac{5,393}{11,031}$ \\
$\quad$ Hydro total & $\frac{24,433}{35,464}$ \\
Therma 1 & $\frac{42,625}{(7,161)}$ \\
$\quad$ Total generation &
\end{tabular}

Comment

This event took place during the early drawdown period, September through December. The natural river flow during that period was low, providing only 5638 average MW over the 4-month period. Storage was drafted to provide 5393 average MW, including 313 average MW of provisional energy (energy borrowed 
from the following period reserves with agreement of participants). This is the maximum allowable. The thermai energy production with the HNEC out for two months was 24,433 average $M W$, whereas without the outage it would have been about 33,000 MW. The total thermal and hydro energy production fell 7161 MW below the load. The combination of the low natural river flow in this particular year, and the HNEC outage, resulted in the energy deficit.

\section{EXAMPLE 2 - HNEC, 7518 AVERAGE MW DEFICIT}

Period 3, May to August:

\begin{tabular}{lc} 
& $\begin{array}{c}\text { Generation (Deficits) } \\
\text { MW, Average }\end{array}$ \\
\cline { 2 - 2 } Run of river & $\frac{17,134}{11,994}$ \\
Draft & $\frac{18,638}{30,632}$ \\
Hydro total & $\frac{38,150}{(7,518)}$ \\
Thermal & \\
Total generation & \\
Load &
\end{tabular}

Comment

This event took place in May through August, the refill and hold period. The natural river flow was moderately high, but the draft of stored water in the previous period had been large and it was necessary to refill reservoir in this period to fulfill Coordination Agreement requirements. The maximum provisional energy ( $313 \mathrm{MW})$ was taken, however, to support the loads to the maximum allowable extent. The thermal generation in this period was reduced even below the amount caused by the HNEC outage, indicating that some of the other thermal capacity on the system was also down during the period on planned or unplanned outages. The load loss was due, therefore, to a combination of low stored water at the start of the period, and other thermal generation having outages in the same period, possibly for refueling since this activity is concentrated in this period. 
EXAMPLE 3 - HVEC, 6533 AVERAGE MW SURPLUS

Period 3, May to August:

Run of river

Draft

Hydro total

Therma 1

Total generation

Load

Surplus
Generation (Refill

Reservoirs) MW, Average

33,314

$(8,000)$

25,314

19,369

44,683

38,750

6,533

Comment

This event took place in May to August, the refill and hold period. The natural flaw was very large during this period in this year. No drafting was required, reservoirs could be refilled to replace a substantial draft in the preceding period. The thermal generation was somewhat lower than would be due to HNEC alone, indicating some other thermal plant outages. The loads in this period were less than in winter months, the generation requirements (10ad) being only $38,150 \mathrm{MW}$ as compared to 42,625 and 45,600 in other periods. The combination of low load and high river flow placed a very low requirement on the thermal system in this case. Even with the HNEC outage there is a surplus of 6533 average MW.

EXAMPLE 4 - HNEC, 1300 AVERAGE MW SURPLUS

Period 2, January to Apri1

Generation

MW, Average

Run of river

12,981

Draft

Hydro total

Therma 1

Total generation Load

Surplus
10,874

23,855

23,045

46,900

45,600

1,300

C. 3 
Comment

This event occurred in January to Apri1, the late drawdown period. The natural river flow was average, providing 12,891 MW over the period. A relatively large draft of reservoirs could be made, generating 10,874 average MW. Thermal generation with the HNEC outage was 23,045 MW. Loads were relatively high in this period 45,600. The result was a surplus of 1300 average MW. The relatively high loads of the early winter season were met in this case, even with the HNEC outage, through a combination of heavy use of available stored water, a moderate river flow, and most other thermal capacity being on line.

EXAMPLE 5 - DS CASE, 1842 MW DEFICIT

Period 1, September to December:

\begin{tabular}{lc} 
& $\begin{array}{c}\text { Generation (Deficit) } \\
\text { MW, Average }\end{array}$ \\
\cline { 2 - 2 } Run of river & 8,188 \\
Draft & $\frac{3,875}{12,063}$ \\
Hydro total & $\frac{28,720}{40,783}$ \\
Therma 1 & $\frac{42,625}{(1,842)}$ \\
Total generation &
\end{tabular}

Comment

The thermal generation in the period indicates that at least one DS cluster was down, and possibly other system thermal units with planned or unplanned outages. The run of river flow was relatively low. With provisional energy the total draft was only 3875 average MW. The combination of low thermal generation, moderately low run of river hydro capability, and limited draft in a period of substantial load resulted in a deficit of 1843 average MW in the period. 


\section{EXAMPLE 6 - DS CASE, 1098 MW DEFICIT}

Period 1, September to December:

\begin{tabular}{lc} 
& $\begin{array}{r}\text { Generation (Deficit) } \\
\text { MW, Average }\end{array}$ \\
\cline { 2 - 2 } Run of river flow & 7,327 \\
Draft & $\frac{2,120}{9,447}$ \\
Hydro total & $\frac{32,078}{41,527}$ \\
Therma & $\frac{42,625}{(1,098)}$ \\
Total generation &
\end{tabular}

Comment

In the period previous to this one in the simulation, the maximum provisional draft had been taken, and in this period the equivalent to 872 average MW was returned to storage (not shown above). The run of river flow was relatively low. With the negative provisional energy restriction, the draft could be only $2120 \mathrm{MW}$. Not more than one DS cluster could have been down, but the relatively low run of river flow, together with the low net draft energy, could not meet the early winter loads. This period had followed a period in which thermal generation had been very low and the reservoirs had been drafted to the 1 imit.

RATIONALE FOR ADJUSTMENT OF NUMBERS OF DEFICIT PERIODS IN DS CASE, TABLE 15

In the simulation of the DS case, each of the five clusters had approximately 2500 situations in which extended outages caused by the rare events analyzed in this report occurred. These 12,500 situations $(5 \times 2500)$ took place in a total of 24,000 four-month periods covering the entire span of the study. With 12,500 situations occurring at random in 24,000 periods more than $\therefore$ one precipitating rare event occurred in a number of periods. A sampling of games indicated that two events occurred in the same four-month period on $6.6 \%$

$m$ of the periods; and three events in a four-month period occurred in $0.83 \%$ of the periods. 
Although the DS case does have potential outages that involve more than one cluster, the actual probability of such occurrences is less than the 6.6 and 0.83 percentages that were experienced in the computer run through random distribution of the events. If analyses of the contributions from the DS case is to be limited to 6000 GWh outages, the effects of the multiple cluster outages (>6000 GWh) should be removed.

This was accomplished by removing about $7 \%$ of the greatest DS deficits from the DS column of number of deficits in Table 14 . Perhaps not a11 of the greatest deficits were caused by these multiple-cluster outages, but it is judged that most of them were. The adjustment described above gives an adequate approximation to a DS case, limited to single-cluster events, as a reference base for HNEC comparisons.

Calculations from Table 15

In Table 15, some of the items in the Load Loss column were not caused by simulated HNEC outages. A count of the HNEC outage events from the computer runs gave 2497 events in 24,000 periods, or 10.4 percent. Applied to the 6000 trials, the number of events is shown to be 624 . The following amounts are added:

1) 35 events in which the deficits were in the 8000 to $10,000 \mathrm{MW}$ range,

2) 154 events in which the deficits were in the 5000 to 8000 MW range, and

3) 120 events, by which the number of HNEC deficits exceeded that of DS, in the 2000 to $5000 \mathrm{MW}$ range,

for a total of 309 events, and subtracted from the 624 total number. The result is 315 events in which the effect of HNEC on user energy shortage was no greater than that of DS.

Calculation of User Energy Shortage Probabilities

The data for construction of Figure 30 were computed in the following manner:

- From the computer runs for a 30,000 GWh loss at HNEC, and a 6000 GWh loss at DS, curves were drawn with the abscissa being the ratio of energy short- age to generation 10ss, and the ordinate being incremental probability 
of occurrence. Thus two bounding curves were available, with interpolations between them being possible for intermediate values of generation loss between 30,000 and 6000 GWh.

- A 20,000 GWh curve was developed from the above data, and from that curve incremental probabilities were obtained for steps from 0.2 to 1.0 in the ratio of energy shortage to generation loss. From Figure 28 a point was selected on the $20,000 \mathrm{GWh}$ curve, for example, at 0.8 on the abscissa, having a probability of 0.14 . This point would correspond to a $0.8 \times 20,000=16,000 \mathrm{GWh}$ user energy shortage. From the curve of Figure 28 the incremental probability of an energy shortage of the $20,000 \mathrm{GWh}$ is $1.68 \times 10^{-3}$. The probability of a 16,000 Gwh user shortage on the 20,000 GWh curve is $0.14 \times 1.68 \times 10^{-3}=2.4 \times 10^{-4}$. Other points on the 20,000 GWh can be obtained in the same manner. The corresponding cumulative probability value for this point is $3.07 \times 10^{-4}$.

- A similar procedure is followed for curves of 15,000, 10,000 etc. GWh and plotted on the curve of energy shortage versus cumulative probability.

- The several curves form an envelope that defines the area of probable risk difference of Figure 30 . 
TABLE C-1. Data for Figure 30, Comparison

of Risk of Energy Shortage

\begin{tabular}{|c|c|c|c|c|c|c|c|}
\hline \multicolumn{8}{|c|}{ HNEC } \\
\hline $\begin{array}{c}\text { Gen. Loss, } \\
\text { GWh }\end{array}$ & $\begin{array}{c}\text { Cum. }\left(P_{1}\right)(a) \\
\text { Figure } 28 \\
\end{array}$ & $\begin{array}{c}\text { Increment } \\
\mathrm{P}_{1}\end{array}$ & $\begin{array}{l}\text { Ratio } \\
\text { Gen. Loss } \\
\text { Shortage }\end{array}$ & $\begin{array}{l}\text { Shtg., } \\
\text { GWh }\end{array}$ & ${ }_{\left(P_{2}\right)}^{\text {Inc }}(\dot{b})$ & $\begin{array}{c}\text { Increpent } \\
\left(\mathrm{P}_{3}\right)(\mathrm{c})\end{array}$ & $\begin{array}{l}\text { Cum. } \\
\left(\mathrm{P}_{3}\right)\end{array}$ \\
\hline $\mathrm{a}$ & b & c & d & e & $f$ & $(c \times f)$ & $g$ \\
\hline 20,000 & $1.68 \times 10^{-3}$ & $1.68 \times 10^{-3}$ & $\begin{array}{l}0.1 \\
0.3 \\
0.5 \\
0.7 \\
0.9 \\
1.0\end{array}$ & $\begin{array}{r}2,000 \\
6,000 \\
10,000 \\
14,000 \\
18,000 \\
20,000\end{array}$ & $\begin{array}{l}0.35 \\
0.23 \\
0.20 \\
0.18 \\
0.10 \\
0.04\end{array}$ & $\begin{array}{l}5.88 \times 10^{-4} \\
3.86 \\
3.36 \\
3.00 \\
1.68 \\
0.67\end{array}$ & $\begin{array}{l}17.78 \times 10^{-4} \\
11.90 \\
8.04 \\
4.68 \\
1.68 \\
0.67\end{array}$ \\
\hline 13,000 & $1.68 \times 10^{-3}$ & $1.68 \times 10^{-3}$ & $\begin{array}{l}0.1 \\
0.3 \\
0.5 \\
0.7 \\
0.9 \\
1.0\end{array}$ & $\begin{array}{r}1,300 \\
3,900 \\
6,500 \\
9,100 \\
11,700 \\
13,000\end{array}$ & $\begin{array}{l}0.44 \\
0.36 \\
0.31 \\
0.27 \\
0.15 \\
0.08\end{array}$ & $\begin{array}{l}7.39 \\
6.04 \\
5.21 \\
4.54 \\
2.52 \\
1.34\end{array}$ & $\begin{array}{r}25.70 \\
18.31 \\
12.21 \\
7.06 \\
2.52 \\
1.34\end{array}$ \\
\hline 6,000 & $2.1 \times 10^{-3}$ & $1.68 \times 10^{-3}$ & $\begin{array}{l}0.1 \\
0.3 \\
0.5 \\
0.7 \\
0.9 \\
1.0\end{array}$ & $\begin{array}{r}600 \\
1,800 \\
3,000 \\
4,200 \\
5,400 \\
6,000\end{array}$ & $\begin{array}{l}0.53 \\
0.48 \\
0.42 \\
0.35 \\
0.22 \\
0.12\end{array}$ & $\begin{array}{l}8.90 \\
8.06 \\
7.06 \\
5.88 \\
3.70 \\
2.02\end{array}$ & $\begin{array}{r}35.60 \\
24.70 \\
16.64 \\
9.58 \\
3.70 \\
2.02\end{array}$ \\
\hline 700 & & $=$ DS $11.23 \times 10^{-3}$ & $\begin{array}{l}0.5 \\
1.0\end{array}$ & $\begin{array}{l}350 \\
700\end{array}$ & $\begin{array}{l}0.62 \\
0.24\end{array}$ & $\begin{array}{l}6.96 \times 10^{-3} \\
2.69\end{array}$ & $\begin{array}{l}9.65 \\
2.69\end{array}$ \\
\hline 1,051 & & 5.50 & $\begin{array}{l}0.5 \\
1.0\end{array}$ & $\begin{array}{r}525 \\
1,051\end{array}$ & $\begin{array}{l}0.61 \\
0.21\end{array}$ & $\begin{array}{l}3.35 \\
1.15\end{array}$ & $\begin{array}{l}4.50 \\
1.15\end{array}$ \\
\hline 1,752 & & 0.011 & $\begin{array}{l}0.5 \\
1.0\end{array}$ & $\begin{array}{r}876 \\
1,752\end{array}$ & $\begin{array}{l}0.57 \\
0.17\end{array}$ & $\begin{array}{l}0.0063 \\
0.0019\end{array}$ & $\frac{0.0082}{0.0019}$ \\
\hline
\end{tabular}

(a) $P_{1}$ - Probability of generation outage.

(b) $P_{2}$ - Probability of ratio, energy shortage to generation outage.

(c) $P_{3}$ - Probability of energy shortage. 


\section{DISTRIBUTION}

No. of

Copies

OFFSITE

A. A. Churm

DOE Patent Division

9800 S. Cass Avenue

Argonne, IL 60439

Lyman J. Harris

Northwest Area Power Manager

Aluminum Company of America

P. 0. Box 120

Vancouver, WA 98660

Robert W. Blodgett

Manager

Benton County Public Utility Dist.

P.0. Box 2670

Kennewick, WA 99336

C. Ray Foleen

Deputy Administrator

Bonneville Power Administration

P.0. Box 3621

Portland, $O R \quad 97208$

Gordon Culp

Culp, Dwyer, Guterson \& Grader

1300 Hoge Building

Seattle, WA 98104

Laura Henning

Electric Power Research Institute

P.0. Box 10412

Palo Alto, CA 94303

Chaim Braun

Electric Power Research Institute

P.0. Box 10412

Palo Alto, CA 94303

Robert Williams

Electric Power Research Institute

P.0. Box 10412

Palo Alto, CA 94303
No. of

Copies

15 William L. Fitch

Energy Facility Site Evaluation Counc $i 1$

820 E. Fifth Avenue

Olympia, WA 98504

20 W. F. Savage

Chief, Advanced Concepts

Evaluation Branch

Mail Stop F-309

Washington, DC 20545

R. Kloman

National Academy of Public

Administration

1225 Connecticut Avenue, N.W. Washington, DC 20036

Nuclear Regulatory Commission Washington, DC 20555

27 DOE Technical Information Center

2 W. Kelly Woods

Oregon Department of Energy

528 Cottage Street, N.E.

Salem, OR 97310

Howard C. Elmore

Chairman

Pacific Northwest Utilities

Conference Committee

P.0. Box 1231

Wenatchee, WA 98801

David J. Lewis

Consultant

Pacific Northwest Utilities

Conference Committee on

Engineering and Planning

2730 Northwest 77 th Place

Portland, OR 97213 
DISTRIBUTION, contd.

No. of

Copies

A. J. Porter
Vice President
Portland General Electric Co.
621 Southwest Alder Street
Portland, OR 97205
John W. Ellis
President
Puget Sound Power \& Light Co.
Puget Power Building

P.0. Box 535

Bellevue, WA 98004

Jack Criswel1

General Manager

Springfield Utility Board

250 North "A" Street, Box 300

Springfield, OR 97477

2 Larry Bradley

Washington State Energy Office

400 East Union Avenue 1st Floor

Mail Stop - PD-11

01 ympia, WA 98504

J. Vetrano

Washington Public Power Supply

System

3000 George Washington Way

Richland, WA 99352

D. L. Renberger

Washington Public Power Supply

System

3000 George Washington Way

Richland, WA 99352

John L. Watson

Executive Director

Western Interstate Energy

Board/WINB

2500 Stapleton Plaza

3333 Quebec

Denver, CO 80207
John Sharp

South Carolina Energy

Research Institute

Suite 670

First National Bank Building

Main at Washington

Columbia, South Carolina 29201

Tom Cole

Oak Ridge National Laboratory

Post Office Box $X$

Oak Ridge, TN 37830

Scott Fellows

Director, Applied Research

and Technology

Southern Interstate Nuclear Board

One Exchange Place

Suite 1230

Atlanta, GA 30341

R. T. Jaske

U.S. Nuclear Regulatory Commission

Mail Stop 7609 MNBB

Washington, DC 20555

Barry Benator

Battelle Southern Services

101 Marietta Tower

Suite 3313

Atlanta, GA 30303

\section{ONSITE}

8 DOE Richland Operations Office

0. J. Elgert

P. W. Gottschalk

R. H. Lindsey

H. E. Ransom

F. R. Standerfer

M. W. Tiernan

Energy Programs Division

W. A. Burns

H. E. Ransom 


\section{Battelle-Northwest}

F. W. Albaugh

A. Brandstetter

N. E. Carter

D. B. Cearlock

R. G. Clark

C. E. Diemond - Consultant

W. J. Dowis - Consultant

D. W. Dragnich

R. L. Drake

E. A. Eschbach

R. F. Foster

J. C. Fox

J. J. Fuquay

H. Harty (25)

A. J. Haverfield

D. L. Hesse 1

L. D. Kennberg

R. C. Liikala

D. E. Olesen

L. T. Pedersen

J. V. Ramsde1 1

R. L. Richardson

W. H. Rickard

A. C. Rither

L. C. Schmid

C. L. Simpson

J. A. Stottlemyer

B. E. Vaughan

D. G. Watson

R. D. Widrig

Technical Information (5)

Technical Publications (2) 
